\title{
Musculoskeletal complaints in musicians
}

Citation for published version (APA):

Baadjou, V. A. E. (2018). Musculoskeletal complaints in musicians: Epidemiology, Phenomenology, and Prevention. [Doctoral Thesis, Maastricht University]. Maastricht University. https://doi.org/10.26481/dis.20180201vb

Document status and date:

Published: 01/01/2018

DOI:

10.26481/dis.20180201vb

Document Version:

Publisher's PDF, also known as Version of record

\section{Please check the document version of this publication:}

- A submitted manuscript is the version of the article upon submission and before peer-review. There can be important differences between the submitted version and the official published version of record.

People interested in the research are advised to contact the author for the final version of the publication, or visit the DOI to the publisher's website.

- The final author version and the galley proof are versions of the publication after peer review.

- The final published version features the final layout of the paper including the volume, issue and page numbers.

Link to publication

\footnotetext{
General rights rights.

- You may freely distribute the URL identifying the publication in the public portal. please follow below link for the End User Agreement:

www.umlib.nl/taverne-license

Take down policy

If you believe that this document breaches copyright please contact us at:

repository@maastrichtuniversity.nl

providing details and we will investigate your claim.
}

Copyright and moral rights for the publications made accessible in the public portal are retained by the authors and/or other copyright owners and it is a condition of accessing publications that users recognise and abide by the legal requirements associated with these

- Users may download and print one copy of any publication from the public portal for the purpose of private study or research.

- You may not further distribute the material or use it for any profit-making activity or commercial gain

If the publication is distributed under the terms of Article $25 \mathrm{fa}$ of the Dutch Copyright Act, indicated by the "Taverne" license above, 
Musculoskeletal complaints in musicians:

Epidemiology, Phenomenology

and Prevention

Vera A.E. Baadjou 
ISBN: 978-90-825680-4-2

Omslagontwerp: M. Nix

Layout, typesetting and printing: *studio Michał Sławiński, thesisprint.eu 


\title{
Musculoskeletal complaints in musicians: Epidemiology, Phenomenology and Prevention
}

\author{
PROEFSCHRIFT
}

ter verkrijging van de graad van doctor aan de Universiteit Maastricht, op gezag van de Rector Magnificus, Prof. dr. Rianne M. Letschert volgens het besluit van het College van Decanen, in het openbaar te verdedigen op 1 februari 2018 om 16.00 uur

door

Vera Anna Eugenie Baadjou 


\section{Promotores}

Prof. Dr. R.J.E.M. Smeets

Prof. Dr. J.A.M.C.F. Verbunt

Prof. Dr. R.A. de Bie

\section{Copromotor}

Dr. M.D.F. van Eijsden-Besseling

\section{Beoordelingscommissie}

Prof. Dr. A.E.R.C.H. Boonen (voorzitter)

Prof. Dr. E. Altenmüller (Institute of Music Physiology and Musicians' Medicine)

Prof. Dr. G.M. Rommers

Dr. J. Stubbe (Codarts)

Dr. M.E.J.B. Goossens

The research presented in this thesis was conducted at Adelante, Centre of Expertise in Rehabilitation and Audiology (Hoensbroek, The Netherlands) and the Care and Public Health Research Institute: CAPHRI, Department of Rehabilitation Medicine, of Maastricht University (Maastricht, The Netherlands). CAPHRI participates in the Netherlands School of Primary Care Research CaRe.

This work was financially supported by a grant from the University Fund Limburg, Ans Samama Fund. The person who funded the grant (Mrs. Ans Samama) was because of her specific knowledge regarding postural exercise therapy Mensendieck, method Samama involved in design of the protocol. She was not involved in collection, analysis and interpretation of data, neither in writing of the report.

Further financial support has been kindly provided by: Ipsen Farmaceutica B.V. Hoofddorp, Livit B.V. Amsterdam, and Ortho-technics B.V. Heerlen. 


\section{Table of contents}

Chapter 1 General Introduction 7

\section{Part I Characteristics of playing-related musculoskeletal disorders}

Chapter 2 The musician as (in)active athlete? Exploring the association between physical activity and musculoskeletal complaints in music students

Chapter 3 Systematic review on risk factors for musculoskeletal complaints in musicians

Chapter 4 Psychometric properties of the performing arts module of the Disabilities of the Arm, Shoulder and Hand questionnaire

\section{Part II Effects of body posture while playing a musical instrument}

Chapter 5 Energy expenditure in brass and woodwind instrumentalists:

Chapter 6a Playing the clarinet: influence of body posture on muscle activity and sound quality

Chapter 6b Addendum

Playing the clarinet: influence of body posture on sound quality

Part III Can musculoskeletal complaints in music students be prevented?

Chapter 7 PREvention Study On preventing or reducing disability from musculoskeletal complaints in music school students (PRESTO): Protocol of a randomized controlled trial

Chapter 8 Preventing musculoskeletal complaints in music students.

A biopsychosocial prevention course is not superior at reducing disability compared to physical activity promotion: a randomized controlled trial

Chapter 9 External validation and process evaluation of a health promotion and injury prevention progam in music students: Lessons learnt from the PRESTO trial 

Chapter 1

General Introduction 



\section{General introduction}

\section{Playing-related musculoskeletal disorders}

Musculoskeletal complaints are symptoms originating from the human body's movement or musculoskeletal system; i.e. muscles, tendons, joints, blood vessels or nerves. Symptoms are pain, discomfort, numbness, tingling sensations, or a sensation of stiffness and swelling in the affected area. Musculoskeletal complaints can be related to work. Professional musicians are an example of an occupational group that is at particular risk of encountering musculoskeletal complaints due to their job demands. ' Musculoskeletal disorders that are related to the job as musician are called playing-related musculoskeletal disorders, and are defined as follows: "pain, weakness, lack of control, numbness, tingling, or other symptoms that interfere with the ability to play the instrument at the level the musician is accustomed to." ${ }^{2}$

About 23\% of the European working population has experienced musculoskeletal complaints in neck, shoulders and upper limbs related to their occupation. ${ }^{3}$ Musculoskeletal complaints in musicians occur more frequently compared to the general working population, with lifetime prevalence reported up to even $93 \% .{ }^{4}$ Complaints mostly occur in the upper extremity and the back. ${ }^{4}$ Based on history taking and clinical examination, a range of well-known specific diagnoses can be made, such as carpal tunnel syndrome or lateral epicondylitis. In many cases, no specific diagnosis can be made and complaints are referred to as non-specific., ${ }^{5,6}$ Evaluation of 1000 musicians presenting with upper-extremity problems in an orthopedic hand surgery clinic in the US with a special emphasis for musicians revealed that non-specific complaints in musicians are common. After excluding trauma diagnoses, not related to music playing, about half of the complaints were of specific origin, i.e. arthritis-related, nerve entrapment syndromes or Dupuytren's disease; whereas the other half was diagnosed as non-specific or overuse.? Lederman ${ }^{8}$ even reports up to two thirds of the complaints in a US neurology clinic as non-specific. Controversies exist regarding the term overuse injury, since there is no evidence that musicians with complaints actually have tissue damage. ${ }^{9}$ In fact, there is only very limited research done that investigates the pathophysiology of musculoskeletal disorders in musicians. Besides, the pathophysiology of musculoskeletal disorders in the general working population is also not exactly known yet.10 Research suggests that continuous contractions of muscles could result in reduced local blood circulation and muscle fatigue, along with electrochemical and metabolic imbalances, leading to muscle strain., 5,10 Initial nociceptor stimulation may be a response to metabolite accumulation, preceding tissue damage. In the long run, pain sensors could become hypersensitive leading to a pain response at low levels of stimulation and cause chronic upper-extremity pain., 5 .10 Pain is not only regulated by central ascending pain facilitation pathways, but also descending pain inhibitory pathways, and an extensive pain neuromatrix is involved. It is believed that central sensitization, or increased hypersensitivity of bottom-up nociceptive transmission, and malfunctioning of descending pain inhibitors, ${ }^{11}$ is a prognostic factor for poor outcomes in chronic musculoskeletal pain. ${ }^{12}$ In conclusion, non-specific playing-related musculoskeletal disorders in musicians are common. However, limited evidence is currently available regarding their pathophysiology. 


\section{The role of body posture in playing-related musculoskeletal disorders}

Reviews on associated and risk factors for specific upper extremity disorders in the general working population show that force, posture, movement, hand-arm vibration, shoulder load, and psychosocial factors play a role. ${ }^{13}$ More recently, it was shown that body posture, and more specifically arm elevation and shoulder load, are associated with specific shoulder complaints. ${ }^{13,14}$ Biomechanical factors are especially related to the onset of these specific complaints, whereas psychosocial factors are more likely to be involved in the persistence and experience of complaints. ${ }^{14}$ Physical risk factors like body posture have also been associated with non-specific complaints. ${ }^{5}$ However, a strong causal relationship has not been found..$^{15}$ In contrast to specific complaints, it is believed that psychosocial, work-related, and personal factors are involved in both onset and persistence of non-specific complaints. Eijckelhof et al. ${ }^{16}$ showed that computer workers with low reward and high over-commitment showed higher trapezius muscle activity. Also psychoneuroticism, neurotic perfectionism, and catastrophizing seem to be associated with the onset of non-specific work-related upper limb disorders. ${ }^{17,18}$

Overplaying, muscle fatigue and muscle tension are the most important self-reported causes of injuries in musicians. ${ }^{19}$ Rickert et al. ${ }^{20}$ showed that the right supraspinatus muscle was under intermittent extremely high levels of activation while playing the cello. Furthermore, Nyman et al. ${ }^{21}$ showed that playing for more than 3 hours per day with elevated arms (e.g. playing the violin) was associated with a 5.35 times greater risk for neck-shoulder pain compared to playing with arms in neutral position for less than 2 hours per day (e.g. playing the clarinet). In clinical practice, strong associations between sustained 'poor' posture and musculoskeletal complaints in musicians are assumed. ${ }^{22}$ However, there is no consensus about what a 'good' or 'poor' posture for a musician is. ${ }^{23}$ General postural aspects commonly taken into consideration are location of axis of gravity, pelvic attitude, spinal curvature, and alignment of the head, shoulder, and lower limbs. ${ }^{24,25}$ In a recent literature review ${ }^{23}$ on postural quality and musculoskeletal health in musicians it was found that most of the included studies reported that inadequate posture were frequently present. For example, van Eijsden-Besseling et al. ${ }^{26}$ examined body posture in first year medical school and music students. It was found that scoliosis, thoracokyphosis, and asymmetry of shoulders and pelvis were equally occurring in both groups during normal standing. However, musicians displayed more abnormal anteroposition of the head, kyphosis, scoliosis, swayback, and shoulder asymmetry while playing their instrument. Steinmetz et al. ${ }^{27}$ even found that $93 \%$ of musicians had dysfunctions in the postural stabilization system. However, no conclusions on the causality between posture and musculoskeletal complaints could be made. ${ }^{23}$ To further illustrate, Kaufman-Cohen and Ratzon ${ }^{28}$ performed a cross-sectional study amongst 59 professional classical string and wind players. The musicians answered validated questionnaires and a physical examination was performed by an experienced occupational therapist. Body posture and the perceived physical environment (e.g. weight of the instrument) were found to be strongly associated with playing-related musculoskeletal disorders. However, multivariate regression analysis showed that asymmetry of postural loading alone explained only $7 \%$ of functional limitations due to symptomatic upper limbs and $13 \%$ of the number of symptomatic upper limbs. The model with the highest predictive value (27\%) for numbers of symptomatic limbs included asymmetry of posture, weight 
of the musical instrument and average of weekly orchestra hours, and left $73 \%$ of the model unexplained. Woldendorp et al. ${ }^{22}$ conducted a cross-sectional study in 146 bassists. Hypotheses were formulated with regard to the existence of musculoskeletal complaints based on playing characteristics of double bassists versus bass guitarists and bowing style. No association was found between 'poor'posture and the location of musculoskeletal complaints. It was questioned whether the assumed association between posture and musculoskeletal complaints should be reconsidered. ${ }^{22}$ Besides, Woldendorp et al..$^{29}$ earlier found no association between muscle activation pattern and musculoskeletal pain in bassists. A recent qualitative survey concluded that physiotherapists, Alexander Technique teachers and music teachers all agreed that an optimal posture means "efficient coordination that enables the best performance with the least strain." 30 Further, they found that posture while playing is "a dynamic expression of biopsychosocial factors specific to time, place, person, and context that supersedes the conventional biomechanical model of posture." ${ }^{30}$ In summary, playing-related musculoskeletal disorders are common. The exact pathophysiology is not known. Posture could play a causal role, however it seems very likely that psychosocial factors also play a role. Therefore, more knowledge on the interplay between biological, psychological and social risk factors for musculoskeletal disorders in musicians is important.

\section{The life as a musician}

Important insights on the complex relationship between physical, psychological and social factors in the experience of playing-related musculoskeletal disorders were acquired through a series of interviews with professional orchestra players. ${ }^{31}$ Musicians usually start playing their instrument at a very young age, spend many hours of practice and integrate music as part of their identity when they grow up. ${ }^{31}$ Music teachers have a great influence on further development, for example with regard to playing and practice routines, but also with respect to self-esteem or dealing with stress. Professional orchestra jobs are limited and competitiveness is high. Musicians themselves compare the preparation for auditions with the training of elite athletes for competition. A regular day for orchestra musicians comprises of about 6 playing hours, consisting of highly repetitive, fine motor movements. Employment is mostly on a freelance basis and salary is low. ${ }^{31}$ In comparison with the general working population, professional orchestral musicians encounter high emotional and cognitive work demands, low influence at work and low social support. ${ }^{32}$ For example, one has to play constantly at his best and work is at irregular hours with little or no influence on scheduling. Associations have been found between increasing psychosocial demands and stress symptoms. ${ }^{32}$ Besides, general health aspects as healthy nutrition and sufficient physical activity are often impeded during busy touring schedules. Concluding, the burden that musicians encounter when at work is high. But foremost, when complaints occur, the culture of silence that appears to surround musicians' injuries can have detrimental effects. Musicians do not easily discuss their physical problems with their peers because the orchestral culture implies that injury is a sign of weakness, failure, and poor musicianship. ${ }^{19}$ Musicians fear to become stigmatized and have concerns about employability. ${ }^{31}$ Playing-related musculoskeletal disorders can therefore be devastating to the musician:

"... they fear that it will mean an end of being a musician - thus, an end of life as they know it" 31 


\section{Impact of complaints}

The perception of musculoskeletal complaints in musicians is different from the perception of normal aches and pain. Professional musicians were asked to explain their complaints in a qualitative study. ${ }^{2}$ They felt that playing-related musculoskeletal disorders differ from normal aches and pain, in the way that they are attributed to affect playing, are chronic, severe, and unusual, individually determined (personal), and that the symptoms are beyond the musician's control. ${ }^{2}$ Music students already experience musculoskeletal complaints more negatively than do medical students. Music students perceived that their musculoskeletal complaints had more consequences, they were more concerned about their complaints, and they assumed to have less personal control over the complaints. Further, complaints had a larger effect on identity and emotions in music students compared to medical students.

"Musicians won't admit there's a problem until playing is affected" 2

In chronic pain, it is known that physical complaints are related to disability and quality of life. However, in musicians specific, these relations have not been established yet. Our hypothesis is that more complaints will lead to more disability and a lower quality of life.

\section{International Classification of Functioning, Disability, and Health (ICF)}

The aforementioned information exemplifies that in musculoskeletal complaints in musicians a complex interplay between biological, psychological, and social factors is present. For example, Jeany, she is a violin player at a regional symphony orchestra, she is 40 years old and mother of 3 young children. She recently got divorced from her husband who is now living abroad. Some months ago, after coming home from a 2-month during tour, she experienced pain in her right arm that later migrated toward neck and shoulder. The pain got worse; she could not sleep on her right arm and noticed that she had problems reaching when hanging the laundry to dry. In the orchestra, she could hardly manage to fulfill the 6-hour working days. Because of the arm pain, she had troubles keeping up with the virtuosic tempi. That was hard for her since she always wanted to perform perfectly. During the last rehearsal, the conductor insulted her after having made a mistake. Her general practitioner advised to take rest and call in sick, but she cannot do that because she needs the money to support her family, as she is only employed on a freelance basis with no disability cover insurance.

The International Classification of Functioning, Disability, and Health (ICF) is a framework that represents a broad view of functioning across all domains of daily life-body function and structures, activities, and participation-accounting for environmental and personal factors. ${ }^{33}$ The ICF-model provides a good illustration of the complex interplay between all factors associated with playing-related musculoskeletal disorders. The ICF-model for Jeany is: 


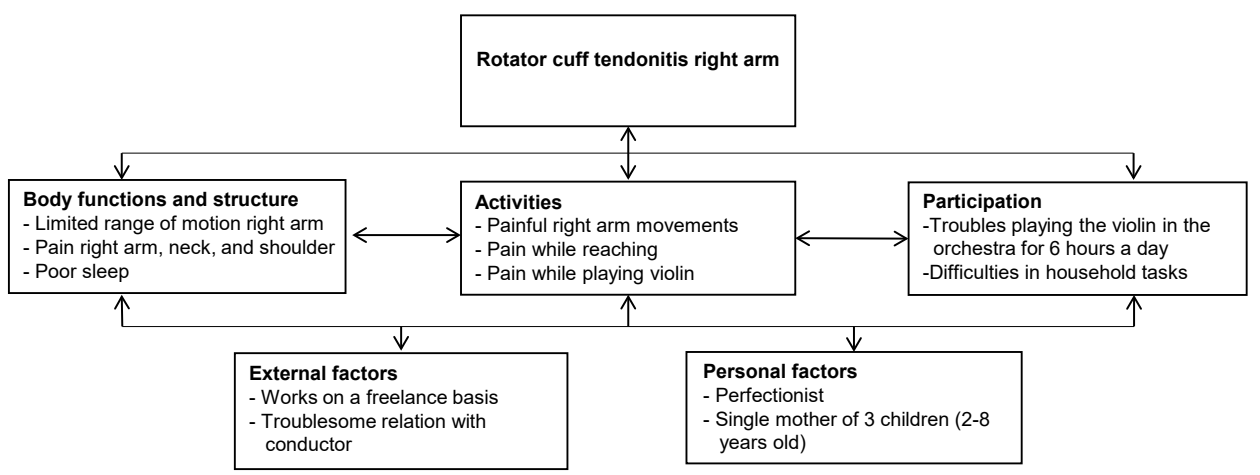

Figure 1: ICF-model of a violinist with right arm pain

\section{Measuring complaints and disability}

It is important to realize that there is a difference between disease and disability. Where disease is the medical diagnosis, disability includes impairments and the losses in activity and participation the individual person encounters. ${ }^{33}$ Disease and disability are often measured using self-reported questionnaires. Self-reported outcome measures are accepted means of assessing population characteristics and disease. ${ }^{34}$ Self-reported outcome measures can be very illustrative, if they measure the right construct in the right population. When applied correctly, they are valuable, objective outcome measures. ${ }^{35}$ To be able to correctly interpret results, one needs to assess validity, reliability, responsiveness and acceptability for that specific population. Language, culture, and other population characteristics have a great influence on the value of the outcome measure. ${ }^{35}$ However, one also needs to consider that self-reported outcome measures are vulnerable to distortion, for example by social desirability, dissimulation, and response style. ${ }^{34}$ In musician's research often non-validated questionnaires are used. ${ }^{4}$ Several questionnaires have been developed specifically for musicians, of which two are recently validated: The Musculoskeletal Pain Intensity and Interference Questionnaire for professional orchestra Musicians ${ }^{36}$ and the Musculoskeletal Pain Questionnaire for Musicians. ${ }^{37}$ However, these questionnaires are validated based on small sample sizes and are not yet widely used. Items from the Disability of Arm, Shoulder, and Hand questionnaire (DASH) ${ }^{38}$ were incorporated into both these questionnaires. The general DASH questionnaire asks about disabilities in activities and participation restriction in daily living. For example, "Do you experience difficulties opening a tight or new jar", or "To what extent has your arm, shoulder, or hand problem interfered with your normal social activities with family, friends, neighbors or groups?"The DASH also offers a performing arts module containing 4 questions related to the amount of difficulties experienced using the usual technique for playing the instrument; playing the instrument because of arm, shoulder, or hand pain; playing the instrument as well as the musician would like; and spending the usual amount of time practicing or playing. A wealth of information is available on psychometric properties of the DASH in varying 
populations. ${ }^{39-43}$ This enables comparisons between musicians and the general population and can put results into perspective. Disadvantage is that validity and responsiveness of the DASH and the performing arts module in a musician's specific population are not known. Musicians are different from the general population. As they function at an elite level, only a minor disturbance in their capacity may have large consequences for their musical performance. ${ }^{44}$ It is not known whether the general DASH is able to detect these minor effects on activities of daily living. It is suspected that the DASH performing arts module will be better at detecting these disturbances. Knowing the psychometric properties of the DASH performing arts module will increase the interpretability of its scores.

\section{Musicians are athletes}

In performing arts medicine, musicians are considered to be athletes because of the physical capacity required for playing. Self-perceived playing effort is described as somewhat hard during private practice and rehearsal, and increases during a live performance. ${ }^{45}$ Over the course of a performance, mean heart rates can peak as high as $72 \%$ of predicted maximum heart rate. ${ }^{46}$ Just like athletes, musicians have to use their body in the most optimal way to allow optimal neuromuscular control and support of the sustained loading of the instrument. Musicians and health professionals view posture as an important contributing factor to the high prevalence of playing-related musculoskeletal disorders. ${ }^{30}$ There is no definition of what an optimal body posture for a musician is..$^{30}$ The body posture of interest in the current thesis is the posture according to postural exercise therapy Mensendieck/ Cesar. Postural exercise therapy according to Mensendieck or Cesar is frequently offered for the treatment of musculoskeletal complaints in the Netherlands and Scandinavian countries. Central themes are body awareness, balanced posture and controlled movements, awareness of tension and relaxation, and functional respiration. ${ }^{47,48}$ A previous randomized controlled trial showed that postural exercise therapy Mensendieck/ Cesar was equally effective at reducing non-specific work-related upper limb disorders as strength and fitness exercise. ${ }^{49}$ Principles of postural exercise therapy are adapted to the specific treatment of musicians by Samama. ${ }^{50}$ Fundamental issue in the treatment of musicians is to adopt a stable body balance, to prevent overload on muscles used to play the instrument. Additionally, instrument-specific instructions guide how to play the musical instrument in a biomechanically optimal position..$^{50}$

In contrast to athletes, music students report that they lack time to exercise. ${ }^{51}$ It is assumed that physical activity contributes to health and prevention of musculoskeletal complaints. ${ }^{52}$ Little is known about actual physical activity levels of music students and whether physical activity is related to musculoskeletal complaints in this population. Currently, musicians seem not to identify themselves with athletes and rather want to be recognized as artists. Music students lack the awareness that playing music at an elite level requires engagement in preventive measures, early assessment and injury management. ${ }^{19}$ Principles as warming-up, injury prevention, psychological preparation, adequate nutrition, cardiovascular fitness, and health-checks are common in sportsmen, but are only practiced by a small number of musicians. To improve future musician's health behavior, it seems worthwhile incorporating health education in the music schools. 


\section{Health education at the conservatory}

In The Netherlands, a conservatory study is part of Higher Vocational Education. The bachelor study lasts four years in which varying major programs, such as classical music, pop/jazz music, music in education, and historical music are offered. The curriculum is organized around a main topic (musical instrument), combining practice and theory. Students work individually with their teachers, in groups, and in regular contact with the professional world. It has been shown that music students experience more musculoskeletal complaints ${ }^{53}$ and a worse mental health compared to other students. ${ }^{54}$ A survey among Dutch conservatory students (year 1 to 4 ) showed that $62.7 \%$ reported current musculoskeletal complaints. ${ }^{53}$ A longitudinal study in 5 German conservatories showed that incidence of playing-related health problems was already $29 \%$ at the start of year 1, meaning that students started their study already with a health problem, probably due to a pre-university injury history. Health problems further increased to $42 \%$ in year 2 and slightly decreased to $36 \%$ in year $3 .{ }^{55}$ Most of these complaints were physical. In this study, more than $80 \%$ stated that playing limitations due to the health problem were low or not restrictive. The remaining students reported considerable restrictions during playing.$^{55}$ Other studies confirm that average disability levels as measured with the DASH are low, however individual music students do display moderate to worse disabilities, foremost when related to instrument playing. ${ }^{56,57}$ The level of disability was found to be related to the amount of pain ${ }^{56}$ and a lower quality of life. ${ }^{57}$ Considering mental health, it has been shown that the first year is an especially challenging year, with increment of fatigue, depression, and stage fright..$^{58}$ Next to the risk factors already associated with studying in higher education, such as being a full-time student, being under financial strain, and being a young person, ${ }^{59}$ it is found that the music school can be considered as an extra stressful place. The high competition, isolation, and teaching style are assumed to contribute to this. ${ }^{60}$ Music students themselves perceive specific lifestyle challenges related to studying music, resulting from busy or irregular schedules, drinking cultures, and sedentary practice behaviors. ${ }^{51}$ The notion increases that conservatories should take care of health and wellbeing of their students, however this is not common practice yet. Higher education institutions are an appropriate setting to promote healthy lifestyles since they have access to a large proportion of students living away from home for this first time, and have the capacity to provide support and establish healthy behavioral patterns that may continue throughout the lifespan. ${ }^{61}$ A systematic review showed that interventions that were embedded within other university courses were effective at improving physical activity, nutrition, and weight-related outcomes ${ }^{61}$ It is believed that offering education about health promotion and prevention strategies during the bachelor's program will benefit musicians throughout their entire careers. Performing arts medicine specialists agree that topics such as healthy practice habits, diet and exercise, mental wellbeing, and hearing health should be incorporated in music students' education..$^{51}$ Although several programs have been described and applied in music schools, 62,63 the scientific evidence on the effectiveness of such programs is limited. There is some evidence that prevention programs may influence psychological, although not physical health. ${ }^{64}$ Therefore, we designed a randomized controlled trial studying the effectiveness of a biopsychosocial prevention program based on postural exercise therapy Mensendieck/ Cesar, method Samama, incorporating performance-related psychosocial factors. 
At the moment of initiation of our studies performed within this thesis, there were very limited curricular initiatives on health and wellbeing at the Dutch conservatories. Most of the health care was offered during workshops. None of the participating conservatories offered obligatory health screenings or structural health promotion courses. Therewith we were the first to introduce a biopsychosocial health course at the Dutch conservatories.

\section{Aims and outline of this dissertation}

The prior section showed that musculoskeletal complaints are a complicated interplay of bio-, psycho-, and social factors with a potentially great impact on the musician's life. Music students seem to be an important group to educate about health promotion and injury prevention. This thesis presents results of the research project "PRESTO": PREvention STudy On physical complaints in conservatory students. Overall goal of this thesis is to examine how to prevent or reduce musculoskeletal complaints and disability in music students. In order to do this, several studies have been undertaken to provide a thorough scientific foundation for our conclusions. This dissertation consists of three sections followed by a general discussion.

PART I Characteristics of playing-related musculoskeletal disorders

Chapter 2 presents results of a study on the incidence of musculoskeletal disorders in third and fourth year conservatory students in the Netherlands. To analyze impact of complaints, students were asked about current complaints, levels of disability, quality of life and physical activity. Chapter 3 outlines a systematic review of current literature on risk factors for musculoskeletal complaints in musicians. Further, as we emphasized that it is important to know psychometric properties of our main measurement instrument, we analyzed reliability and validity of the performing arts module of the Disability of Arm, Shoulder, and Hand questionnaire in Chapter 4. Additionally, the association between playing-related musculoskeletal disorders and pain was further explored.

PART II Effects of body posture while playing a musical instrument.

This part provides more information about the influence of the body posture according Mensendieck/ Cesar method Samama on physical functioning in musicians. In Chapter 5 we elaborate on the effects of body posture on energy expenditure in brass and woodwind instrumentalists; and in Chapter 6 we examine the influence of body posture on muscle activity and quality of sound in clarinetists.

PART III Can musculoskeletal complaints in music students be prevented?

Finally, we present the study protocol (Chapter 7) and short and long term (2-year follow up) results (Chapter 8) of a randomized controlled trial with the aim to study the effectiveness of a biopsychosocial prevention program in first or second year bachelor students of five Dutch conservatories. As it is not only important to examine whether the program was effective in preventing and reducing disability, but also to evaluate whether the trial was valid and the interventions were implemented as planned, we conducted an external validation and process evaluation which are described in Chapter 9. This dissertation concludes with discussion of results, highlighting strengths, limitations, and implications for current daily practice in Chapter 10. 


\section{References}

1. Zaza C, Farewell VT. Musicians' playing-related musculoskeletal disorders: an examination of risk factors. Am J Ind Med. 1997;32:292-300.

2. Zaza C, Charles C, Muszynski A. The meaning of playing-related musculoskeletal disorders to classical musicians. Soc Sci Med. 1998;47: 2013-2023.

3. Bevan S. Economic impact of musculoskeletal disorders (MSDs) on work in Europe. Best Pract Res Clin Rheumatol. 2015;29(3):356-373.

4. Kok LM, Huisstede BM, Voorn VM, Schoones JW, Nelissen RG. The occurrence of musculoskeletal complaints among professional musicians: a systematic review. Int Arch Occup Environ Health. 2016;89(3):373-396.

5. van Tulder M, Malmivaara A, Koes B. Repetitive strain injury. Lancet. 2007;369(9575):1815-1822.

6. Huisstede BM, Miedema HS, Verhagen AP, Koes BW, Verhaar JA. Multidisciplinary consensus on the terminology and classification of complaints of the arm, neck and/or shoulder. Occup Environ Med. 2007:64(5):313-319.

7. Dawson WJ. Experience with hand and upper-extremity problems in 1000 instrumentalists. Med Probl Perform Art. 1995;10:128-133.

8. Lederman RJ. Neuromuscular and musculoskeletal problems in instrumental musicians. Muscle Nerve. 2003;27:549-561.

9. Winspur I. Controversies surrounding 'misuse', 'overuse', and 'repetition' in musicians. Hand Clin. 2003;19:325-329.

10. Visser B, van Dieen JH. Pathophysiology of upper extremity muscle disorders. J Electromyograph Kinsesiol. 2006;16(1):1-16.

11. Malfliet A, Leysen L, Pas R, et al. Modern pain neuroscience in clinical practice: applied to post-cancer, paediatric and sports-related pain.Braz J Phys Ther. 2017;21(4):225-232.

12. Mallen CD, Peat G, Thomas E, Dunn KM, Croft PR. Prognostic factors for musculoskeletal pain in primary care: a systematic review. Br J Gen Pract. 2007;57(541):655-661.

13. van Rijn RM, Huisstede BM, Koes BW, Burdorf A. Associations between work-related factors and specific disorders of the shoulder-a systematic review of the literature. Scand J Work Environ Health. 2010;36(3):189-201.

14. Van der Molen, Foresti, Daams, Frings-dresen, Kuijer. Work-related risk factors for specific shoulder disorders: a systematic review and meta-analysis. Occup Environ Med. 2017.Oct;74(10):745-755.

15. da Costa BR, Vieira ER. Risk factors for work-related musculoskeletal disorders: A systematic review of recent longitudinal studies. Am J Ind Med. 2010;53(3):285-323.

16. Eijckelhof BH, Bruno Garza JL, Huysmans MA, et al. The effect of overcommitment and reward on muscle activity, posture, and forces in the arm-wrist-hand region-a field study among computer workers. Scand J Work Environ Health. 2013;39(4):379-389.

17. Van Eijsden-Besseling MD, van Attekum A, de Bie RA, Staal JB. Pain catastrophizing and lower physical fitness in a sample of computer screen workers with early non-specific upper limb disorders: a case-control study. Ind Health. 2010;48(6):818-823. 
18. van Eijsden-Besseling MD, Peeters FP, Reijnen JA, de Bie RA. Perfectionism and coping strategies as risk factors for the development of non-specific work-related upper limb disorders (WRULD). Occup Med. 2004;54(2):122-127.

19. Ackermann B. ARC Sound Practice Project Final Report Vol v 1/03/2017. University of Sydney.2017.

20. Rickert D, Halaki M, Ginn K, Barrett S, Ackermann B. The use of fine-wire EMG to investigate shoulder muscle recruitment patterns during cello bowing: The results of a pilot study. J Electromyograph Kinesiol.2013;23:1261-1268.

21. Nyman T, Wiktorin C, Mulder M, Liljeholm Johansson Y. Work postures and neck-shoulder pain among orchestra musicians. Am J Ind Med. 2007;50:370-376.

22. Woldendorp KH, Boonstra AM, Tijsma A, Arendzen JH, Reneman MF. No association between posture and musculoskeletal complaints in a professional bassist sample. Eur J Pain. 2016;20(3):399-407.

23. Blanco-Pineiro P, Diaz-Pereira MP, Martinez A. Musicians, postural quality and musculoskeletal health: A literature's review. J Bodyw Mov Ther. 2017;21(1):157-172.

24. Blanco-Pineiro P, Diaz-Pereira MP, Martinez A. Common postural defects among music students. J Bodyw Mov Ther. 2015;19(3):565- 572.

25. Ackermann B, Miller C. Pre-participation screening tool for dancers, instrumentalists, vocalists, and actors (DIVA). A consensus document of the Performing Arts Medicine Association. Paper presented at: Performing Arts Medicine Association2017; Snowmass, Colorado, CA.

26. van Eijsden-Besseling MDF, Kuijers B, Stam H, Terpstra-Lindeman E. Differences in posture and postural disorders between music and medical students. Med Probl Perform Art.1993;8:110-114.

27. Steinmetz A, Seidel W, Muche B. Impairment of postural stabilization systems in musicians with playing-related musculoskeletal disorders. J Manipulative Physiol Ther. 2010;33:603-611.

28. Kaufman-Cohen Y, Ratzon NZ. Correlation between risk factors and musculoskeletal disorders among classical musicians. Occup Med. 2011;61:90-95.

29. Woldendorp KH, van de Werk P, Boonstra AM, Stewart RE, Otten E. Relation Between Muscle Activation Pattern and Pain: An Explorative Study in a Bassists Population. Arch Phys Med Rehabil. 2013;94:10951106.

30. Shoebridge A, Shields N, Webster E. Minding the Body: An interdisciplinary theory of optimal posture for musicians. Psychol Mus. 2017:1-18.

31. Guptill CA. The lived experience of professional musicians with playing-related injuries: a phenomenological inquiry. Med Probl Perform Art. 2011;26(2):84-95.

32. Holst GJ, Paarup HM, Baelum J. A cross-sectional study of psychosocial work environment stress in the Danish symphony orchestras. Int Arch Occcup Environ Health. 2012;85:639-649.

33. World Health Organization. International Classification of Functioning, Disability and Health (ICF). Geneva: World Health Organization; 2001.

34. Lenderink AF, Zoer I, van der Molen HF, Spreeuwers D, Frings-Dresen MH, van Dijk FJ. Review on the validity of self-report to assess work-related diseases. Int Arch Occup Environ Med.2012;85(3):229-251.

35. de Vet HC, Terwee CB, Mokking LB, Knol DL. Measurement in Medicine. Cambridge, UK: Cambridge University Press; 2011.

36. Berque P, Gray H, McFadyen A. Development and psychometric evaluation of the Musculoskeletal Pain Intensity and Interference Questionnaire for professional orchestra Musicians. Manual therapy. 2014;19(6):575-588. 
37. Lamontagne $V$, Belanger $C$. Development and validation of a questionnaire on musculoskeletal pain in musicians. Med Probl Perform Art. 2012;27(1):37-42.

38. Hudak PL, Amadio PC, Bombardier C. Development of an upper extremity outcome measure: the DASH (disabilities of the arm, shoulder and hand). Am J Ind Med. 1996;29:602-608.

39. Huisstede BMA, Feleus A, Bierma-Zeinstra SM, Verhaar JA, Koes BW. Is the Disability of Arm, Shoulder, and Hand Questionnaire (DASH) also valid and responsive in patients with neck complaints? Spine. 2009;34(4):E130-E138.

40. Hunsaker FG, Cioffi DA, Amadio PC, Wright JG, Caughlin B. The American Academy of Orthopaedic Surgeons Outcomes Instruments. Normative values from the general population. J Bone Joint Surg Am.2002.

41. Jester A, Harth A, Germann G. Measuring levels of upper-extremity disability in employed adults using the DASH questionnaire. J Hand Surg. 2005;30A:1074e1071-1075e1010.

42. Jester A, Harth J, Raugh G, Germann G. DASH Data of Non-Clinical versus Clinical Groups of Persons-A Comparative Study of T-norms for Clinical Use. Handchir Mikrochir Plast Chir.2010 Feb;42(1):55-64.

43. Veehof MM, Sleegers EJA, van Veldhoven NHMJ, Schuurman AH, van Meeteren NLU. Psychometric qualities of the Dutch language version of the disabilities of the arm, shoulder, and hand questionnaire (DASH-DLV). J Hand Ther. 2002;15:347-354.

44. Gallagher J, Needleman I, Ashley P, Sanchez RG, Lumsden R. Self-Reported Outcome Measures of the Impact of Injury and IIIness on Athlete Performance: A Systematic Review. Sports Med. 2017;47(7):13351348.

45. Chan C, Driscoll T, Ackermann BJ. Effect of a musicians' exercise intervention on performance-related musculoskeletal disorders. Med Probl Perform Art. 2014;29(4):181-188.

46. McCrary JM, Halaki M, Ackermann BJ. Effects of Physical Symptoms on Muscle Activity Levels in Skilled Violinists. Med Probl Perform Art. 2016;31(3):125-131.

47. Haugstad GK, Haugstad TS, Kirste UM, Leganger S, Klemmetsen I, Malt UF. Mensendieck somatocognitive therapy as treatment approach to chronic pelvic pain: Results of a randomized controlled intervention study. Am J Obstet Gynecol 2006;194:1303-1310.

48. Haugstad GK, Haugstad TS, Kirste UM. Continuing improvement of chronic pelvic pain in women after short-term Mensendieck somatocognitive therapy: results of a 1-year follow-up study. Am J Obstet Gynecol 2008;199:615.

49. van Eijsden-Besseling MD, Staal JB, van Attekum A, de Bie RA. No difference between postural exercises and strength and fitness exercises for early, non-specific, work-related upper limb disorders in visual display unit workers: a randomised trial. Aust J Physiother. 2008;54(2):95-101.

50. Samama ALW. Making music without pain. Assen, The Netherlands: Van Gorcum; 1998.

51. Perkins R, Reid H, Araujo LS, Clark T, Williamon A. Perceived Enablers and Barriers to Optimal Health among Music Students: A Qualitative Study in the Music Conservatoire Setting. Front Psychol. 2017;8:968.

52. Warburton DE, Nicol CW, Bredin SS. Health benefits of physical activity: the evidence. CMAJ. 2006;174(6):801-809. 
53. Kok LM, Nelissen RG, Huisstede BM. Prevalence and Consequences of Arm, Neck, and/or Shoulder Complaints Among Music Academy Students: A Comparative Study. Med Probl Perform Art. 2015;30(3):163-168.

54. Spahn C, Strukely S, Lehmann A. Health conditions, attitudes toward study, and attitudes toward health at the beginning of university study: music students in comparison with other student populations. Med Probl Perform Art. 2004;19:26-33.

55. Spahn C, Voltmer E, Mornell A, Nusseck M. Health status and preventive health behavior of music students during university education: Merging prior results with new insights from a German multicenter study. Musicae Scientiae. 2017;21(2):213-229.

56. Barton R, Killian C, Bushee M, et al. Occupational performance issues and predictors of dysfunction in college instrumentalists. Med Probl Perform Art. 2008;23:72-78.

57. Rodriguez-Romero B, Perez-Valino C, Ageitos-Alonso B, Pertega-Diaz S. Prevalence and Associated Factors for Musculoskeletal Pain and Disability Among Spanish Music Conservatory Students. Med Probl Perform Art. 2016;31(4):193-200.

58. Hildebrandt H, Nübling M, Candia V. Increment of Fatigue, Depression, and Stage Fright During the First Year of High-Level Education in Music Students. Med Probl Perform Art. 2012;27(1):43-48.

59. Stallman HM. Psychological distress in university students: a comparison with general population data. Aust Psychol. 2010;45:249-257.

60. Demirbatir RE. Relationships between psychological well-being, happiness, and educational satisfaction in a group of university music students. Educ Res Rev 2015;10:2198-220\6.

61. Plotnikoff RC, Costigan SA, Williams RL, et al. Effectiveness of interventions targeting physical activity, nutrition and healthy weight for university and college students: a systematic review and meta-analysis. Int J Behav Nutr Phys Act. 2015;12:45.

62. Williamon A, Thompson S. Awareness and incidence of health problems among conservatoire students. Psychol Mus. 2006;34:411-430.

63. Chesky K, Dawson WJ, Manchester R. Health promotion in schools of music: initial recommendations for schools of music. Med Probl Perform Art. 2006;21(3):142-144.

64. Zander MF, Voltmer E, Spahn C. Health promotion and prevention in higher music education. Results of a longitudinal study. Med Probl Perform Art. 2010;25:54-65. 


\section{Part I}

Characteristics of playing-related musculoskeletal disorders 



\title{
Chapter 2
}

\author{
The musician as (in)active athlete? Exploring \\ the association between physical activity and \\ musculoskeletal complaints in music students
}

Published as: Baadjou VA, Verbunt JA, van Eijsden-Besseling MD, Huysmans SM, Smeets RJ. The musician: (in)active athlete? Exploring the association between physical activity and musculoskeletal complaints in music students. Med Probl Perform Art.2015;30(4):231-7. 


\section{Abstract}

Objective: Musicians are often compared to athletes because of the physical exertion required to play music. The aim of this study was to explore the physical activity level of music students and to study its relationship with musculoskeletal complaints. A second goal was to assess associations between pain, quality of life, and disability.

Methods: This cross-sectional study among third- and fourth-year music students used an electronic survey including measures for physical activity (Short Questionnaire to Assess Health-enhancing physical activity), musculoskeletal complaints (Dutch Musculoskeletal Questionnaire), disability (Disability Arm, Shoulder, Hand questionnaire) and quality of life (Short Form-12). Students were classified as compliers or non-compliers with moderate- and vigorous-intensity physical activity recommendations. Statistical analysis was done using (non)parametric tests (t-test, Pearson chi-square test, Mann-Whitney U-test) and correlational testing.

Results: Participants were 132 students, 63.6\% female, with a median age of 23 years (range 21.3 - 25.0). 67\% reported musculoskeletal complaints in the past 7 days. Their median physical activity level was 6390 MET-min/ wk, and $62 \%$ and $10 \%$ of the students accomplished recommendations for moderate-intensity and vigorous-intensity physical activity levels, respectively. No significant differences were found in prevalence of musculoskeletal complaints between students who met moderate- or vigorous-intensity physical activity recommendations and students who did not. Physical activity level was not associated with musculoskeletal complaints $(r=0.12, p=0.26)$. Higher pain intensity was associated with a lower quality of life $(r=-0.53, p<0.01)$ and higher disability $(r=0.43$, $\mathrm{p}<0.01)$.

Conclusions: Music students are mainly involved in light- to moderateintensity physical activities and rarely in vigorous-intensity activities. No correlation was found between physical activity level in the past months and musculoskeletal complaints in music students. 


\section{Introduction}

The level of physical exertion required to play music is often compared with that of an athlete. Performing a concert can be exhausting and requires intensive exercise. To illustrate, in Händel's Messiah, a music piece lasting a total of 3 hours, the right bowing arm of the first cellist moves up and down 740 times in just one single 2-minute aria.' Energy costs for music-playing range from 1.8 to 5.5 metabolic equivalents (MET) depending on the type of instrument, playing position (sitting/ standing), and activity (e.g. playing in a marching band). ${ }^{2,3}$ Moreover, in one study, after musicians played three times in a period of 10 minutes in a research setting, musicians described the level of perceived exertion as heavy. ${ }^{4}$ This same study showed that performance quality improved concurrently with the initial increase in signs of exertion (i.e. respiratory rate, heart rate) between the first and second period. However, maintaining a high level of exertion caused a reduction of performance quality between the second and third periods. ${ }^{4}$ Musicians often play continuously for several hours; it seems logical that optimizing physical capacity can contribute to a better performance. In addition to a plausible positive effect on performance, an optimal physical activity level also benefits health. It is known that regular physical activity contributes to the primary and secondary prevention of several chronic diseases and premature death. ${ }^{5}$ National and international guidelines recommend that healthy adults aged 18-65 years will experience substantial health benefits from moderate-intensity physical activity for a minimum of 30 minutes on 5 days each week or vigorous-intensity physical activity for a minimum of 20 minutes on 3 days each week. ${ }^{6,7}$ A dose-response relationship is assumed, with further health benefits with increasing levels of activity., ${ }^{5,8}$ Results concerning the relationship between physical activity and the musculoskeletal symptoms are less clear, but Ratzlaff et al. ${ }^{9}$ showed that an active lifestyle is associated with a decreased risk of upper body occupational repetitive strain injury. Musculoskeletal complaints in musicians are rather common and are often referred to as playing-related musculoskeletal disorders (PRMDs). The point prevalence of PRMDs ranges from 25\% at the start of conservatory study, ${ }^{10}$ to $34-62 \%$ for music students overall, and is even $39-87 \%$ for professional classical musicians. ${ }^{11}$ PRMDs can result in serious playing-related disability and even be a potential threat to the quality of performance as well as to the musician's quality of life.

Physical activity level seems to be important for the musician, affecting both performance and health. But how active is the musician? In contrast to athletes, musicians could be characterized as having a sedentary lifestyle, composed of numerous rehearsals and long traveling hours, which could negatively influence their physical activity level. In addition, musicians can be reluctant to practice sports because of the risk of sports-related injuries that impact on playing music. Brandfonbrener ${ }^{12}$ described that $62 \%$ of freshman music students reported to exercise regularly, defined as 2 times/week for 30 minutes or more. Ginsborg et al. ${ }^{13}$ concluded that music students are less physically active when compared to other students. Our hypothesis is that a lower physical activity level is associated with more musculoskeletal complaints in musicians. In a cross-sectional design, it has already been shown that instrumentalists with pain were less engaged in physical activity than instrumentalists without pain. ${ }^{14}$ However, exact knowledge on the amount or intensity of physical activity that could prevent the development of PRMDs is lacking and needs further research. ${ }^{15}$ The aim of this study was to explore the level of physical activity in music students and 
to study the relationship between different levels of physical activity (moderate and vigorous intensity) and the presence of musculoskeletal complaints in this specific population. A second goal was to assess the strength of the associations between physical activity level, pain intensity, quality of life, and disability in music students.

\section{Methods}

\section{Subjects and Procedures}

In this cross-sectional study, an electronic questionnaire was sent by e-mail to 1406 music students in their third or fourth year of study. Eight of nine Dutch music schools (conservatories) participated. Questionnaires were designed, distributed, and collected using a well-secured, web-based tool (Formdesk, Innovero Software Solutions B.V.). Questionnaires were available in both Dutch and English language, since a large number of conservatory students are from abroad and do not speak Dutch. Students were asked to answer the questionnaire in the language they understood best. Informed consent was signed before the digital questionnaire could be entered. Every participant was rewarded with a small gift (pencil with pencil holder) after completion and return of the questionnaire. To further enhance the response, a reminder e-mail was sent to non-responders at 2 and 4 weeks after sending the initial questionnaire. Additionally, posters and flyers were distributed in the participating music schools. The Medical Ethical Committee of Maastricht University Medical Centre approved the study (METC 12-4-031). The study was conducted in accordance with the Declaration of Helsinki.

\section{Measures}

\section{Demographic Variables}

Demographic characteristics recorded were age, sex, height, and weight. Body mass index (BMI) was calculated based on height and weight. Music-specific characteristics recorded were conservatory (ArtEZ School of Music, Codarts University for the Arts, Fontys School of Fine and Performing Arts, Maastricht Academy of Music, Music Academy Haarlem, Prince Claus Conservatoire Groningen, Royal Conservatoire The Hague, Utrecht School of the Arts), study year (year 3 or 4), study major (classical music, jazz/pop, music in education, historical instruments), instrument played (string, keyboard, wind, vocal, percussion, other), and playing hours per day ( $<2$ hours, $2-4$ hours, $4-6$ hours, $6-8$ hours, $>8$ hours).

\section{Activities of Daily Life and Physical Activity}

Activities of daily life in an average week in the past month were measured using a selfreport inventory, the Short QUestionnaire to Assess Health-enhancing physical activity (SQUASH). ${ }^{16}$ Reproducibility ( $\mathrm{rs}=0.58,95 \% \mathrm{Cl} 0.36-0.74$ ) and validity ( $\mathrm{rs}$ with activity monitoring $=0.45,95 \% \mathrm{Cl}$ $0.17-0.66)$ for the Dutch and English versions are moderate. ${ }^{16}$ This questionnaire assesses the 
level of activity in four domains: commuting activities, activities at work and school, household activities, and leisure time activities (e.g. sports). Students were asked to indicate the average time (days per week, hours and minutes per day) and type of activity. Total activity level was calculated into MET $\times$ minutes/week according to Ainsworth's compendium of physical activities. ${ }^{2}$ An MET is defined as the ratio of metabolic rate during a specific physical activity to the resting metabolic rate. ${ }^{2}$ Time (minutes/week) spent in different activities was presented in three categories: light intensity (MET<4.0), moderate intensity (MET 4.0 - 6.5), vigorous intensity (MET>6.5). Students were classified into two groups according to Dutch physical activity recommendations?: 1. Students who accomplish 30 minutes of moderate-intensity physical activity (MET 4.0 - 6.5) on a minimum of 5 days a week. Moderate-intensity activity is generally equivalent to a brisk walk and noticeably accelerates heart rate. ${ }^{6}$ 2. Students who accomplish 20 minutes of vigorous-intensity physical activity (MET > 6.5) on a minimum of 3 days/week. Vigorous-intensity activity is exemplified by jogging and causes rapid breathing and a substantial increase in heart rate. ${ }^{6}$

\section{Musculoskeletal Complaints, Disability, and Quality of Life}

Musculoskeletal complaints were recorded using one item from the Dutch Musculoskeletal Questionnaire $(\mathrm{DMQ})^{17}$ in which subjects indicate in which body regions they experienced complaints (pain, discomfort) during the last 7 days. Both English and Dutch versions have good psychometric properties. ${ }^{17,18}$ In addition, pain intensity was rated using a numerical rating scale (NRS, range 0 - 10). Disability was measured with the Disabilities of Arm, Shoulder, and Hand (DASH) questionnaire..$^{19}$ The DASH is a self-reported 30-item questionnaire for subjects with upper extremity musculoskeletal conditions that assesses symptoms and functional status focused on physical function, measured at the level of disability with 5-point Likert scales. Total score represents disability in general and ranges from 0 to 100, with a higher score meaning more disability. In addition, the questionnaire offers an optional module on specific disability for playing a musical instrument and consists of four additional questions that relate to the impact of the arm, shoulder, or hand problem on playing a musical instrument (score ranges from 0 - 100). Validity $(r>0.69)$, test-retest reliability $(I C C=0.96)$, and responsiveness are good..$^{20}$ The internal consistency (Cronbach's alpha $=0.95)$ and validity $(81 \%$ consistency with COPM; $k$-coefficient $=0.79)$ of the Dutch language version are good. ${ }^{21}$ Quality of life was assessed using the Short Form-12 Health Survey (SF-12). The SF-12 was developed to provide a brief alternative for the Short Form-36, which is a commonly used generic health status measure with good psychometric properties.22,23 The SF-12 is composed of 12 questions from the SF-36 in order to construct physical component summary scores (PCS) and mental component summary scores (MCS). ${ }^{24}$ Correlations between the SF-36 and SF-12 summary measures are 0.95 and 0.97 for PCS and MCS, respectively. ${ }^{25}$ Dutch oblique scoring algorithms were used to calculate component summary scores normed to a mean score of 50 with an SD of 10, with a higher score representing better quality of life. ${ }^{26}$ 


\section{Statistical Analysis}

SPSS version 19 (SPSS Inc., Chicago, IL) was used for statistical analysis. Summary statistics of continuous variables were presented in mean and standard deviation (SD). In case data were skewed, values are presented as median with interquartile range (IQR). A probability level of 0.05 $(p<0.05)$ was set for statistical significance. Differences between groups of students who accomplished and who did not accomplish recommendations for physical activity were assessed using independent samples t-test (t) when data were normally distributed and the Mann-Whitney $U$ test $(U)$ for non-normally distributed data. Pearson chisquare test $\left(x^{2}\right)$ was used for comparison of categorical data. Correlation coefficients ( $r$ ) were calculated to test for associations between pain intensity, BMI, quality of life, disability, and level of physical activity; Pearson's correlation coefficient was used for parametric data, and Spearman's correlation coefficient for non-parametric data. In order to compare groups of students with different levels of physical activity, comparisons were made between: 1 . Students who accomplished moderate-intensity physical activity recommendations and those who did not accomplish these levels; and 2. Students who accomplished vigorous intensity physical activity recommendations and those who did not. Differences in gender, BMI, pain, disability, quality of life, and participation in sports were studied.

\section{Results}

\section{Population Characteristics}

A total number of 132 students were included in the study. The response rate was $9.4 \%(132 / 1406)$. Half of the participating students (50.8\%) were in their third year of study. Sixty-four percent were female. The median age was 23 years (range $21.25-25.0$ ). Mean BMI was $22.16 \pm 3.53$ for females and $22.66 \pm 2.80$ for males. Students studied different majors: classical 34.1\%, jazz/pop 19.7\%, music in education 13.6\%, vocal 12.9\%, historical instruments $7.6 \%$, and other $12.1 \%$. Twenty-eight percent played a stringed instrument, 23\% a keyboard instrument, 22\% a wind instrument, 21\% vocalist, $2 \%$ percussion, and $4 \%$ others. Playing hours per day varied: $28 \%$ played $<2$ hours, $39.4 \%$ $2-4$ hours, $26.5 \% 4-6$ hours, and $6.1 \% 6-8$ hours a day.

\section{Activities of Daily Life and Physical Activity}

In the analysis of activities in daily life, one outlier (scoring higher than the maximum number of minutes per week) was removed. Table 1 shows the level of physical activity of music students in different activity domains. Total reported physical activity level had a median value of 6390 MET-min/wk. Most time was spent in light-intensity activities (median $1370 \mathrm{~min} / \mathrm{wk}$, IQR 700 - 2160), followed by moderate-intensity activities (median $480 \mathrm{~min} / \mathrm{wk}, \mathrm{IQR} 220$ - 780) and vigorous-intensity activities (median 0 min/wk, IQR 0 - 60). Most time was dedicated to household activities, followed by activities at work and school, leisure time, and commuting (Table 1). One single sport was practiced by $45 \%$ of the students, and $17 \%$ practiced two sports. Thirty-nine 
percent did not participate in any sports activity. The students practicing sports spent a median of 120 min (60 - 240) per week. The top 5 most practiced sports were running (32\%), fitness (19\%), swimming (12\%), yoga (6\%), and dancing (4\%). Sixty-two percent of the music students reported to perform moderate-intensity physical activity for a minimum of 30 min on 5 days each week. They thus accomplished moderate-intensity physical activity recommendations. Only $10 \%$ of the music students accomplished vigorous-intensity physical activity recommendations (at least 20 min of intense physical activity at least 3 times a week).

Table 1: Music students' physical activity

\begin{tabular}{ll}
\hline & $\begin{array}{l}\text { Physical activity level } \\
\text { median (interquartile range) }\end{array}$ \\
\hline Total amount (MET-min/week) & $6390(4285-9645)$ \\
Activity by intensity category (min/week) & $1370(700-2160)$ \\
Light & $480(220-780)$ \\
Moderate & $0(0-60)$ \\
Vigorous & \\
Activity by domain (min/week) & $200(90-300)$ \\
Commuting activities & $840(360-1500)$ \\
Activities at work and school & $1058(570-2040)$ \\
Household activities & $220(90-450)$ \\
Leisure time activities & $60(0-150)$ \\
-Sports & $30(0-120)$ \\
-Walking & $30(0-120)$ \\
-Cycling & $2010(1210-1330)$ \\
Total time spent in physical activity (min/week) &
\end{tabular}

\section{Comparing students with different levels of physical activity}

No significant differences were found between students who accomplished moderate-intensity physical activity recommendations and those who did not, nor between those of different:

- gender (\% female, $x^{2}=0.59, p=0.44$ )

- BMI (male $t=-0.09, p=0.93$; female $t=1.42, p=0.16$ )

- pain (\% yes $\left.x^{2}=0.54, p=0.46\right)$

- disability (general $U=1899, p=0.59$; music module $U=1958, p=0.80$ ), or

- quality of life (MCS U $=2004, p=0.98 ; P C S U=1965, p=0.83$ ).

Differences between students who accomplished recommendations for vigorous-intensity physical activity and those who did not are presented in Table 2. Results are comparable with the abovementioned for moderate-intensity physical activity: no significant differences between compliers and noncompliers to vigorous-intensity activity recommendations were found, except that students who met vigorous-activity levels were more likely to practice sports $\left(x^{2}=9.20\right.$, 
$p<0.01)$. Although not significantly different, the percentage of complaints in the group of students who were vigorous active (46.2\%) seemed lower when compared to the group of students not complying to vigorous intensity physical activity levels (69.5\%).

Table 2: Differences between musicians who accomplish (vigorous +) or do not accomplish (vigorous-) vigorous-intensity physical activity recommendations

\begin{tabular}{lcc}
\hline & Vigorous $+(\mathbf{n}=\mathbf{1 3})$ & Vigorous - $(\mathbf{n}=\mathbf{1 1 8})$ \\
\hline Gender (\% female) & $69 \%$ & $63 \%$ \\
BMI male & 25.73 SD 1.00 & 21.94 SD 2.70 \\
BMI female & 22.94 SD 2.29 & 22.06 SD 3.68 \\
Complaints past 7 days (\% yes) & $46.2 \%$ & $69.5 \%$ \\
Pain score NRS & 5 IQR 2-7.5 & 5 IQR 3-7 \\
Disability general & 2.5 IQR 0-15 & 3.33 IQR 0-9.2 \\
Disability music module & 0 IQR 0-18.8 & 6.25 IQR 0-25 \\
SF-12 MCS & 43.5 IQR 28.3-53.0 & 43.9 IQR 31.9-49.2 \\
SF-12 PCS & 54.4 IQR 28.3-53.9 & 51.6 IQR 44.6-56.3 \\
Minimal 1 sport (\%yes) & $100 \%$ & $57 \% *^{*}$ \\
\hline
\end{tabular}

Significance level: ${ }^{*} p<0.01$

\section{Musculoskeletal Complaints, Disability, and Quality of Life}

Prevalence of complaints (pain, discomfort) in the past 7 days was $67.4 \%$. Complaints were most commonly experienced in the upper extremities (Table 3). The mean level of pain intensity scored on the NRS was $4.73 \pm 2.17$ for those who experienced pain. Median disability DASH score was 3.33 (0 - 9.79) with a median music module score of 6.25 (0-25). With respect to quality of life, the median PCS was 51.67 (44.77 - 56.38) and median MCS was 43.71 (31.96 - 49.25).

Table 3: Occurrence of complaints in music students by body part in the past 7 days

\begin{tabular}{ll}
\hline Body part & Frequency (\%) \\
\hline Head/ neck & $43.2 \%$ \\
Upper back & $34.8 \%$ \\
Lower back & $28.8 \%$ \\
Shoulder & $33.3 \%$ \\
Elbow & $5.3 \%$ \\
Wrist/hand & $22.0 \%$ \\
Hip/thigh & $3.8 \%$ \\
Knee & $7.6 \%$ \\
Ankle/foot & $5.3 \%$ \\
\hline
\end{tabular}




\section{Associations}

In Table 4, associations are given between pain intensity, BMI, quality of life, disability, and physical activity. No significant associations were found between physical activity and pain intensity $(r=0.12, p=0.26)$, BMI $(r=0.07, p=0.43)$, quality of life (PCS $r=-0.06, p=0.50$; MCS $r=-0.15$, $p=0.09$ ), or disability (general $r=0.09, p=0.34$; playing a musical instrument $r=0.03, p=0.70$ ). Pain intensity showed a negative association with the physical subscale ( $P C S r=-0.53, p<0.01$ ) and mental subscale (MCS $r=-0.33, p<0.01$ ) of quality of life. A positive association was found between pain intensity and disability in general $(r=0.43, p<0.01)$ and disability playing a musical instrument $(r=0.35, p<0.01)$. Both subscales of quality of life were negatively associated with disability in general (PCS $r=-0.54, p<0.01$; MCS $r=-0.28, p<0.01)$.

Table 4: Association matrix of physical activity with pain intensity, BMI, quality of life and disability in music students

\begin{tabular}{lcrrrrrrr}
\hline & $\mathbf{1}$ & $\mathbf{2 \#}$ & $\mathbf{3}$ & $\mathbf{4}$ & $\mathbf{5}$ & $\mathbf{6}$ & $\mathbf{7}$ & $\mathbf{8}$ \\
\hline 1. pain (NRS) & & & & & & & & \\
2. BM!* & -0.066 & & & & & & \\
3. PCS & $-0.532^{*}$ & -0.025 & & & & & \\
4. MCS & $-0.328^{*}$ & 0.082 & $0.522^{*}$ & & & & \\
5. DASH_g & $0.427^{*}$ & -0.153 & $-0.535^{*}$ & $-0.275^{*}$ & & & \\
6. DASH_m & $0.350^{*}$ & -0.154 & $-0.408^{*}$ & -0.144 & $0.738^{*}$ & & \\
7. PA_It & 0.062 & 0.155 & 0.052 & -0.046 & 0.048 & -0.011 & \\
8. PA_t & 0.122 & 0.070 & -0.059 & -0.150 & 0.085 & 0.033 & $0.440^{*}$ \\
\hline
\end{tabular}

* $\mathrm{p}<0.01$; \# controlled for gender; BMI, body mass index; PCS physical component score Short-Form 12; MCS, mental component score Short-Form 12; DASH_g, general score in Disability of Arm Shoulder Hand; DASH_m, Music module score of Disability of Arm Shoulder Hand; PA_It physical activity in leisure time (minutes per week); PA_t, total physical activity (minutes per week)

\section{Discussion}

Sixty-seven percent of third-and fourth-year music students reported musculoskeletal complaints (pain, discomfort) in the past 7 days. Median physical activity level was 6390 MET-min/wk. A median of 2010 minutes was spent per week in physical activity. Sixty-two percent of music students accomplished 30 minutes of moderate-intensity physical activity on a minimum of 5 days a week. Ten percent of the students accomplished 20 minutes of vigorous intensity physical activity on a minimum of 3 days a week. No correlation was found between physical activity in the past months and pain in the last week. Results have to be interpreted in the light of the methodological shortcomings of this study. The response rate of $9.4 \%$ is low. Despite two reminder e-mails and the distribution of posters and flyers to the conservatories to remind students to return the questionnaires, the response remained low. The low response rate might have induced a selection bias: students with complaints might have been more motivated to fill out a questionnaire concerning health than did students without complaints. Since we were not able or allowed to collect any data on the non-responders, it is not possible to confirm or reject this hypothesis. 
Using web-based questionnaires in the general population seems feasible, ${ }^{27}$ but the response rate is often lower compared to a postal survey. ${ }^{28}$ Other studies using electronic questionnaires in a music student population also reported low response rates. ${ }^{29,30}$ In these studies, prevalence of complaints $^{29}$ and physical activity leve ${ }^{30}$ are comparable to our findings. The response rate might be increased by asking students to fill out questionnaires in class or providing better incentives, though the latter is not always possible due to local ethical considerations. Another shortcoming of this study is the cross-sectional design. No causal relationships can be shown using a retrospective research design, only associations can be studied. Future research based on a prospective design is therefore recommended. The median physical activity level was $6390 \mathrm{MET}-\mathrm{min} / \mathrm{wk}$. This does not include the physical activity required to play the instrument. Energy costs for music playing (excluding marching band players) are in the light intensity category. ${ }^{2}$ The largest category of students reported playing their instrument for $2-4$ hours/day. When extrapolating these results, it could be considered that the actual median physical activity level of music students is higher than 6390 MET-min/wk. Nonetheless, since health benefits are assumed to originate from moderate- or vigorous-intensity activities, it is not likely that this extra light-intensity activity contributes to better health. Contrasting music students with healthy adolescents, the median physical activity level and median time per week spent on physical activity are comparable. ${ }^{31}$ Although Ginsborg et al..$^{13}$ concluded that music students are less physically active than other students, this general finding could not be confirmed in our study. More specifically, the percentage of music students complying with moderate-intensity physical activity guidelines conformed to Dutch national results in students (62\% vs 47\%). ${ }^{32}$ However, the percentage of music students complying with vigorous-intensity physical activity recommendations was lower (10\% vs 39.5\%) when set against the Dutch general student population..$^{32}$ The physical activity measurement tool we used enables researchers to differentiate between intensity categories and activities in several domains. This provides stronger evidence to conclude that music students are as active as other students when considering moderate-intensity activity, but they are less involved in vigorous-intensity activities. An even larger difference in vigorous-intensity activities exists between music students and adolescent athletes. Athletes reported in an activity diary being involved for a mean of 94 minutes/day in high intensity exercise. ${ }^{33}$ This is in marked contrast with the music student, who is only minimally involved in vigorous-intensity activities (median 0 minutes/week). Physical activity was not significantly associated with musculoskeletal complaints in music students. Physical activity level was not associated with pain level on a numerical rating scale and there were no differences in prevalence of complaints in the past 7 days between students complying with moderate- or vigorous-intensity recommendations and students who did not. No dose-response relationship could be shown. Our hypothesis that a lower physical activity level is correlated with more musculoskeletal complaints has to be rejected. It is plausible that neither the amount nor intensity of physical activity, but rather the specificity of the training, is the most important element in the relationship between physical activity and PRMDs. Previous studies ${ }^{34,35}$ showed that specific exercise programs for musicians, improving strength of supporting musculature and enhancing postural and movement efficacy relevant to instrument playing, resulted in a decrease in PRMDs and enhanced physical competence of the musician. In contrast, generic exercises were 
found to be inadequate. ${ }^{34}$ On the other hand, our results do show that there is also no negative association between physical activity and complaints. Being involved in vigorous-intensity physical activity or sports was not associated with more complaints. Hence, the fear of musicians getting injured while playing sports (top 5 practiced sports were endurance sports such as running, fitness, swimming, yoga, and dancing), can be challenged. Emphasizing the remarkably low vigorous-intensity activity level of the music student compared with the general student and the even larger difference with the adolescent athlete, music students might be encouraged to practice vigorous-intensity physical activity, embedded in a specific exercise program, to optimize health and contribute to performance.

The percentage of music students reporting having experienced pain or discomfort in the past 7 days (67\%) is comparable with previous research. ${ }^{10,11}$ Mean pain intensity was $4.73 \pm 2.17$ for those who experienced pain. Concerning quality of life, we found a discrepancy between the median physical (PCS 51.67) and mental (MCS 43.71) component summary score, indicating a relatively lower quality of mental well-being. Lower mental quality of life scores have been previously mentioned in music students. ${ }^{10}$ Reported disability levels were low and are also comparable with previous research. ${ }^{36}$ An added value of this research was that we were able to confirm associations between higher pain intensity with more disability and a lower quality of life (both physical and mental), showing the impact of pain on the musician's life. These associations are well accepted in chronic pain literature, but are up till now just barely mentioned in the field of music medicine. It should be encouraged not only to measure complaints, but also focus at the consequences of the complaints (i.e., disability) for playing and quality of life. In addition to the aforementioned methodological limitations, some remarks on measurements have to be made. First, extension of measurements of physical activity using more objective physical activity monitoring methods, such as accelerometers or exercise tests, to measure physical fitness would have strengthened the current findings on music student's physical activity, since questionnaires only measure subjectively experienced physical activity. Second, physical complaints (pain, discomfort) were measured using the Dutch Musculoskeletal Questionnaire. This provides information on a broad range of musculoskeletal complaints. To focus on complaints related to playing music, it would be better to measure playing-related complaints with a properly designed and validated questionnaire. Such a questionnaire was developed only after our research was performed. ${ }^{37}$

\section{Conclusions}

Sixty-seven percent of third- and fourth-year music students reported musculoskeletal complaints (pain, discomfort) in the past 7 days. Music students were mainly involved in light- to moderate-intensity physical activities and were barely involved in vigorous-intensity physical activity. Sixty-two percent of music students accomplished 30 minutes of moderate-intensity physical activity on a minimum of 5 days/week. Ten percent of the students accomplished 20 minutes of vigorous-intensity physical activity on a minimum of 3 days a week. Physical activity level was not correlated with musculoskeletal complaints. Higher pain intensity was found to be associated with lower level quality of life, and higher disability. 


\section{Acknowledgements}

The authors thank the conservatories for participation in our study: ArtEZ School of Music, Codarts University for the Arts, Fontys School of Fine and Performing Arts, Maastricht Academy of Music, Music Academy Haarlem, Prince Claus Conservatoire Groningen, Royal Conservatoire The Hague, and Utrecht School of the Arts. 


\section{References}

1. Horvath J. An orchestra musician's perspective on 20 years of performing arts medicine. Med Probl Perform Art.2001;16(3):102-108.

2. Ainsworth BE, Haskell WL, Herrmann SD, et al. 2011 compendium of physical activities: a second update of codes and MET values. Med Sci Sports Exerc. 2011;43(8):1575-81.

3. Baadjou VAE, van Eijsden-Besseling MD, Samama-Polak AL, et al. Energy expenditure in brass and woodwind instrumentalists: the effect of body posture. Med Probl Perform Art. 2011;26(4):218-23.

4. Drinkwater EJ, Klopper CJ. Quantifying the physical demands of a musical performance and their effects on performance quality. Med Probl Perform Art. 2010;25:66-71.

5. Warburton DE, Nicol CW, Bredin SS. Health benefits of physical activity: the evidence. CMAJ. 2006;174(6):801-9.

6. Haskell WL, Lee IM, Pate RR, et al. Physical activity and public health: updated recommendation for adults from the American College of Sports Medicine and the American Heart Association. Med Sci Sports Exerc. 2007;39(8):1423-34.

7. Kemper HGC, Ooijendijk WTM, Stiggelbout M. Consensus over de Nederlandse Norm voor Gezond Bewegen. Tijdschr Soc Gezondheidsz. 2000;78:180-183.

8. Warburton DER, Charlesworth S, Ivey A, et al. A systematic review of the evidence for Canada's physical activity guidelines for adults. Int J Behav Nutr Phys Act. 2010;7:39.

9. Ratzlaff CR, Gillies JH, Koehoorn MW. Work-related repetitive strain injury and leisure-time physical activity. Arthritis Rheum. 2007;57(3):495-500.

10. Spahn C, Strukely S, Lehmann A. Health conditions, attitudes toward study, and attitudes toward health at the beginning of university study: music students in comparison with other student populations. Med Probl Perform Art. 2004;19:26-33.

11. Zaza C. Playing-related musculoskeletal disorders in musicians: a systematic review of incidence and prevalence. CMAJ. 1998; 158:1019-1025.

12. Brandfonbrener AG. History of playing-related pain in 330 university freshman music students. Med Probl Perform Art. 2009;24:30-36.

13. Ginsborg J, Kreutz G, Thomas M, Williamon A. Healthy behaviours in music and non-music performance students. Health Educ. 2009;109(3):242-258.

14. Roach KE, Martinez MA, Anderson N. Musculoskeletal pain in student instrumentalists: a comparison with the general student population. Med Probl Perform Art. 1994;9:125-130.

15. Clark T, Williamon A, Redding E. The value of health screening in music schools and conservatoires. Clin Rheumatol. 2013;32:497-500.

16. Wendel-Vos GC, Schuit AJ, Saris WH, Kromhout D. Reproducibility and relative validity of the short questionnaire to assess health-enhancing physical activity. J Clin Epidemiol. 2003; 56 (12):1163-1169.

17. Hildebrandt VH, Bongers PM, van Dijk FJH, et al. Dutch musculoskeletal questionnaire: description and basic qualities. Ergonomics. 2001;44(12):1038-1055.

18. Kuorinka I, Jonsson B, Kilbom A, et al. Standardised Nordic questionnaire for the analysis of musculoskeletal symptoms. Appl Ergon. 1987;18:233-237.

19. Hudak PL, Amadio PC, Bombardier C. Development of an upper extremity outcome measure: the DASH (disabilities of the arm, shoulder and hand). Am J Ind Med. 1996;29:602-608. 
20. Beaton DE, Katz JN, Fossel AH, et al. Measuring the whole or the parts? Validity, reliability, and responsiveness of the Disabilities of the Arm, Shoulder and Hand outcome measure in different regions of the upper extremity. J Hand Ther. 2001;14(2):128-146.

21. Veehof MM, Sleegers EJA, van Veldhoven NHMJ, Set al. Psychometric qualities of the Dutch language version of the disabilities of the arm, shoulder, and hand questionnaire (DASHDLV). J Hand Ther. 2002;15:347-354.

22. Aaronson NK, Muller M, Cohen PD, et al. Translation, validation, and norming of the Dutch language version of the SF-36 Health Survey in community and chronic disease populations. J Clin Epidemiol. 1998;51(11):1055-68.

23. Ware JE Jr., Sherbourne CD. The MOS 36-item short-form health survey (SF-36): I. Conceptual framework and item selection. Med Care. 1992;30(6):473-83.

24. Ware J Jr., Kosinski M, Keller SD. A 12-Item Short-Form Health Survey: construction of scales and preliminary tests of reliability and validity. Med Care. 1996;34(3):220-33.

25. Gandek B, Ware JE, Aaronson NK, et al. Cross-validation of item selection and scoring for the SF-12 Health Survey in nine countries: results from the IQOLA Project. International Quality of Life Assessment. J Clin Epidemiol. 1998;51(11):1171-8.

26. Mols F, Pelle AJ, Kupper N. Normative data of the SF-12 health survey with validation using postmyocardial infarction patients in the Dutch population. Qual Life Res. 2009;18(4):403-14.

27. Ekman A, Dickman PW, Klint A, et al. Feasibility of using webbased questionnaires in large population-based epidemiological studies. Eur J Epidemio.I 2006;21(2):103-11.

28. Balajti I, Darago L, Adany R, Kosa K. College students' response rate to an incentivized combination of postal and web-based health survey. Eval Health Prof. 2010;33(2):164-76.

29. Kok LM, Vliet Vlieland TPM, Fiocco M, Nelissen RGHH. A comparative study on the prevalence of musculoskeletal complaints among musicians and non-musicians. BMC Musculoskelet Disord. 2013;14:9.

30. Kreutz G, Ginsborg J, Williamon A. Health-promoting behaviours in conservatoire students. Psychol Mus. 2009;37:47.

31. Stommen NC, Verbunt JA, Gorter SL, Goossens MEJB. Physical activity and disability among adolescents and young adults with non-specific musculoskeletal pain. Disabil Rehabil. 2012; 34(17):1438-1443.

32. Bernaards CM. Bewegen in Nederland 2000-2013 : resultaten TNO-monitor bewegen en gezondheid. TNO. Leiden2014.

33. Aerenhouts D, Zinzen E, Clarys P. Energy expenditure and habitual physical activities in adolescent sprint athletes. J Sports Sci Med. 2011;10:362-368.

34. Chan C, Driscoll T, Ackermann BJ. Effect of a musician's exercise intervention on performance-related musculoskeletal disorders. Med Probl Perform Art. 2014;29(4):181-188.

35. de Greef M, van Wijck R, Reynders K, et al. Impact of the Groningen exercise therapy for symphony orchestra musicians program on perceived physical competence and playing-related musculoskeletal disorders of professional musicians. Med Probl Perform Art. 2003;18:156-160.

36. Barton R, Killian C, Bushee $M$, et al. Occupational performance issues and predictors of dysfunction in college instrumentalists. Med Probl Perform Art. 2008;23(2):72-78.

37. Berque P, Gray H, McFayden A. Development and psychometric evaluation of the Musculoskeletal Pain and Interference questionnaire for professional orchestra musicians. Manual Ther. 2004;19:575-588. 


\section{Chapter 3}

\section{Systematic review on risk factors for musculoskeletal complaints in musicians}

Published as: Baadjou VA, Roussel NA, Verbunt JAMCF, Smeets RJEM, de Bie RA. Systematic review on risk factors for musculoskeletal disorders in musicians. Occup Med. 2016; 66 (8): 614-622. 


\section{Abstract}

Background: Although many musicians suffer from musculoskeletal disorders, aetiological factors are unclear.

Aims: To systematically search for and synthesize the best available evidence on risk factors for musculoskeletal disorders in musicians.

Methods: A database search was performed in PubMed, EMBASE, CINAHL, Pedro, OTseeker and Psychinfo. A manual search was conducted in the journals Medical Problems of Performing Artists and Psychology of Music. Studies with an objective to investigate determinants associated with playing-related musculoskeletal disorders were included. Papers were selected based on adequacy of statistical methods for the purpose of the study. Search, first screening and selection were performed by one author. Two reviewers independently performed the final selection using full-text reports. Methodological quality assessment was performed by two reviewers independently.

Results: One case-control and 14 cross-sectional studies were included. Methodological quality was in general low. Large heterogeneity existed in study design, population, measurement of determinant and outcome and analysis techniques. Data were presented descriptively. Consistent results were found indicating that previous musculoskeletal injury, music performance anxiety, high levels of stress and being a female playing a stringed instrument seemed to be associated with more musculoskeletal disorders. Influence over or support at work, orchestra category/status, exercise behaviour and cigarette smoking seemed to be unrelated with musculoskeletal disorders. No conclusions could be made on causality, as the current data only represent cross-sectional associations.

Conclusions: Because of lack of prospective studies, no causal relations could be identified in the aetiology of (playing-related) musculoskeletal disorders in instrumental musicians. 


\section{Introduction}

Musicians are at risk for musculoskeletal symptoms, frequently referred to as playing-related musculoskeletal disorders (PRMD). PRMD are defined as 'pain, weakness, numbness, tingling or other symptoms that interfere with the ability to play the instrument at the level you are accustomed to.' ' A recent systematic review in musicians concluded that lifetime prevalence of pain affecting the playing capacity was as high as $85 \%{ }^{2}$ Factors such as job insecurity, denial, injury stigmatization and fear of judgment mean that musicians often play regardless of the existence of injury to the point of chronic disability. Insight into the aetiology of PRMD is necessary to be able to implement preventative measures. Until now, mainly single, physical and biomechanical factors have been studied. ${ }^{3}$ Two previous reviews judged that no conclusions on causality could be made since studies are of retrospective design, lack an operational definition of PRMD, do not use valid and reliable measurement tools or use inappropriate statistical tests. ${ }^{4,5}$ In addition, possible effects of differences in biomechanical playing load between instruments were often ignored. ${ }^{4}$ A model with multiple risk factors combining physical, biomechanical and psychosocial risk factors seems more likely to predict the occurrence of PRMD. ${ }^{3}$ The optimal way to search for risk factors is to conduct a prospective study, with an a priori-defined (multivariate) risk model based on current literature. ${ }^{6}$ The study sample should adequately represent the population, and data should adequately represent the study sample. Furthermore, it is important to provide clear definitions and valid measurements of risk factor, outcome and possible confounders. The statistical model should be adequate for the design of the study. ${ }^{6}$ The objective of the current study was to review prospective cohort, case-control or cross-sectional studies examining risk factors for musculoskeletal pain or disability of spine and/or extremities as measured by a questionnaire in a population of pre-professional (full-time music students) and professional instrumentalists. Since the publication of the two previous reviews, new quality assessment instruments have become available to assess the risk of bias in studies of prognostic factors allowing us to better interpret results. ${ }^{4-6}$

\section{Methods}

The study protocol was registered: PROSPERO 2013:CRD42013006929. The preferred reporting items for systematic reviews and meta-analyses (PRISMA) statement and checklist were used for reporting. Ethical approval was not required for this review. A search for peer-reviewed articles was performed in the following databases: PubMed (1971 - April 2015), EMBASE (1974 - April 2015), CINAHL (1982 - April 2015), Pedro (1929 - April 2015), OTseeker (2002 - April 2015), Psychinfo (2001 - April 2015). A manual search was performed in the journals Medical Problems of Performing Artists (1986 - April 2015) and Psychology of Music (1973 - April 2015). Reference lists from included papers were screened for unidentified papers. A comprehensive search string was formulated for PubMed consisting of three parts: 1. 'Musculoskeletal Diseases' [Mesh] with relevant related terms; AND 2.' Music' with relevant related terms; AND 3. 'Risk factor' with relevant related terms (Appendix 1). For CINAHL, EMBASE, Psychinfo, Pedro and OTseeker, only parts 1 and 2 of the search string ('music' AND 'musculoskeletal' with relevant synonyms) were explored. 
Eligibility criteria were presented according to the PICOS (participant, intervention, control, outcome, study design) model in Table 1. Two additional categories were added: language and statistics. Only peer-reviewed papers were considered for inclusion. Conference proceedings and dissertations were excluded. Study titles were first screened on relevance by the first author (V.A.E.B.), thereafter a second selection was made on title and abstract using eligibility criteria (V.A.E.B.). Third and last selection was performed independently by two authors (V.A.E.B. and N.A.R.) using full text, applying eligibility criteria, with a strong focus on outcome measurements used and quality of statistical analyses. In case of discrepancy, consensus was reached by discussion (V.A.E.B. and N.A.R.) and consultation of a third reviewer (R.A.B.). Corresponding authors were contacted when the paper lacked information to perform adequate selection or quality assessment. Given that a standard tool to assess quality of retrospective observational studies is lacking, we constructed a specific quality assessment tool for this review. The tool was based on information provided in a review on tools for assessing quality and susceptibility to bias in observational studies, the quality in prognostic studies (QUIPS) tool, the strengthening the reporting of observational studies in epidemiology (STROBE) statement, and a previously used quality assessment checklist in observational research. ${ }^{6,8-10}$

Table 1. PICOS model of eligibility criteria

\begin{tabular}{|c|c|c|}
\hline & Inclusion & Exclusion \\
\hline Population & $\begin{array}{l}\text { - Pre-professional (fulltime music students) } \\
\text { and professional instrumentalists } \\
\text { - All instruments }\end{array}$ & $\begin{array}{l}\text { - Amateur musicians } \\
\text { - High school students } \\
\text { - College (not fulltime music) students } \\
\text { - Marching band musicians } \\
\text { - Vocalists }\end{array}$ \\
\hline Intervention & $\begin{array}{l}\text { - Objective to investigate determinants associated } \\
\text { with (playing-related) musculoskeletal disorders }\end{array}$ & $\begin{array}{l}\text { - Studies with aim only to investigate } \\
\text { prevalence of complaints }\end{array}$ \\
\hline $\begin{array}{l}\text { Control (only applicable } \\
\text { in case-control design) }\end{array}$ & $\begin{array}{l}\text { - Instrumentalists without } \\
\text { musculoskeletal complaints }\end{array}$ & \\
\hline Outcome & $\begin{array}{l}\text { - Musculoskeletal pain/ disability (playing- } \\
\text { related) of spine and/or extremities } \\
\text { as measured by questionnaire }\end{array}$ & $\begin{array}{l}\text { - Neurologic disease } \\
\text { - Temporomandibular disorders } \\
\text { - Headache } \\
\text { - Trauma } \\
\text { - Physical parameters }\end{array}$ \\
\hline Study Design & $\begin{array}{l}\text { - Cohort } \\
\text { - Case-control } \\
\text { - Cross-sectional }\end{array}$ & $\begin{array}{l}\text { - Case studies } \\
\text { - Qualitative research } \\
\text { - Review } \\
\text { - Randomised controlled trial }\end{array}$ \\
\hline Language & All & \\
\hline Statistics & $\begin{array}{l}\text { - Use adequate statistical method to determine } \\
\text { risk factors (i.e. regression analysis) } \\
\text { - Present adequate measure of association (i.e. } \\
\text { standardized beta / } \mathrm{r}^{2}, \text { OR/RR with } 95 \% \mathrm{Cl} \text { or } \\
\text { present sufficient data to calculate OR/RR) }\end{array}$ & $\begin{array}{l}\text { - Only descriptive statistics } \\
\text { - When comparing prevalence of } \\
\text { complaints between groups only using } \\
\text { simple t-tests or correlations }\end{array}$ \\
\hline
\end{tabular}


Key domains were study objective and design, study population, measurement instruments, data reporting and analysis. In total, 14 criteria were included. For case-control studies, one extra item was taken into account (rationale for cases and controls). Criteria and scores are presented in Table 2. A positive score (1) indicated that the item was well described and well performed. A negative score (0) indicated that the item was not reported, not well performed or unclear. Quality assessment was performed by two reviewers independently (V.A.E.B. and N.A.R.). Interrater agreement was calculated with a four-field Cohen's kappa. One reviewer (V.A.E.B.) extracted study methods and outcomes. Extracted items were participant characteristics, instrument, demographics, study design, outcome definition, (adjusted) analysis, univariate and multivariate results. Determinants were categorized in socio-demographic, health-related, physical, psychosocial, workrelated and prevention. If data were sufficient, results were categorized according to instrument group and pain localization. The principle summary measure was the odds ratio (OR) with its corresponding 95\% confidence interval (CI). When OR was unavailable, standardized beta values (b) with corresponding P value and/or $r^{2}$ were presented. Data extraction was discussed with three other reviewers (N.A.R., R.A.B. and R.J.E.M.S.) in separate sessions. If results could be compared methodologically and clinically, pooling was considered. If the quality of data were sufficient, a subgroup analysis was performed on instrument type. When pooling was not possible, a qualitative analysis would be executed. Quality of the studies was rated according to the Royal College of General Practitioners (RCGP) three-star system grading of evidence. ${ }^{11} \mathrm{~A}$ three-star $\left(^{* * *}\right)$ rating was given in case of a generally consistent finding in a majority of multiple acceptable studies. A two-star $(* *)$ rating was either based on a single acceptable study or a weak or inconsistent finding in some of multiple acceptable studies. One star $\left(^{*}\right)$ was given when limited scientific evidence does not meet all the criteria of acceptable studies. Acceptable studies were defined as cohort or case-control studies. Retrospective observational studies were found inadequate to research risk factors. Results were defined as consistent if at least two papers reported the determinant to be associated or not to be associated with the outcome. Univariate and multivariate results were described separately. 
Table 2. Results of methodological quality assessment

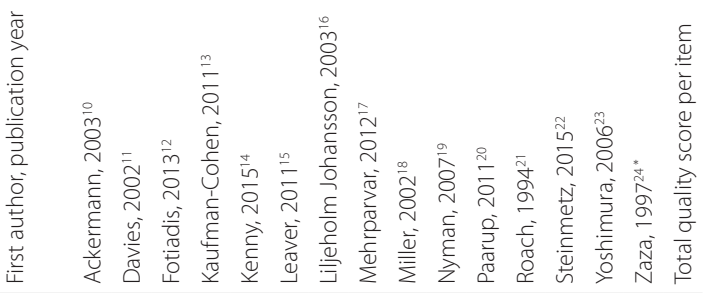

Study objective and design

1. Clearly stated objective $\begin{array}{llllllllllllllll}1 & 1 & 1 & 1 & 1 & 1 & 0 & 1 & 1 & 1 & 1 & 1 & 1 & 1 & 1 & 14\end{array}$

Study population

\section{Description of eligibility criteria \\ 3. Description of selection of study population \\ 4. Description of population characteristics \\ 5. If case-control study: Provide rationale for cases and controls \\ 6. Participation rate $>80 \%$}

Measurement instruments

7. Appropriate outcome definition and assessment

8. Appropriate definition and assessment of determinants

Data reporting

$\begin{array}{llllllllllllllllll}\text { 9. Frequencies of most important outcome measures } & 0 & 0 & 0 & 0 & 0 & 1 & 0 & 1 & 0 & 0 & 1 & 0 & 0 & 0 & 0 & 3 \\ \begin{array}{l}\text { 10. Frequencies of most important determinants } \\ \text { 11. Measures of association presented }\end{array} & 1 & 1 & 0 & 1 & 1 & 0 & 0 & 0 & 0 & 0 & 1 & 1 & 1 & 1 & 1 & 9 \\ & 1 & 1 & 1 & 1 & 1 & 1 & 1 & 1 & 1 & 1 & 1 & 1 & 1 & 1 & 1 & 15\end{array}$
Analysis

12. Appropriate statistical model $\begin{array}{llllllllllllllll}0 & 1 & 0 & 0 & 1 & 1 & 1 & 0 & 0 & 1 & 0 & 0 & 1 & 1 & 1 & 8\end{array}$

13. Controlled for confounding or effect modification $\begin{array}{llllllllllllllll}0 & 1 & 0 & 1 & 1 & 1 & 1 & 0 & 0 & 1 & 1 & 0 & 1 & 0 & 1 & 9\end{array}$ Other

14. No conflicts of interest, identification of funding sources

15. Other sources of bias, not mentioned before

$\begin{array}{llllllllllllllll}0 & 0 & 0 & 1 & 0 & 1 & 0 & 0 & 0 & 0 & 1 & 0 & 1 & 0 & 0 & 4 \\ 0 & 0 & 0 & 0 & 1 & 1 & 0 & 0 & 0 & 0 & 0 & 0 & 0 & 0 & 1 & 3 \\ 5 & 7 & 3 & 8 & 11 & 11 & 5 & 4 & 4 & 6 & 9 & 5 & 8 & 7 & 12 & \end{array}$

1: positive score, item is well-described and/ or well-performed; 0: negative score, item is not reported, not well performed or unclear;-not applicable; * case-control study 


\section{Results}

The electronic search yielded 2141 citations. After first screening and removal of duplicates, 131 papers remained. Hand search yielded 38 additional papers. After a second selection on title and abstract using eligibility criteria, 61 papers remained. Most articles were excluded because of intervention (for example studies with the aim only to investigate prevalence of complaints), study design or outcome measures. Three authors were contacted to provide more information on population. ${ }^{12-14}$ In a third selection round using full-text reports, another 46 papers were excluded. Adequacy of statistical analysis was the main reason for exclusion in this round. Six authors were contacted to provide additional information concerning statistical analysis, ${ }^{12,15-19}$ for example, when insufficient data were provided in the text to assess whether appropriate statistical analysis was performed or when not enough data were provided to calculate OR/risk ratio (RR). Finally, 15 papers were included. ${ }^{12,15-17,20-30}$ See figure 1. The results of methodological quality assessment are presented in Table 2. Proportion of agreement over and above chance (Cohen's kappa) between the two quality assessors was based on 211 items for the 15 papers, and was 0.773 , $\mathrm{P}<0.001$, indicating substantial agreement. ${ }^{31}$ Fourteen of the included papers used a cross-sectional design 12,15-17,20-29 and one paper used a case-control design, 30 in which a maximum quality score of 14 and 15 points could be obtained, respectively. In general, methodological quality was low. Median score per paper for the cross-sectional studies was 6.5 (minimum 3, maximum 11). The case-control study scored 12 out of 15 points. Median total quality score per item was 7.5 (range 1 - 15). Quality of statistical analyses was moderate (8/15 papers appropriately described the statistical model used, 9/15 papers appropriately controlled for confounding or effect modification). Items with a score below the median were (from lowest to highest) participation rate, other sources of bias, description of eligibility criteria, reporting of frequencies of most important outcome measures, appropriate outcome definition and assessment, presentation of conflicts of interest or identification of funding sources. Due to heterogeneity between studies, pooling of results was not possible. The case-control study received a RCGP ** rating..$^{30}$ The 14 cross-sectional studies were not considered to be acceptable studies to research risk factors and were scored RCGP * 12,15-17,20-29. Quality of data was not sufficient to perform subgroup analysis on instrument type. A qualitative analysis was executed presenting results from cross-sectional and case-control research separately. Participant characteristics are presented in Table 3. Number of participants varied between $32{ }^{20}$ to $408{ }^{17}$, with a response rate between $45 \%{ }^{21}$ and $99.7 \%{ }^{16}$ Most studies included classical professional orchestra players. $12,15,17,21-25,27,28$ One paper also included non-classical and freelance musicians. ${ }^{21}$ Five papers included music students or a combination of professionals and students. ${ }^{16,20,26,29,30}$ Mean age varied between $23{ }^{16}$ and 48 years. ${ }^{28}$ One paper only included players of viola or violin ${ }^{20}$, one paper only pianists. ${ }^{29}$ Study design and significant results of final models are presented in Supplmental Table S1. Appendices 2 and 3 present all determinants with univariate and multivariate results by category. Two papers used the same data set and reported on psychosocial ${ }^{25}$ and postural determinants ${ }^{27}$ separately. Two papers only presented univariate results, ${ }^{12,22}$ four only multivariate results, ${ }^{20,26-28}$ nine reported both univariate and multivariate results. ${ }^{15-17,21,23-25,29,30}$ From one study, only univariate results have been analyzed in this review since interaction terms in multivariate analysis were unclear. ${ }^{16}$ Outcome was described as pain, 
musculoskeletal complaints, PRMD, number of symptomatic upper limbs, pain severity, frequency of complaints, disability or functional limitations. Studies reported on complaints overall or specific complaints per body region. Outcome was assessed at different moments in time (current pain, last 7 days, last 4 weeks, last 12 months, ever). Outcome was often measured using self-developed non-validated questionnaires. Adaptations from the Nordic Musculoskeletal Questionnaire and questions adapted from the PRMD definition by Zaza were also used as outcome measures. ${ }^{1}$ In total, 84 distinct determinants for musculoskeletal disorders in musicians were analyzed.

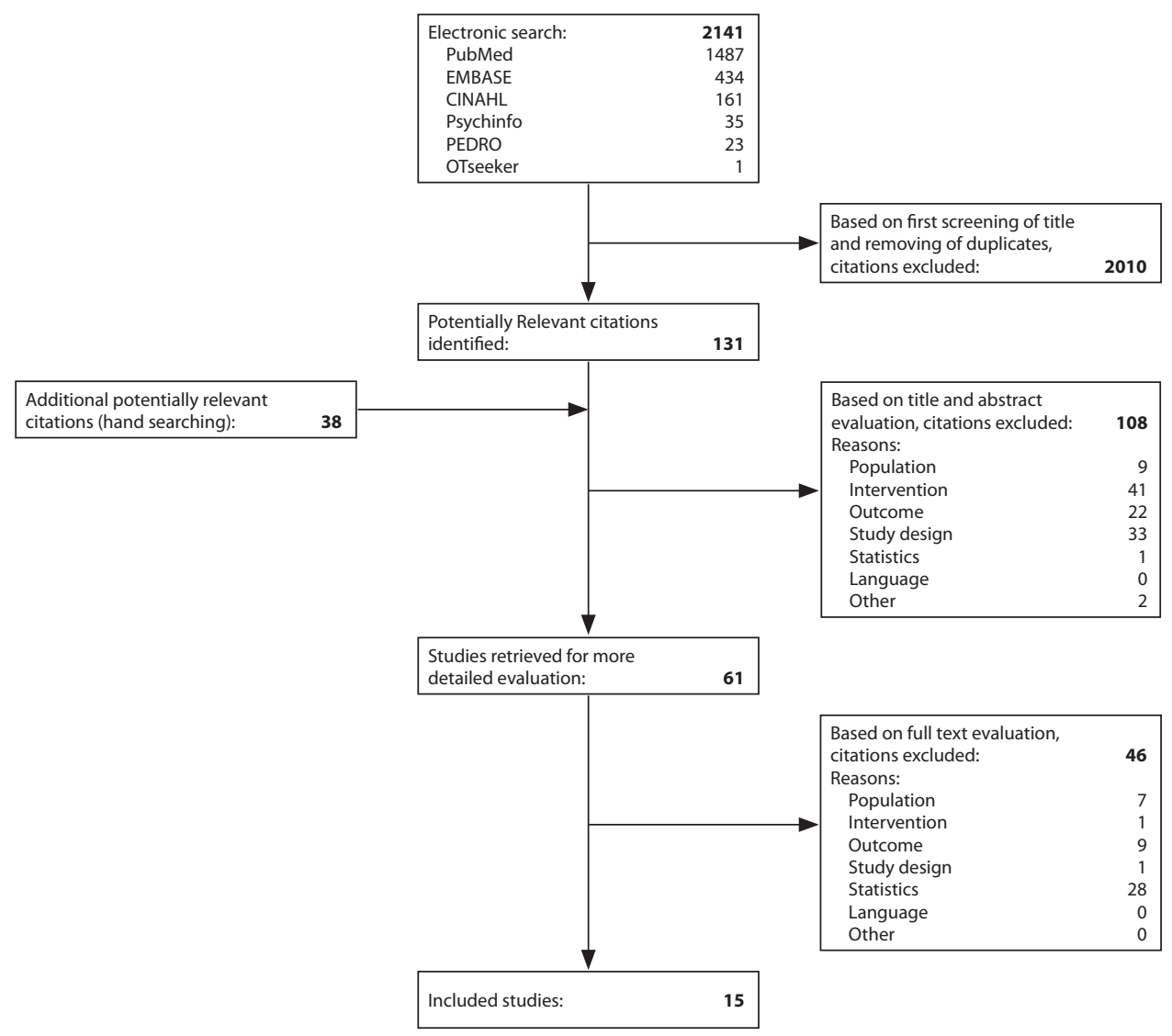

Figure 1: Flow chart of search and selection 
Table 3: Participant characteristics

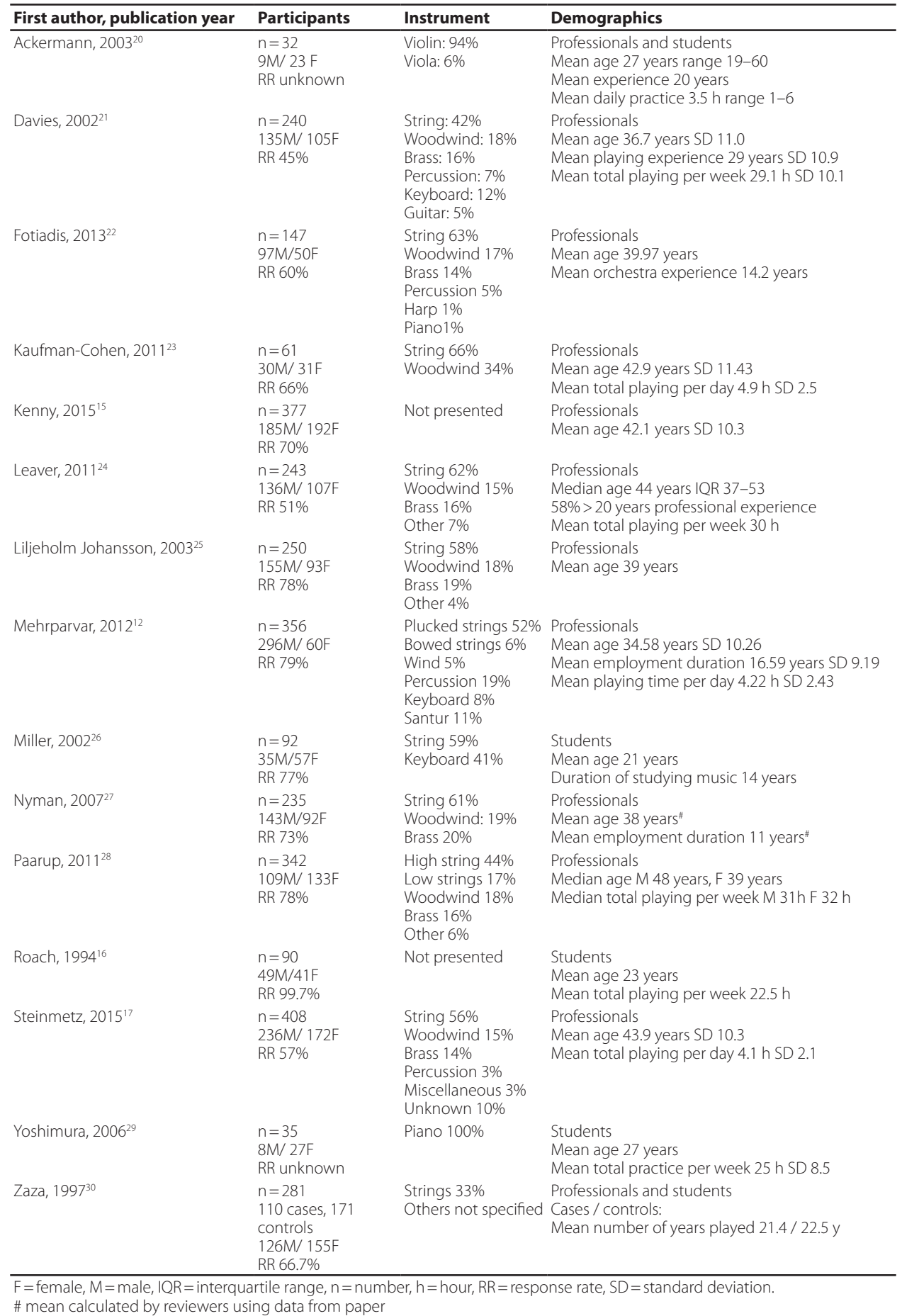




\section{Overview of consistent results by category}

\section{Socio-demographic factors}

Effect of gender as a determinant for musculoskeletal disorders has been frequently examined. 12,16,17,21,23-28,30 In multivariate analysis in the case-control study, it was found that women were more likely to experience a first episode of PRMD compared with men (OR 2.84, 95\% Cl $1.08-7.46) .{ }^{30}$ Also, the results of three multivariate and four univariate analyses in cross-sectional papers showed that females were more likely to experience musculoskeletal disorders. ${ }^{16,17,21,23-25,28}$ However, results of papers reporting both univariate and multivariate analysis showed that the positive univariate association between gender and musculoskeletal disorders often disappeared when applied in a multivariate model. ${ }^{17,24,25}$ Moreover, it has been shown that there is an interaction between female gender and violin playing, meaning that women have a higher probability of experiencing symptoms while playing the violin. ${ }^{21}$ Age was not found to be associated with first-episode PRMD in the case-control study. ${ }^{30}$ Univariate results suggest that a higher age was related to more PRMD. ${ }^{17,24}$ However, when applied in multivariate analyses, no effect of age was found. $17,24,26-28$

\section{Health-related factors}

Past PRMD was found to be positively associated with recurrent PRMD in multivariate analysis in the case-control study $(\mathrm{OR} 2.52,95 \% \mathrm{Cl} 1.03-6.15)$ and in two cross-sectional studies $(b=-0.24$ and OR 9.31, 95\% Cl $1.02-85)^{22,26,30}$ No association was found between sports activities or exercise behavior and musculoskeletal disorders. ${ }^{20,21,23}$ Although cigarette smoking was found to be correlated with musculoskeletal disorders in univariate analysis, papers performing multivariate analysis showed no such effect. 23,24

\section{Physical factors}

Several physical or anthropometric factors (e.g. hand span, tendon anomalies, hypermobility) have been considered, but no consistent results were found. 10,18,23,24

\section{Psychosocial factors}

A positive association between performance anxiety and musculoskeletal disorders was found in the multivariate analysis of two cross-sectional studies. ${ }^{15,17}$ In the case-control study, an association between performance anxiety and recurrent PRMD (OR 1.09, 95\% Cl $1.00-1.18$ ) was shown in the univariate analysis. ${ }^{30}$ In multivariate analysis, no effect was found for first-episode or recurrent PRMD. ${ }^{30}$ Trait anxiety was found not to be associated with complaints in multivariate analysis. $^{15,30}$ 


\section{Work-related factors}

A protective effect of number of years playing on first episode PRMD was found in the multivariate analysis in the case-control study (OR 0.95, 95\% Cl $0.91-0.99) .{ }^{30}$ Of the cross-sectional studies, one also found a small protective effect of playing years in multivariate results $(b=-0.01){ }^{21}$ Another study found several univariate associations between duration of employment and pain in different body parts; however, in multivariate analysis, only the negative association between duration of employment and right shoulder pain remained (OR 0.90, 95\% Cl $0.84-0.97$ ). ${ }^{17}$ Two papers found no association in univariate or multivariate analysis. ${ }^{25,28}$ Eight papers studied the association between instrument and musculoskeletal disorders. ${ }^{12,17,21,24-26,28,30}$ Results seem to indicate that (upper) string players are more likely to experience symptoms when compared with players of other instruments. ${ }^{17,24,25,28,30}$ The case-control study reported a multivariate positive association for first episode (OR 4.69, 95\% Cl 1.52 - 14.52) and recurrent PRMD (OR 1.94, 95\% Cl $1.02-3.70) .{ }^{30}$ When adjusted for other factors as, for example, gender, the univariate positive association often decreased or disappeared. ${ }^{17,21}$ One paper reported a positive association between average weekly orchestra hours with number of symptomatic upper limb joints in univariate $(r=0.30)$ and multivariate $(b=0.25)$ analyses. ${ }^{23}$ Other papers only presented positive univariate association for the wrist/ hand region $(b=-0.21)$, or no positive association at all. ${ }^{21,22,26}$ Different papers reported on biomechanical risk factors related to playing the musical instrument.23,24,27 As they all studied different biomechanical risk factors, no consistent results could be identified. Work-related psychosocial factors were studied in seven papers. ${ }^{21,23-25,27,28,30}$ Work-related stress was shown to be positively associated with first episode and recurrent PRMD in univariate (not multivariate) results in the case-control study (OR 1.66, 95\% Cl $1.15-2.39$ and OR $1.41,95 \% \mathrm{Cl}$ $1.10-1.81$, respectively)..$^{30}$ This association was also found in univariate $(b=0.44)$ and multivariate $(b=0.20)$ results in one cross-sectional study. ${ }^{21}$ Consistent results showed that choice over work/ influence, support at work and orchestra category/status were not related to musculoskeletal disorders. $^{24,25,27}$

\section{Prevention}

In the case-control study, a musical warm-up was found to be protective for a first episode PRMD in univariate and multivariate analysis (OR $0.37,95 \% \mathrm{Cl} 0.15-0.91)$ but was not associated with recurrent PRMD. ${ }^{30}$ Considering physical warm-up, univariate results for recurrent PRMD showed a negative relationship (OR $0.38,95 \% \mathrm{Cl} 0.17-0.84$ ), but no effect could be found in multivariate analysis. ${ }^{21,24,30}$ Also, lack of warm-up/break provision was found to be positively associated with PRMD in univariate results $(b=0.26)$, not in multivariate results of one cross-sectional study. ${ }^{21}$ However, one cross-sectional paper did find an association between warm-up and severity of symptoms, both in univariate $(r=-0.55)$ and multivariate analysis $(b=0.31){ }^{23}$ 


\section{Discussion}

The principle finding of this review is that no conclusion can be drawn regarding risk factors for musculoskeletal disorders in (pre-) professional instrumental musicians because of the low methodological quality and large heterogeneity of the available studies. No studies using a prospective design were found, making it impossible to draw conclusions about causality. Terms such as prognostic factor or predictor are inappropriately used to indicate associations. Current available information only gives us an indication of possible relationships. Consistent results indicate that (upper) string players experience more musculoskeletal disorders than other instrumentalists. An interaction between being female and violin playing suggests that not gender, but rather type of instrument is the most important factor in the relationship between gender and PRMD. Performance anxiety and work-related stress seemed to be positively related with musculoskeletal disorders in musicians. Musicians who have experienced PRMD seemed to be at higher risk of developing recurrent PRMD. Consistent results indicating no association with PRMD were found for sports or exercise behavior, cigarette smoking and work-related factors such as choice/ influence over work, support at work or orchestra category. No consistent results were found considering the effect of physical/anthropometric features of the musician and biomechanical factors or playing load related to playing the instrument. Also, no conclusions can be made regarding the association of age, number of years playing or duration of employment with PRMD and the possible protective role of physical or musical warm-up. A strength of this study is that a critical review of the quality of included studies was performed before interpreting results and differences between univariate and multivariate analyses were clarified. Several types of bias were considered: detection bias due to systematic differences in outcome definition and measurement period; selection bias because of systematic differences between instrument groups; and recall bias when asking musicians about complaints in the past. The healthy worker effect could have occurred since often only the musicians still working were questioned. Weakness of the current study is that our subject, including all instrumentalists, is broad. This might explain why no consistent results were found regarding the effect of physical/biomechanical features and playing load. A subgroup analysis was planned but was not possible due to heterogeneity of the included studies. Application of strict selection criteria especially regarding objective, outcome measurement and statistical analysis is both a strength and a weakness of this study. We aimed to set up a review encompassing high quality articles. On the contrary, applying these strict eligibility criteria may also have resulted in exclusion of articles with an additive value to the topic of this review. When initiating this review, it was assumed that additional studies would be available with better methodologic quality and a biopsychosocial (multivariate) risk factor model for the aetiology of PRMD. This review adds to the reviews already performed, by the application of PRISMA guidelines and a thorough quality assessment to assess risk of bias. It is striking that the conclusions are comparable. This review again highlights the lack of adequate research into risk factors for musculoskeletal complaints in musicians. Although additional studies were included, they were not of the high quality, which is to be expected when researching prognostic factors. At this moment, there is too little scientific information on which clinical prevention of PRMD can be based. Based on international guidelines, to be able to draw conclusions 
on causation between risk factors and PRMD, a prospective cohort study, with a large sample size and follow-up duration of minimally one year should be performed. ${ }^{6}$ The study should include only one instrument group, so that biomechanical playing load is equal for every participant. Validated questionnaires should be used to measure outcome and determinants and there is a need for guidelines on how to measure outcome in musicians. Multivariate analysis is required to be able to control for confounders. The interaction between instrument and gender should be examined more thoroughly. As musculoskeletal disorders are believed to be multifactorial in origin, the combination of biological, psychological and social factors should always be taken into account in the multivariate model. Currently, no clear evidence on risk factors for (playingrelated) musculoskeletal disorders in instrumental musicians could be found mainly due to the lack of prospective studies and large heterogeneity between studies. 


\section{References}

1. Zaza C, Charles C, Muszynski A. The meaning of playing-related musculoskeletal disorders to classical musicians. Soc Sci Med. 1998;47:2013-2023.

2. Silva AG, La FMB, Afreixo V. Pain prevalence in instrumental musicians: a systematic review. Med Probl Perform Art. 2015;30:8-19.

3. Rickert DL, Barrett MS, Ackermann BJ. Injury and the orchestral environment: part I. The role of work organization and psychosocial factors in injury risk. Med Probl Perform Art. 2013;28:219-229.

4. Wu SJ. Occupational risk factors for musculoskeletal disorders in musicians: a systematic review. Med Probl Perform Art. 2007;22:43-51.

5. Bragge P, Bialocerkowski A, McMeeken J. A systematic review of prevalence and risk factors associated with playing- related musculoskeletal disorders in pianists. Occup Med (Lond).2006;56:28-38.

6. Hayden JA, van der Windt DA, Cartwright JL, Cote P, Bombardier C. Assessing bias in studies of prognostic factors. Ann Intern Med. 2013;158:280-286.

7. Moher D, Liberati A, Tetzlaff J, Altman DG, Group P. Preferred reporting items for systematic reviews and meta-analyses: the PRISMA statement. J Clin Epidemiol. 2009;62:1006-1012.

8. Sanderson S, Tatt ID, Higgins JP. Tools for assessing quality and susceptibility to bias in observational studies in epidemiology: a systematic review and annotated bibliography. Int J Epidemiol. 2007;36:666676.

9. von Elm E, Altman DG, Egger M et al. Strengthening the Reporting of Observational Studies in Epidemiology (STROBE) statement: guidelines for reporting observational studies. Br Med J. 2007;335:806-808.

10. van der Windt DAWM, Thomas E, Pope DP et al. Occupational risk factors for shoulder pain: a systematic review. Occup Environ Med. 2000;57:433-442.

11. Waddell G, Burton AK. Occupational Health Guidelines for the Management of Low Back Pain at WorkEvidence Review. London: Faculty of Occupational Medicine, 2000.

12. Mehrparvar AH, Mostaghaci M, Gerami RF. Musculoskeletal disorders among Iranian instrumentalists. Med Probl Perform Art. 2012;27:193-196.

13. Levy JJ, Lounsbury JW, Kent KN. Big five personality traits and marching music injuries. Med Probl Perform Art. 2009;24:135-140.

14. Barton R, Killian C, Bushee M et al. Occupational performance issues and predictors of dysfunction in college instrumentalists. Med Probl Perform Art. 2008;23:72-78.

15. Kenny D, Ackermann B. Performance-related musculoskeletal pain, depression and music performance anxiety in professional orchestral musicians: a population study. Psychol Mus. 2015;43:43-60.

16. Roach KE, Martinez MA, Anderson N. Musculoskeletal pain in student instrumentalists: a comparison with the general student population. Med Probl Perform Art. 1994;9:125-130.

17. Steinmetz A, Scheffer I, Esmer E, Delank KS, Peroz I. Frequency, severity and predictors of playing-related musculoskeletal pain in professional orchestral musicians in Germany. Clin Rheumatol. 2015;34:965973.

18. Yeung E, Chan W, Pan F et al. A survey of playing-related musculoskeletal problems among professional orchestral musicians in Hong Kong. Med Probl Perform Art. 1999;14:43-47.

19. Zetterberg C, Backlund H, Karlsson J, Werner H, Olsson L. Musculoskeletal problems among male and female music students. Med Probl Perform Art. 1998;13:160-166. 
20. Ackermann B, Adams R. Physical characteristics and pain patterns of skilled violinists. Med Probl Perform Art. 2003;18:65-71.

21. Davies J, Mangion S. Predictors of pain and other musculoskeletal symptoms among professional instrumental musicians: elucidating specific effects. Med Probl Perform Art. 2002;17:155-168.

22. Fotiadis D, Fotiadou EG, Kokaridas DG, Mylonas AC. Prevalence of musculoskeletal disorders in professional symphony orchestra muscians in Greece. Med Probl Perform Art. 2013;28:91-95.

23. Kaufman-Cohen Y, Ratzon NZ. Correlation between risk factors and musculoskeletal disorders among classical musicians. Occup Med (Lond). 2011;61:90-95.

24. Leaver R, Harris EC, Palmer KT. Musculoskeletal pain in elite professional musicians from British symphony orchestras. Occup Med (Lond). 2011;61:549-555.

25. Liljeholm Johansson Y, Theorell T. Satisfaction with work task quality correlates with employee health. Med Probl Perform Art. 2003;19:141-149.

26. Miller G, Peck F, Watson JS. Pain disorders and variations in upper limb morphology in music students. Med Probl Perform Art. 2002;17:169-172.

27. Nyman T, Wiktorin C, Mulder M, Liljeholm Johansson Y. Work postures and neck-shoulder pain among orchestra musicians. Am J Ind Med. 2007;50:370-376.

28. Paarup HM, Baelum J, Holm JW, Manniche C, Wedderkopp N. Prevalence and consequences of musculoskeletal symptoms in symphony orchestra musicians vary by gender: a cross-sectional study. BMC Musculoskel Disord. 2011;12:223.

29. Yoshimura EMM, Mia Paul P, Aerts C, Chesky K. Risk factors for piano-related pain among college students. Med Probl Perform Art. 2006;21:118-125.

30. Zaza C, Farewell VT. Musicians' playing-related musculoskeletal disorders: an examination of risk factors. Am J Ind Med. 1997;32:292-300.

31. Landis JR, Koch GG. The measurement of observer agreement for categorical data. Biometrics. 1977;33:159-174. 


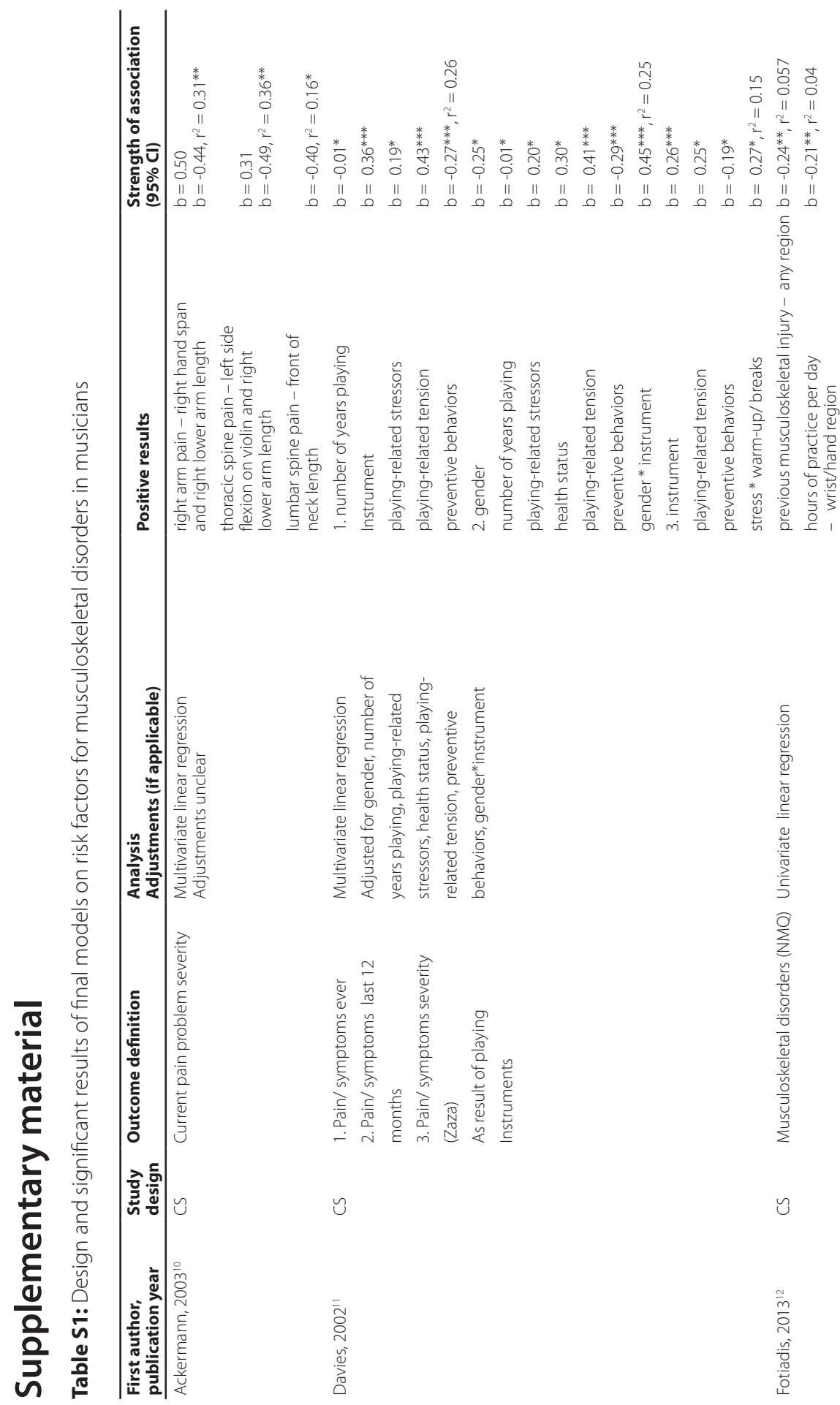




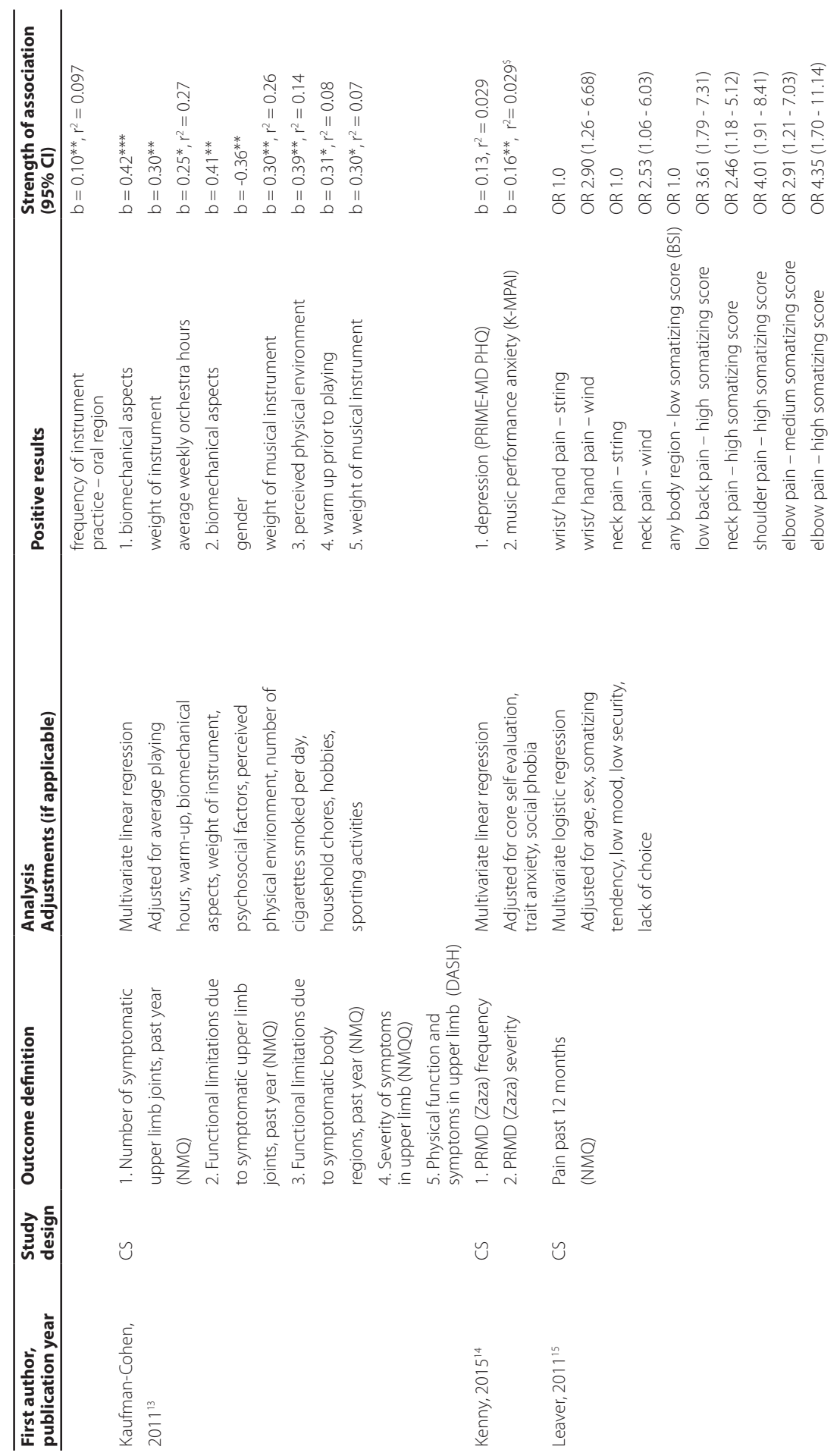




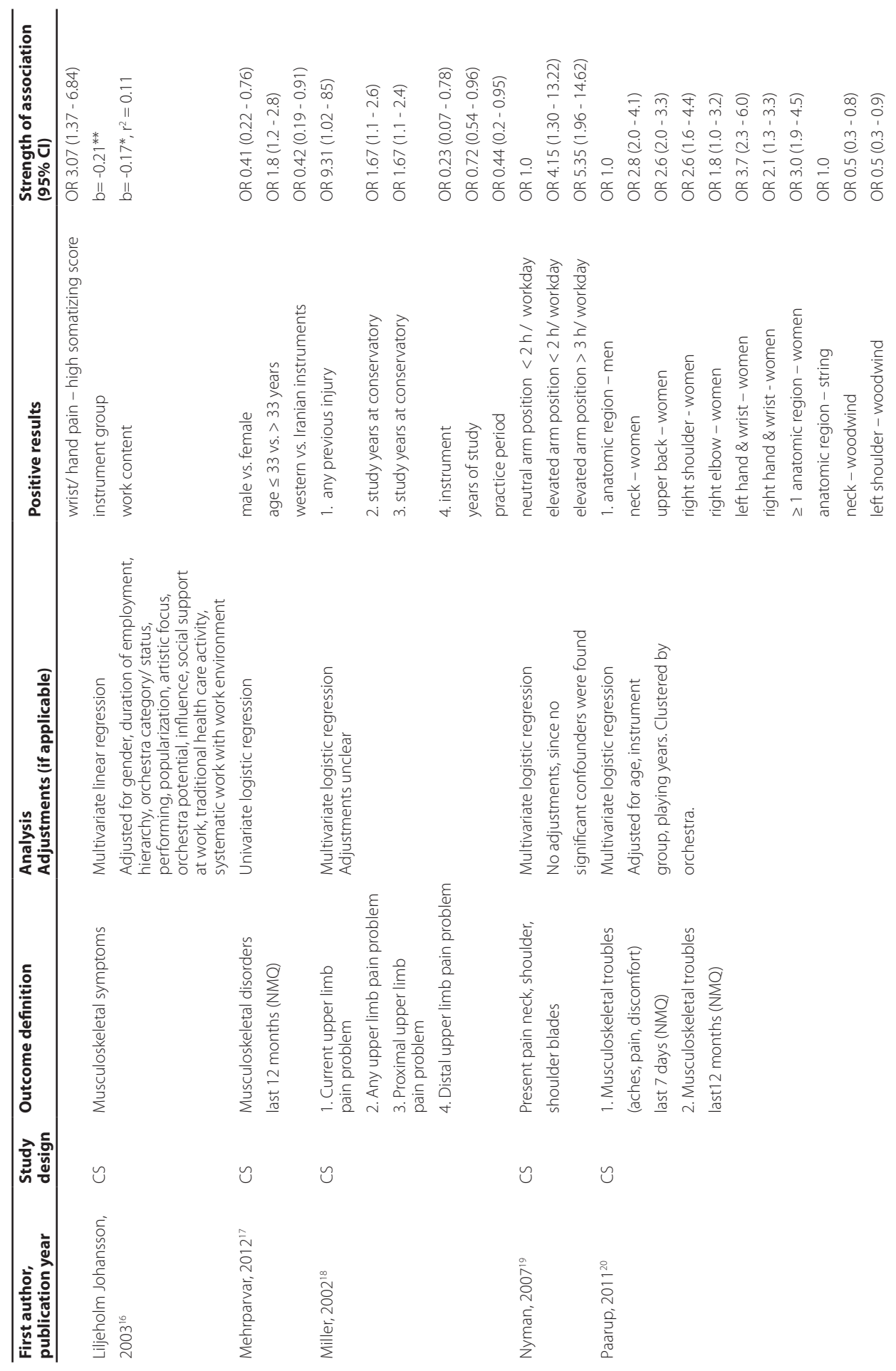




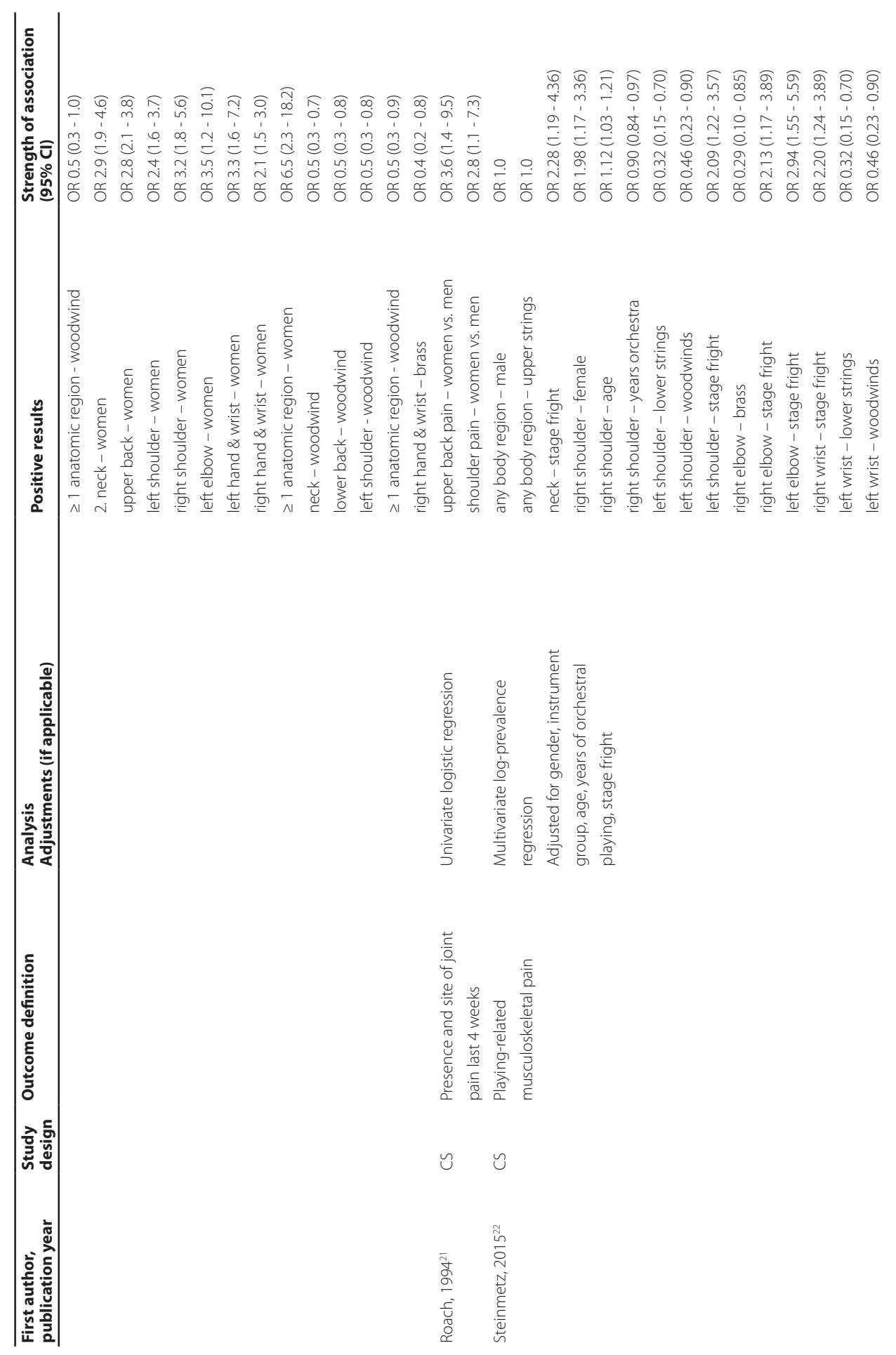




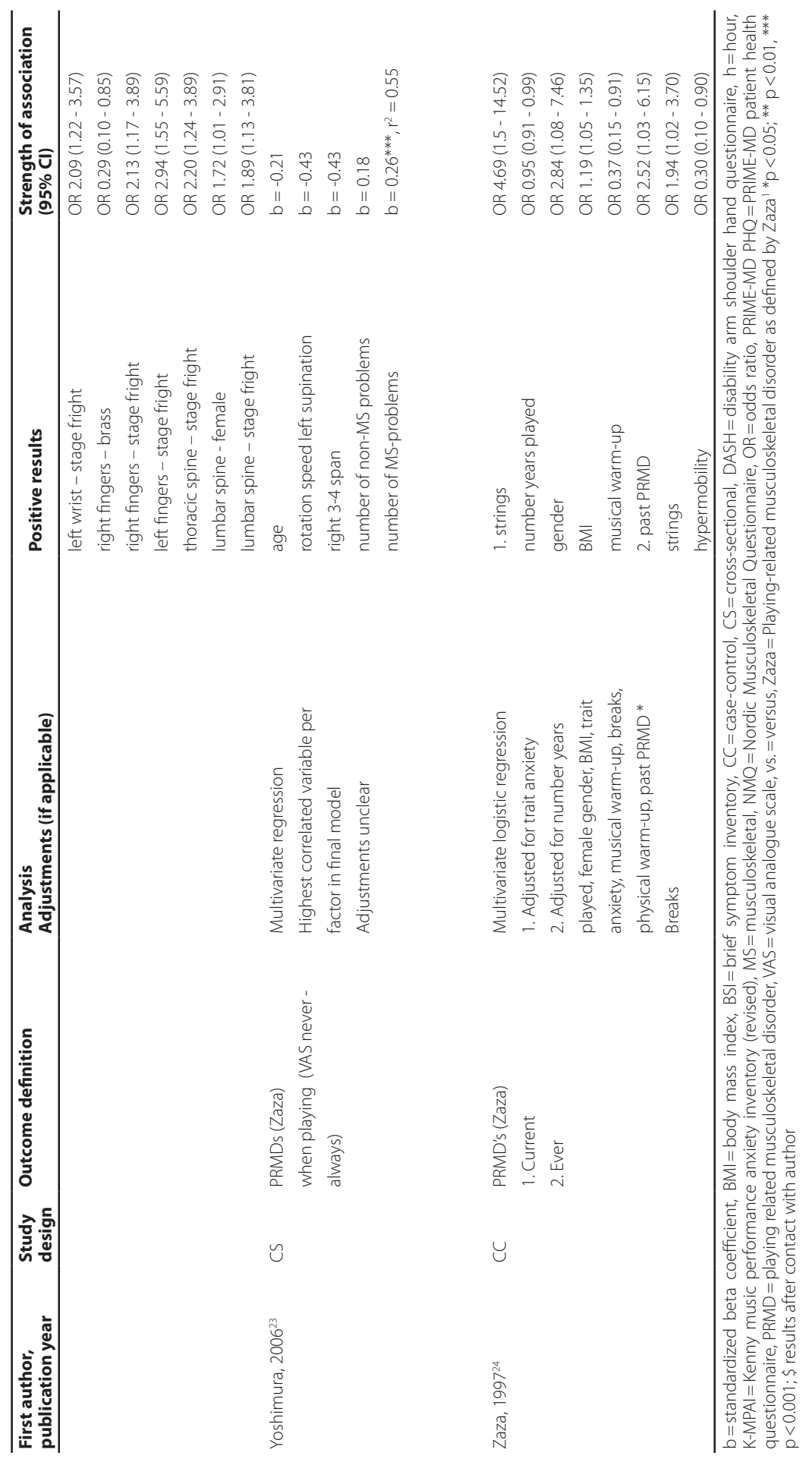




\section{Appendix 1: Pubmed search}

Key words:

\begin{tabular}{|c|c|c|}
\hline 1 & 2 & 3 \\
\hline "Musculoskeletal Diseases"[Mesh] & "Music"[Mesh] & Risk factor* \\
\hline musculoskeletal disorder* & musician* & Risk factors [Mesh] \\
\hline musculoskeletal complaint* & music* & Prognos* \\
\hline musculoskeletal pain & instrumentalist & Prognosis [Mesh] \\
\hline musculoskeletal sign* & instrumentalist* & Predictor* \\
\hline musculoskeletal symptom* & performing art* & Predict* \\
\hline Strain & conservatory & Determinant \\
\hline "Sprains and strains" [Mesh] & conservatoire & Etiology \\
\hline "Occupational Injuries"[Mesh] & "music school" & Etiology [Mesh] \\
\hline "Occupational Diseases"[Mesh] & "school of music" & Etiol* \\
\hline Occup* & & Aetiology \\
\hline Pain & & Aetiol* \\
\hline "Pain"[Mesh] & & Caus* \\
\hline "Chronic pain" [ Mesh] & & Causality [ Mesh] \\
\hline "Musculoskeletal pain"[Mesh] & & Epidemiol* \\
\hline "Wounds and injuries" [Mesh] & & Epidemiology [Mesh] \\
\hline "cumulative trauma disorders" & & "Risk assessment \\
\hline \multicolumn{3}{|l|}{ "complaints arm neck shoulder" } \\
\hline \multicolumn{3}{|l|}{ "repetitive strain injury" } \\
\hline \multicolumn{3}{|l|}{ "overuse" } \\
\hline "overuse syndrome" & & \\
\hline
\end{tabular}

Combine 1 AND 2 AND 3; key words combined with OR 


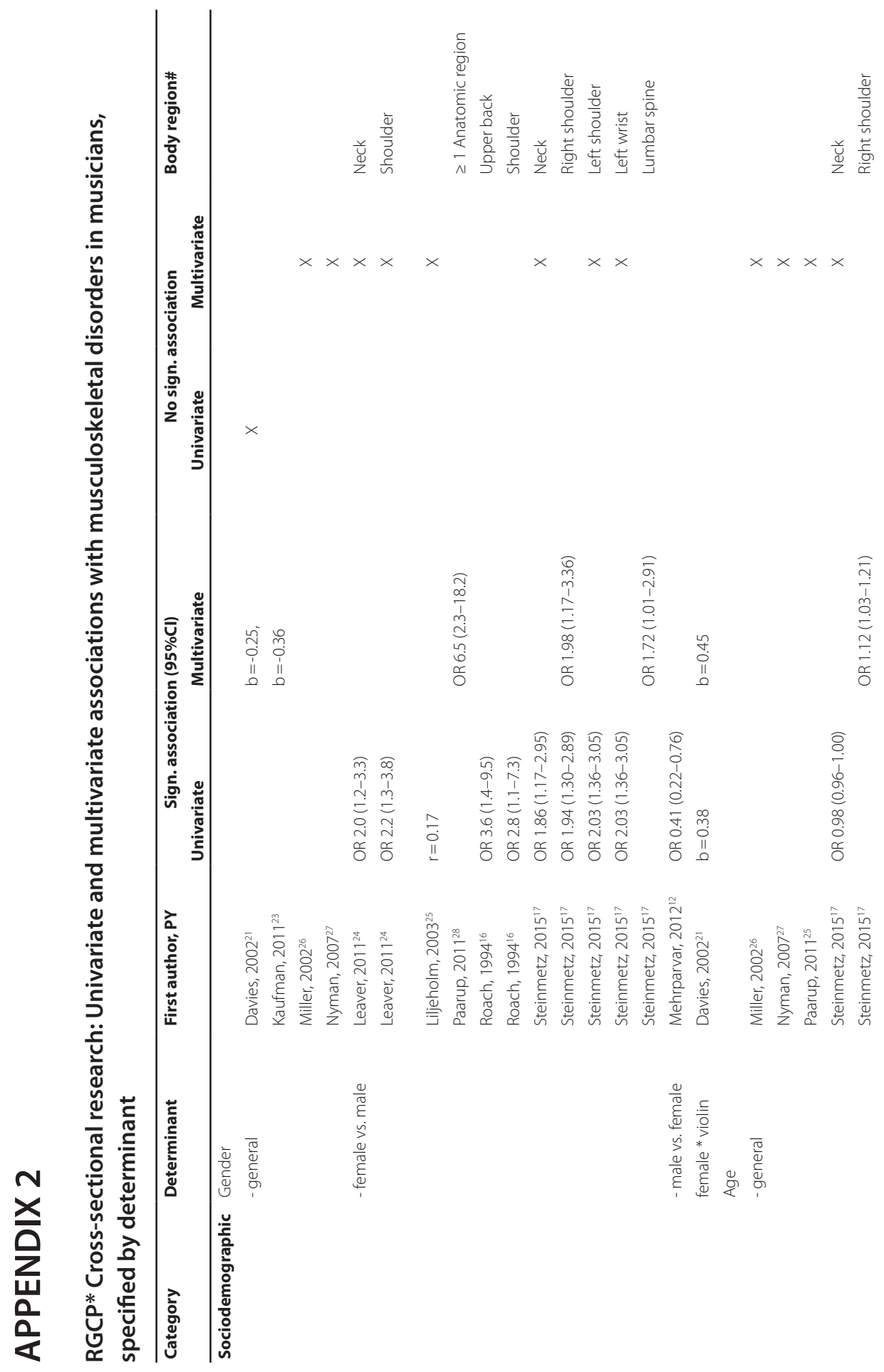




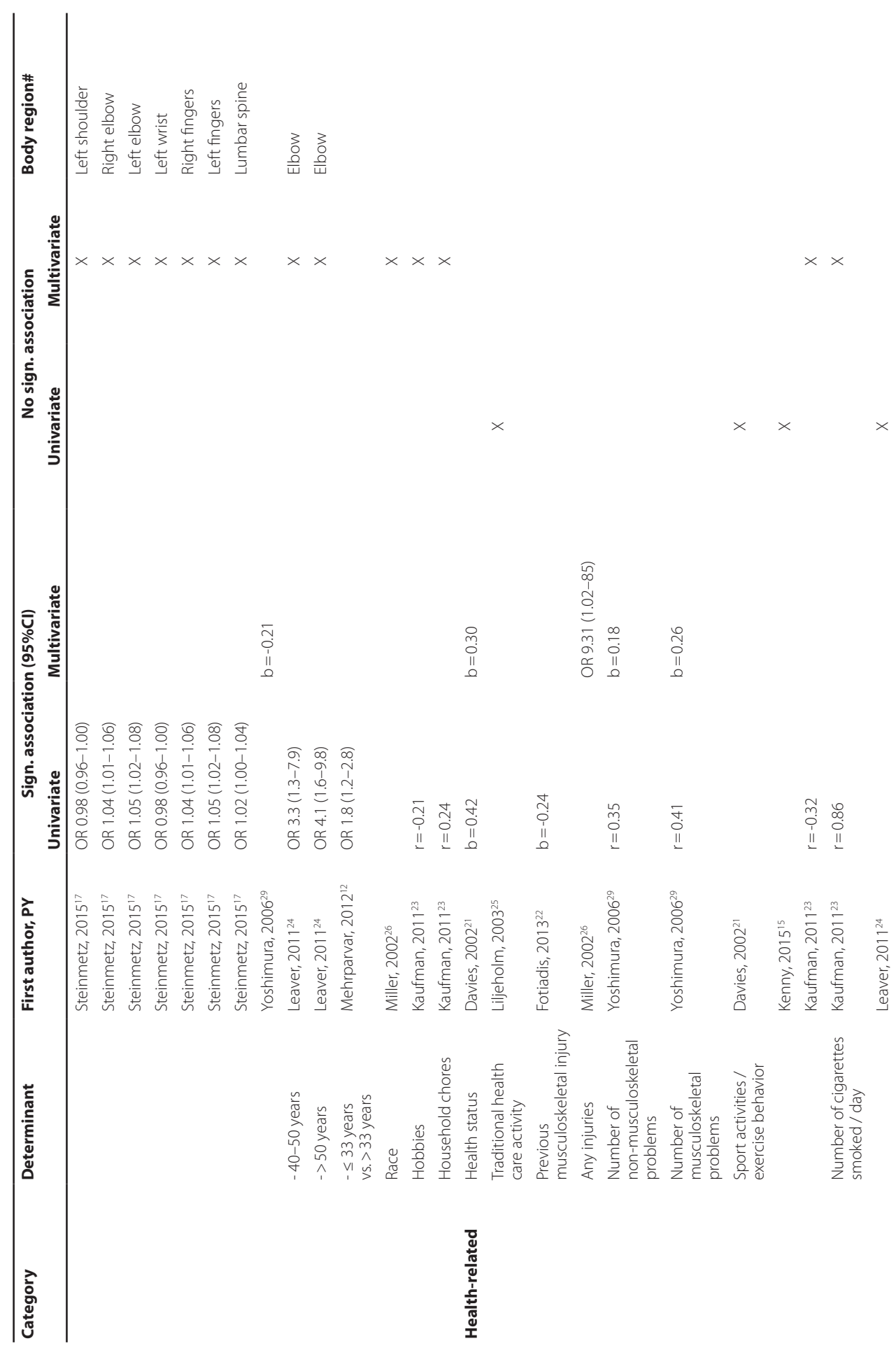




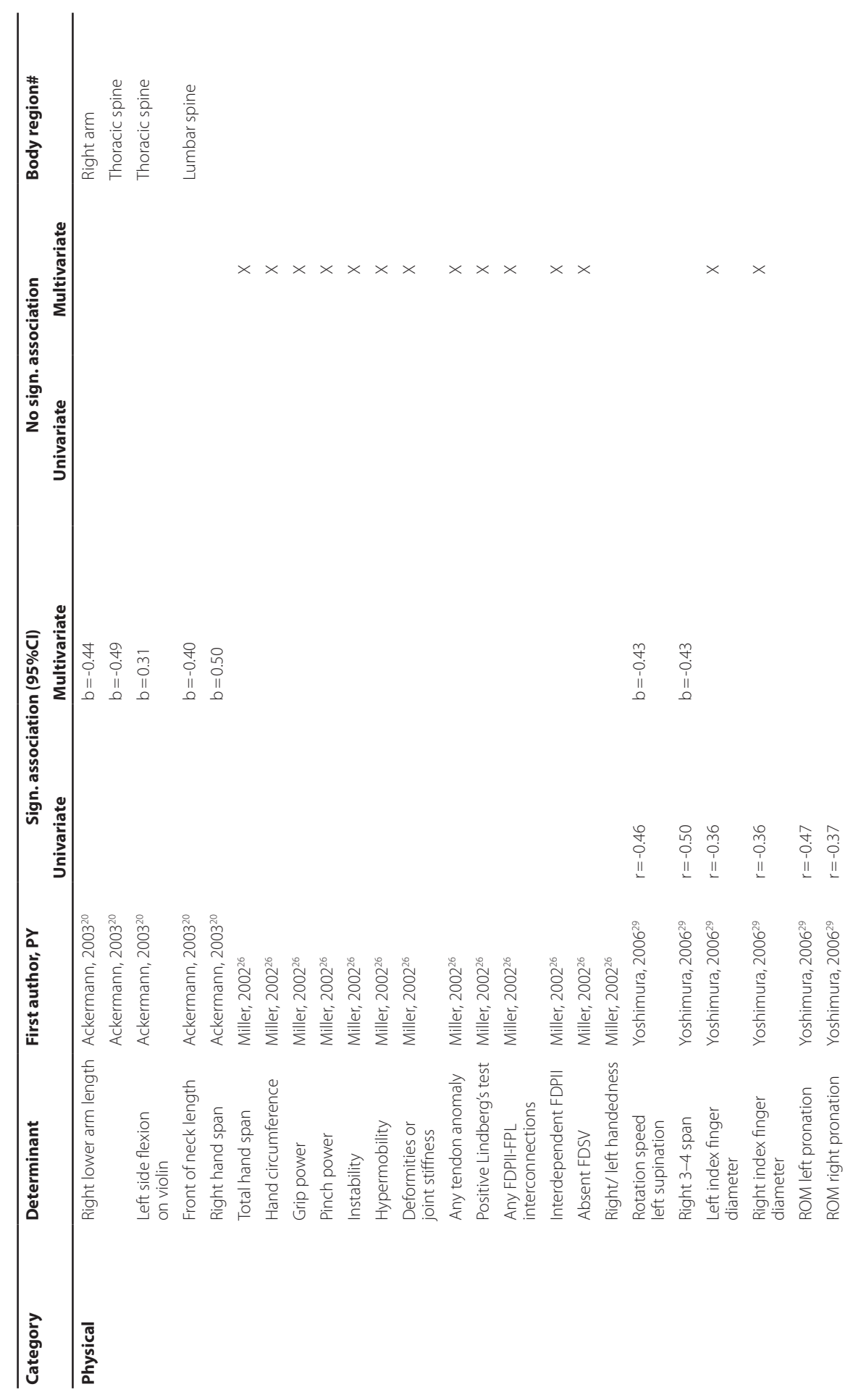




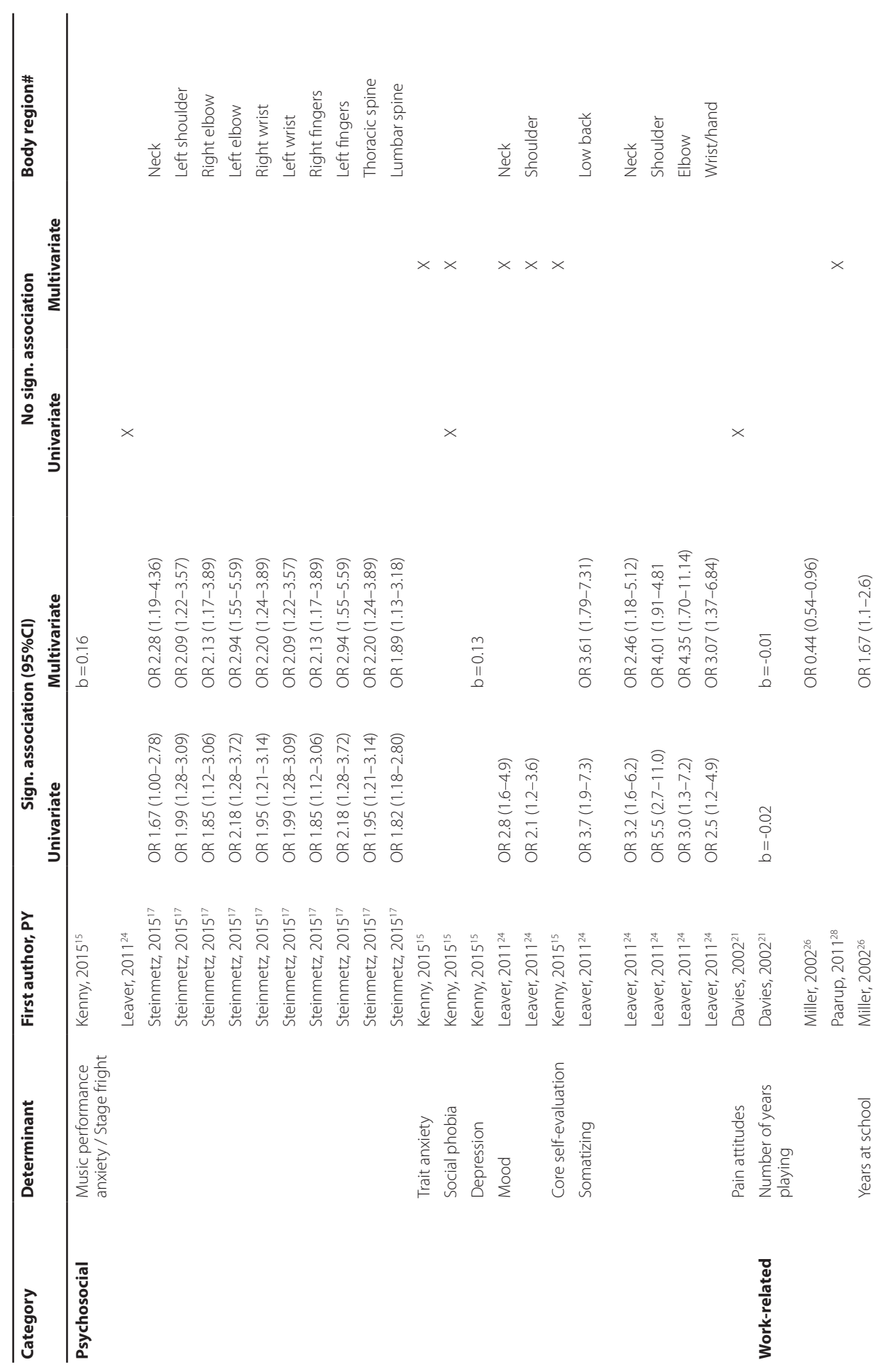




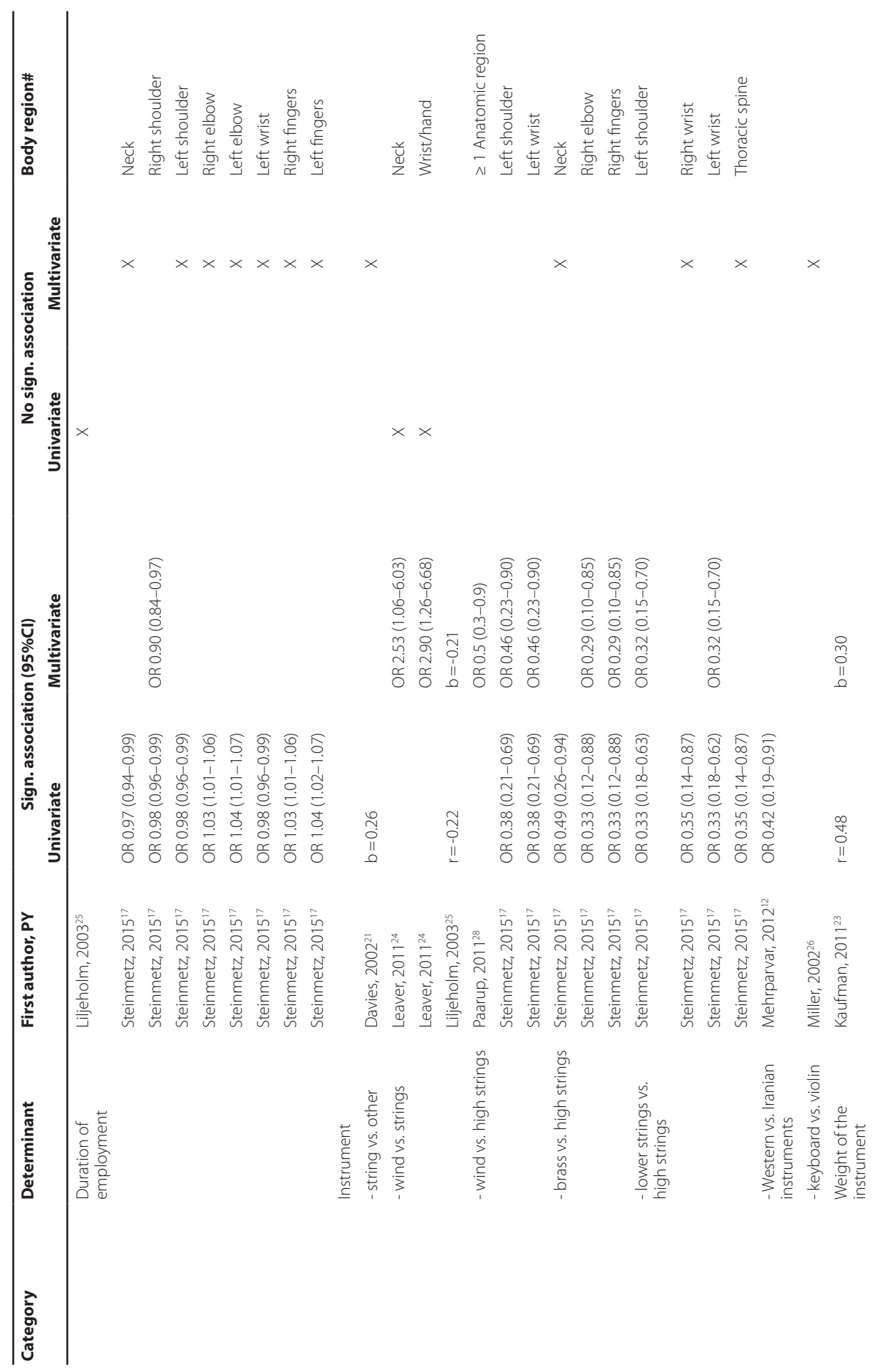




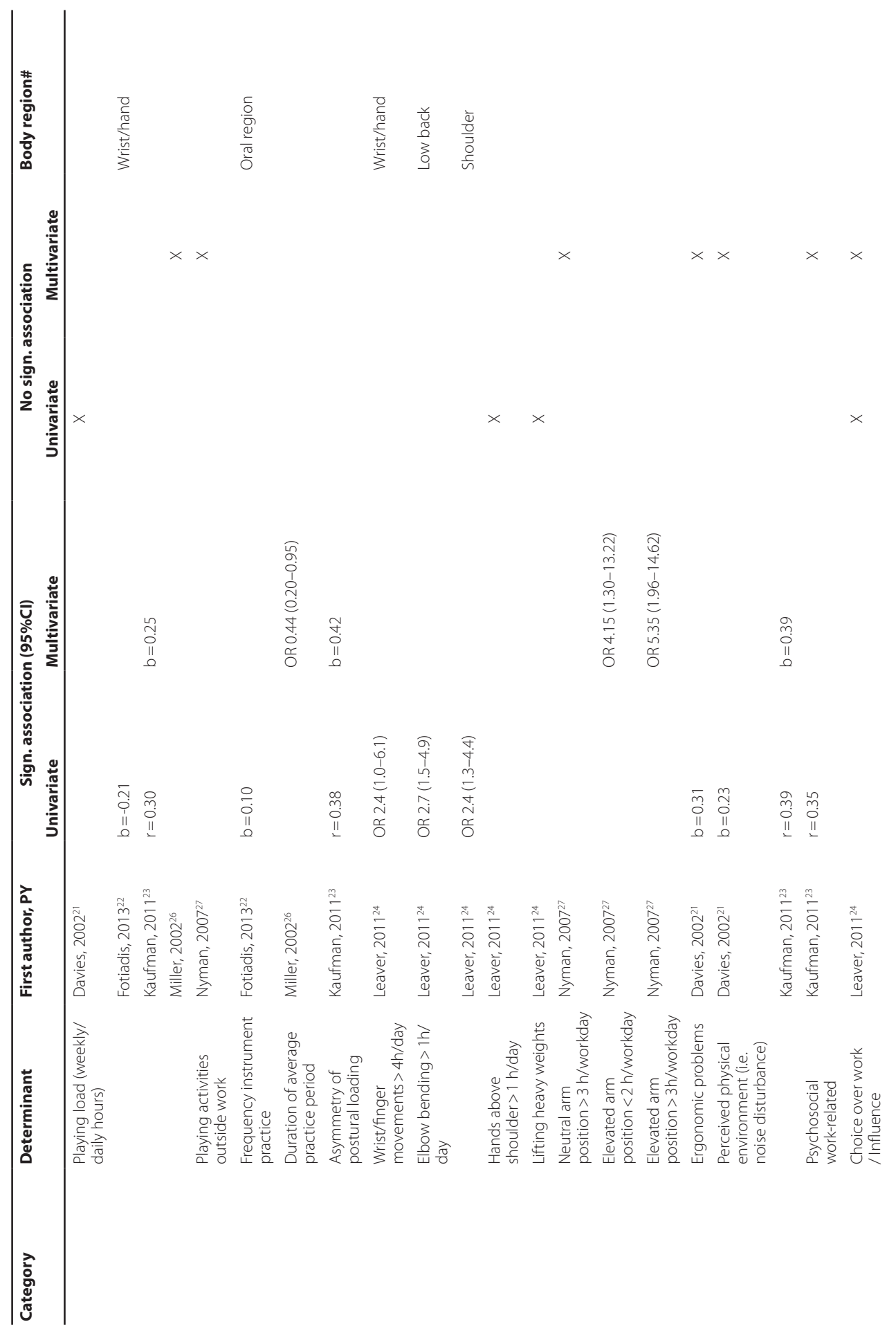




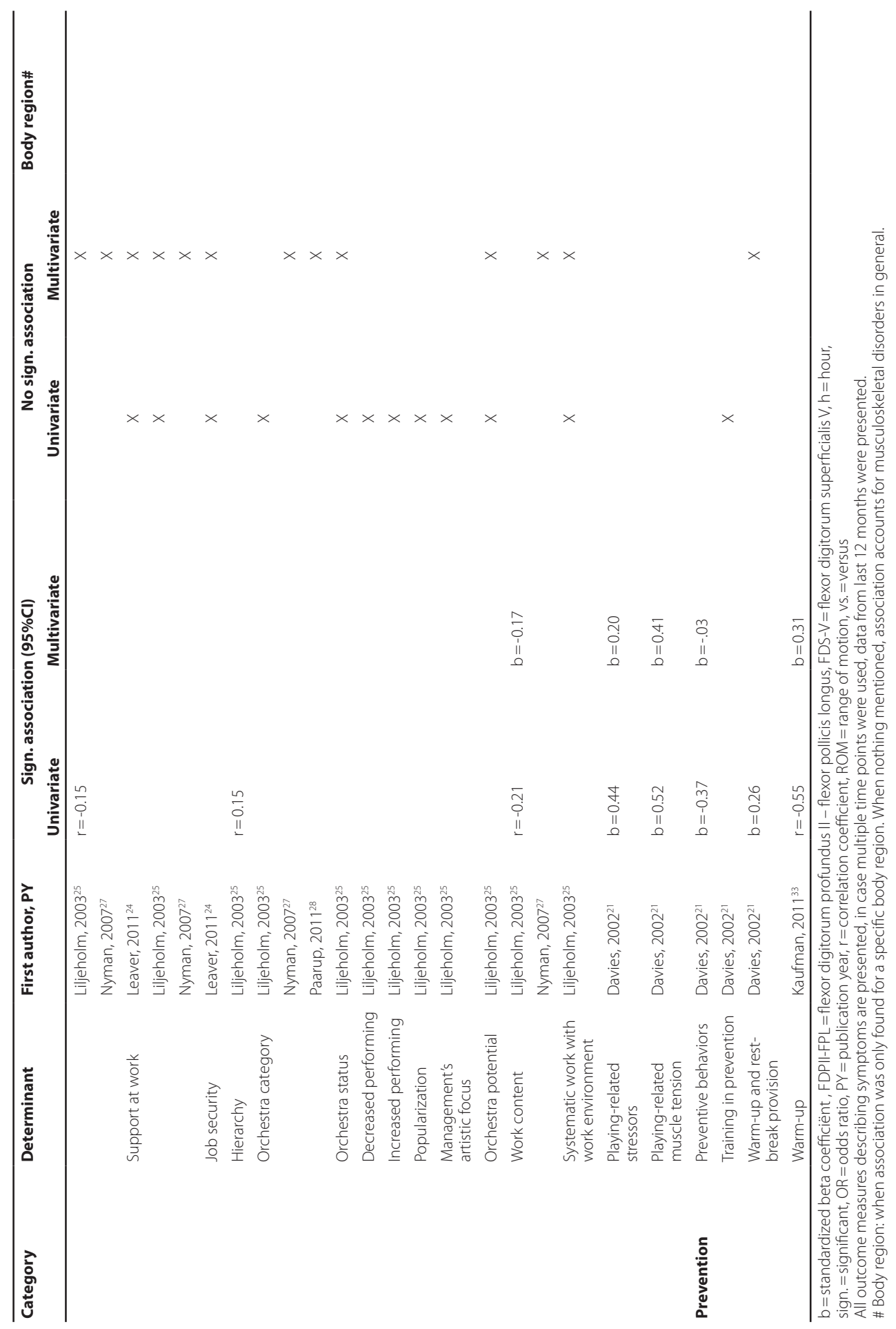




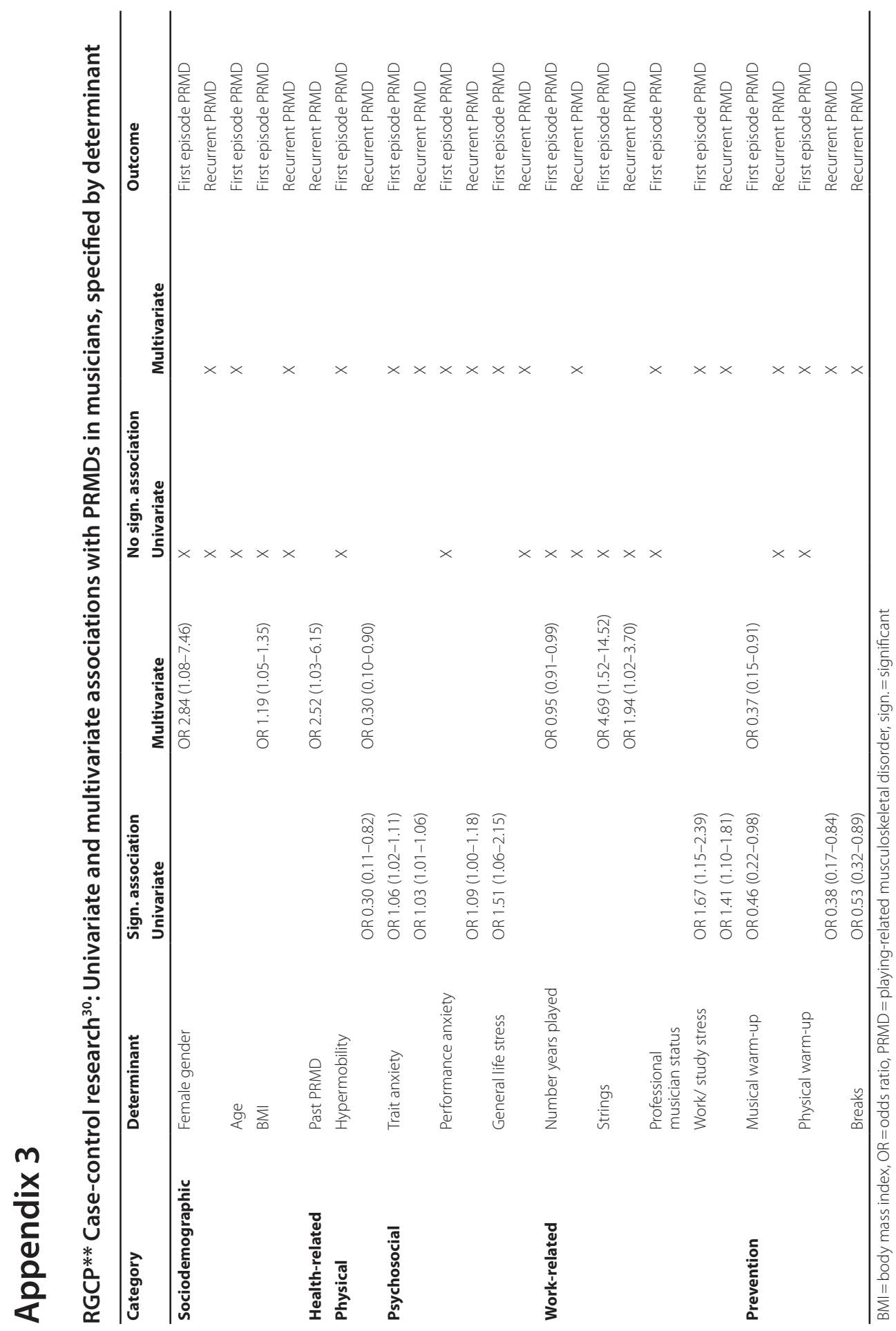





\section{Chapter 4}

\section{Psychometric properties of the performing arts module of the Disabilities of the Arm, Shoulder and Hand questionnaire}

Published as: Baadjou V, de Bie R, Guptill C, Smeets R. Psychometric properties of the performing arts module of the Disabilities of the Arm, Shoulder and Hand questionnaire. Disabil Rehabil.2017;Aug 16:1-7. 


\section{Abstract}

Background: The Disabilities of the Arm, Shoulder, and Hand questionnaire (DASH) offers an optional performing arts module. The goal was to examine the psychometric properties of this module in musicians.

Methods: This study is a secondary analysis of a randomized controlled trial on the effectiveness of a biopsychosocial intervention to prevent or reduce playing-related disability in conservatory students.

Baseline data were used to examine internal consistency and discriminative validity of the performing arts module of the DASH questionnaire. Construct validity was analyzed by hypotheses testing. The performing arts module outcomes were compared to scores from the general DASH questionnaire, pain disability index, Short-Form 36, playing-related musculoskeletal disorder (PRMD) intensity, and pain intensity.

Results: Questionnaires completed by 130 conservatory students were analyzed, 55\% of the population was female. Median age was 20 years (IQR 4). The performing arts module showed good internal consistency (Cronbach's alpha 0.893). Discriminative validity between students with and without PRMDs was good. Three out of six hypotheses were accepted, indicating moderate construct validity.

Conclusions: The performing arts module showed good internal consistency, good discriminative validity and moderate construct validity in a population of conservatory students. 


\section{Introduction}

Outcome measures used to quantify physical complaints in musicians vary widely and little is known about the validity of these measures when used in this specific population. ' When measuring outcomes, it is important to know what the questionnaire intends to measure and how the quality of the measurement instrument might affect results. For example, is the construct of interest really measured and does the questionnaire provide reliable answers? In a recent review on pain prevalence in instrumental musicians, ${ }^{1}$ several self-reported questionnaires were summarized, with outcomes ranging from the presence of pain in general to disabling pain or playing-related pain and symptoms affecting playing capacity. The most common constructs used were pain, playing-related musculoskeletal disorder (PRMD), and disability. According to the International Classification of Functioning, Disability, and Health, pain is a function, which can be described as an unpleasant sensation. Disability is an umbrella term that includes impairments, activity limitations and participation restrictions. ${ }^{2}$ Playing-related musculoskeletal disorders can be seen as a specific disability because, according to the definition established by Zaza et al., symptoms must interfere with the ability to play the instrument at the level to which the musician is accustomed. ${ }^{3}$ Thus far, non-validated questionnaires have often been used which makes interpretation and generalization of results difficult. Several questionnaires have been developed specifically for musicians, of which two are recently validated: The Musculoskeletal Pain Intensity and Interference Questionnaire for professional orchestra Musicians ${ }^{4}$ and the Musculoskeletal Pain Questionnaire for Musicians. ${ }^{5}$ However, these questionnaires are validated based on small sample sizes and are not yet widely used. Items from the Disabilities of Arm, Shoulder, and Hand questionnaire (DASH) were incorporated into both these questionnaires. ${ }^{4,5}$ The DASH has been proposed as a valuable tool in quantifying disability of the upper extremity in musicians and has been used frequently to quantify musician's disability. ${ }^{1,6,7}$ The DASH includes an optional work module and an optional sports/ performing arts module. The optional performing arts module consists of four items on disability when playing a musical instrument. Up until now, no research has been done to establish the internal consistency and validity of the DASH performing arts module for use in a population of musicians. The DASH performing arts module was administered in a randomized controlled trial examining the effectiveness of a biopsychosocial intervention in preventing or reducing disabilities from musculoskeletal complaints in conservatory students. ${ }^{8}$ This paper presents the results of the baseline questionnaire, to increase insights into several psychometric properties of this measurement instrument. The primary objective of this study is to examine the score distribution, internal consistency, discriminative and construct validity of the performing arts module of the DASH. A second goal is to broaden current knowledge on the relationship between PRMD and pain, by investigating the correlation between these two constructs. 


\section{Methods}

\section{Study design}

This study is part of a randomized controlled trial studying the effectiveness of a biopsychosocial intervention in preventing or reducing disabilities from musculoskeletal complaints in conservatory students. ${ }^{8}$ The trial is registered in the Nederlands Trial Register NTR3561. The Medical Ethical Committee of Maasstad Ziekenhuis Rotterdam approved the study (NL39564.101.12). During lectures at the start of the school year, first year students from 2012 to 2013 and first and second year students from the academic year 2013-2014, from five Dutch conservatories were invited to participate. Students were required to be able to understand Dutch or English language. Students with a specific self-reported comorbidity that could be associated with musculoskeletal complaints, such as rheumatoid arthritis or multiple sclerosis, were excluded. After providing written informed consent, students completed the baseline questionnaire. Since many conservatory students are from abroad, the main language of instruction at the music schools is English. General understanding of the English language in the Netherlands is at high level. We choose therefore to provide English questionnaires to all participants. A translation booklet was provided for Dutch students if needed. Only English outcome measures with valid Dutch translations were used. Data from the baseline questionnaire were analyzed for the present study. The data presented here include data for the whole population, as well as split between students who experience PRMD and students who do not experience PRMD.

\section{Outcome measures}

\section{DASH}

The DASH questionnaire is a self-reported 30-item questionnaire designed for use in a population with a variety of upper-extremity musculoskeletal conditions. It assesses symptoms as well as the ability to perform certain activities specific to arm, shoulder and hand function. Items are answered based on the condition during the last week. Components are symptoms (pain, weakness, stiffness, tingling/numbness) and functional status (physical, social, and psychological dimension). Physical components include: daily activities, house/yard chores, shopping/errands, recreational activities, self-care, dressing, eating, sexual activities, and sleep. Social components consist of: family care, occupation and socializing with friends/relatives. The psychological component is self-image. Scores are calculated using a scale ranging from 0 to 100. A higher score represents more disability. For the English version, validity is good, and correlation with a range of other upper extremity measures exceeded 0.70 for all tests in a cohort of patients with wrist/ hand or shoulder problems. Test-retest reliability $(I C C=0.96)$ and responsiveness are good. ${ }^{9}$ The Dutch version's internal consistency, Cronbach's alpha $=0.95$, and validity $81 \%$ consistency with COPM; k-coefficient $=0.79$ ) are good..$^{10}$ Additionally, it has been shown that the DASH is not only valid for measurement of non-traumatic upper extremity musculoskeletal complaints, but also for non-traumatic neck complaints. ${ }^{11}$ 


\section{DASH performing arts module}

The performing arts module is presented in Box 1. The optional module scores are presented as a sub score ranging from 0 (not disabled) to 100 (most severe disability). In a content validity study, about $60 \%$ of the clinicians reported using the DASH optional modules. These included the work module (16.2\%), sports/performing arts module (4.6\%), or both work and sports/ performing arts module (41.5\%). ${ }^{12}$ Cronbach's alpha for the work and sports/performing arts scales was found to be 0.94 in a Swedish population with upper extremity condition..$^{13}$ Since the sports/performing arts categories form one module, data are often reported jointly which makes it impossible to split results into sports and performing arts categories. DASH norm scores for the general population have been reported, ${ }^{14}$ however, studies evaluating validity and norm scores for specific subgroups are limited and no data on the validity of the performing arts module are published to date. The DASH registry was contacted and they confirmed that they were not aware of any studies specifically reporting data or methodological appraisal of the performing arts module.

Box 1: The Disabilities of Arm, Shoulder, and Hand questionnaire, performing arts module

The following questions relate to the impact of your arm, shoulder or hand problem on playing your musical instrument. Tick the answer that best describes your physical ability in the past week. Did you have any difficulty:

1. Using your usual technique for playing your instrument?

2. Playing your instrument because of arm, shoulder or hand pain?

3. Playing your musical instrument as well as you would like?

4. Spending your usual amount of time practicing or playing your instrument

Answer options: no difficulty, mild difficulty, moderate difficulty, severe difficulty, unable.

\section{Pain Disability Index}

The Pain Disability Index ${ }^{15,16}$ is a generic measure for disability. Participants report on seven different daily activities (family/home responsibilities, recreation, social activity, occupation, sexual behavior, self-care, life-support activities), and whether or not they were disabled due to pain (score per question ranging from 0: no disability to 10: worst disability). The seven categories were summed into a total score ranging from 0 to 70 . The higher the total score, the more disability. Evaluation of psychometric properties showed good construct validity, good internal consistency (Cronbach's alpha $=0.86$ ), and good validity when compared to reports of psychological distress, pain intensity, and other measures of pain disability. ${ }^{16}$ For the Dutch version, there was good internal consistency and test-retest reliability $(I C C=0.76) .{ }^{17}$ 


\section{Playing-related musculoskeletal disorders}

Playing-related musculoskeletal disorders have been defined as: "pain, weakness, lack of control, numbness, tingling, or other symptoms that interfere with your ability to play your instrument at the level you are accustomed to." ${ }^{3}$ This definition, which was developed from qualitative research with stakeholders, guides questionnaire development in the majority of research studies on PRMD. Based on self-reporting, the participants in this study first indicated whether or not they experienced playing-related complaints while playing their instrument in the past week. If they had, they indicated the location of their PRMD symptoms on a drawing of a human figure. ${ }^{18}$ A Numeric Rating Scale (NRS) was used to quantify the severity of complaints experienced in the past week, where 0 means no complaints, and 10 indicates the worst complaints possible.

\section{Pain}

The presence of pain was assessed using parts of the Dutch language version of the McGill Pain questionnaire. ${ }^{18}$ "With this questionnaire we want to get an overview of the pain you experience currently. It does not matter where you have pain or what causes the pain. Do you experience pain right now?"When the answer was positive, participants indicated on a drawing of a human figure where they experienced pain and circled the number on an NRS (0-10) which represented the severity of pain they experience currently. Reliability was good, Cronbach's alpha was 0.89.19

\section{Short Form-36}

Quality of life was assessed using the Short Form-36 Health Survey, SF-36v1. ${ }^{20}$ The Short-Form-36 is a generic measure composed of 36 items, of which physical and mental sub scores were calculated. Scores represent a reference to a standard population with an average score of 50 and standard deviation of 10 . Scores higher than 50 represent a better quality of life compared to the reference population, while scores below 50 represent worse quality of life. ${ }^{21}$ Much research has been conducted on reliability and validity of this survey in different populations. Most published statistics on reliability exceeded the estimate of 0.80 . Reliability for physical and mental sub scores generally exceeds 0.90.22 For the Dutch version, internal consistency (Cronbach's alpha $=0.84$ ) and validity are also good.21

\section{Statistical analyses}

Population characteristics and outcomes are presented descriptively as mean \pm standard deviation or median with interquartile range for parametric and non-parametric data, respectively. 


\section{Analyses of the psychometric properties of the performing arts module}

Frequencies, distribution of data and ranges of scores were calculated. Frequencies of missing items per question were evaluated. Floor or ceiling effects were considered present if more than $15 \%$ of respondents achieved the highest or lowest possible score on the performing arts module. ${ }^{23}$ Internal consistency between the four items of the performing arts module was evaluated by calculating Cronbach's alpha. Values of Cronbach's a between 0.70 and 0.95 are considered good. ${ }^{24}$ Discriminative validity: Our hypothesis was that subjects with PRMD would have higher disability scores as compared to subjects without PRMD. Independent samples t-test, or Mann-Whitney's $U$ tests in case of non-parametric data, were performed to test this hypothesis. Construct validity: Only participants with PRMD were included for this part of the analysis. Correlation testing (Pearson for data with normal distributed, Spearman for data with non-normal distribution) was applied to calculate correlations between the scores on the performing arts module and the general DASH, pain disability index, PRMD severity score, pain severity score, short-form 36 physical and mental sub score. A correlation lower than 0.30 was defined as weak, 0.30-0.60 moderate, and higher than 0.60 as strong. ${ }^{24} \mathrm{~A}$ priori hypotheses were formulated on the strength of the correlation between the different scores and are summarized in Table 1. A higher number of confirmed hypotheses indicate stronger support for construct validity. Hypothesis 1: the score on the performing arts module correlates strongly ( $>0.60)$ with the DASH since they are supposed to measure the same construct; i.e., disability. Hypothesis 2: Pain disability index score correlates moderately $(0.30$ to 0.60 ) with the performing arts module score because this measure is not specific enough to correlate highly with performance-related disability. Hypotheses 3 and 4: Both PRMD severity score and pain severity score correlate strongly with the performing arts module score (>0.60). Prior research showed a 0.662 correlation between DASH and pain severity score in musicians. ${ }^{7}$ It is assumed that performing arts module and PRMD severity score are even more specific measures for this population, so correlations are expected to be high. Hypotheses 5 and 6: Scores of the performing arts module correlate moderately $(-0.30$ to -0.60$)$ with both the physical and the mental sub score of the SF-36. The DASH is based on parts of the SF-36, and incorporates common constructs. ${ }^{25}$ More severe upper-extremity disability has been found to correlate with worse quality of life. ${ }^{13}$ However, for the performing arts module particularly, we hypothesize that the correlation will only be moderate, because the SF-36 subscales will not be specific enough to capture the total influence of music-related disability. Statistical testing was performed using IBM SPSS Statistics for Windows, version 23 (IBM Corp., Armonk, NY). 
Table 1: Hypothesized correlations between performing arts module and other measures

\begin{tabular}{clcr}
\hline Performing arts module & & \\
\hline 1 & DASH & Strong & $>0.60$ \\
2 & PDI & Moderate & $0.30-0.60$ \\
3 & PRMD severity score & Strong & $>0.60$ \\
4 & Pain severity score & Strong & $>0.60$ \\
5 & SF36-PCS & Moderate & $-0.30--0.60$ \\
6 & SF36-MCS & Moderate & $-0.30--0.60$ \\
\hline
\end{tabular}

DASH: Disabilities of Arm, Shoulder, and Hand questionnaire; PDI: pain disability index; PRMD: playing-related musculoskeletal disorders; SF-36: Short Form-36; PCS: physical component score; MCS: mental component score.

\section{Correlations between PRMD and pain}

Prevalence of PRMD and pain according to location indicated on the human drawing were categorized into five body regions: head/neck, hand/arm/shoulder, back, lower extremity, abdomen. Correlations between the dichotomous outcome measures PRMD (yes/no) and pain (yes/no) were evaluated using Spearman's correlation testing.

\section{RESULTS}

\section{Sample characteristics}

All of the 130 music students interested in participation were determined to be eligible and were included. Of these, 71 were female and 59 were male. Median age was 20 years (IQR 4). More than half (57\%) of the students were from the Netherlands, $29 \%$ were from other European countries, $14 \%$ were from other continents. Most of the students started in year 1 (91\%) and were enrolled in the bachelor of classical music program (64\%). Instruments played were strings (39\%), wind (22\%), keyboard (18\%), percussion (11\%), and vocals (10\%). See also Table 2. Sixty-five percent of the students reported current PRMD, with an average severity score of $4.55 \pm$ SD 1.88. Forty-one percent reported pain. Mean pain severity score was $3.36 \pm$ SD 1.97. Unfortunately, we did not have access to the total number of students at each conservatory, and we did not have ethics approval to seek information on drop-outs. 
Table 2: Population characteristics and outcome measures

\begin{tabular}{|c|c|c|c|}
\hline & $\mathbf{N}$ & & $\mathrm{N}(\%)$, median (IQR), or mean $\pm \mathrm{SD}$ \\
\hline \multirow[t]{2}{*}{ Sex } & 130 & Female & $71(55 \%)$ \\
\hline & & Male & $59(45 \%)$ \\
\hline Age (y) & 129 & & $20(4)$ \\
\hline Height $(\mathrm{cm})$ & 129 & & $1.73 \pm 0.10$ \\
\hline Weight (kg) & 129 & & $65.98 \pm 13.08$ \\
\hline BMI & 129 & & $21.92 \pm 3.09$ \\
\hline \multirow[t]{6}{*}{ Nationality } & 129 & Dutch & $74(57 \%)$ \\
\hline & & Other European & $38(29 \%)$ \\
\hline & & Asian & $8(6 \%)$ \\
\hline & & South American & $5(4 \%)$ \\
\hline & & Australian & $2(2 \%)$ \\
\hline & & African & $2(2 \%)$ \\
\hline \multirow[t]{3}{*}{ School year } & 130 & 1 & $118(91 \%)$ \\
\hline & & 2 & $11(8 \%)$ \\
\hline & & 3 & $1(1 \%)$ \\
\hline \multirow[t]{4}{*}{ Bachelor } & 129 & Classical music & $83(64 \%)$ \\
\hline & & Pop/Jazz music & $19(15 \%)$ \\
\hline & & Music in education & $18(14 \%)$ \\
\hline & & Other & $9(7 \%)$ \\
\hline \multirow[t]{5}{*}{ Instrument } & 130 & Strings & $51(39 \%)$ \\
\hline & & Wind & $28(22 \%)$ \\
\hline & & Keyboard & $24(18 \%)$ \\
\hline & & Percussion & $14(11 \%)$ \\
\hline & & Vocal & $13(10 \%)$ \\
\hline
\end{tabular}

N: number; IQR: interquartile range; SD: standard deviation

\section{Psychometric properties of the performing arts module}

No missing responses in performing arts module scores were present. The frequencies of responses to performing arts module questions are presented in Table 3. Twenty-seven percent reported moderate or severe difficulty, or were unable to use their usual technique for playing the instrument. Thirty-two percent reported moderate difficulty or worse while playing the instrument because of arm, shoulder, or hand pain. Thirty-four percent reported moderate difficulty or worse in playing the instrument as well as they would like, and 42\% reported moderate difficulty or worse in spending their usual amount of time practicing. For the total sample, data were positively skewed (skewness 0.952, kurtosis 0.192). Little differences in skewness existed between questions, and exact skewness was 1.08, 1.07, 0.90, and 0.92 for question 1, 2, 3, and 4 , respectively. The median score was 18.75 , interquartile range 31.25 , minimum 0 , maximum 
81.25. For the students with PRMD, the median performing arts module score was 25 (31.35). Seven (8.3\%) of the students with PRMD scored the lowest possible score (0). Score range was 0 81.25. Of the students not reporting PRMD, $62 \%$ scored 0 on the performing arts module (median score 0, IQR 6.25, range 0 - 31.25). Internal consistency was good, with Cronbach's alpha of 0.893, indicating good reliability. None of the items increased reliability when deleted. Discriminative validity was good, since a significantly higher performing arts module score was found in musicians with PRMD compared to musicians without PRMD. In Table 4, a schematic presentation of the aforementioned scores, supplemented with scores of the general DASH questionnaire, pain disability index, and SF-36 physical and mental sub scores, is provided. The differences in scores between students who do and do not experience PRMD were found to be highly significant for the performing arts module, DASH, and physical component score of SF-36. The difference in score distribution for the two groups is larger in the performing arts module as compared to the general DASH. Construct validity: Table 5 depicts the Spearman correlations between the questionnaires. Missing values were handled by excluding cases pairwise. Correlation between performing arts module with DASH was strong, correlation with pain disability index and SF-36 physical sub score was moderate, and correlation with PRMD severity score was weak. No correlation was found between the performing arts module with pain severity score and mental sub score of the SF-36. Three out of six (50\%) of hypotheses were confirmed. Hypotheses on the relationship between performing arts module with PRMD severity score, pain severity score and mental sub score of short-form-36 were rejected.

Table 3: Frequencies of answers according to the performing arts module

\begin{tabular}{|c|c|c|c|c|c|c|c|c|c|c|}
\hline \multirow[b]{2}{*}{ Did you have any difficulty: } & \multicolumn{2}{|c|}{ No difficulty } & \multicolumn{2}{|c|}{ Mild } & \multicolumn{2}{|c|}{ Moderate } & \multicolumn{2}{|c|}{ Severe } & \multicolumn{2}{|c|}{ Unable } \\
\hline & PRMD + & PRMD- & PRMD + & PRMD- & PRMD + & PRMD- & PRMD + & PRMD- & PRMD + & PRMD- \\
\hline $\begin{array}{l}\text { Using your usual technique } \\
\text { for playing your instrument? }\end{array}$ & $33 \%$ & $89 \%$ & $40 \%$ & $11 \%$ & $20 \%$ & $0 \%$ & $7 \%$ & $0 \%$ & $0 \%$ & $0 \%$ \\
\hline $\begin{array}{l}\text { Playing your instrument } \\
\text { because of arm, shoulder } \\
\text { or hand pain? }\end{array}$ & $29 \%$ & $89 \%$ & $39 \%$ & $11 \%$ & $24 \%$ & $0 \%$ & $7 \%$ & $0 \%$ & $1 \%$ & $0 \%$ \\
\hline $\begin{array}{l}\text { Playing your musical } \\
\text { instrument as well as } \\
\text { you would like? }\end{array}$ & $19 \%$ & $76 \%$ & $46 \%$ & $22 \%$ & $20 \%$ & $2 \%$ & $13 \%$ & $0 \%$ & $1 \%$ & $0 \%$ \\
\hline $\begin{array}{l}\text { Spending your usual } \\
\text { amount of time practicing or } \\
\text { playing your instrument? }\end{array}$ & $26 \%$ & $76 \%$ & $32 \%$ & $18 \%$ & $24 \%$ & $7 \%$ & $13 \%$ & $0 \%$ & $5 \%$ & $0 \%$ \\
\hline
\end{tabular}

PRMD +: students with playing-related musculoskeletal disorders, PRMD-:students without playing-related musculoskeletal disorders 
Table 4: Score distribution split for students with and without playing-related musculoskeletal disorders

\begin{tabular}{lccccccc}
\hline & $\mathbf{n}$ & Total & $\mathbf{n}$ & PRMD & $\mathbf{n}$ & PRMD- & Sig. \\
\hline Performing arts module & 130 & $18.75(31.25)$ & 84 & $25(31.35)$ & 45 & $0(6.25)$ & $0.000^{* * *}$ \\
DASH & 129 & $8.33(11.31)$ & 84 & $10.83(11.25)$ & 44 & $3.75(7.08)$ & $0.000^{* * *}$ \\
PDI & 127 & $2(9)$ & 81 & $4(11)$ & 45 & $1.5(4.75)$ & $0.005^{* *}$ \\
SF36-PCS & 130 & $50.69 \pm 7.75$ & 84 & $48.34 \pm 7.69$ & 45 & $54.79 \pm 5.76$ & $0.000^{* * *}$ \\
SF36-MCS & 130 & $41.62 \pm 12.09$ & 84 & $40.94 \pm 12.30$ & 45 & $42.83 \pm 11.88$ & 0.366 \\
\hline
\end{tabular}

Scores are presented as median (interquartile range) or mean \pm standard deviation; PRMD +: students with playing-related musculoskeletal disorders; PRMD-: students without playing-related musculoskeletal disorders. DASH: Disabilities of Arm, Shoulder, and Hand questionnaire; PDI: pain disability index; PRMD: playing-related musculoskeletal disorders; SF-36: Short Form-36; PCS: physical component score; MCS: mental component score. Sig.: significance according Mann-Whitney U-test. * $p<0.05$, ${ }^{* *} p<0.01,{ }^{* * *} p<0.001$

Table 5: Spearman correlations between performing arts module and other measures

\begin{tabular}{ccc}
\hline Performing arts module & Hypothesized & True \\
\hline DASH & $>0.60$ & $\mathbf{0 . 6 2 6}$ \\
PDI & $0.30-0.60$ & $\mathbf{0 . 3 4 0}$ \\
PRMD severity score & $>0.60$ & 0.232 \\
Pain severity score & $>0.60$ & 0.044 \\
SF36-PCS & $-0.30--0.60$ & $\mathbf{- 0 . 3 3 7}$ \\
SF36-MCS & $-0.30--0.60$ & -0.035 \\
\hline
\end{tabular}

DASH: Disabilities of Arm, Shoulder, and Hand questionnaire; PDI: pain disability index; PRMD: playing-related musculoskeletal disorders; SF-36: Short Form-36; PCS: physical component score; MCS: mental component score. Bold values indicate accepted hypotheses

\section{Association between PRMD and pain}

Most of the PRMD occurred in hand, arm or shoulder (50\%), followed by back (26\%) and head/ neck (18\%). Most of the pain in the back (36\%), followed by hand, arm, or shoulder (33\%), and head, neck (19\%). When comparing PRMD and pain locations, PRMD was more reported in the hand, arm, shoulder region; and pain was more reported in the back and lower extremity regions. Spearman's correlation coefficient between the presence of PRMD and pain was 0.240 . See also Table 6. 
Table 6: Characteristics of playing-related musculoskeletal disorders and pain

\begin{tabular}{lcc}
\hline & PRMD (n=130) & Pain (n= 130) \\
\hline Positive answer $n$ (\%) & $84(65 \%)$ & $53(41 \%)$ \\
Average score (NRS 0-10) & $4.55 \pm 1.88$ & $3.36 \pm 1.97$ \\
Complaints per body region & & \\
Head, neck & $44(18 \%)$ & $20(19 \%)$ \\
Hand, arm, shoulder & $121(50 \%)$ & $36(33 \%)$ \\
Back & $63(26 \%)$ & $39(36 \%)$ \\
Lower extremity & $12(5 \%)$ & $12(11 \%)$ \\
Abdomen & $2(1 \%)$ & $1(1 \%)$ \\
Total & $242(100 \%)$ & $108(100 \%)$ \\
\hline
\end{tabular}

PRMD: playing-related musculoskeletal disorders. NRS: numerical rating scale. Results are presented as number(\%) or mean \pm standard deviation

\section{Discussion}

This first analysis of the psychometric properties of the performing arts module of the DASH demonstrated a good internal consistency, meaning that the items measure the same constructs. ${ }^{23}$ None of the items would increase reliability if deleted. The performing arts module showed a good discriminative validity between students with and without PRMD. The DASH also was able to discriminate between students with and without PRMD, but the score distribution in the performing arts module was larger, presumably because the performing arts module is more sensitive than the DASH. Construct validity is moderate, the performing arts module correlates highly with the DASH and moderately with pain disability index and physical sub score of SF-36 as expected. Sixty-five percent of our population experienced PRMD. For the students with PRMD, the median performing arts module score was 25. No floor or ceiling effects were found when considering this specific group. Scores reported in the current study were similar to prior reported results in a Spanish conservatory population ${ }^{26}$ and correspond with the disability level of highlevel amateur student musicians at the end of an intensive music project. ${ }^{27}$ Results of the general DASH questionnaire in this population of music students are comparable with prior reported disability levels of college instrumental musicians, ${ }^{7}$ and are only somewhat higher than disability levels in young, active adults without complaints. ${ }^{28}$ Since the occupational demands of music students are much higher than the demands in general daily life, this suggests that more general assessments such as the DASH are not sensitive enough to reveal disability due to PRMD. Unexpectedly low correlations were found between the performing arts module and the mental sub score of the SF-36, pain severity score and PRMD severity score, resulting in only moderate construct validity. When considering these results, some arguments might explain these three unexpected low correlations and possibly false a priori hypotheses. First, in retrospect, the absence of a correlation between the performing arts module and the mental sub score of the SF-36 seems logical, because the four performing arts module questions all relate to physical ability. Besides, our results show that levels of mental wellbeing in music students is lower when compared to a reference group, yet there are no differences in wellbeing scores between students 
who experience PRMD and students who do not. This could suggest that the level of mental wellbeing is not influenced by experiencing PRMD and thus may also not have a large influence on disability levels. A second unexpected low correlation was found between the performing arts module score and pain severity score. When reviewing the performing arts module items, we realized that performing arts module is particularly related to measuring disability due to PRMD, and only one of the four items is related to pain. Since we also found only a weak correlation between PRMD and pain, this implies that PRMD and pain are different constructs. This could explain the absence of a correlation between performing arts module and pain severity score. Third, the finding that the performing arts module only correlates weakly with PRMD severity score is interesting. A point of consideration is the use of the NRS to measure PRMD- and pain severity. In a recent study on psychometric properties of the pain NRS in musicians, it was found that the ability of the NRS to distinguish between different levels of pain was poor among musicians with milder pain. ${ }^{29}$ It appears that an NRS is not a valid tool to assess pain in musicians with low pain levels. Although we do not know whether these results impacted the relationship with PRMD severity scores, we can speculate that if the NRS is not sensitive enough to measure PRMD severity in our population with only moderate levels of PRMD and pain, this could have caused the lower correlation between the performing arts module and PRMD severity score. This might also indicate that the performing arts module is a more sensitive measure than the NRS for measuring the extent of PRMD in a population with mild to moderate levels of PRMD. However, these speculations should be substantiated by future research on the psychometric properties of numerical rating scales for measuring PRMD severity. In retrospect, it seems likely that we formulated some false hypotheses, leading to only three out of six hypotheses being accepted. Hence, the conclusion that the performing arts module has only moderate construct validity is conservative. The lack of correlation between PRMD and pain is an interesting secondary finding of this study. For our participants, PRMD were mostly reported in the arm, shoulder, and hand region; pain was mostly reported in the back and lower extremity region. PRMD is related to performance symptoms (including weakness, paresthesia, and lack of control, for e.g.), and not just pain. One can have relatively mild symptoms, and these can still have a major impact on the ability to perform at the level to which one is accustomed. In other words, PRMD are not always experienced as pain. Our findings may point to an underlying tolerance for pain as a "normal" occurrence during the everyday work of conservatory students. Results underline that some musicians might interpret PRMD and pain as different constructs, whereas the construct PRMD seems more sensitive than pain when asking about their physical complaints. It is important to note, however, that in this study, the participants were also reflecting on different time periods when reporting PRMD (in the past week) and pain (right now). The outcome measures in this study were chosen for two main reasons. First, these outcome measures are widely used in different (pain) populations. Extensive information is available on validity of these measures which makes results clearly interpretable. This allows comparison of results between musicians and other population and provides insight on difference in pain experience between these groups. Second, we selected only questionnaires that had a validated Dutch translation. An issue encountered in this study was the multinational origin of the population under study. The validity of a score is dependent on the situation in which the questionnaire is distributed. For example, language and cross-cul- 
tural differences may lead to different interpretation of the question and can affect scores. ${ }^{23}$ In a multinational population such as ours it is not practical to provide every student with a questionnaire in his/her own language. We chose to provide everyone with an English questionnaire and gave the Dutch students a translation booklet in case it was needed. As Dutch students have significant English language skills, most classes at the conservatory are given in English, and all students were living in the same cultural environment at the time of participation in our study, we believe that cross-cultural and language issues on validity in this study were minimal. When interpreting results, it should be noted that this study was not originally designed to validate outcome measures. However, we believe that the results of this study aid in interpreting outcomes in musician populations and will also assist clinicians and researchers in determining which outcome measure to use. A new study should be conducted with the specific goal of validating the performing arts module of the DASH. Information from this study can also be used to formulate more accurate hypotheses regarding construct validity. We believe it is also important to make use of experts (i.e., music students themselves) to determine the construct validity of the four questions. It would be useful to establish normative data to be able to correctly interpret research results and to detect treatment-related changes in scores. Also, test-retest reliability of the DASH performing arts module and interpretation of score changes (smallest detectable change and minimal clinically important difference, and responsiveness) should be researched in future. With the new information provided by this study, we conclude that the performing arts module is a short four-item additional module of the DASH which gives a fair representation of music students' physical disability. The performing arts module seems to be more sensitive than the DASH in this population, and can be used on its own. Internal consistency and discriminative validity are good. Conservative estimates are that construct validity is moderate; the performing arts module primarily reflects physical aspects of disability. The weak correlation found between PRMD and pain severity scores suggests that PRMD and pain are different constructs and should be measured separately. 


\section{References}

1. Kok LM, Huisstede BM, Voorn VM, et al. The occurrence of musculoskeletal complaints among professional musicians: a systematic review. Int Arch Occup Environ Health.2016;89:373-396.

2. ICF: international classification of functioning, disability and health. Geneva: World Health Organization; 2001.

3. Zaza C, Charles C, Muszynski A. The meaning of playingrelated musculoskeletal disorders to classical musicians. Soc Sci Med. 1998;47:2013-2023.

4. Berque P, Gray H, McFadyen A. Development and psychometric evaluation of the Musculoskeletal Pain Intensity and Interference Questionnaire for professional orchestra Musicians. Manual Ther. 2014;19:575-588.

5. Lamontagne $\mathrm{V}$, Belanger $\mathrm{C}$. Development and validation of a questionnaire on musculoskeletal pain in musicians. Med Probl Perform Art. 2012;27:37-42.

6. Ackermann B, Driscoll T. Development of a new instrument for measuring the musculoskeletal load and physical health of professional orchestral musicians. Med Probl Perform Art.2010;25:95-101.

7. Barton R, Killian C, Bushee M, et al. Occupational performance issues and predictors of dysfunction in college instrumentalists.Med Probl Perform Art. 2008;23:72-78.

8. Baadjou VA, Verbunt JA, Eijsden-Besseling MD, et al. PREvention STudy On preventing or reducing disability from musculoskeletal complaints in music school students(PRESTO): protocol of a randomised controlled trial. J Physiother. 2014;60:232.

9. Beaton DE, Katz JN, Fossel AH, et al. Measuring the whole or the parts? Validity, reliability, and responsiveness of the Disabilities of the Arm, Shoulder and Hand Outcome measure in different regions of the upper extremity. J Hand Ther. 2001;14:128-146.

10. Veehof MM, Sleegers EJA, van Veldhoven NHMJ, et al. Psychometric qualities of the Dutch language version of the disabilities of the arm, shoulder, and hand questionnaire(DASH-DLV). J Hand Ther. 2002;15:347-354.

11. Huisstede BMA, Feleus A, Bierma-Zeinstra SM, et al. Is the Disability of Arm, Shoulder, and Hand Questionnaire (DASH) also valid and responsive in patients with neck complaints? Spine. 2009;34:E130.

12. Kennedy CA, Beaton DE. A user's survey of the clinical application and content validity of the DASH (Disabilities of the Arm, Shoulder and Hand) outcome measure. J Hand Ther. 2017;30:30-40.

13. Atroshi I, Gummeson C, Andersson B, et al. The disabilities of the arm, shoulder and hand (DASH) outcome questionnaire: reliability and validity of the Swedish version evaluated in 176 patients. Acta Orthop Scand. 2000;71:613-318.

14. Hunsaker FG, Cioffi DA, Amadio PC, et al. The American Academy of Orthopaedic Surgeons Outcomes Instruments. Normative values from the general population. J Bone Joint Surg Am. 2002;84:208-215.

15. Pollard CA. Preliminary validity study of the pain disability index. Percept Mot Skills. 1984;59:974.

16. Tait CR, Chibnall JT, Krause S. The Pain Disability Index: psychometric properties. Pain. 1990;40:171-182.

17. Soer R, Koke AJ, Vroomen PC, et al. Extensive validation of the pain disability index in 3 groups of patients with musculoskeletal pain. Spine. 2013;38:E562-E568.

18. Vanderiet K, Adriaensen $\mathrm{H}$, Carton $\mathrm{H}$, et al. The McGill Pain Questionnaire constructed for the Dutch language (MPQIN). Preliminary data concerning reliability and validity. Pain. 1987;30:395-408. 
19. van der Kloot WA, Oostendorp RAB, van der Meij J, et al. De Nederlandse versie van "McGill pain questionnaire": een betrouwbare pijnvragenlijst. Ned Tijdschr Geneesk.1995;139:669-673.

20. Ware JE Jr, Sherbourne CD. The MOS 36-item short-form health survey (SF-36). I. Conceptual framework and item selection. Med Care. 1992;30:473-483.

21. Aaronson NK, Muller M, Cohen PD, et al. Translation, validation, and norming of the Dutch language version of the SF-36 Health Survey in community and chronic disease populations. J Clin Epidemiol. 1998;51:1055-1068.

22. McHorney CA, Ware JEJ, Lu JF, et al. The MOS 36-item Short-Form Health Survey (SF-36): III. Tests of data quality, scaling assumptions, and reliability across diverse patient groups. Med Care. 1994;32:40-66.

23. de Vet HC, Terwee CB, Mokking LB, et al. Measurement in medicine. Cambridge, UK: Cambridge University Press;2011.

24. Terwee CB, Bot SD, de Boer MR, et al. Quality criteria were proposed for measurement properties of health status questionnaires. J Clin Epidemiol. 2007;60:34-42.

25. Hudak PL, Amadio PC, Bombardier C. Development of an upper extremity outcome measure: the DASH (disabilities of the arm, shoulder and hand) [corrected]. The Upper Extremity Collaborative Group (UECG)). Am J Ind Med.1996;29:602-608.

26. Rodriguez-Romero B, Perez-Valino C, Ageitos-Alonso B, et al. Prevalence and associated factors for musculoskeletal pain and disability among Spanish Music Conservatory Students. Med Probl Perform Art. 2016;31:193-200.

27. Kok LM, Haitjema S, Groenewegen KA, et al. The influence of a sudden increase in playing time on playing-related musculoskeletal complaints in high-level amateur musicians in a longitudinal cohort study. PLoS One. 2016;11:e0163472.

28. Clarke MG, Dewing CB, Schroder DT, et al. Normal shoulder outcome score values in the young, active adult. J Shoulder Elbow Surg. 2009;18:424-428.

29. Saltychev M, Vastamaki $H$, Mattie R, et al. Psychometric properties of the pain numeric rating scale when applied to multiple body regions among professional musicians.PLoS One. 2016;11:e0161874. 


\section{Part II}

Effects of body posture while playing a musical instrument 



\section{Chapter 5}

\section{Energy expenditure in brass and woodwind instrumentalists: the effect of body posture}

Published as: Baadjou VA, van Eijsden-Besseling MD, Samama-Polak

AL, Smeets RJ, Lima Passos V, Westerterp KR. Energy expenditure in brass and woodwind instrumentalists; the effect of body posture. Med Probl Perform Art. 2011;26(4):218-222.

Awarded: "NVDMG Aanmoedigingsprijs voor jong talent 2011", Nederlandse Vereniging van Dans- en Muziekgeneeskunde. Leiden. (Young Talent Award Dutch Performing Arts Medicine Association) 


\section{Abstract}

Objective: Body posture appears to influence fatigue and musculoskeletal complaints in musicians. Our aim was to determine energy expenditure and to investigate whether energy expenditure is affected by body posture in brass and woodwind instrumentalists.

Methods: Eighteen musicians (10 women, 8 men; 6 brass, 12 woodwinds), with a mean age of $39 \pm 14$ years and mean body mass index of $23.8 \pm 4.9 \mathrm{~kg} / \mathrm{m}^{2}$, played their instruments for 30 minutes twice: once in nonoptimized body posture (posture A), and once in a posture according to the postural exercise therapy method Mensendieck (posture B). Patients were randomized to the order of postures in a crossover design $A B / B A$. Playing sessions were preceded and followed by 60 minutes of rest. Energy expenditure was measured in a respiration chamber with indirect calorimetry. Basal metabolic rate was measured with a ventilated hood.

Results: Mean metabolic equivalents (MET) for playing a wind instrument in the sitting position in a nonoptimized posture and posture according postural exercise therapy were 1.69 (SD 0.18) and 1.80 (SD 0.22), respectively. Percent change between resting metabolic rate and total energy expenditure while playing was 32\% (95\% Cl 25 - 39\%) in posture B and $23 \%(95 \% \mathrm{Cl} 17-30 \%)$ in posture $\mathrm{A}(\mathrm{p}=0.021)$.

Conclusion: Average physical activity while playing a wind instrument approximates 1.8 MET. Our data show an association between energy expenditure and body posture while playing a brass or woodwind instrument: playing a musical instrument in a posture according to postural exercise therapy leads to higher energy expenditure as compared to a nonoptimized body posture. These results suggest that fatigue and the general feeling of lack of energy after playing a musical instrument are not related to actual higher energy expenditure. 


\section{Introduction}

Many musicians develop playing-related disorders during their careers. Previous studies have indicated a prevalence of medical problems among musicians of up to $87 \%$. $^{1-3}$ Most common are nonspecific musculoskeletal disorders. ${ }^{4}$ Musical performance should be seen as a physically demanding process. Fatigue is a commonly heard complaint, resulting from physical, cognitive, and emotional exertion., Ergonomics, efficiency of movement, and body posture have been mentioned to attribute to a more healthy way of performing. ${ }^{3,6}$ Recently, several articles have been published on health promotion and prevention which emphasize the importance of improvement of movement patterns and posture when playing a musical instrument.7.8 Although there is no actual scientific evidence that postural techniques reduce musculoskeletal problems in musicians, postural and postural awareness techniques like Feldenkrais and Alexander technique are generally accepted in music education. ${ }^{9}$ Another postural technique, postural exercise therapy according to the method Mensendieck (hereafter called postural exercise therapy), has widespread use in northern Europe and should also be considered. The aim of postural exercise therapy is optimization of posture and movement patterns in relation to daily activities. ${ }^{10}$ Its cornerstone is knowledge about and awareness of the body and muscles. Body posture is re-educated with help from visual, audible, and proprioceptive feedback. ${ }^{11,12}$ Goals are achieved by stimulation of quantitative and qualitative movement behavior and by postural and exercise advice. ${ }^{10}$ Participants improve mobility, coordination, and condition and learn to move optimally in daily life. ${ }^{10}$ Mensendieck therapy is well known in the Netherlands, France, and Scandinavian countries for treatment of musculoskeletal complaints and is frequently administered to musicians.

According to the theory of postural exercise therapy, three muscle groups can be discerned which are in use while playing a musical instrument: balance muscles, active playing muscles, and passive playing muscles. Balance muscles are used to support body weight (e.g., m. latissimus dorsi, lower part of m. trapezius), active playing muscles are used to play the instrument (e.g., arm, hand, and breathing musculature). 12,13 Passive playing muscles need to be relaxed during playing (e.g., upper part of $\mathrm{m}$. trapezius and $\mathrm{m}$. levator scapulae). 12,13 An optimized body posture enabling all these muscles to function properly is the basis of treatment according to the method Mensendieck. Inadequate control of balance muscles will lead to overuse of both active and passive playing muscles, resulting in physical exertion, fatigue, tiredness, and musculoskeletal complaints. ${ }^{12,13}$ Furthermore, this general overall feeling of exertion in the whole body system as perceived by the musician is described as fatigue. Based on our experience, musicians who have suffered from musculoskeletal pain and participated in postural exercise therapy reported that making music in the instructed body posture is less troublesome and less fatiguing when compared to playing in their former body posture. We hypothesize that fatigue and musculoskeletal pain after playing in a nonoptimized body posture are related to higher energy expenditure. Only limited data on energy expenditure while playing music are available in literature. ${ }^{14-18}$ Ainsworth et al..$^{14}$ described multiple metabolic equivalents for playing music. A metabolic equivalent (MET) is the ratio of work metabolic rate to resting metabolic rate. ${ }^{14}$ Energy costs for playing the flute, horn, and woodwind while sitting are reported to be 2.0 MET. For playing the trumpet and trombone, the METs are 2.5 and 3.5, respectively. ${ }^{14}$ No studies could be found that examined 
the effect of playing postures on energy expenditure in musicians. The aim of the current study was to determine energy expenditure for playing brass and woodwind instruments and to investigate how body posture affects energy expenditure in brass and woodwind instrumentalists.

\section{Methods}

\section{Subjects}

Eighteen musicians were included in this study. Because this is an explorative study, we included as many participants as possible in the available time. Participants were brass and woodwind players who had recently suffered from nonspecific musculoskeletal problems associated with playing music as diagnosed by a rehabilitation consultant or a postural exercise therapist specialized in treating musicians. Subjects had to be treated for their nonspecific musculoskeletal pain by a specialized postural exercise therapist in the last year for at least eight sessions of 1 hour (by the same therapist). Musicians needed to be able to make music both in a body posture according to postural exercise therapy and in the former, nonoptimized body posture. Three therapists participated in the project, two of whom were educated by the third, senior postural exercise therapist. Excluded were patients with lung diseases, rheumatoid arthritis or fibromyalgia. The Medical Ethical Committee of Maastricht University Medical Center, Maastricht, The Netherlands, granted permission for the study. Characteristics of the subjects are listed in Table 1. Six participants played brass instruments (1 woman, 5 men), and 12 participants were woodwind players (9 women, 3 men). Musicians had different grades of experience playing their instrument.

TABLE 1. Participant Characteristics

\begin{tabular}{llll}
\hline & Men $(\mathbf{n}=\mathbf{8})$ & Women $(\mathbf{n}=\mathbf{1 0})$ & Total $(\mathbf{n}=\mathbf{1 8})$ \\
\hline Age $(\mathrm{y})$ & $47 \pm 14$ & $32 \pm 11^{*}$ & $39 \pm 14$ \\
Height $(\mathrm{m})$ & $1.86 \pm 0.07$ & $1.70 \pm 0.06^{* *}$ & $1.77 \pm 0.10$ \\
Weight $(\mathrm{kg})$ & $82.3(64-100.6)$ & $63.1(43.9-82.3)^{*}$ & $73.3(50.4-96.2)$ \\
BMl $\left(\mathrm{kg} / \mathrm{m}^{2}\right)$ & $23.1(18.7-27.5)$ & $21.4(15.5-27.3)$ & $22.9(17.1-28.7)$ \\
\hline
\end{tabular}

Data presented as mean \pm SD or median (interquartile range). ${ }^{*} p<0.05,{ }^{* *} p<0.01$

\section{Procedure}

Participants were approached by a specialized rehabilitation consultant or postural exercise therapist for participation in this study. The main researcher invited the participants, informed them about the protocol, and obtained written informed consent. Participants were scheduled for one appointment at the laboratory, which lasted from 8:00 am to 1:30 pm. Participants were instructed to fast after 10:00 pm the evening before. At 8:00 am the experiment started with basal metabolic rate assessment and anthropometric measurements. At 9:00 am, participants entered a respiration chamber where they ate breakfast and acclimatized. At 9:30 am, the experiment started with a 1-hour rest period. Subsequently, participants played their musical instruments 
between 10:30 and 11:00 am, followed by a 1-hour rest, a second playing period between 12:00 and 12:30 pm, and finally a 1-hour rest until 1:30 pm. During resting periods participants were asked to sit at ease. Musicians played once in a nonoptimized playing posture (posture A) and once in an optimized playing position according to postural exercise therapy (posture B), both in the sitting position. The order of positions per person was randomized into AB or BA. Musicians played their own repertoire which consisted of warm-up pieces and etudes or concert pieces they were used to playing, the same repertoire being played in both sessions. This was done to avoid additional stress and energy expenditure if they had to play music that was unfamiliar to them. The main researcher, who was instructed about the postural exercise theory, observed the postures and gave additional instructions for postural correction in case this was needed.

\section{Basal Metabolic Rate}

Basal metabolic rate (BMR) was both predicted (formula of Schofield ${ }^{19}$ ) and measured. Standard procedures for measurements were followed. Measurements were performed during 35 minutes using a ventilated hood system (Omnical, Maastricht University, Maastricht, The Netherlands), after a 10-hour fasting period, in a thermoneutral environment, in complete physical and mental rest and awake. Values for a 20-minute period, starting 15 minutes after onset of measurements, were taken into analysis. Gas analyses were performed by dual paramagnetic $\mathrm{O}_{2}$ analyzers and dual infrared $\mathrm{CO}_{2}$ analyzers (type 1156, 1507, 1520; Servomex, Crowborough, Sussex, UK). Respiratory gas measurements were adjusted for standard temperature, pressure, and dry conditions. The formula of Brouwer ${ }^{20}$ was used to calculate energy expenditure from average $\mathrm{O}_{2}$ and $\mathrm{CO}_{2}$ values.

\section{Diet}

Participants received breakfast adjusted for their predicted BMR. Total daily energy intake was calculated as 1.75 times the predicted BMR as an estimate of energy requirement for average activity. Breakfast contained $20 \%$ of the calculated daily requirement.

\section{Body Posture}

Posture A was defined as the former, nonoptimized body posture in which the musicians were used to playing at the time they experienced problems: e.g., playing in sway back, leaning backward behind the ischial tuberosities, or legs crossed. Posture B was the optimized body posture according to postural exercise therapy. The biomechanical aspects of this posture focus on pelvis, spine, and shoulder girdle position. ${ }^{12,13}$ With a minimal posterior rotation of the pelvis, the vertebral column is positioned straight above the pelvis, hence transferring the weight of the axial skeleton to the ischial tuberosities. By controlling the curvatures of the vertebral column (e.g., decrease of cervical and lumbar lordosis), overload of intervertebral joints and discs is prevented. Anterior positioning of the thoracic spine decreases tension in thoracic and shoulder musculature. The arms can move freely, by support of the $\mathrm{m}$. latissimus dorsi and lower part of $\mathrm{m}$. trapezius. ${ }^{12,13}$ 


\section{Energy expenditure}

Energy expenditure was measured by indirect calorimetry in a dual respiration chamber system with automated calibration, according to Schoffelen et al. ${ }^{21}$ Composition and volume of inlet and outlet air streams were measured. Energy expenditure was calculated from $\mathrm{O}_{2}$ consumption $\left(\mathrm{VO}_{2}, \mathrm{~mL} / \mathrm{min}\right)$ and $\mathrm{CO}_{2}$ production $\left(\mathrm{VCO}_{2^{\prime}} \mathrm{mL} / \mathrm{min}\right)$ with the formula of Brouwer. ${ }^{20} \mathrm{VO}_{2}$ and $\mathrm{VCO}_{2}$ were averaged over 30-minute intervals. The analysis system consisted of infrared $\mathrm{CO}_{2}$ (ABB/Hartman\&Braun Uras, Frankfurt a.M., Germany) and paramagnetic $\mathrm{O}_{2}$ analyzers (Servomex 4100, Crowborough, UK, and ABB/Hartman\&Braun Magnos, Frankfurt a.M., Germany). Flow was measured using electronically modified dry gas meters (G6, gasmeterfabriek Schlumberger, Dordrecht, The Netherlands). ${ }^{21,22}$ Each room had a volume of $14 \mathrm{~m}^{3}$. The climate was controlled and set at 19 to $22^{\circ} \mathrm{C}$. Physical activity was measured with an analogue ultrasonic Doppler system (Advisor DU160, Aritech BV, Roermond, The Netherlands) and expressed in counts. The system was validated each month with combustion of alcohol. Resting energy expenditure (REE) was determined for the periods before and after each playing session as the average of the two 30-minute intervals during one resting period. Differences in energy expenditure are expressed in percentage of change between total energy expenditure (TEE) during playing and REE, for both playing postures. Metabolic equivalent (MET) was calculated as TEE during playing divided by measured BMR.

\section{Statistics}

SPSS version 15 (SPSS Inc., Chicago, IL) was used for statistical analysis. Summary statistics of continuous variables are presented in mean and standard deviation (SD) or median and interquartile range (when skewed). Independent group comparisons were conducted with parametric or nonparametric tests. Categorical variables are presented as absolute counts. Paired samples t-tests were used to test for differences between the two body postures in physical activity, REE, and MET. Independent samples t-tests were used to test for differences in MET between brass and woodwinds and men and women. Chi-squared test was used to test for associations between categorical variables. Mixed model analysis was conducted to test differences in energy expenditure for the different playing postures. Subjects were taken as a random factor, whereas the variables posture (A vs B), period (first vs second) and type of instrument (brass vs woodwind) were the fixed effect factors. Restricted maximum likelihood was applied to the estimation of model parameters. A probability level of 0.05 was selected for statistical significance.

\section{Results}

\section{Energy expenditure in different body postures}

An example of analysis of energy expenditure and physical activity from one of the participants is shown in Figure 1. During playing periods, a peak in energy expenditure and physical activity can be seen. The energy expenditure curve resembles the curve of physical activity. Table 2 displays 
the estimated fixed effect parameters of the mixed model (random intercept and error variances were, respectively, 67.15 and 105.39). When playing in posture A, TEE increased by a mean of $23 \%$ (95\% Cl 17-30\%) above the values of REE. Playing in posture B resulted in a TEE that was $32 \%$ (95\% Cl 25-39\%) higher than REE. The absolute difference (9\%) between the mean rise in energy expenditure in both postures was found to be statistically significant $(p=0.021)$. It is unlikely that the significant effect of body posture is explained by differences in physical activity in both postures, as mean physical activity was 3553 ( \pm 1946) counts/min in posture A, and 3182 ( \pm 1070 ) counts/min in the posture $B$, which is statistically not significant. Similarly, REE values before and after playing did not differ. A period effect was found that was independent of body posture $(p=0.027)$. Energy expenditure in period 1 , independently of posture, was on average higher than in period 2. The rise in energy expenditure between REE and TEE in the first playing period averaged 32\% (95\% Cl 25 - 38\%) and was significantly higher than the increase in the second playing period of 23\% (95\% Cl 17 - 30\%), with an almost equal difference for both body postures. Differences in energy expenditure between brass and woodwind instrumentalists, independent of body posture, were not significant $(p=0.144)$, although the magnitude of the effect size was similar to the period and posture effect, i.e. about $9 \%$ on average. Brass instrumentalists showed a mean increase in energy expenditure of $32 \%(95 \% \mathrm{Cl} 22$ - 41\%), while wood wind instrumentalists showed a mean increase of 23\% (95\% Cl 17 - 30\%). A significant association between sex and type of instrument was found, with women more often playing a woodwind instrument (odds ratio $15 ; 95 \% \mathrm{Cl} 1.22-185.21)$.

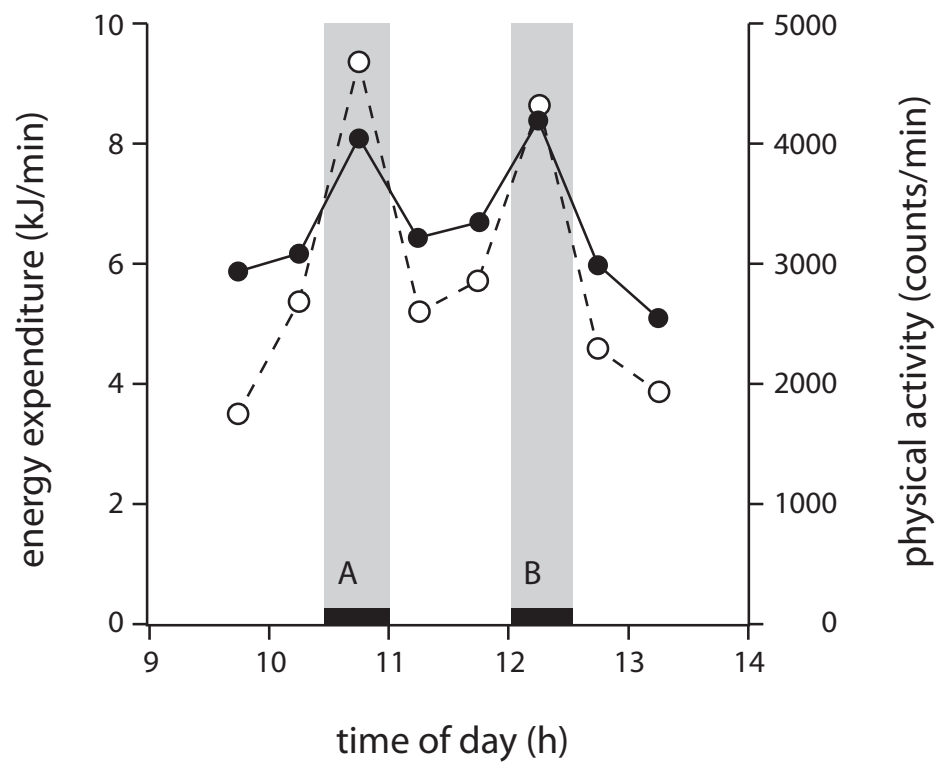

Figure 1: Energy expenditure (solid circles) and physical activity (open circles) of a test person averaged over 30-minute periods. Playing periods in posture A and B are shown by the grey bars. 
Table 2: Model parameters estimates of the mixed model (fixed effects only) with compound symmetric covariance structure

\begin{tabular}{lccc}
\hline & $\boldsymbol{\beta}$ & SE & P -value \\
\hline Intercept & 23.58 & 3.97 & 0.000 \\
Posture & -8.74 & 3.42 & 0.021 \\
Period & 8.30 & 3.42 & 0.0 .27 \\
Instrument category & 8.41 & 5.47 & 0.144 \\
\hline
\end{tabular}

SE: standard error

\section{Metabolic Equivalent (MET)}

Mean physical activity when playing in posture A was $1.66( \pm 0.16)$ MET for brass instruments and $1.70( \pm 0.19)$ MET for woodwind instruments. When playing in posture B, mean MET was 1.87 $( \pm 0.21)$ and $1.76( \pm 0.22)$, respectively. A significant difference in MET was found between both body postures for brass instrumentalists, but not for woodwind instrumentalists. Four musicians (woodwind) actually showed lower energy expenditure in posture B. No differences in MET were found between brass and woodwind instrumentalists. For wind instruments in general, mean MET was $1.69( \pm 0.18)$ for posture $A$ and $1.80( \pm 0.22)$ for posture $B$, this difference being statistically significant $(p=0.013)$. Independent of posture, mean MET for wind instrument playing is 1.76. For women, mean MET was $1.70( \pm 0.18)$ in posture $A$ and $1.77( \pm 0.24)$ in posture $B(p=0.18)$. For men, these results were $1.67( \pm 0.18)$ and $1.84( \pm 0.19)(p=0.05)$, respectively. No statistical differences between men and women occurred in both playing postures: $p=0.75$ for posture $A$ and $p=0.47$ for posture B. An overview of the results in relation to gender, instrument type, and experience is shown in Table 3. 
Table 3: Overview of metabolic equivalents in association with participant characteristics

\begin{tabular}{ccllcr}
\hline & & & & \multicolumn{2}{c}{ MET } \\
\cline { 4 - 5 } Participant & Gender & Instrument & Experience & Posture A & Posture B \\
\hline 1 & M & French horn & Professional & 1.73 & 1.80 \\
2 & F & Flugelhorn & Amateur & 1.71 & 1.96 \\
3 & F & Clarinet & Student & 1.48 & 1.49 \\
4 & M & Clarinet & Professional & 1.87 & 1.89 \\
5 & M & Contrabass clarinet & Amateur & 1.81 & 1.63 \\
6 & M & Trumpet & Amateur & 1.87 & 2.22 \\
7 & M & Trumpet & Amateur & 1.39 & 2.60 \\
8 & F & Baritone sax & Amateur & 1.28 & 1.37 \\
9 & F & Alto saxophone & Amateur & 1.67 & 1.52 \\
10 & M & French horn & Professional & 1.62 & 1.80 \\
11 & M & Clarinet & Professional & 1.47 & 1.91 \\
12 & F & Flute & Student & 1.81 & 1.70 \\
13 & F & Flute & Professional & 1.85 & 2.03 \\
14 & F & Alto saxophone & Professional & 1.80 & 1.76 \\
15 & F & Oboe & Professional & 1.85 & 1.87 \\
16 & M & Trombone & Professional & 1.62 & 1.89 \\
17 & F & Flute & Professional & 1.76 & 1.94 \\
18 & F & Clarinet & Professional & 1.80 & 2.02 \\
\hline
\end{tabular}

\section{Discussion}

When interpreting the results of our investigation, it is important to realize that this study was a pilot study with the aim of researching whether the amount of energy expenditure can be a possible explanation for the general overall feeling of exertion in the body while making music and whether this energy expenditure is related to body posture in patients who had been suffering from nonspecific musculoskeletal pain. We included a broad range of participants to provide a more complete view. Consequently, there are some methodological points for discussion. Gender was unequally distributed. This, combined with the observed association between sex and type of instrument, makes it difficult to consider the separate effect in the multiple model. In any future studies, gender should be equally distributed. It is also advisable to include only one instrument group, the same repertoire should be played by each participant, and participants should be of equal experience grade. However, this might seriously limit the feasibility of including a sufficient number of subjects. Furthermore, a systematic measurement on subjectively reported fatigue and physical complaints did not occur. We did ask participants systematically about their experiences in both postures. Participants favored playing in the Mensendieck posture because of less fatigue and complaints. An objective measurement of fatigue should be recommended for future research to get a better understanding of the relationship between body posture, fatigue, and physical complaints. Nevertheless, we believe our protocol was sufficient for this pilot study to provide a first overview of metabolic results and to test our hypothesis. Our results showed that there is an association between energy expenditure and body posture while playing a wind 
instrument. Both in terms of percent change in energy expenditure between rest and playing and in MET, playing a musical instrument in a posture according to postural exercise therapy leads to higher energy expenditure as compared to a nonoptimized body posture. Our hypothesis that fatigue and musculoskeletal complaints occurring while playing in a nonoptimized position are related to higher energy expenditure could not be supported by these experimental data. Results seem to indicate that fatigue and the general feeling of lack of energy after playing a musical instrument are not related to actual higher energy expenditure. Besides a postural effect, a period effect was found. We hypothesize that the difference in energy expenditure between body postures is caused by the use of relatively larger postural muscles in the optimized body posture. We also propose that the optimized body posture is a more active posture; musicians must concentrate and focus on their posture, striving constantly to play in the right posture. Whether these hypotheses are correct must be researched in later studies. Electromyography could be used to monitor playing muscles. The period effect might possibly be explained by the effect of diet-induced thermogenesis (DIT). DIT is the increase in energy expenditure caused by digestion of food. Participants ate breakfast 1.15 and 2.45 hours before playing period 1 and 2 , respectively. The mean pattern of DIT throughout the day shows larger energy expenditure shortly after breakfast, which decreases with time. ${ }^{23}$ This is then exemplified by the higher overall energy expenditure we found in period 1 compared to period 2. The objective finding of this period effect in energy expenditure might also be supportive for the hypothesis that warming-up prior to a performance truly is important for a musician. ${ }^{5}$ It must be noticed that our MET values, particularly those associated with playing a brass instrument, are lower than the values reported by Ainsworth et al..$^{14} \mathrm{As}$ it is not clear how their data were obtained, we can offer no explanation for the differences. The average MET values for playing a brass or woodwind instrument in the sitting position are around 1.8 This value is in the category of light intensity activities and is comparable with sitting —writing, desk work, typing. ${ }^{14}$ In conclusion, the average physical activity while playing a wind instrument in a sitting posture according to postural exercise therapy method Mensendieck is 1.8 MET. This pilot study points out that an association between energy expenditure and body posture while playing a brass or woodwind instrument is assumable. Results suggest that fatigue and the general feeling of lack of energy after playing a musical instrument are not related to actual higher energy expenditure. Larger studies are needed to provide a mechanistic explanation for the relationship between body posture and fatigue after playing in brass and woodwind instrumentalists. 


\section{References}

1. Chesky K, Devroop K, Ford J. Medical problems of brass instrumentalists: prevalence rates for trumpet, trombone, French horn and low brass. Med Probl Perform Art. 2002;17:93-98.

2. Nemoto K, Arino H. Hand and upper extremity problems in wind instrument players in military bands. Med Probl Perform Art. 2007;22:67-69.

3. Zaza C. Playing-related musculoskeletal disorders in musicians: a systematic review of incidence and prevalence. Can Med Assoc J. 1998;158:1019-1025.

4. Lederman RJ. Neuromuscular and musculoskeletal problems in instrumental musicians. Muscle Nerve. 2003;27:549-561.

5. Drinkwater EJ, Klopper CJ. Quantifying the physical demands of a musical performance and their effects on performance quality. Med Probl Perform Art. 2010;25:66-71.

6. Hansen PA, Reed K. Common musculoskeletal problems in the performing artist. Phys Med Rehabil Clin N Am. 2006;17:789-801.

7. Hildebrandt $\mathrm{H}$, Nublin M. Providing further training in musicophysiology to instrumental teachers: do their professional and preprofessional students derive any benefit? Med Probl Perform Art. 2004;19:62-69.

8. Zander MF, Voltmer E, Spahn C. Health promotion and prevention in higher music education. Med Probl Peform Art. 2010;25:45-65.

9. Schlinger M. Feldenkrais method, Alexander technique, and yoga-body awareness therapy in the performing arts. Phys Med Rehabil Clin N Am. 2006;17:865-875.

10. Beroepsprofiel Oefentherapeut, VvOCM. Den Haag: Boom/Lemma 2011.

11. van Eijsden MD, Staal BJ, van Attekum A, et al. No difference between postural exercises and strength and fitness exercises for early, non-specific, work-related upper limb disorders in visual display unit workers: a randomised trial. Aust J Physiother. 2008;54:95-101.

12. Samama ALW. Making Music Without Pain. Assen: Van Gorcum; 2003.

13. Samama ALW. Muscle Control for Musicians. Houten: Bohn Stafleu van Loghum; 1994.

14. Ainsworth BE, Haskell WL, Whitt MC, et al. Compendium of physical activities: an update of activity codes and MET intensities. Med Sci Sports Exerc. 2000;32(suppl):S498-S516.

15. Fletcher GF, Balady G, Froelicher VF, et al. Exercise standards: a statement for healthcare professionals from the American Heart Association. Circulation. 1995;91:580-615.

16. Loewy A, Schroetter H. Uber den energieverbrauch bei musikalischer betatigung. Pfluger's Arch ges Physiol. 1926;211:1-63.

17. McArdle WD, Katch Fl, Katch VL. Exercise Physiology: Energy, Nutrition, and Human Performance. Baltimore, MD: Lippincott Williams\& Wilkins; 2001: pp1103-1115.

18. Passmore R, Durnin JVGA. Human energy expenditure. Physiol Rev. 1955;35:801-840.

19. Schofield WN, Schofield C, James WPT. Basal metabolic rate-review and prediction, together with an annotated bibliography of source material. Hum Nutr Clin Nutr. 1985;39C:5-96.

20. Brouwer E. On simple formulae for calculating the heat expenditure and the quantities of carbohydrate and fat oxidized in metabolism of men and animals, from gaseous exchange (oxygen intake and carbonic acid output) and urine-N. Acta Physiol Pharmacol Neerl. 1957; 6:795-802.

21. Schoffelen PFM, Westerterp KR, Saris WHM, ten Hoor F. A dual respiration chamber system with automated calibration. J Appl Physiol. 1997;83:2064-2072. 
Chapter 5

22. Schoffelen PFM, Westerterp KR. Intra-individual variability and adaptation of overnight- and sleeping metabolic rate. Physiol Behav. 2008;94:158-163.

23. Westerterp KR. Diet induced thermogenesis. Nutr Metab. 2004; 18:1-5. 


\section{Chapter 6a}

\section{Playing the clarinet: influence of body posture on muscle activity and sound quality}

Published as: VAE Baadjou, MDF van Eijsden-Besseling, JAMCF Verbunt, RA de Bie, RPJ Geers, RJEM Smeets, HAM Seelen. Playing the clarinet: influence of body posture on muscle activity and sound quality. Med Probl Perform Art.2017;32(3)125-31.

Awarded: Alice G. Brandfonbrener Young Investigator Award, Performing Arts Medicine Association. 2017 Snowmass, Colorado, USA. 


\section{Abstract}

Musculoskeletal complaints are highly prevalent in clarinetists and are related to high arm load while playing. It is hypothesized that postural exercise therapy may be used to adapt muscle activity patterns while playing, and contributes to better sound quality. Goal of the present study was to investigate the relationship between body posture, muscle activity, and sound quality in clarinetists while playing the instrument in two different postures, their habitual sitting posture (control, CO) vs an experimental sitting posture (EXP) based on Mensendieck postural exercise therapy, method Samama. Twenty healthy (pre)professional clarinet players, aged 18-60 years, were included in this cross-sectional study. Participants played a 60-second musical excerpt in $\mathrm{CO}$, followed by instruction on the EXP body posture, and then played in EXP. Twodimensional goniometric analysis was used to calculate body posture, muscle activity was measured bilaterally using surface electromyography. In EXP, a significantly smaller low thoracic angle, smaller high thoracic angle, and larger pelvic tilt angle (all $p<0.001$ ) were found. EMG results indicated that the left and right erector spinae $\mathrm{L} 3$ and left and right lower trapezius were more active in EXP compared to $\mathrm{CO}$, whereas left upper trapezius and right brachioradialis were less active in EXP compared to CO. Most participants experienced better sound quality in EXP, whereas blinded experts found no consistent pattern between body posture and sound quality. To conclude, it seems that postural exercise therapy may change muscle activity patterns. By increasing stability, a decrease in activity of the upper extremity muscles can be induced. 


\section{Introduction}

Playing a musical instrument requires virtuosic sensorimotor control. The musician greatly relies on the postural control system to provide a stable base against the load of playing the instrument. To illustrate, playing the clarinet involves repetitive finger movements and non-neutral wrist and hand postures for extended periods of time. The right arm, and especially the right thumb, carries the full weight of the instrument. This generally static load on the thumb is to a certain extent dependent on body posture. 'This may be the reason why physical complaints, mainly in the hand and wrist, are highly prevalent in clarinetists. ${ }^{2}$ Likewise, many clinicians emphasize that there is a relationship between inadequate postural alignment and musculoskeletal complaints. It has been demonstrated that $93 \%$ of musicians with playing-related musculoskeletal disorders (PRMD) show dysfunction in the postural stabilization system. ${ }^{3}$ However, there is little scientific evidence to support a direct relationship between body posture and musculoskeletal complaints in general and in musicians in particular. ${ }^{4}$ The relationship between body posture, muscle activity, and musculoskeletal complaints in musicians needs to be further explored. Posture analysis during performance is an important aspect in the current approach to PRMDs. ${ }^{5}$ It is suggested that playing in an inadequate posture requires more muscle activity, compensating for a lack of balance and control and possibly increasing the risk of developing PRMD. ${ }^{6}$ Until now, we are not aware of previous research specifically assessing muscle activity and musculoskeletal complaints in clarinetists, although such work has been done in upper string players. When comparing violinists with and without pain, lower activity of the upper trapezius muscle was found in subjects with shoulder pain. ${ }^{7}$ It was hypothesized that when playing with pain, violinists redistribute muscle activity to distal synergistic muscles. This hypothesis was partially confirmed by McCrary et al., ${ }^{6}$ who showed an altered humeroscapular rhythm in violinists with pain. The decrease in upper trapezius activity was compensated for by increased activity of synergistic muscles such as the pectoralis major, biceps brachii, and anterior deltoid. It is hypothesized that therapy focusing on body posture while playing may be used to adapt muscle activity patterns. However, in prior research no differences could be detected in upper trapezius muscle activation between a group of string players offered body and movement awareness therapy and a reference group. ${ }^{8}$ Besides a relationship between body posture and musculoskeletal complaints, a relationship between body posture and quality of sound also is expected, as posture is thought to influence respiratory muscle recruitment patterns. ${ }^{6}$ As breathing endurance and control are of the utmost importance for the quality of sound of the wind instrumentalist, it is expected that by optimizing the quality of posture, the quality of sound may also increase. The goal of the present study was to investigate the relationship between body posture, muscle activity, and quality of sound in clarinetists while playing the instrument in two different postures. The habitual sitting posture was contrasted with a sitting posture according to postural exercise therapy based on Mensendieck, method Samama (MmS). ${ }^{9}$ Postural exercise therapy based on Mensendieck is used to treat or prevent complaints of the musculoskeletal system. Central themes of this therapy are body awareness, balanced posture and controlled movements, awareness of tension and relaxation, and functional respiration. ${ }^{10,11}$ A specialized Mensendieck treatment protocol for musicians has been developed by Samama. ${ }^{9}$ A key element of this protocol is the prevention of imbalance of muscle load between muscles 
providing stability and the upper extremity muscles actively used to play the instrument. Our hypothesis was that while playing the clarinet in a body posture according to postural exercise therapy MmS, ${ }^{9}$ stability is increased by higher activity of the erector spinae, latissimus dorsi, lower trapezius, and pectoralis major muscles. Consequently, the improved control provided by these muscles might reduce the muscle activity of the upper trapezius, biceps brachii, and brachioradialis, thereby enabling the player to use the arm and shoulder muscles more dynamically and coordinated while playing the instrument. Additionally, we hypothesized that sound quality would improve in the posture advocated in postural exercise therapy MmS.

\section{Methods}

\section{Subjects}

Healthy professional clarinet players or conservatory clarinet students, aged 18-60 years, were included in the study, unless they had complaints of the musculoskeletal system (arm, shoulder, neck, back) in the past 2 weeks. Participants had to be naïve to the principles of the postural exercise therapy MmS. Professional clarinet teachers, clarinet players in local orchestras, and colleagues from the professional network of participants were approached by email or telephone. Students were informed about the study by their music teacher and, after a positive approval, approached by the research team. The Medical Ethical Committee of Atrium-Orbis-Zuyd Hospital Heerlen, The Netherlands, decided that the study is exempt, since the participants were healthy volunteers who were asked to perform a task that was similar to their daily activities. Only informed consent of the subjects was obligatory.

\section{Study design}

This was a cross-sectional study, in which two postural conditions were contrasted while playing the clarinet. Postural conditions were defined as control (CO) and experimental (EXP, i.e., MmS). All participants played while seated. A standardized chair with adjustable height, flat seat surface, and no back support was used for all participants. In the control (CO) sitting posture, no restrictions regarding sitting were provided, and participants were asked to play in their habitual posture. Before playing, subjects adjusted the height of the chair and music stand to their own preference. In the experimental (EXP) sitting posture, according to postural exercise therapy $\mathrm{MmS}^{9}$ chair height was adjusted so that the subject's knees were flexed at $90^{\circ}$, and their feet were placed parallel to each other on the floor. The music stand height was adjusted to be able to read sheet music without neck flexion, with a gaze direction that pointed slightly downward. Subjects were instructed to sit on the ischial tuberosities. The thoracic spine was moved forward in the sagittal plane so that the plumb line from the earlobe was in front of the trochanter major. The sternum was directed anteriorly. The pelvic tilt was either neutral or directed posteriorly. The head position was neutral. The shoulder blades were slightly retracted. This combination of movements induced a decrease in lumbar and cervical lordosis and thoracic kyphosis (Fig. 1). 

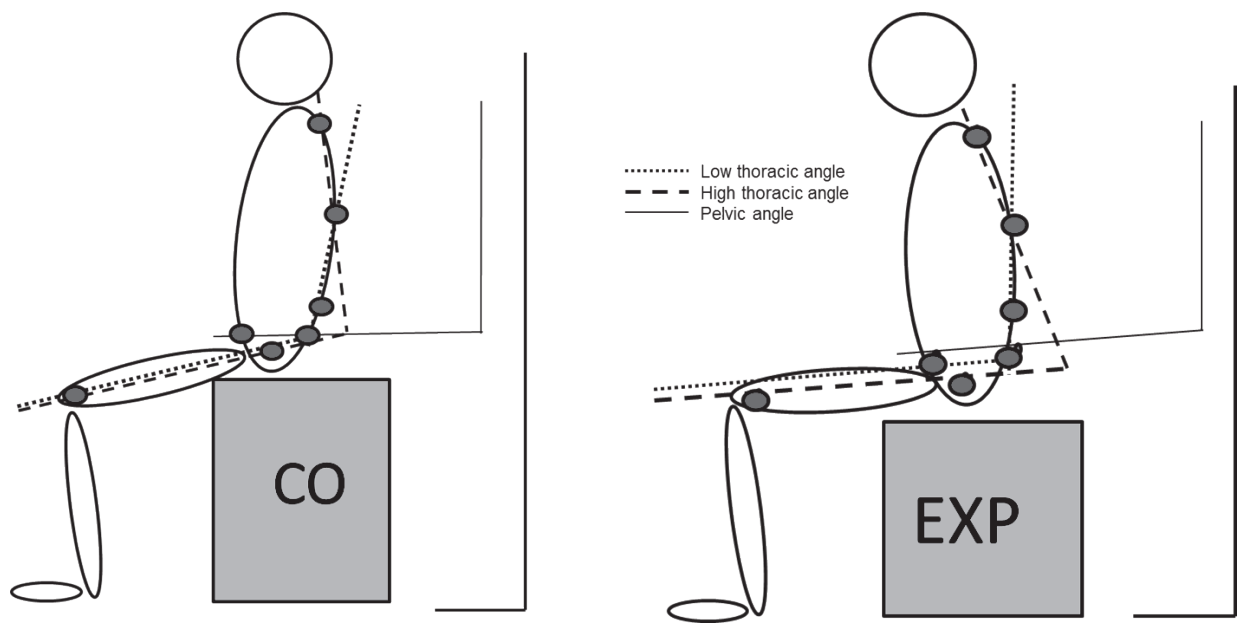

Figure 1: schematic view of postural conditions; CO: Habitual sitting posture; EXP: Sitting posture according to postural exercise therapy based on Mensendieck, method Samama. ${ }^{8}$

\section{Procedures and assessments}

The experiment started with a baseline assessment and application of the measurement equipment. During the experiment, participants played a selected part of approximately 60 seconds duration of the adagio in the clarinet concerto of Mozart in A major (KV.622) on a B b clarinet. The timing of the music was set and controlled with a metronome; participants were instructed to play at mezzoforte loudness. The music piece was sent to the participants approximately 1 week before the experiment. Recordings started with five repetitions (5 trials) of the 60 -second piece in the $\mathrm{CO}$ condition. This was followed by 30 minutes of instruction on body posture according postural exercise therapy MmS (EXP), provided by two therapists or a medical doctor who were highly experienced in the Samama method. Finally, participants played five trials in the EXP condition. Total duration of the experiment was 2 hours. To assess demographics and body-related variables, subjects filled out a short questionnaire regarding demographics, years of experience playing the clarinet, and physical and mental health. Height and weight of the participant were measured. Clinical tests were performed to assess joint laxity and calculate the Beighton score (maximum Beighton score is 9 , and a score of 4 or more indicates the presence of hypermobility). ${ }^{12}$ Additional examination of laxity of the CMC, MCP, PIP and DIP joints of the hand was performed. Environmental variables in this study included the weight of the clarinet and room temperature and humidity, which were recorded using calibrated equipment. The height of the music stand and chair was measured in both conditions. 


\section{Muscle activity}

Muscle activity was measured using surface electromyography (Delsys Trigno Wireless, Delsys Inc., Boston, MA, USA) with an interelectrode distance of $1 \mathrm{~cm}$. Muscles were recorded bilaterally: i.e., erector spinae L3 (ES), latissimus dorsi (LD), lower trapezius (LT), upper trapezius (UT), pectoralis major (PM) clavicular part, short head of biceps brachii (BI), and brachioradialis (BR). Guidelines from the SENIAM project ${ }^{13}$ were adhered to regarding sensor location. As for the muscles not mentioned in the SENIAM guidelines, the electrodes for latissimus dorsi were located $3.5 \mathrm{~cm}$ caudo-lateral to the inferior angle of the scapula; for pectoralis major, two fingers below the mid of the clavicular; for brachioradialis, at one-fourth of the distance between the elbow crease and processus styloideus radii. Electrodes were applied using double-sided tape. Placement was confirmed using manual muscle testing. Raw EMG signals were sampled with a frequency of 2,000 Hz. The rectified EMG signals were filtered using a zero time lag second-order low-pass Butterworth filter with a cut-off frequency of $2 \mathrm{~Hz}$. Offset was determined by performing EMG measurements during rest before the start of the experiment. Mean rectified and filtered EMG values (signal power values) were presented for the different conditions. Signals were analyzed using Matlab software (MathWorks Inc., Natick, MA, USA).

\section{Body posture}

To objectify body posture, the principal investigator (VB) placed markers on bony landmarks. Reference points were: lateral femur condyle, greater trochanter, anterior superior iliac spine (ASIS), posterior superior iliac spine (PSIS), and spinous process levels L2, T7, and C7. A twodimensional goniometric analysis program was used to calculate pelvic and trunk angles (Fig. 1). During one trial, joint angles were calculated at four moments: start of playing, at selected notes at approximately 20 and 40 seconds into the piece, and at the end of the piece. Video recording enabled the investigators to view the experiment retrospectively, aid in interpretation of EMG results, and perform 2-D joint goniometry analyses.

\section{Sound quality}

Audio was recorded using a large diaphragm studio condenser microphone (Audio Technica AT2050), placed at $80 \mathrm{~cm}$ perpendicular to the lower third part of the clarinet, and a matched pair of small diaphragm condenser microphones (AKG P170) placed in a XY-configuration at $260 \mathrm{~cm}$ from the chair at $175-\mathrm{cm}$ height. Sound was recorded with multi-track audio editor and recorder (Zoom R24). Sound quality was measured twofold: First, the subjective experience of participants was examined by asking them to denote in which condition they experienced sound quality best and to write down first impressions about the experiment. Second, three blinded experts were asked to review sound quality. The experts were an internationally respected conductor, a highly experienced piano performer and teacher at a conservatory, and a high-level professional wind instrument player. The blinded experts listened in a standardized environment to the 
excerpts recorded on a compact disc. In randomized order, a fragment played in the CO condition was followed by a fragment played in EXP, or vice versa. After having listened to two fragments, reviewers were instructed to point out the fragment in which sound quality was better, considering the aspects pitch, timbre, stability, and breathing capacity. Three assessments per participant were made. Subjects were not told beforehand that sound quality would be evaluated.

\section{Data processing and statistical analysis}

Summary statistics of continuous variables were presented in mean and standard deviation (SD) or median and interquartile range in case of non-normal distribution. The primary study parameter was muscle activity. Activity levels were measured per person $(n=20)$, per muscle (14), per trial (5), and per posture (2). In each of the two postural conditions (CO/EXP), participants repeated the music playing five times ( $n=5$ trials). In order to improve EMG data stability, from each of these five repetitions, the three most resembling similar repetitions in terms of rectified EMG signal power produced were chosen for further analyses. This was based on a fixed procedure involving three steps. First, for each trial and for each muscle, rectified EMG signal power was calculated. Next, for each muscle, the trials representing the 25,50, and 75 percentile of rectified EMG signal power were identified among the 5 repetitions. Finally, across all muscle conditions, the three trials most frequently identified (in the previous step) were chosen for further analyses. Next, for each subject, for each postural condition, for each muscle, rectified EMG signal power values as well as rectified EMG signal variance values were averaged across the three most resembling similar trials identified earlier. Subsequently, within-subject differences in mean rectified EMG signal power values as well as differences in mean EMG signal variance values between postural conditions (CO/EXP) were statistically tested for each muscle using paired-samples t-tests. Because of multiple testing, a conservative alpha of 0.01 was used. Because the signal content of the raw recorded EMG data depends on a number of (physiological) processes such as exact electrode position, skin and subcutaneous tissue conductance, muscle (fibre) composition, muscle type, muscle volume, etc., these data could not be compared across different muscles directly, nor could they be compared directly between subjects. Therefore, a normalization procedure was necessary. As in our study, EMG recordings were performed in two postural conditions, and within-muscle ratios (quotients) as to EMG signal parameters were calculated between the CO and EXP conditions. However, because from a mathematical point of view, in these quotients the denominator value is "disadvantaged" over the numerator value when calculating an average quotient (e.g., across subjects), a log-transform was applied to all quotients prior to the averaging procedures. Mean log-transformed ratios for all 20 participants per muscle were calculated. A positive mean log value means that muscle activity is higher in the CO condition, as compared to EXP. A negative mean log value means that muscle activity is higher in the EXP condition. To objectify body posture, mean trunk (higher and lower thoracic part) and pelvic angles in the CO and EXP conditions were measured. Differences between postures, trials, and variation within one trial were calculated regarding the low thoracic angle, high thoracic angle, and pelvic angle using three-way ANOVAs for repeated measures. Independent factors were posture (CO vs EXP), trial 
(3 selected trials), and time (four moments during one trial). Analysis of sound quality by participant's opinion and reviewer's comments was reported descriptively. SPSS version 22 (SPSS Inc., Chicago, IL, USA) was used for statistical analysis.

\section{Results}

Twenty clarinetists participated, including 9 men and 11 women. Their mean age was $29.25 \pm$ 10.16 years. Mean body mass index (BMI) was $24.30 \pm 4.90$. Nine participants were conservatory students, and 11 were professional clarinetists. Mean playing experience was $19.4 \pm 10.69$ years. Mean hours playing per week was $18.90 \pm 11.75$. Twelve participants scored 0 on the Beighton scale, and 1 participant scored at the cut-off level of 4 , indicating presence of hypermobility. Hypermobility of the small joints of the hand was found in 6 out of the 18 tested clarinetists, and for 2 participants' data concerning hand joint mobility were missing. For environmental variables, the average room temperature was $23.1^{\circ} \mathrm{C}$. Average atmospheric humidity was $63.87 \pm 6.16 \%$. Height of the chair was on average $5.65 \mathrm{~cm}$ lower (range $0-11 \mathrm{~cm}$ ) in the EXP compared to CO condition. Height of the music stand was on average $1 \mathrm{~cm}$ lower (range $25 \mathrm{~cm}$ lower to $10 \mathrm{~cm}$ higher) in the EXP condition.

\section{Body posture}

Mean values for low thoracic, high thoracic, and pelvic tilt angle in the different conditions are presented in Table 1. No trial effect was found, indicating that within one condition, the body posture in the three trials was comparable. Two-way repeated measures ANOVA were conducted with the median trial illustrating the general effect. Because of violation of the assumption of sphericity, Greenhouse-Geisser corrections were applied to correct for degrees of freedom. In the experimental condition, a significant smaller low thoracic angle $(F(1.000,19.000)=138.620$, $p<0.001)$, a smaller high thoracic angle $(F(1.000,19.000)=56.201, p<0.001)$, and a larger pelvic tilt angle $(F(1.000,19.000)=50.535, p<0.001)$ were found. Also, a time effect was found indicating difference in angles within one trial. Only for the high thoracic part, an interaction between posture and time was found. Visual inspection of our data suggests that back angles seemed to increase over time and pelvic tilt angles decreased. The interaction term suggests that the posture variability between measurement moments in one trial is larger in $\mathrm{CO}$, as compared to EXP, the latter being seemingly more static. Appendix 1 illustrates the ANOVA results in more detail.

Table 1: means of postural angles (degrees)

\begin{tabular}{|c|c|c|c|c|c|c|}
\hline & $\begin{array}{c}\text { Low thoracic } \\
\text { mean }\end{array}$ & $95 \% \mathrm{Cl}$ & $\begin{array}{c}\text { High thoracic } \\
\text { mean }\end{array}$ & $95 \% \mathrm{Cl}$ & $\begin{array}{c}\text { Pelvic tilt } \\
\text { mean }\end{array}$ & $95 \% \mathrm{Cl}$ \\
\hline $\mathrm{CO}$ & 118 & $115-121$ & 89 & 85-93 & 90 & $87-94$ \\
\hline EXP & $102^{* * *}$ & 99-105 & $76^{* * *}$ & $73-80$ & $98^{* * *}$ & $95-101$ \\
\hline
\end{tabular}

*** significant difference $p<0.001$ 


\section{Muscle activity}

An example of a raw EMG registration of a typical participant is shown in Figure 2. Mean rectified EMG signal power values and mean EMG signal variance values for both conditions are presented in Appendix 2. Paired samples t-tests showed significant within-subject differences in mean rectified EMG signal power values between CO and EXP for the left erector spinae $L 3(p<0.01)$, left and right lower trapezius $(p<0.001$ and $p<0.001)$, and right brachioradialis $(p<0.001)$ (Table 2$)$. The left upper trapezius muscle showed significantly more variance in CO compared to EXP $(p<0.01)$ (Appendix 2). Mean log-transformed ratios confirmed these results, indicating that left and right erector spinae $L 3$ and left and right lower trapezius were more active in EXP compared to CO, whereas left upper trapezius and right brachioradialis were less active in EXP compared to CO (Fig. 3).
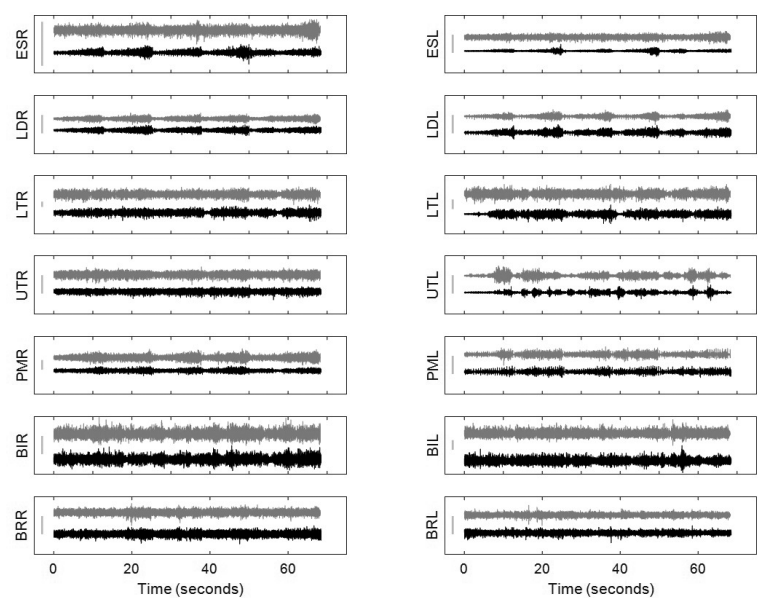

\section{Legend}
ESR: erector spinae L3 right
ESL: erector spinae L3 left
LDR: latissimus dorsi right
LDL: latissimus dorsi left
LTR: lower trapezius right
LTL: lower trapezius left
UTR: upper trapezius right
UTL: upper trapezius left
PMR: pectoralis major right
PML: pectoralis major left
BIR: biceps brachii right
BIL: biceps brachii left
BRR: brachioradialis right
BRL: brachioradialis left

Figure 2: A sample raw (non-normalized) EMG for a typical subject during one trial in CO (black) and EXP (grey) showing muscle activation patterns. The vertical lines indicate the scale equivalent to $300 \mu \mathrm{V}$.

Table 2: Paired samples t-tests of within-subject differences in mean rectified EMG signal power values

\begin{tabular}{lcccccccccccccc}
\hline CO vs. EXP & ESR & ESL* $^{*}$ & LDR & LDL & LTR* $^{*}$ & LTL* $^{*}$ & UTR & UTL & PMR & PML & BIR & BIL & BRR* $^{*}$ & BRL \\
\hline Significance & 0.014 & 0.007 & 0.318 & 0.424 & 0.000 & 0.000 & 0.596 & 0.135 & 0.030 & 0.114 & 0.912 & 0.920 & 0.007 & 0.355 \\
\hline${ }^{*}$ significance level: $\mathrm{p}<0.01$ & & & & & & & & & & & & & &
\end{tabular}




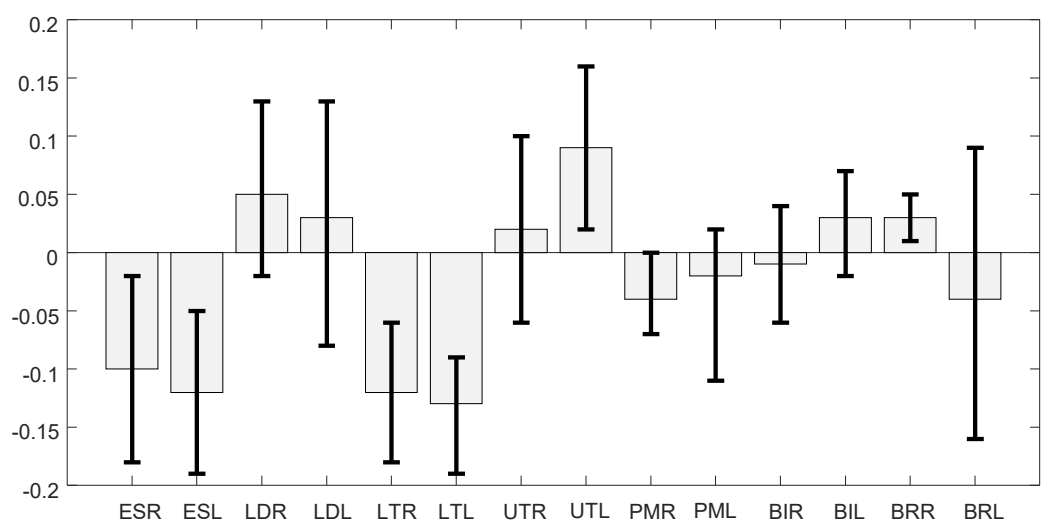

Figure 3: Mean log transformed ratios with $95 \% \mathrm{Cl}$

\section{Sound quality}

In the participants' opinion, 14 of the 20 subjects felt that they experienced a better sound quality in EXP as compared to CO; however, they felt in general that it was odd playing in EXP. They sensed more tension in the lower back and it felt like wearing armor around the thorax. However, that feeling diminished over time. Participants noticed that playing in EXP created a feeling of more space or capacity to breathe, and it was easier to support breathing well, leading to a better sound quality. For the reviewers, results were not consistent over reviewers. Reviewer 2 was very accurate in discriminating postures, favoring in $80 \%$ of the cases the sound quality of CO over EXP. However, results of reviewer 1 and 3 were ambiguous (Table 3). Combined results showed that reviewers reported to hear differences in sound quality between the two postures, but no consistent findings were found as to which body posture had the best sound quality. Retrospectively, remarks were made indicating that EXP seemed to have more volume and a brighter tone, but lacked depth of tone and gave problems in legato.

Table 3: assessment of sound quality by blinded experts

\begin{tabular}{ccccc}
\hline & Expert 1 & Expert 2 & Expert 3 & Total \\
\hline CO > EXP & $14(23 \%)$ & $48(80 \%)$ & $31(52 \%)$ & $93(52 \%)$ \\
EXP $>$ CO & $25(42 \%)$ & $11(18 \%)$ & $25(42 \%)$ & $61(34 \%)$ \\
$=$ & $21(35 \%)$ & $1(2 \%)$ & $4(7 \%)$ & $26(14 \%)$ \\
Total & 60 & 60 & 60 & 180 \\
\hline CO > EXP: CO better sound quality, EXP > CO: EXP better sound quality, $=$ : no difference detectable
\end{tabular}




\section{Discussion}

This article explored the influence of body posture on muscle activity and sound quality of musicians while playing the clarinet contrasting two postures. It was hypothesized that muscle activity of muscles providing stability would be increased while playing in the EXP body posture according postural exercise therapy MmS. Consequently, activity of the upper extremity musculature actively used to play the clarinet would be reduced when compared to the habitual CO posture. In addition, playing in the EXP posture according postural exercise therapy MmS would lead to an improvement of sound. These hypotheses could partly be confirmed since our study demonstrated that erector spinae and lower trapezius muscles bilaterally were more active and the left upper trapezius and right brachioradialis were less active in the EXP posture. Most participants experienced a better sound quality in the EXP posture. Blinded experts noticed that sound quality depended on body posture, but were not able to consistently appoint whether one of the two postures had the better sound quality. A change in posture corresponded with a change in muscle activity pattern and a change in sound. While playing clarinet in the EXP posture according postural exercise therapy MmS, the upper body is placed forward and the pelvis tilts posteriorly, as compared to the habitual posture. Clinically important changes in muscle activity pattern are the lower activity of the left upper trapezius and right brachioradialis. The left upper trapezius is often moved excessively in clarinet players to express musicality and is in that way at risk to develop PRMD. The right brachioradialis is also at risk to develop PRMD since it is statically loaded for prolonged periods of time, by carrying the weight of the instrument. Any reduction of redundant muscle activity in these muscles above the muscle activity truly needed to play the instrument could be beneficial for the prevention and/or treatment of PRMDs. A factor that needs to be further explored in this relationship is the role of the thumb support, which has been mentioned before as a way to reduce the load on the upper extremity. 'The lower trapezius muscle was clearly more active bilaterally in the EXP posture according to MmS. In our opinion, this serves two purposes. First, it contributes to the distribution of muscle activity from distal to proximal, and second, it contributes to more openness of the thorax. The lower trapezius muscle retracts the shoulders; this in combination with the forward translation of the upper body creates more space in the thorax. Pectoralis major could be used more efficiently as an accessory breathing muscle. Breath control could be improved by better control over the diaphragm and other inspiratory and expiratory muscles. This potentially ameliorates sound quality. Literature to date shows that among wind instrumentalists, there is no difference in abdominal muscle activation in different sitting positions. Also, spirometric data show little difference in breathing capacity caused by different sitting postures. ${ }^{14,15}$ As we did not measure abdominal muscle contraction or respiratory indices, we can only rely on the participants' opinion. After a period of habituation in the EXP posture, subjects sensed a greater breathing capacity, with more ability to support breath, leading to better sound quality. In future research, respiratory indices should be measured to test whether breath control is improved in the EXP posture according to MmS. Results of this first explorative study are promising. However, a major limitation is that we only studied the effects of a short instruction on body posture, which does not equal a total therapy effect. Postural exercise therapy MmS requires adaptation to new motor control programs and a change 
in behavior while playing. As participants were not used to playing in the posture according MmS, one might expect that they consequently may have increased muscle activation in the changed body posture ${ }^{16}$ and that our results do not fully represent muscle activity patterns over a longer period of time. To be able to draw conclusions about the true effectiveness of postural exercise therapy based on Mensendieck method Samama, one should provide therapy for a prolonged period (2-3 months) so that musicians can gradually adapt to the new playing posture, with measurements performed afterwards. ${ }^{8}$ Also, the quality of the study protocol could have been improved by including a larger number of participants, thereby increasing statistical power. The limited number of participants in this study may have obscured possible statistically significant results. Furthermore, in retrospect, only one trial per condition would have sufficed to detect muscle activity patterns. As principles from the experimental posture condition are applicable to all instruments, it is believed that results can be generalized to other instruments. Thus, in future research, it should be investigated whether these changes in muscle activity could also be detected in musicians playing other instruments. Finally, as postural exercise therapy aims at both prevention and treatment, studying the effects of the therapy in musicians with PRMDs would also be worthwhile. To conclude from this sample of clarinetists, it seems that principles from the postural exercise therapy based on Mensendieck method Samama may change muscle activity patterns. Erector spinae and lower trapezius muscles were more active, and the left upper trapezius and right brachioradialis were less active, compared to the habitual playing posture. These findings thereby confirm parts of our hypotheses that by increasing stability, a decrease in activity of the upper extremity muscles can be induced. Body posture is related to sound quality. Further research is needed to explore the exact effect size after a longer treatment period and to examine whether results are generalizable to other instruments. 


\section{References}

1. Chesky KS, Kondraske G, Rubin B. Effect of elastic neck strap on right thumb force and force angle during clarinet performance. J Occup Environ Med. 2000;42(8):775-6.

2. Silva AG, La FMB, Afreixo V. Pain prevalence in instrumental musicians: a systematic review. Med Probl Perform Art. 2015; 30(1):8-19.

3. Steinmetz A, Seidel W, Muche B. Impairment of postural stabilization systems in musicians with playing-related musculoskeletal disorders. J Manip Phys Ther. 2010;33:603-611.

4. Sahrmann SA. Does postural assessment contribute to patient care? J Orthop Sports Phys Ther. 2002;32(8):376-9.

5. Chan C, Ackermann B. Evidence-informed physical therapy management of performance-related musculoskeletal disorders in musicians. Front Psychol. 2014;5:706.

6. McCrary JM, Halaki M, Ackermann BJ. Effects of physical symptoms on muscle activity levels in skilled violinists. Med Probl Perform Art. 2016;31(3):125-31.

7. Berque $P$, Gray $H$. The influence of neck-shoulder pain on trapezius muscle activity among professional violin and viola players: an electromyographic study. Med Probl Perform Art. 2002;17:68-75.

8. Fjellman-Wiklund A, Grip H, Andersson H, et al. EMG trapezius muscle activity pattern in string players: part II-influences of basic body awareness therapy on violin playing technique. Int J Indust Ergon. 2004; 33:357-67.

9. Samama ALW. Making Music Without Pain. Assen, The Netherlands: Van Gorcum; 1998.

10. Haugstad GK, Haugstad TS, Kirste UM, et al. Mensendieck somatocognitive therapy as treatment approach to chronic pelvic pain: results of a randomized controlled intervention study. Am J Obstet Gynecol. 2006;194:1303-10.

11. Haugstad GK, Haugstad TS, Kirste UM. Continuing improvement of chronic pelvic pain in women after short-term Mensendieck somatocognitive therapy: results of a 1-year follow-up study. Am J Obstet Gynecol. 2008;199:615.

12. Beighton P, Solomon S, Soskolne CL. Articular mobility in an African population. Ann Rheum Dis. 1973;32:413-8.

13. Hermens HJ, Freriks B, Disselhorst-Klug C, Rau G. Development of recommendations for sEMG sensors and sensor placement procedures. J Electromyograph Kinesiol. 2000;10(5):361-74.

14. Price $K$, Schartz $P$, Watson AHD. The effect of standing and sitting postures on breathing in brass players. Springer Plus. 2014;3:210.

15. Ackermann B, O'Dwyer N, Halaki M. The difference between standing and sitting in 3 different seat inclinations on abdominal muscle activity and chest and abdominal expansion in woodwind and brass musicians. Front Psychol. 2014;5.

16. McLean L. The effect of postural correction on muscle activation amplitudes recorded from the cervicobrachial region. J Electromyograph Kinesiol. 2005;15(6):527-35. 


$$
\text { 鼠 }
$$




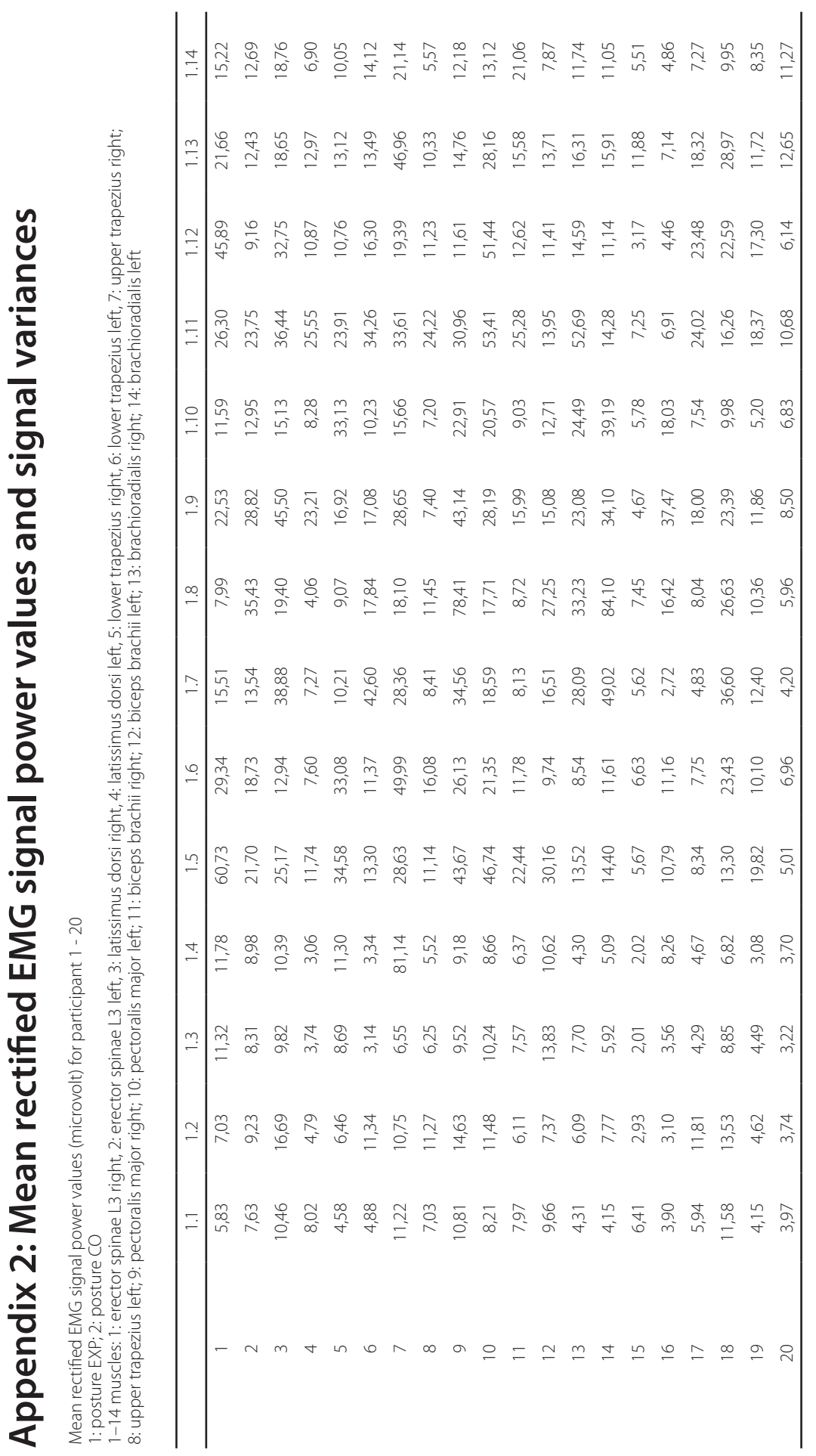




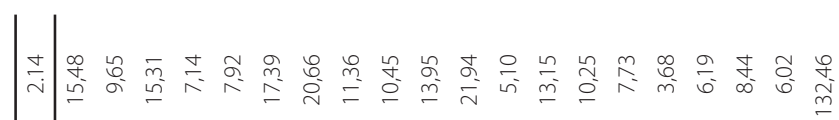

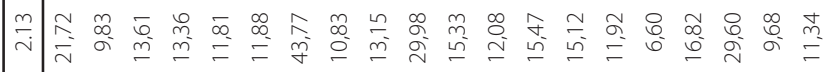

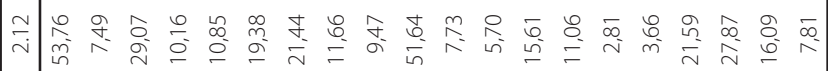

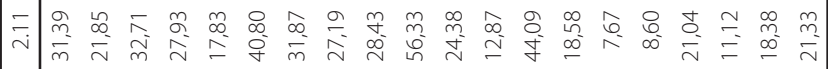

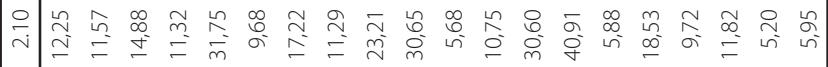

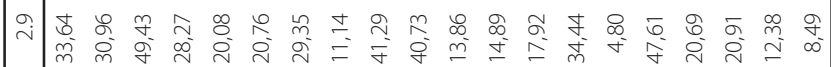

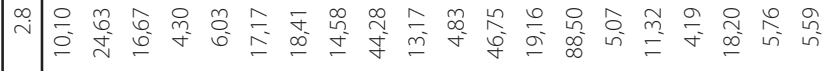

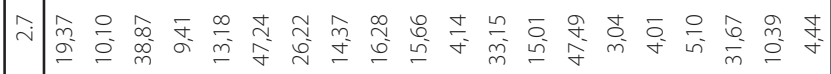

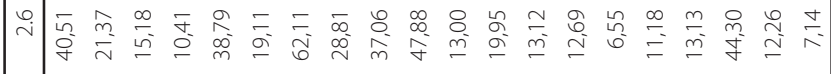

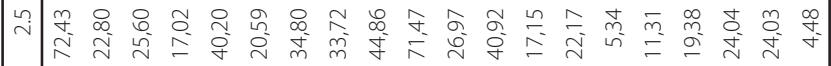

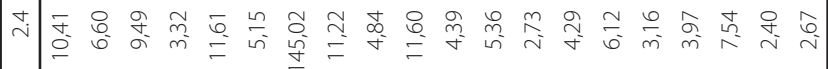

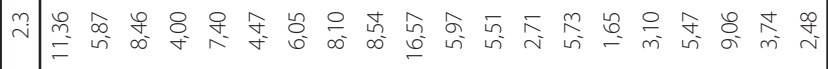

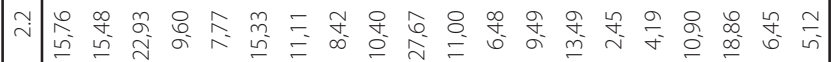

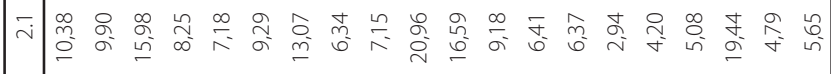

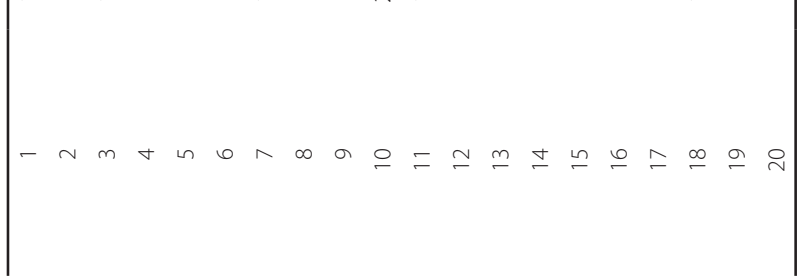




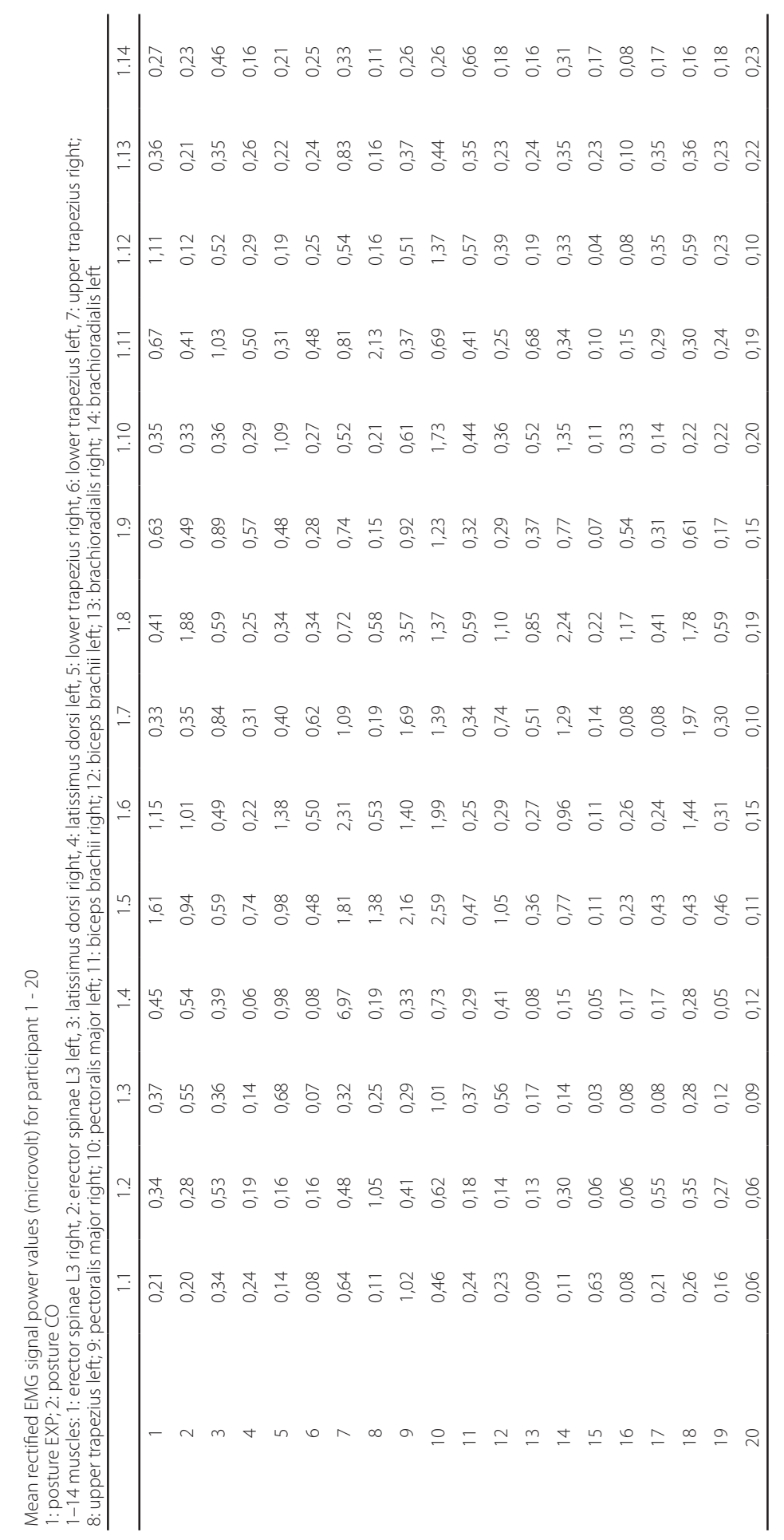




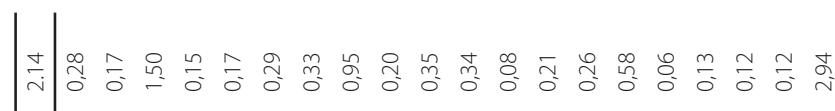

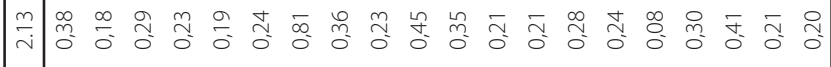

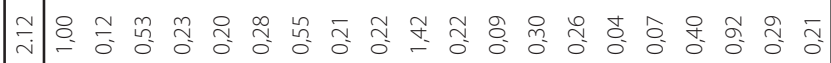

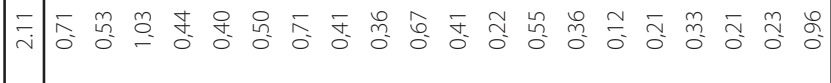

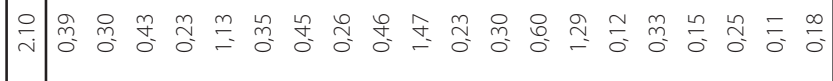

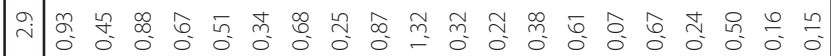

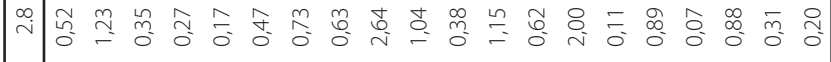
స

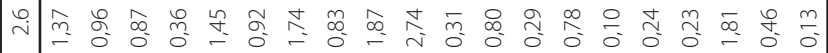
设

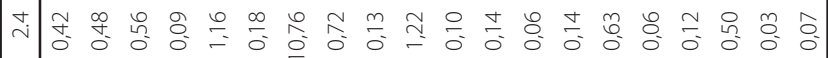
min m m

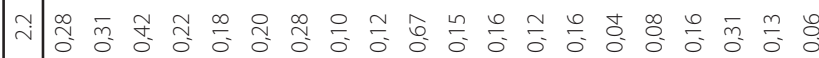

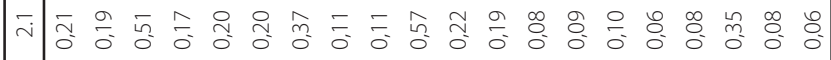

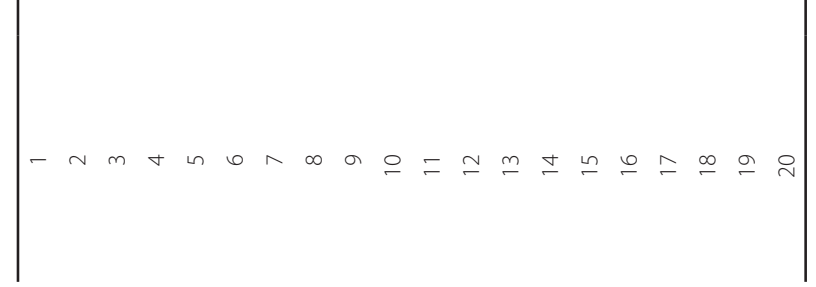




\title{
Chapter 6b
}

\author{
Addendum \\ Playing the clarinet: influence of \\ body posture on sound quality
}





\section{Introduction}

Sound quality is reflected by tone color. Each tone consists of a fundamental frequency followed by a harmonic series of partial tones. ${ }^{1}$ Partial tones are multiples of the fundamental frequency. The fundamental is principally responsible for the perceived pitch. A sound spectrum is the decomposition of sound into the individual partials. The spectrum of partials is dependent on several factors. For example, partial tones are different in the three different phases of the tone (start, middle, end part). The upper boundary is especially dependent on dynamics. Room acoustics play a large role in the low frequencies. Other factors that influence the spectrum are distance and direction of measurement point and attack of the tone. Furthermore, the phase position of the partials is also relevant, i.e. the frequency and amplitude of each partial in relationship with the others. As an example: overtone- poor sounds have a tendency for dark or soft timbre. While the dominance of odd partials leads to a covered tone, strong even harmonics and, above all, octave components lead to an open and bright timbre. The characteristic sound spectrum of the clarinet shows that the odd partials typically outweigh the even ones in the lower register. In the upper register the even tone contributions are in favor. A sound spectrum can be used to objectify the quality of sound; however, perceived characteristics of each tone are not determined by only one single physical quantity. Body posture is supposed to be an important determinant of sound while playing a musical instrument. The clinical impression is that sound in posture according postural exercise therapy MmS is more bright compared to playing in habitual posture. We performed a sound spectrum analysis to objectify the hypothesis that playing in posture according postural exercise therapy MmS (experimental, or EXP) produces a brighter tone which will be depicted in a higher number of partials and a different slope compared to playing in the habitual posture (control, or CO).

\section{Methods}

Spectral analysis was performed for each participant, in each condition (EXP vs CO), in the 3 selected trials, for two notes of 1 second duration: C5 and F5. For further information see Chapter $6 a$. The stereo recordings were selected so that for every tone a right and a left component could be analyzed. The course of the sound spectrum was described as 1) the absolute number of harmonics; and 2) the slope of the decay in level of harmonics. MATLAB was used for analysis of the spectrum. Two-way repeated measures ANOVA were used to detect a difference between the numbers of harmonics and a difference in slope between posture, trial, and the interaction of posture $x$ trial.

\section{Results}

An example of a typical sound power spectrum of the $\mathrm{C} 5$ on the $\mathrm{Bb}$ clarinet is presented in figure 1. There were no significant differences in number of harmonics for the $\mathrm{C} 5$ between both conditions (analysis of left microphone: 7.90 harmonics in CO, 7.81 in EXP; right microphone: 8.02 in CO, 8.22 in posture EXP). The same accounted for F5 (analysis of left microphone: 7.47 in CO, 7.53 
in EXP; right microphone: 7.68 in CO, 7.57 in EXP). No trial effects or posture $x$ trial interactions were found. No significant difference was found in slope. For C5: analysis of left microphone: estimated effect of the slope -0.012 in CO, -0.011 in EXP; right microphone: -0.012 in CO, -0.012 in EXP). For F5: analysis of left microphone: -0.010 in CO, -0.010 in EXP; right microphone: -0.010 in $C O,-0.010$ in EXP.

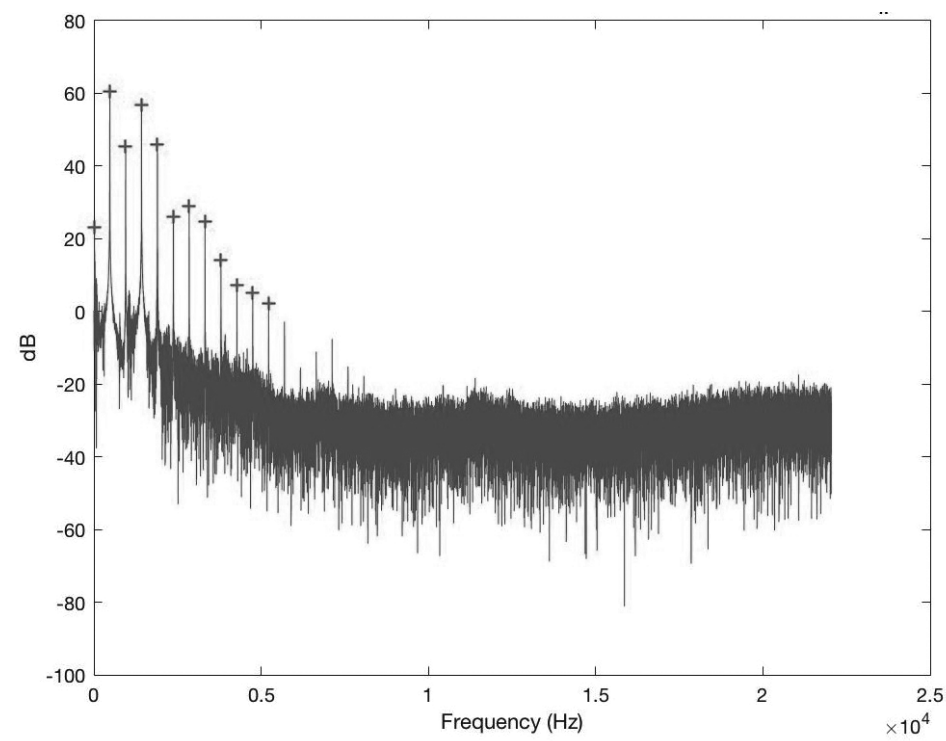

Figure 1: Example of a typical sound power spectrum of the $\mathrm{C} 5$ on the Bb clarinet.

\section{Discussion}

Sound quality is an important outcome for the musician. In this experiment, we tried to find an objective measure for sound quality. While performing the abovementioned analysis we contacted an acoustics expert in order to check our results. However, it turned out that there were large limitations considering the method used to measure the sound spectrum. Best way to measure sound spectrum is while playing in an anechoic room. Problem of the current measurements, not performed in an anechoic room, is that we included both the direct and the indirect sound in the analyses. Also we did not standardize the angle of the clarinet in both postures, which can be of serious influence to the sound spectrum. Although we did not measure the angle of the clarinet, retrospective inspection of video recordings of the experiment showed that clarinet angle was not equal within and between participants. As the angle of the clarinet influences the directivity of the clarinet and thus the reflections of the sound it influences the sound spectrum directly. Also, the presence of a varying number of people at varying places in the room has influenced the direction of the sound and thus the sound spectrum. Furthermore, dynam- 
ics were not constant. Additionally, it is assumed that the interdependent relationship of the harmonics is important, i.e. the relative amplitude of one compared to another harmonic. And, dependent on which tone is analyzed, some harmonics are more important in the color of the tone than others. These factors were not taken into account while performing the spectral analysis. Since music tone is the most important outcome measure for the musician himself, it is a very worthwhile measure to incorporate in research. For future research, and in case sound spectrum will be used as an outcome measure, we recommend to perform measurements in an anechoic room to measure only the direct sound with standardized clarinet position and constant dynamics. Not only the number of harmonics, but especially the interdependent relationship between the harmonics should be investigated.

\section{References}

1. Meyer. Acoustics and the performance of music. $5^{\text {th }}$ edition Bochinsky, Bergkirchen, Deutschland; 2009. 



\section{Part III}

Can musculoskeletal complaints in music students be prevented? 



\section{Chapter 7}

\section{PREvention Study On preventing or reducing disability from musculoskeletal complaints in music school students (PRESTO): Protocol of a randomized controlled trial}

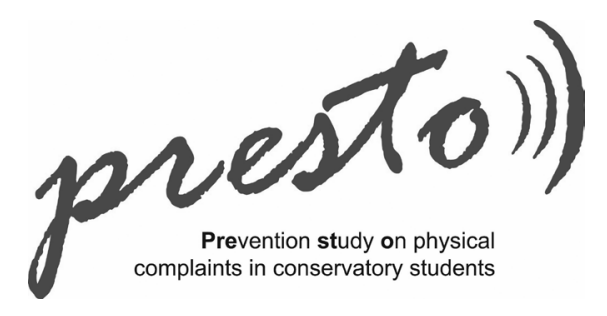

Published as: Baadjou, VA, Verbunt, JAMCF, Eijsden-Besseling, MDF van, SamamaPolak, AL., Bie, RA de \& Smeets, RJEM. PREvention STudy On preventing or reducing disability from musculoskeletal complaints in music school students (PRESTO): protocol of a randomised controlled trial. Journal of Physiotherapy. 2014;60 (4), 232.

Awarded: "NVDMG Aanmoedigingsprijs voor jong talent 2014", Nederlandse Vereniging van Dans- en Muziekgeneeskunde. Maastricht. (Young Talent Award Dutch Performing Arts Medicine Association) 


\section{Abstract}

Introduction: Up to $87 \%$ of professional musicians develop work-related complaints of the musculoskeletal system during their careers. Music school students are at specific risk for developing musculoskeletal complaints and disabilities. This study aims to evaluate the effectiveness of a biopsychosocial prevention program to prevent or reduce disabilities from playing-related musculoskeletal disorders. Secondary objectives are evaluation of cost-effectiveness and feasibility.

Methods: Healthy, first or second year students ( $n=150)$ will be asked to participate in a multicenter, single-blinded, parallel-group randomized controlled trial. Students randomized to the intervention group $(n=75)$ will participate in a biopsychosocial prevention program that addresses playing-related health problems and provides postural training according to the Mensendieck or Cesar methods of postural exercise therapy, while incorporating aspects from behavioral change theories. A control group $(n=75)$ will participate in a program that stimulates a healthy physical activity level using a pedometer, which conforms to international recommendations. No long-term effects are expected from this control intervention. Total follow-up duration is two years. The primary outcome measure is disability (Disabilities of Arm, Shoulder and Hand questionnaire). The secondary outcome measures are pain, quality of life and changes in health behavior. Multilevel mixed-effect logistic or linear regression analyses will be performed to analyze the effects of the program on the aforementioned outcome measurements. Furthermore, cost-effectiveness, cost-utility and feasibility will be analyzed.

Conclusion: It is believed that this is the first comprehensive randomized controlled trial on the effect and rationale of a biopsychosocial prevention program for music students. 


\section{Introduction}

Every profession has its own occupational risk factors and injury burden. Being a professional musician is mostly acknowledged as an artistic and free profession; however, it is not so commonly known that musicians experience a high physical and psychological burden associated with their occupation. A noteworthy number of musicians develop playing-related complaints of the musculoskeletal system during their careers. ${ }^{1}$ The number of musculoskeletal complaints in musicians seems to be at the extreme end of the range, compared to the prevalence in the general working population. ${ }^{2}$ Since different definitions for these playing-related musculoskeletal disorders have been used in the past, reported prevalence varies widely. In this article, playing-related musculoskeletal disorders are defined according to Zaza ${ }^{3}$ as: 'pain, weakness, lack of control, numbness, tingling, or other symptom that interferes with your ability to play your instrument at the level you are accustomed to.' Reported point prevalence of playing-related musculoskeletal disorders ranges from $25 \%$ for students at the start of their music school study, ${ }^{4} 34$ to $62 \%$ for music students overall, ${ }^{5}$ and between 39 and $87 \%$ for professional classical musicians. ${ }^{5}$ Most of the complaints in musicians, and up to $70 \%$ of the complaints in music students, are labelled as non-specific. ${ }^{6}$ The high prevalence of playing-related musculoskeletal disorders leads to considerable disabilities while performing (work), as well as in leisure time. ${ }^{2}$ Hence, playing-related musculoskeletal disorders seem to be a threat to the quality of performance, as well as to the musician's quality of life.

Previous research has shown that physical, occupational and psychological, as well as social and behavioral factors influence work-related complaints and disability. ${ }^{7-9}$ This combination of biomedical and psychosocial factors can be incorporated in the biopsychosocial model. ${ }^{8}$ Several studies support the hypothesis that this theory of biopsychosocial factors can also be applied to the etiology of playing-related musculoskeletal disorders in musicians. ${ }^{2,10}$ For example, a high physical workload, the psychosocial adaptation to a new environment, stress while practicing or performing, striving to perform at the highest level, and abrupt increases in playing time are known risk factors for the development of playing-related musculoskeletal disorders for (novice) music students." Accordingly, it has been shown that fatigue, depression and stage fright increase during the first year of study. ${ }^{12}$ This combination of risk factors underlines the importance of offering education on preventing playing-related complaints to music students early in their study ${ }^{13}$ and highlights the importance of including physical, psychosocial and behavioral aspects.

Some earlier programs aiming to prevent playing-related musculoskeletal disorders in music students have been evaluated. Results warrant cautious interpretation, since methodological quality and study power are often unsatisfactory. An educational program on health promotion was able to increase preventive behaviour. ${ }^{14}$ Ackermann et $a . .^{15}$ showed that a program aiming to increase physical endurance significantly reduced perceived exertion, when compared with strength training. Spahn et al. ${ }^{16}$ combined theory and practice in a course focused at both physical and psychological aspects. Students who participated in the prevention program improved their ability to cope with the requirements of the music study when compared with a control group. ${ }^{16}$ The longest and largest longitudinal, observational study in music students up till now has shown that a prevention program incorporating physical, psychosocial and behavioral aspects seems to 
provide additional value to students' psychological health. ${ }^{17}$ However, none of the aforementioned studies were actually able to influence occurrence or intensity of playing-related musculoskeletal disorders. Only a recent study by Lopez and Martinez ${ }^{18}$ showed a decrease in physical complaints in music students who took part in a prevention program focusing on physical aspects in theory and practice; however, results of this study have to be interpreted with caution since no validated questionnaires were used and a possible expectation bias cannot be ruled out. Recapitulating, few prevention programs were able to actually reduce physical complaints and only a minority of the programs studied and combined physical, psychological and behavioral aspects.

The present hypothesis is that a prevention program should incorporate biomedical, psychological and social features to be able to be effective in reducing physical complaints in musicians. Therefore, a new prevention program has been designed with a biopsychosocial focus, primarily to address the biomedical or physical component. Awareness and knowledge about the human body and body posture as a way to prevent physical complaints is an important corner stone of the intervention. ${ }^{16,17,19,20}$ The postural stabilization system plays an important role in the manifestation of playing-related musculoskeletal disorders in musicians. ${ }^{21}$ In the Netherlands and Scandinavian countries, postural exercise therapy according to the Mensendieck or Cesar methods is frequently offered as a treatment for complaints of the musculoskeletal system. Postural exercise therapy is also used in the treatment of playing-related musculoskeletal disorders. Central themes of postural exercise therapy are body awareness, balanced posture and controlled movements, awareness of tension and relaxation, and functional respiration. ${ }^{22,23} \mathrm{~A}$ fundamental issue in the treatment of musicians is the prevention of imbalance between the postural muscles such as Latissimus dorsi and the muscles actively used to play the instrument. ${ }^{24}$ Postural exercise therapy, and strength and fitness exercises were found to be equally cost-effective in reducing early non-specific work-related upper limb disorders., ${ }^{9,25}$ Soukup et al. ${ }^{26}$ showed that Mensendieck therapy was as effective as secondary prevention of recurrent low back pain episodes. Mensendieck therapy was also found to be effective in diminishing psychological distress and pain experience, and improving motor functions in women with chronic pelvic pain. ${ }^{23}$ Although scientific evidence is still lacking, clinical practice shows that the Mensendieck or Cesar postural exercise therapy methods contribute to the prevention of playing-related musculoskeletal disorders in musicians.

Next to the biomedical factor of body posture, psychosocial and behavioral aspects also play an important role in the development of playing-related musculoskeletal disorders and should therefore be included in prevention programs. Stress, ability to cope, perfectionism and anxiety must be taken into account. ${ }^{4}$ Education on learning or practice skills could also be incorporated. It is advised that music students should be encouraged to believe in their ability to influence their own state of health and learn how they can specifically contribute to it. ${ }^{4}$ The Integrated Change (I-Change) model can be used to explain motivational and behavioral change, and provides a scientific rationale on which health-promotion programs can be built. ${ }^{27}$ In short, this theory assumes that preventive action can only be taken after students first become aware of the problem and be motivated for change. By creating a prevention program using these already known components from behavioral-change theories, such a program is thought to be more successful in the short and long term. To summarize: the importance of introducing a course 
on health promotion and injury prevention for music students is high. The scientific evidence to support the contents of a prevention program is, however, limited. A new prevention program combining biomedical, psychosocial and behavioral factors has been designed and will be evaluated in the present research. This paper presents the study protocol.

The research questions are:

1. Is a biopsychosocial prevention program effective in preventing or reducing disability due to playing-related musculoskeletal disorders in music school students?

2. Is a biopsychosocial program to prevent or reduce disabilities from playing-related musculoskeletal disorders in music school students cost-effective?

3. What is the feasibility of a biopsychosocial program to prevent or reduce disabilities from playing-related musculoskeletal disorders in music school students?

\section{Methods}

\section{Design}

The PRESTO study (PREvention STudy On preventing or reducing disability from musculoskeletal complaints in music school students) is a multicenter, single-blinded, parallel-group randomized controlled trial. Participants are randomized into an intervention or control group. The Medical Ethical Committee of Maasstad Ziekenhuis Rotterdam has given approval for the study. The study is registered in a public trial registry (Nederlands Trial Register NTR3561). Reporting of the randomized controlled trial will adhere to the recommendations of the CONSORT statement. ${ }^{28,29}$ Measurements will be performed using questionnaires at baseline (T0), week 10 (T1), week 20 (T2), post-treatment (T3), 16-month follow-up (T4), and 24-month follow-up (T5). The participating first-year students receive the T4 and T5 questionnaires in their third year of study and the students starting with the program in their second year will receive the final questionnaires in their fourth study year. A flow chart is presented in Figure 1 below. Since a large number of the students are from abroad and do not speak Dutch, questionnaires will be printed in English. Dutch translation booklets are available for every Dutch student. Questionnaires T0, T1, T2 and T3 will be filled out in class. The cost questionnaires and T4 and T5 questionnaires will either be distributed by the conservatory or will be sent to the home address of the student.

\section{Participants and centres}

First and second year music students studying at five Dutch music schools (also known as conservatories) will be asked to participate in this project. In The Netherlands, a conservatory study is part of Higher Vocational Education. The bachelor education program lasts for four years, in which time various major programs such as classical music, jazz music, popular music, music in education or historical music are offered. Two cohorts will be included: one group in study year 2012/2013 and one group in study year 2013/2014; first-year and second-year students are included. Students must be able to understand Dutch or English. Students with a specific comor- 
bidity that can be associated with their complaints, such as Rheumatoid Arthritis, Ankylosing Spondylitis or Multiple Sclerosis, are excluded. Comorbidity can be a serious confounder since it affects both the effect of a prevention program as well as the development of disability.

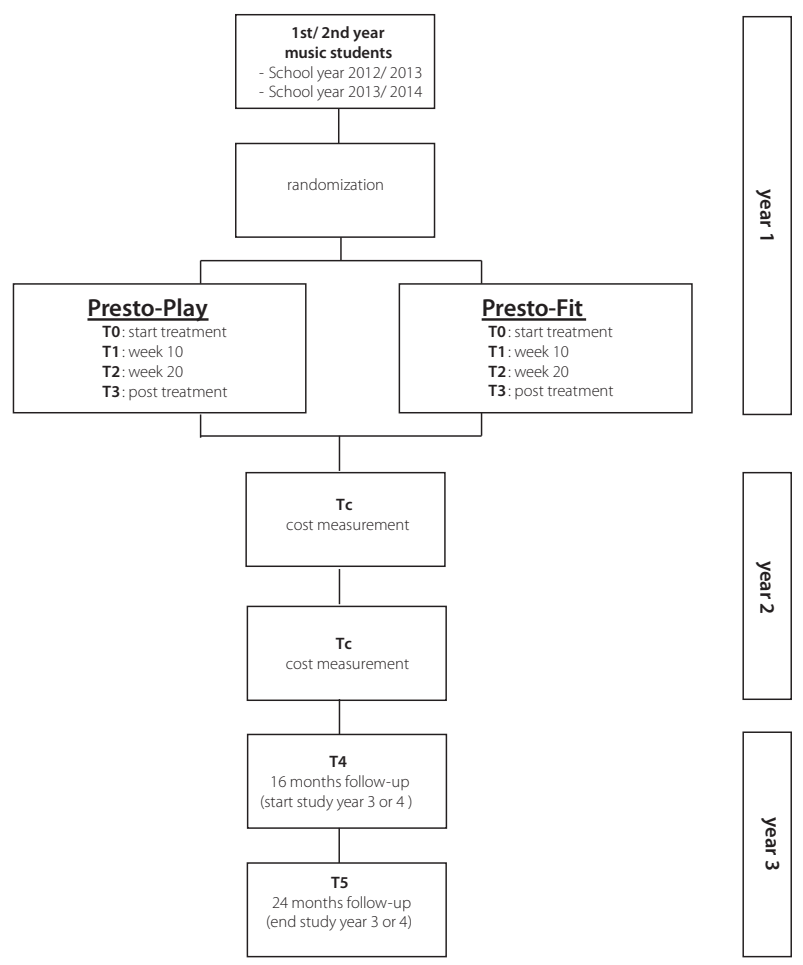

Figure 1: Flow chart of study.

\section{Intervention/control}

\section{Intervention group: PRESTO-Play}

PRESTO-Play is a biopsychosocial prevention program based on the Mensendieck or Cesar postural exercise training methods, and education about playing-related health problems. The aim of the program is to induce a change in behavior, leading to a more healthy way of music making, which hypothetically results, in the long term, in a reduction in disabilities from playing-related complaints. The PRESTO-Play program comprises of 11 lessons of 1.5 hours each, divided up over one study year. Lesson 1 is a general education lesson to create awareness of the physical complaints and to teach about the anatomy and physiology of the human body in relation to playing a musical instrument. Starting from lesson 2, the focus lies on body posture while playing the instrument, according to the Mensendieck or Cesar postural exercise therapy 
methods, ${ }^{24}$ body posture is visualized with the help of mirrors. In lessons 2 to 11 , half of the time is spent playing music with a correct body posture, the other half is spent on education about a specific theme such as: warming-up and cooling down, hypermobility, breathing, ergonomics, practice behavior, arm/neck/shoulder complaints, stress, over commitment, coping strategies, relaxation, anxiety, and physical activity. After each lesson, students receive a homework assignment in order to stimulate active learning: to describe key elements and important exercises from the past lesson in their exercise books. Postural exercise therapists who are specialized in the Mensendieck or Cesar methods will lead the PRESTO-Play program. Therapists who are experienced in the treatment of musicians and are familiar with the principles of treatment of musicians according to Samama, ${ }^{24}$ are recruited to teach the PRESTO-Play lessons.

Behavioural change: The I-Change model ${ }^{27}$ assumes that three main factors determine a person's motivation for behavioral change: 1) attitudes, 2) social influences and 3) self-efficacy expectations. Before a person is motivated to change, they should become aware of the problem. Awareness factors are: knowledge, cues to action and risk perception. Awareness itself is influenced by predisposing and information factors. Once motivated to change, there could be several ability factors and barriers, which are crucial to the acceptance and, finally, maintenance of behavior. Aspects from the I-Change model are incorporated in the PRESTO-Play program. In short, students are first made aware of the prevalence and consequence of musculoskeletal complaints, thereafter their motivation for change is stimulated by exploring personal attitudes towards health and exploring the influences of their peers and music teachers. Self-efficacy is influenced by teaching the students how to be responsible for their own health, and by giving them personal feedback.

\section{Control group: PRESTO-Fit}

The PRESTO-Fit program was designed to control for attention. The aim of the PRESTO-Fit program is to reach a healthy physical activity level, which conforms to international recommendations for the general population. Students receive a pedometer and a step diary with which to monitor daily activity for a total of 7 weeks during the study year. Students are encouraged to take 10,000 steps a day. The PRESTO-Fit program comprises of five lessons of 1 hour each, planned over 1 study year. In classes, students are made aware of the importance of being physically fit. A teacher assists the students in formulating goals and a plan to reach 10,000 steps a day. By giving feedback on individual and group activity (graphs showing progress) students are stimulated to continue their work. The contents of the program are inspired by the work of Jackson and Howton, ${ }^{30}$ Tully and Cupples, ${ }^{31}$ and De Cocker et al. ${ }^{32}$ The exception is, however, that in the PRESTO-Fit program, no efforts are made to induce long-term behaviour change. Since the long-term follow-up measurement is the present study's primary outcome measure, this program serves as a placebo control. It is expected that the average step count of a student is around 7000 steps at baseline. Students have to increase their activity in order to reach the goal of 10,000 steps a day. This activity will take approximately 20 minutes extra per measurement day. This extra time invested, next to the lessons, leads to a total investment time of approximately 18 hours. Therapists with a specific interest in physical activity are recruited to teach the PRESTO-Fit lessons. 
Both courses have a total duration of 18 hours. Classes and information materials are presented in Dutch as well as in English. Lessons will be taught in Dutch, but if there is a student present who does not understand Dutch, lessons will be taught in English. Therapists are instructed to deliver programs according to protocol. Training and a refresher workshop are organized for all participating therapists in order to facilitate the implementation of the program in all centers. Progress and implementation of the research is routinely discussed with program coordinators at the conservatories. Two conservatories will award the students with study credits for their participation in both treatment programs. Conservatory music teachers are informed about the program by e-mail and by local information (i.e. intranet) at the start of the school year. All participating students and interested conservatory personnel will receive a quarterly newsletter.

\section{Outcome measures}

\section{Baseline measurements}

The following socio-demographic characteristics will be recorded at baseline: gender, age, height, body weight, country of birth, attending conservatory, bachelor program enrolled in, instrument played (primary and/or secondary), years of experience playing primary instrument, playing hours per day, (previous) health problems, smoking, alcohol consumption, use of drugs, sleep, and nutrition.

\section{Primary outcome measure}

The primary outcome measure is disability, as it is believed that it is not the number or intensity of complaints that is of the greatest importance to musicians, but the limitations in playing music. To specify disability, in order to elaborate different concepts, different outcomes are used. Two separate scores of one primary outcome instrument (Disabilities of the Arm, Shoulder and Hand questionnaire; DASH) will be presented: a general DASH score, and a sub score from the music module for disability playing a musical instrument. These scores are complementary to each other, that is, the combination gives a more specific view of disability in musicians.

Disabilities of the Arm, Shoulder and Hand (DASH) questionnaire: The DASH questionnaire is a self-reported 30-item questionnaire for people with upper-extremity musculoskeletal conditions. It assesses symptoms and functional status, and focuses on physical function, which are measured on a 5 -point Likert scale. ${ }^{35}$ Scores range from 0 to 100, with a higher score representing more disability. The questionnaire offers two optional modules. One module concerns four work-related questions, and the other module on music and sports contains four additional questions on the impact of the arm, shoulder or hand problem on playing sports or a musical instrument. The work-related module will not be used in this study. Outcome of the optional modules is presented as a sub score ranging from 0 (not disabled) to 100 (most severe disability). Validity (correlation with other tests $r>0.69$ ), test-retest reliability $(I C C=0.96)$ and responsiveness are good. ${ }^{36}$ Two separate scores will be presented: a general DASH score, and a more-specific score from the music module for disability playing a musical instrument. 
Disabilities related to playing a musical instrument: The presence of disability related to playing a musical instrument is expressed as the absolute number of students with disabilities, and defined as a positive answer to one of the questions from the extra module of the Disabilities of the Arm, Shoulder and Hand questionnaire for playing a musical instrument.

\section{Secondary outcome measures}

Pain/playing-related musculoskeletal disorders characteristics: Participants are asked to indicate on a human figure where complaints are experienced in the body. A Numerical Rating Scale ranging from 0 to 10 is used: 1) to quantify the severity of complaints experienced in the past week; 2) to indicate the severity of complaints when they are at their least; 3 ) to indicate the severity of complaints when they are at their worst. Students answer questions separately for playing-related musculoskeletal disorders and pain in general.

Pain Disability Index: The Pain Disability Index ${ }^{37,38}$ is a generic measure for disability, which complements the specific disability scoring of the DASH. Participants report on seven different daily activities, and whether they were fully disabled due to pain or not (score range per question 0 to10). Internal consistency is good (Cronbach's alpha $=0.86$ ); test-retest reliability is moderate (0.44).

Quality of life (physical/ mental health): Quality of life will be assessed using the Short Form36 Health Survey, SF-36. 39,40 The SF-36 is a generic measure composed of 36 questions, which are organized into eight domains on physical and mental health. Physical health items are: physical function, limitations due to physical health problems, body pain, and general health perceptions. Mental health concerns: vitality, social function, limitations due to emotional problems, and general mental health. A lot of research has been undertaken on reliability and validity in different populations: reliability for overall score mostly exceeds 0.80 , reliability for physical and mental sub scores mostly exceeds $0.90 .{ }^{41}$

Health behavior changes: The process leading to health behavior changes and actual changes in behavior is measured with a self-developed questionnaire, which is based on previously used questionnaires. ${ }^{42,43}$ Components of the questionnaire are: predisposing factors, awareness (knowledge, risk perception, personal relevance), attitudes (advantages, social influence, modelling, self-efficacy beliefs) and effectiveness. A priori designated effects of prognostic factors, confounders and mediating factors will be researched additionally. An overview of outcome measures and assessment moments is presented in Table 1. 
Table 1: Outcome measures and assessment times

\begin{tabular}{|c|c|c|c|c|c|c|c|c|c|}
\hline & & \multicolumn{4}{|c|}{ Year 1} & \multicolumn{2}{|c|}{ Year 2} & \multicolumn{2}{|c|}{ Year 3} \\
\hline & & $\begin{array}{c}\text { T0 } \\
\text { baseline }\end{array}$ & $\begin{array}{c}\mathrm{T} 1 \\
\text { treatment } \\
\text { week } 10\end{array}$ & $\begin{array}{c}\mathrm{T} 2 \\
\text { treatment } \\
\text { week } 20\end{array}$ & $\begin{array}{c}\mathrm{T3} \\
\text { post } \\
\text { treatment }\end{array}$ & tc & tc & $\begin{array}{c}\text { T4 } \\
\text { 16-month } \\
\text { follow-up }\end{array}$ & $\begin{array}{c}\text { T5 } \\
\text { 24-month } \\
\text { follow-up }\end{array}$ \\
\hline \multirow{3}{*}{ 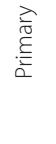 } & Demographics & $x$ & & & & & & & \\
\hline & Disability (DASH) & $x$ & $x$ & $x$ & $x$ & & & $x$ & $x$ \\
\hline & Quality of life (SF-36) & $x$ & & $x$ & $x$ & & & & $x$ \\
\hline \multirow{4}{*}{ 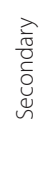 } & Pain/ PRMD & $x$ & $x$ & $x$ & $x$ & & & $x$ & $x$ \\
\hline & Health behavior & $x$ & & $x$ & & & & & $x$ \\
\hline & Process evaluation & & & & $x$ & & & & \\
\hline & Cost evaluation & & $x$ & & $x$ & $x$ & $x$ & $x$ & $x$ \\
\hline
\end{tabular}

DASH: disability arm, shoulder, hand; SF-36: Short-form 36; PRMD: playing-related musculoskeletal disorder; tc: cost measurement

\section{Economic evaluation}

The economic evaluation from a social perspective is embedded in the randomized controlled trial and consists of a cost-effectiveness analysis (CEA) and cost-utility analysis (CUA) in which the costs and effects of the intervention condition will be compared to the control condition. The study is aimed at answering the following research question: Is a biopsychosocial program to prevent or reduce disabilities from playing-related musculoskeletal disorders in music school students cost-effective when compared with a control program to stimulate a healthy physical activity level? Costs are measured with a cost questionnaire, which is derived from the Tic-p questionnaire on healthcare consumption, illness and work. ${ }^{44}$ This questionnaire makes an inventory of costs over the past 3 months. The duration of the economic evaluation is equal to intervention and follow-up period, that is, 3 study years. Students are asked to complete the questionnaire twice per year. Thus, the exact costs over a period of 6 months per year will be known. Costs will be extrapolated over the total period, ${ }_{15}^{45}$ that is, the costs in the other 6 months per year (which are not exactly measured) will be estimated based on the questionnaires. In total, six questionnaires will be distributed in 3 study years. Primary outcome measurement for the cost-effectiveness analysis will be disability, as measured with the DASH music module. 35,46 Quality of life, as measured with the Short Form-6D (SF6-D), which is based on SF-36 ${ }^{47}$ will be used as a functional outcome measure in order to calculate quality of adjusted life years (QALYS) for the cost-utility analysis. Direct healthcare costs, direct non-healthcare costs (e.g., costs of transport to and from healthcare) and indirect non-healthcare costs (e.g., productivity costs) will be considered for evaluation. Costs of healthcare will be calculated using principles and standardized cost prices from the Dutch guideline for cost analysis in healthcare research. ${ }^{48}$ The friction cost method ${ }^{49}$ will be used to calculate indirect costs for production losses due to sick leave; costs associated with delay in study progress will also be calculated. Direct non-healthcare costs will be calculated by using information from the cost questionnaires and standardized values. 


\section{Process evaluation}

The process evaluation will include both formative and summative purposes. The goal of the process evaluation is to evaluate whether the intervention was implemented as planned..$^{50}$ The strength of adding a process evaluation to the randomized controlled trial is that conclusions on effect sizes can be put into perspective or made stronger by obtaining data on the quality of implementation. The following process evaluation is based on work of Steckler and Linnan, ${ }^{51}$ Baranowski and Stables, ${ }^{52}$ and Saunders et al. ${ }^{50}$ Elements of the process evaluation include: fidelity, dose delivered, dose received, reach, recruitment and context. A contamination check will be performed. A process evaluation will be performed for both the intervention and control group on an individual level by using questionnaires for the students and a logbook for the teachers. Analysis will be performed on an aggregated level. Target groups are students, program teachers, conservatory staff and research staff.

\section{Procedure}

Students are informed about the current study during a lecture at their conservatory provided by the first author. Recruitment starts in the 2012 to 2013 study year. Students will receive written information, a registration form and an informed consent form. A research assistant can be contacted for additional information. For each conservatory, a registration deadline is set. After the deadline has passed, all students who gave informed consent will be randomized to the intervention or control group. An independent research assistant will conduct the concealed randomization procedure by means of a computer-generated list. Stratified randomization is conducted per conservatory with variable block sizes to avoid imbalance in groups per conservatory. In addition, by stratifying on a conservatory level it is possible to control for inter-conservatory differences and correct for selection bias. After randomisation, the students are informed by e-mail about the date and location of the first lesson; location is dependent on randomisation. Once students have attended the first session, they will find out what group they are assigned to. Only students who have attended the first class will qualify as study participants. Students and program teachers cannot be blinded for the intervention. A researcher who is blinded for the intervention will perform data collection and data analysis. To minimize the effects of positive expectations, participants are not told what is expected to be the most effective intervention. Participation in the program is free of charge. Students will be rewarded for their participation by several small gifts distributed at different moments in class and during follow-up. Follow-up is expected to end in June 2016. 


\section{Data analysis}

\section{Effect evaluation}

First, baseline data on socio-demographic variables and primary and secondary outcome measures will be analyzed to check for differences between the intervention and control group. Independent sample t-tests (normal distribution) or Mann-Whitney $U$ tests (non-normal distribution) will be used to test for differences in continuous outcome measures. Chi-square tests will be used to test for differences in dichotomous outcome measures. The number of dropouts and loss-to-follow-up will be reported descriptively. A probability level $p<0.05$ is selected for statistical significance. Multilevel analysis and repeated measurements techniques will be used to analyze the overall effect of the intervention and control group on primary and secondary outcome measures. Groups are analyzed according to the intention-to-treat principle. A two-level structure will be applied with the random effects students (first level) and school (second level). Fixed effects are randomization group (Play/ Fit), gender (male/ female), and bachelor program. A correction will be applied for significant baseline differences between groups. The primary study end point is T5 (end of follow-up), and the second most important study end point will be T3 (post treatment). The multilevel logistic regression analysis will be performed with the dichotomous outcome variable disability on the music module (yes/no). Analyses of other primary (DASH) and secondary outcome variables (pain, PDI, quality of life, health behavior change) will be performed using linear regression analysis.

\section{Economic analysis}

Primary analysis (base case analysis) will be executed according to the intention-to-treat principle. Averages are calculated and the t-test will be used to determine significant differences between costs of the intervention and control condition. Differences in costs and effects between the intervention and the control condition will be described in incremental cost-effectiveness ratios (ICERs). The robustness (distribution of differences of costs between intervention and control condition) of the cost-effectiveness analysis will be analyzed with bootstrapping (1000x)..$^{53}$ In the cost-utility analysis, primary outcome measures are measured in terms of QALY, as measured with SF-6D. Standard utility weights ${ }^{47}$ are used to generate a single index score for each state of health, ranging from zero, which is equivalent for death, to 1 representing full health. ${ }^{54}$

\section{Process evaluation}

Results of the process evaluation of students and program teachers will be analyzed descriptively. 


\section{Sample size calculation}

Power calculation was performed using the optional module on playing a musical instrument of the primary outcome variable Disabilities of the Arm, Shoulder, and Hand (DASH). The primary outcome, disability, is defined as a positive answer to one of the questions from the extra DASH module on playing a musical instrument. It is hypothesized that a 50\% reduction in disability is clinically relevant. Currently, approximately $50 \%$ of third-year students experience disabilities while playing a musical instrument, ${ }^{33}$ therefore, the intervention will hypothetically induce a decrease of disabilities, so that after follow-up (T5) only $25 \%$ of the students participating in the intervention condition will experience disabilities while playing their musical instruments. Using these numbers, and based on a power calculation of proportion differences, ${ }^{34}$ with a of 0.05 , power of 0.8 , proportion group 1 of 0.25 , proportion group 2 of 0.50 , and equal group sizes; a total of 65 persons per group (including continuity correction according to Yates) is needed. Taking into account a 15\% dropout rate, the total group size will be 75 people. This means that in total 150 participants are needed for the study.

\section{Discussion}

In this study, the (cost)-effectiveness of a biopsychosocial program on preventing or reducing disabilities from playing-related musculoskeletal disorders in Dutch music school students will be evaluated. The intervention group receiving the prevention program will be compared with a control group of students who receive a program to stimulate a short-term healthy physical activity level conform international recommendations. It is believed that this is the first randomized controlled trial examining the effect of a biopsychosocial prevention program in which costs and feasibility evaluations are also incorporated. It is hypothesized that notice of the combination of physical, psychosocial and behavioral factors is the clue to effective prevention. Zander et al. ${ }^{17}$ conducted an effect study in a comparable population; however, interventions were not randomly allocated. As results were only observational, a direct effect of expectation on outcomes could not be ruled out. The present study is aimed at creating attractive intervention and control programs, so that every participating student, regardless of condition, will experience participation to the project as being beneficial. Any regular physical activity contributes to the primary and secondary prevention of several diseases. ${ }^{55} \mathrm{~A}$ behavioral approach contributes to the effectiveness of the programs aiming to change physical activity level..$^{56}$ In the PRESTO-Fit program, no elements aiming at long-term behavioral changes are included. Also, in general, the long-term effects of (behavioral) programs to stimulate activity in young adults are poor. ${ }^{57}$ Based on these facts, it is believed that the contents of the physical activity program (PRESTO-Fit) will only stimulate physical activity in the short term. Thus, no long-term effects will be expected from the PRESTO-Fit program, which makes the program a placebo or control condition.

A controlled design in patient-centered research has various challenges. In the present study, these challenges are firstly the multicenter design of the study. To be able to recruit the number of students, as computed in the power calculation, it is necessary to include multiple conservatories. An advantage is the reflection of the total Dutch conservatory population in the 
study, facilitating the generalization of the outcome and providing an overview of a broad range of the field. Disadvantages are the differences between participating conservatories, such as for example, diversity in teaching curriculums, regional health conditions, and variance in population characteristics (including country of origin). By using stratified randomization on school level, the aim is to control for these inter-conservatory differences. The second challenge is that blinding of both participants and therapists is not possible. To minimize the effects of positive expectations, participants are not informed about the hypotheses regarding the most effective intervention. Blinding of the researcher and/or research assistant when performing outcome assessments, data collection and data analysis will prevent measurement bias. Furthermore, by offering two different programs at each participating conservatory, the risk of contamination is present. Students of the intervention condition can inform the students of the control condition on aspects of the program and vice versa; students are therefore asked to keep the content of the program secret. A contamination check will be performed; however, the exact content of the biopsychosocial based prevention program is difficult to convey completely. Lastly, to achieve the highest possible degree of therapist commitment, a consensus meeting will be organized in which every therapist will be able to comment on the study protocol so that all participating therapists agree on the final version of the protocol.

To conclude, this paper describes the design of a parallel-group randomized controlled trial evaluating the (cost-)effectiveness of a biopsychosocial program on preventing or reducing disabilities from playing-related musculoskeletal disorders in music students. The results of the present study will provide evidence on the effectiveness and rationale of the intervention, as presented, and will contribute to the implementation of health promotion and prevention programs at (Dutch) conservatories. Specifically trained postural-exercise therapists and physical therapists can use the findings worldwide to improve quality of care for musicians.

\section{Acknowledgements}

We wish to thank the following conservatories for participation in our study: Codarts University for the Arts, Rotterdam; Fontys School of Fine and Performing Arts, Tilburg; Maastricht Academy of Music; Prince Claus Conservatoire, Groningen; Utrecht School of the Arts. We thank Marielle Goossens for her contribution to the design of the cost-effectiveness part of the study, Ilse Mesters for her participation in the design of the health behavior evaluation, and Jolanda van Haastregt for her contribution to the design of the process evaluation. 


\section{References}

1. Chan C, Driscoll T, Ackermann B. The usefulness of on-site physical therapy-led triage services for professional orchestral musicians - a national cohort study. BMC Musculoskel Disord. 2013;14:98.

2. Paarup HM, Baelum J, Holm JW, Manniche C, Wedderkopp N. Prevalence and consequences of musculoskeletal symptoms in symphony orchestra musicians vary by gender: a cross-sectional study. BMC Musculoskel Disord. 2011;12:223.

3. Zaza C, Charles C, Muszynski A. The meaning of playing-related musculoskeletal disorders to classical musicians. Soc Sci Med. 1998;47:2013-2023.

4. Spahn C, Strukely S, Lehmann A. Health conditions, attitudes toward study, and attitudes toward health at the beginning of university study: music students in comparison with other student populations. Med Probl Perform Art. 2004;19:26-33.

5. Zaza C. Playing-related musculoskeletal disorders in musicians: a systematic review of incidence and prevalence. CMAJ. 1998;158:1019-1025.

6. Wynn Parry CB. Managing the physical demands of musical performance, in Musical Excellence: Strategies and techniques to enhance performance. Williamon A, ed. Oxford: Oxford University Press; 2004:41-60.

7. Bongers PM, IJmker S, van den Heuvel S, Blatter BM. Epidemiology of work related neck and upper limb problems: psychosocial and personal risk factors (part I) and effective interventions from a bio behavioural perspective (part II). J Occup Rehabil. 2006;16(3):279-302.

8. Engel GL. The clinical application of the biopsychosocial model. Am J Psychiatry. 1980;137(5):535-544.

9. van Eijsden-Besseling MD, Staal JB, van Attekum A, de Bie RA, van den Heuvel WJ. No difference between postural exercises and strength and fitness exercises for early, non-specific, work-related upper limb disorders in visual display unit workers: a randomised trial. Aust J Physiother. 2008; 54(2):95-101.

10. Fjellman-Wiklund AC, Brulin C, Sundelin G. Physical and psychosocial work-related risk factors associated with neck-shoulder discomfort in male and female music teachers. Med Probl Perform Art. 2003; 18:33-41.

11. Spahn C, Burger T, Hildebrandt H, Seidenglanz K. Health locus of control and preventive behaviour among students of music. Psychol Mus. 2005;33:256-268.

12. Hildebrandt H, Nübling M, Candia V. Increment of Fatigue, Depression, and Stage Fright During the First Year of High-Level Education in Music Students. Med Probl Perform Art. 2012;27(1):43-48.

13. Clark TA, Williamon A, Redding E. The value of health screening in music schools and conservatoires. Clin Rheumatol. 2013;32:497-500.

14. Barton R, Feinberg JR. Effectiveness of an educational program in health promotion and injury prevention for freshman music majors. Med Probl Perform Art. 2008;23: 47-53.

15. Ackermann BPR, Adams R, Marshall E. Strength of endurance training for undergraduate music majors at a university? Med Probl Perform Art. 2002;17:33-41.

16. Spahn $\mathrm{CH}$, Hildebrandt $\mathrm{H}$, Seidenglanz $\mathrm{K}$. Effectiveness of a prophylactic course to prevent playing-related health problems of music students. Med Probl Perform Art. 2001;14:24-31.

17. Zander MF, Voltmer E, Spahn C. Health promotion and prevention in higher music education. Results of a longitudinal study. Med Probl Perform Art. 2010;25:54-65.

18. Martin Lopez T, Farias Martinez J. Strategies to promote health and prevent musculoskeletal injuries in students from the high conservatory of Salamanca, Spain. Med Probl Perform Art. 2013;28(2):100-106. 
19. Brandfonbrener AG. Orchestral injury prevention intervention study. Med Probl Perform Art. 1997;12:9-14.

20. Zaza C. Research-based prevention for musicians. Med Probl Perform Art. 1994;9:3-6.

21. Steinmetz A, Seidel W, Muche B. Impairment of postural stabilization systems in musicians with playing-related musculoskeletal disorders. J Manipulative Physiol Ther. 2010;33:603-611.

22. Haugstad GK, Haugstad TS, Kirste UM, Leganger S, Klemmetsen I, Malt UF. Mensendieck somatocognitive therapy as treatment approach to chronic pelvic pain: Results of a randomized controlled intervention study. Am J Obstet Gynecol. 2006; 194:1303-1310.

23. Haugstad GK, Haugstad TS, Kirste UM. Continuing improvement of chronic pelvic pain in women after short-term Mensendieck somatocognitive therapy: results of a 1-year follow-up study. Am J Obstet Gynecol. 2008;199:615.

24. Samama, ALW. Making music without pain. 1998, Assen, The Netherlands: Van Gorcum.

25. van Eijsden-Besseling MD, Gerhards SA, de Bie RA, Severens JL. Cost-effectiveness of postural exercise therapy versus physiotherapy in computer screen-workers with early non-specific work-related upper limb disorders (WRULD); a randomized controlled trial. Trials. 2009;10:103.

26. Soukup MG, Glomsrod B. The effect of a mensendieck exercise program as secondary prophylaxis for recurrent low back pain. Spine. 1999;24(15):1585-1592.

27. de Vries H, Mudde A, Leijs I, Charlton A, Variainen E, Buijs G, et al. The European Smoking prevention Framework Approach (EFSA): an example of integral prevention. Health Educ Res. 2003;18(5):611-626.

28. Moher D, Hopewell S, Schulz KF, Montori V, Gotsche PC, Deveraux PJ, et al. CONSORT 2010 Explanation and Elaboration: updated guidelines for reporting parallel group randomised trial. BMJ. 2010;340.c869

29. Schulz KF, Altman DG, Moher D. CONSORT 2010 Statement: updated guidelines for reporting parallel group randomised trials. BMC Medicine. 2010; 8:18.

30. Jackson EM, Howton A. Increasing Walking in College Students Using a Pedometer Intervention: Differences According to Body Mass Index. J Am Col Health. 2008; 57(2):159-164.

31. Tully MA, Cupples M. UNISTEP (university students exercise and physical activity) study: a pilot study of the effects of accumulating 10.000 steps on health and fitness among university students. J Phys Act H. 2011;8(5):663-667.

32. de Cocker KA, de Bourdeadhuij IM, Brown WJ, Cardon GM. Effects of ' 10.000 steps Ghent': a whole-community intervention. Am J Prev Med. 2007;33(6):455-463.

33. Baadjou VA, Verbunt JA, van Eijsden-Besseling MD, Huysmans SM, Smeets RJ. The musician: (in)active athlete? Exploring the association between physical activity and musculoskeletal complaints in music students. Med Probl Perform Art.2015;30(4):231-7.

34. Fleiss JL. Statistical methods for rates and proportions. 3th edition ed. 2003, New Yotk: John Wiley \& Sons.

35. Hudak PL, Amadio PC, Bombardier C. Development of an upper extremity outcome measure: the DASH (disabilities of the arm, shoulder and hand). Am J Ind Med. 1996; 29:602-608.

36. Beaton D, Katz J, Fossel A. Measuring the whole or the parts? Validity, reliability, and responsiveness of the Disabilities of the Arm, Shoulder and Hand Outcome measure in different regions of the upper extremity. J Hand Ther. 2001;14(2):128-146.

37. Pollard CA. Preliminary validity study of Pain Disability Index. Percept Mot Skills. 1984;59:974.

38. Tait CR, Chibnall JT, Krause S. The Pain Disabilithy Index: psychometric properties. Pain. 1990;40:171-182.

39. Ware JE, Sherbourne CD. The MOS 36-item short-form health survey (SF-36). I. Conceptual framework and item selection. Med Care. 1992;30(6):473-83. 
40. Aaronson NK, Ahmedzai S, Bergman B, Bullinger M, Cull A, Duez NJ, et al. Translation, validation, and norming of the Dutch language version of the SF-36 Health Survey in community and chronic disease populations. J Clin Epidemiol. 1998; 51(11):1055-68.

41. McHorney CA, Ware JE, Lu JF, Sherbourne CD. The MOS 36-item Short-Form Health Survey (SF-36): III. Tests of data quality, scaling assumptions, and reliability across diverse patient groups. Med Care. 1994;32(1):40-66.

42. de Vries $H$, Mesters I, van de Steeg H, Honing C. The general public's information needs and perceptions regarding hereditary cancer: an application of the Integrated Change Model. Patient Educ Couns. 2005;56:154-165.

43. Segaar D, Bolman C, Willemsen MC, de Vries H. Determinants of adoption of cognitive behavioural interventions in a hospital setting: Example of a minimal-contact smoking cessation intervention for cardiology wards. Pat Educ Counsel. 2006;61:262-271.

44. Hakkaart-van Roijen L. Manual Trimbos/iMTA questionnaire for Costs associated with Psychiatric illness (TiC-P). 2002, Erasmus University Rotterdam: Institute for Medische Technology Assessment.

45. Goossens M, Rutten-van Molken MP, Vlayen JW, van der Linden S. The cost diary: a method to measure direct and indirect costs in cost- effectiveness research. J Clin Epidemiol. 2000; 53:688-695.

46. Veehof MM, Sleegers EJ, van Velhoven NH, Schuurman AH, van Meeteren NL. Psychometric qualities of the Dutch language version of the disabilities of the arm, shoulder, and hand questionnaire (DASHDLV). J Hand Ther. 2002;15:347-354.

47. Brazier J, Roberts J, Deverill M. The estimation of a preference-based measure of health from the SF-36. J Health Econ. 2002;21:271-292.

48. Hakkaart-van Roijen L, Tan S, Bouwmans CAM. Handleiding voor kostenonderzoek. Methoden en standaard kostprijzen voor economische evaluaties in de gezondheidszorg. 2010, Erasmus Universiteit Rotterdam: Instituut voor Medical Technology Assessment.

49. van den Hout WB. The value of productivity: human-capital versus friction cost method. Ann Rheum Dis. 2010; 69(Suppl1):i89-91.

50. Saunders RP, Evans MH, Joshi P. Developing a Process-Evaluation Plan for Assessing Health Promotion Program Implementation: A How-to-Guide. Health Promot Pract. 2005; 6:134.

51. Steckler A, Linnan L. Process evaluation for public health interventions and research. 2002, San Francisco: Jossey Bass.

52. BaranowskiT, Stables G. Process Evaluations of the 5-a-Day Projects. Health educ behav. 2000;27(2):157-66.

53. Briggs, AD, Wonderling DE, Mooney C. Pulling cost-effectiveness analysis up by its bootstraps: a non-parametric approach to confidence interval estimation. Health Econ. 1996;6:327-340.

54. Brazier J, Roberts J, Tsudiya A, Busschbach J. A comparisonof the EQ-5D and SF-6D across seven patient groups. Health Econ. 2004;13:873-884.

55. Vanhees L, De Sutter J, Gelada SV, Duijk F, Prescott E, Cornelissen V, eta al. Importance of characteristics and modalities of physical activity and exercise in defining the benefits to cardiovascular health within the general population: recommendations from the EACPR (Partl). Eur J Prev Cardiol. 2012;19:670.

56. Kahn E, Ramses LT, Brownson RL, Health GW, Howze EH, Powell KE, et al. The effectiveness of interventions to increase physical activity:.A Systematic Review. Am J Prev Med. 2002;22(4S):73-107.

57. Timperio A, Salmon J, Ball K. Evidence based strategies to promote physical activity among children, adolescents and young adults: review and update. J Sci Med Sport. 2004;7(1):Suppl:20-29. 



\title{
Chapter 8
}

\author{
Preventing musculoskeletal complaints \\ in music students. A biopsychosocial \\ prevention course is not superior at reducing \\ disability compared to physical activity \\ promotion: a randomized controlled trial
}




\section{Abstract}

Objectives: Musculoskeletal complaints in musicians are common. Little is known about effectiveness of interventions. Is a biopsychosocial prevention course superior at preventing or reducing disability due to musculoskeletal disorders in music students compared to physical activity promotion?

Methods: Multicenter randomized controlled trial, concealed allocation, assessor blinded, intention-to-treat analysis. Participants were 170 first and second year students from 5 conservatories, randomized to experimental $(n=84)$ or control ( $n=86)$ group. The experimental group participated in 11 classes on body posture playing the instrument according to postural exercise therapy, and performance-related psychosocial aspects. The control group participated in 5 classes promoting physical activity according national guidelines. Time investment for both courses was 18 hours during one academic year. Primary outcome was disability (Disabilities of Arm, Shoulder, and Hand -DASH- questionnaire, including performing arts module). Secondary outcomes were pain disability, quality of life, playing-related musculoskeletal disorders, health behavior. Outcomes were assessed at six moments, from baseline until 2 year follow-up.

Results: Loss to follow-up was 40\% during the trial, and 69\% at 2 year follow-up. Drop-out rate was equal between groups. Overall, there were no significant differences between groups for any outcome adjusted for baseline characteristics (i.e. percentage disability: $\mathrm{OR}=1.31,95 \% \mathrm{Cl} 0.69$ to 2.51; general DASH: $\beta=-0.57,95 \% \mathrm{Cl}-3.23$ to 2.09 , performing arts module: $\beta=-0.40,95 \% \mathrm{Cl}-5.12$ to 4.32$)$.

Conclusion: A biopsychosocial prevention course tailored for musicians was not superior to physical activity promotion in reducing disability. A large number lost to follow-up warrants cautious interpretation. 


\section{Introduction}

Playing a musical instrument at professional level is physically and mentally challenging. Many years of intense practice result in superior levels of sensorimotor control.' The high demands on the musculoskeletal system in combination with psychosocial factors as performance stress make the musician vulnerable to develop musculoskeletal complaints. ${ }^{2}$ Life time prevalence of injuries in musicians is reported up to $93 \%{ }^{3}$ Fundamentals for building a lifelong career as a musician are laid during music education. Music students already experience more musculoskeletal complaints ${ }^{4}$ and a worse mental health ${ }^{5}$ compared to age matched medical students. A longitudinal study showed that the incidence of playing-related health problems was already $29 \%$ at start of year 1 , increasing to $42 \%$ in year 2, after which complaints reclined to $36 \%$ of the students in year $3 .{ }^{6}$ The first study year is especially challenging, since it has also been shown that fatigue, depression, and stage fright increase during the first year. ${ }^{7}$ Complaints are related to a lower quality of life ${ }^{8}$ and lead to considerable levels of playing-related disability for the individual music student ${ }^{6,8-10}$ and are as such a serious threat to performance quality. ${ }^{8}$

There is an increasing call for educational institutions to take their responsibility in teaching music students to take care of their health. Current health responsibility among music students is low. ${ }^{11}$ Creating awareness, providing general information on achieving and maintaining a healthy lifestyle and specific guidance on prevention and treatment of performance-related problems during student life are believed to positively influence the musician's entire career. ${ }^{11,12}$ However, only limited studies evaluating prevention programs are available ${ }^{13}$ and most of these used an observational study design, limiting conclusions. Programs offered varied from concise theoretic ${ }^{14}$ or exercises classes ${ }^{15}$, to extensive programs over the course of a semester ${ }^{16}$ or the academic year ${ }^{17,18}$ combining lectures and practical exercises. Topics frequently covered were functional anatomy and physiology, body posture while playing the instrument, practicing routines, and coping with performance. Effects varied, showing a positive effect on application of prevention strategies in daily life, ${ }^{14}$ perceived exertion, ${ }^{15}$ and mental wellbeing. ${ }^{17}$ Only one study actually found decreased physical complaints. ${ }^{18}$

In order to enhance current knowledge on effective strategies to prevent or reduce musculoskeletal complaints in music students, a randomized controlled trial was designed. As it is believed that physical and psychosocial factors are involved in the etiology of musician's musculoskeletal complaints, ${ }^{19}$ the intervention was approached from a biopsychosocial perspective. Basis is body posture while playing. A poor body posture while playing has been related to more playing-related complaints. ${ }^{13}$ Postural exercise therapy according to Mensendieck or Cesar is frequently offered for the treatment of musculoskeletal complaints in the Netherlands and Scandinavian countries. Central themes are body awareness, balanced posture and controlled movements, awareness of tension and relaxation, and functional respiration. 20,21 Postural exercise therapy has been shown to be equally effective compared to strength and fitness exercises for early, non-specific, work-related upper limb disorders in visual display unit workers. ${ }^{22}$ Principles of postural exercise therapy are adapted to the specific treatment of musicians by Samama. ${ }^{23}$ The intervention further incorporated behavioral change principles, and included themes such as dealing with stress and performance anxiety, practice behavior and pain education. To assess effectiveness, this program was 
contrasted with a control course including physical activity promotion using a daily 10,000 step approach, to stimulate physical activity up to levels as recommended for the general population. Research questions were: 1) Is participation in a biopsychosocial prevention course tailored for musicians more effective in preventing or reducing disability due to musculoskeletal disorders in music students compared to general physical activity promotion? 2) Is the biopsychosocial course also more effective in increasing quality of life, reducing playing-related complaints, and inducing a positive change in health behavior compared to physical activity promotion?

\section{Method}

\section{Design}

The PRESTO study (PREvention STudy On preventing or reducing disability from musculoskeletal complaints in music students) is a multicenter parallel-group randomized controlled trial performed at five conservatories in the Netherlands. ${ }^{24}$ An independent research assistant conducted the concealed randomization procedure by means of a computer-generated list. Randomization was stratified by conservatory with variable block sizes and a 1:1 allocation rate to avoid imbalance in groups. Students were randomized into experimental (PRESTO-Play) or control group (PRESTO-Fit). Outcomes assessors were blinded. The study protocol was published prior to study commencement. ${ }^{24}$ A process evaluation was conducted with the aim to evaluate implementation by analyzing fidelity, dose delivered, dose received, reach, recruitment and context. Results of this process evaluation will be published elsewhere. ${ }^{25}$ Intervention took place in the academic years 2012-2013 and 2013-2014 and follow up lasted to June 2016. Outcomes were measured at baseline (T0), 10 weeks (T1), 20 weeks (T2), post treatment (T3), 16-month follow-up (T4), 24-month follow-up (T5).

\section{Participants, therapists, centers}

Students were informed about the research during a lecture by the first author (VB) at start of the academic year. All participants provided written informed consent prior to randomization. Included were first year students from the academic year 2012-2013 and first and second year students from 2013-2014. All bachelor programs were included (i.e. classical music, pop/ jazz music, music in education, etc.). Excluded were students who were not able to understand Dutch or English and students with a specific comorbidity that could be associated with their complaints, such as rheumatoid arthritis, ankylosing spondylitis, or multiple sclerosis. Participants received several small incentives during the trial to stimulate trial commitment. Two conservatories provided study credits for participation. Logistics: One reminder email was sent before each class. To remind to hand in questionnaires, maximum three emails were sent by conservatory personnel or research assistants before the participants were finally called. Participants could 
stop without disclosing any reason; the moment of quitting was defined as the last completed questionnaire. Therapists of PRESTO-Play were Mensendieck or Cesar postural exercise therapists experienced in treating musicians. PRESTO-Fit therapists needed to have experience in health coaching. All therapists were trained before start and by the end of the first year to ensure fidelity to the standardized course protocol. The five participating conservatories (Academy of Music and Performing Arts Tilburg, Codarts University of the Arts Rotterdam, HKU University of the Arts Utrecht, Maastricht Academy of Music, Prince Claus Conservatoire Groningen) have different curriculums. None offered a structural obligatory health course at start of the present study.

\section{Intervention}

Experimental group (PRESTO-Play): PRESTO-Play is a biopsychosocial course tailored to music students' demands. Aim of PRESTO-Play was to create awareness on musician's health, educate on human anatomy and physiology in relation to playing the instrument (i.e. posture while playing, warming-up and cooling-down, respiration, hypermobility, practice behavior), provide strategies to cope with anxiety, stress, and over commitment, handle pain and discuss general health issues as physical activity and nutrition. The course consisted of 11 classes during one academic year. Following the I Change model, awareness, motivation, and implementation skills were incorporated to induce health behavior change. ${ }^{26}$ Focus of the first six classes was on body posture while playing. Fundamental issue of postural exercise therapy Mensendieck/ Cesar method Samama is to assume a posture that provides a stable body balance and prevents overload on all muscles used to play the instrument. ${ }^{27}$ Instrument-specific instructions were provided on playing in a biomechanically correct position..$^{23}$ From class 7 on, discussion about psychosocial themes was added. Maximum group size was 8 participants. Total time investment was 18 hours. A detailed overview of course contents is presented in table 1.

Control group (PRESTO-Fit): The PRESTO-Fit course provided education about physical activity recommendations for the general population. PRESTO-Fit was designed to control for attention. Students received a pedometer, were instructed to monitor daily physical activity and walk 10,000 steps a day, complying with the (inter)national physical activity recommendations for healthy activity behavior for the general population. The course was inspired on studies by Jackson and Howton, ${ }^{28}$ Tully and Cupples, ${ }^{29}$ and De Cocker et al. ${ }^{30}$ Over five classes during one academic year, students were encouraged to set physical activity goals, while discussing the importance of being physically fit for a musician. However, no efforts were made to induce long-term behavioral changes. Allthough short-term positive health effects of physical activity promotion in young adults have been shown, it was not expected that this program would affect long-term playing-related disability and therefore served as a control for attention. ${ }^{31}$ Maximum group size was 16 participants. Total time investment was equal to the 18 hours of PRESTO-Play, since students in PRESTO-Fit needed to practice in leisure time to increase their daily activity up to the levels as discussed in class. Course content is shown in table 2. 


\section{Outcome measures}

\section{Primary outcome}

Disability was measured using the Disabilities of Arm, Shoulder, and Hand questionnaire (DASH). The DASH is a self-reported 30-item questionnaire which assesses symptoms and functional status. Outcome is measured on a 5-point Likert scale. ${ }^{32}$ Score is transformed into a 0-100 scale, with a higher score representing more disability. Validity, test-retest reliability and responsiveness are good..$^{33}$ The DASH offers an additional performing arts module with 4 questions on disability related to playing a music instrument (range 0-100); with good internal consistency, good discriminative validity and moderate construct validity. ${ }^{34}$ Three values were further explored: 1) a dichotomous outcome performance-related disability (yes/no), defined as a positive answer on one of the questions of the performing arts module; 2 ) the total score on the performing arts module and 3) the total score on the general DASH.

\section{Secondary outcomes}

The Pain Disability Index (PDI) ${ }^{35,36}$ is a generic measure for disability, which complements the specific upper-extremity disability scoring of the DASH. Participants consider seven daily activities and report the extent to which they were disabled due to pain on a numerical rating scale (NRS) from 0 (no disability) to 10 (worst disability) for each of these activities. Total score ranges from 0 to 70. Internal consistency and validity are good. ${ }^{36}$ Quality of life was assessed using the Short Form36 Health Survey (SF-36). ${ }^{37,38}$ The SF-36 is a generic measure composed of 36 questions, organized into a physical component score (PCS) and a mental component score (MCS). Individual scores are converted into standardized scores with a mean of 50 and standard deviation of 10. Reliability and validity are good. ${ }^{38,39}$ Playing-related musculoskeletal disorders (PRMD) were defined as: "pain, weakness, lack of control, numbness, tingling, or other symptoms that interfere with your ability to play your instrument at the level you are accustomed to." ${ }^{40}$ Localization of PRMD was recorded using a drawing of the human body adapted from the McGill Pain Questionnaire. ${ }^{41}$ A NRS (0-10) was used to indicate the average, least and worst severity of complaints experienced in the past week. Health behavior was measured with a self-developed questionnaire consisting of six questions. Subjects answered over the past week, how often they would say... "You paid attention to body posture while playing music, You performed a physical warming-up before playing, You took sufficient breaks while playing, You managed stressful situations successfully, You were sufficiently physically active, You paid attention to general health." Each question was answered on a 7-point Likert scale from 1 (never) to 7 (always). The average score of the item scores was used in the analysis. An overview of primary and secondary outcome measures is presented in table 3. 
Table 1: Contents and components of the program for PRESTO-Play

\begin{tabular}{|c|c|c|}
\hline Contents & Action components & Methods \\
\hline \multicolumn{3}{|c|}{ 1. Health behavior change principles (class 1-11) } \\
\hline Awareness & $\begin{array}{l}\text { Increase knowledge about importance of posture } \\
\text { while playing } \\
\text { Provide cues to action, increase risk perception }\end{array}$ & $\begin{array}{l}\text { Standardized PowerPoint presentation } \\
\text { Semi-structured class discussions, peer model stories } \\
\text { Video of role model with physical complaints }\end{array}$ \\
\hline Motivation & $\begin{array}{l}\text { Attitudes to attention to body posture while playing } \\
\text { Social influences (norms, modelling, pressure) } \\
\text { Self-efficacy }\end{array}$ & $\begin{array}{l}\text { Semi-structured class discussions } \\
\text { Exploring assumptions } \\
\text { Individualized feedback from teacher on body posture } \\
\text { Analyzing own body posture with mirror }\end{array}$ \\
\hline Ability & $\begin{array}{l}\text { Implementation of paying attention to body posture } \\
\text { while playing }\end{array}$ & $\begin{array}{l}\text { Goal setting } \\
\text { Personal feedback } \\
\text { Semi-structured class discussions } \\
\text { Exploring barriers and facilitators }\end{array}$ \\
\hline \multicolumn{3}{|c|}{ 2. Body posture while playing (class $2-11$ ) } \\
\hline & $\begin{array}{l}\text { Anatomy and physiology of the human body } \\
\text { in relation to playing a musical instrument } \\
\text { Basic body posture } \\
\text { Postural regulation } \\
\text { Playing vs. postural muscles } \\
\text { Thoracic and abdominal muscles } \\
\text { Breathing } \\
\text { Dynamic balance } \\
\text { Hypermobility } \\
\text { Warming-up and cooling-down } \\
\text { Stretching } \\
\text { Relaxation } \\
\text { Influence of stress on your body } \\
\text { Instrument-specific biomechanics } \\
\text { Ergonomics }\end{array}$ & $\begin{array}{l}\text { Workshop } \\
\text { Individual feedback on performance posture from } \\
\text { teacher } \\
\text { Visualizing own body posture by use of mirrors } \\
\text { Analyzing each other's body postures } \\
\text { Book:"Making music without pain" } \\
\text { Homework assignments }\end{array}$ \\
\hline \multicolumn{3}{|c|}{ 3. Psychosocial aspects (class 7-11) } \\
\hline & $\begin{array}{l}\text { Practice behavior } \\
\text { Physical activity } \\
\text { Coping with stress } \\
\text { Music performance anxiety } \\
\text { Education on acute vs. chronic pain } \\
\text { Where to get help }\end{array}$ & $\begin{array}{l}\text { Workshop } \\
\text { Semi-structured class discussions on real-life situations }\end{array}$ \\
\hline
\end{tabular}

Table 2: Contents and components of the program for PRESTO-Fit

\begin{tabular}{lll}
\hline Contents & Action components & Methods \\
\hline Health behavior change principles (class 1-5) & \\
Awareness & $\begin{array}{l}\text { Increase knowledge about importance of physical } \\
\text { activity for a musician }\end{array}$ & $\begin{array}{l}\text { Video on general physical activity } \\
\text { Video on musician-specific benefits of physical activity }\end{array}$ \\
& & Assignment on calories and physical activity \\
Motivation & Peer model stories & Semi-structured class discussion \\
& & Visualizing current steps with graphs \\
Ability & Implementation of physical activity & Goal setting \\
& & Keeping step logbooks \\
& Visualizing step counts with graphs \\
& Semi-structured class discussion \\
& Count steps of frequent routes \\
& Introduction of mobile telephone apps \\
\hline
\end{tabular}


Table 3: overview of outcome measures

\begin{tabular}{|c|c|c|c|c|}
\hline Outcome measure & Measurement instrument & Abbreviation & Range & Time point \\
\hline \multicolumn{5}{|l|}{ Primary } \\
\hline Disability & $\begin{array}{l}\text { Performing arts module dichotomous } \\
\text { Performing arts module continuous } \\
\text { General DASH }\end{array}$ & $\begin{array}{l}\text { DASHd } \\
\text { DASHpa } \\
\text { DASHg }\end{array}$ & $\begin{array}{l}\text { Disability yes/no } \\
0-100 \\
0-100\end{array}$ & $\begin{array}{l}\mathrm{T} 0, \mathrm{~T} 1, \mathrm{~T} 2, \mathrm{~T} 3, \mathrm{~T} 4, \mathrm{~T} 5 \\
\mathrm{T0}, \mathrm{T} 1, \mathrm{~T} 2, \mathrm{~T} 3, \mathrm{~T} 4, \mathrm{~T} 5 \\
\mathrm{~T} 0, \mathrm{~T} 1, \mathrm{~T} 2, \mathrm{~T} 3, \mathrm{~T} 4, \mathrm{~T} 5\end{array}$ \\
\hline \multicolumn{5}{|l|}{ Secondary } \\
\hline Disability & Pain disability index & PDI & $0-70$ & $\mathrm{~T} 0, \mathrm{~T} 2, \mathrm{~T} 3, \mathrm{~T} 5$ \\
\hline Quality of life & $\begin{array}{l}\text { Short Form-36 } \\
\text { Physical component score } \\
\text { Mental component score }\end{array}$ & $\begin{array}{l}\text { SF-36 PCS } \\
\text { SF-36 MCS }\end{array}$ & $\begin{array}{l}\text { Standardized scores } \\
\text { (mean 50, SD 10) } \\
\text { Standardized scores } \\
\text { (mean 50, SD 10) }\end{array}$ & $\begin{array}{l}\mathrm{T} 0, \mathrm{~T} 2, \mathrm{~T} 3, \mathrm{~T} 5 \\
\mathrm{~T} 0, \mathrm{~T} 2, \mathrm{~T} 3, \mathrm{~T} 5\end{array}$ \\
\hline PRMD & Single question, defined by Zaza & PRMD & PRMD yes/no & $\mathrm{T} 0, \mathrm{~T} 1, \mathrm{~T} 2, \mathrm{~T} 3, \mathrm{~T} 4, \mathrm{~T} 5$ \\
\hline Health behavior & Self-developed questionnaire & $\mathrm{HB}$ & $0-7$ & T0, T2, T5 \\
\hline
\end{tabular}

\section{Other outcomes}

Recorded baseline values were sociodemographic, playing-related, general health, and personal variables. Eating habits were measured using a NRS from 0 (very unhealthy) to 10 (very healthy). Hypermobility was asked in a five-part questionnaire with good sensitivity and specificity. ${ }^{42}$ Two or more affirmative answers suggest hypermobility. ${ }^{42}$ Psychological distress was measured with the Depression, Anxiety and Stress Scale, DASS-21. ${ }^{43}$ All 21 items are answered on a 4-point Likert scale ranging from 0 (never) to 3 (always). Score is multiplied by 2, resulting in a total score range from 0 to 126. Internal consistency and reliability are good. ${ }^{43,44}$ Perfectionism was measured using the Multidimensional Perfectionism Scale ${ }^{45,46}$ using 29 items answered on a 5-point Likert scale from totally disagree agree (1) to totally agree (5), score range $29-145$. Reliability is good. ${ }^{45}$

\section{Data analysis}

Sample size: Power calculation was performed using the dichotomous outcome disability yes/ no (DASH performing arts module). Pilot data showed that approximately $50 \%$ of third-year students at Dutch conservatories experienced disabilities while playing their musical instrument. ${ }^{8}$ It was hypothesized that a $50 \%$ reduction in disability within a group would be clinically relevant. Therefore, the intervention would hypothetically reduce the disability rate to $25 \%$ in the experimental group. Based on a power calculation of proportion differences ${ }^{47}$ with a of 0.05 , power of 0.8 , proportion group 1 of 0.25 , proportion group 2 of 0.50 , and equal group sizes; a total of 65 persons per group (including continuity correction according to Yates) is needed. Taking into account a 15\% dropout rate, the total group size was set at 75 persons and thus a total sample size of 150 students. 
Statistical methods: Baseline differences between groups and between responders and non-responders were examined using independent samples t-test, Mann-Whitney $U$ test, or chi square test. To compare the two groups, intention-to-treat analysis was performed. Overall group effects on primary and secondary outcome measures were analyzed using logistic generalized estimating equations with exchangeable correlation matrix for dichotomous outcome and linear multilevel analysis with two-level structure for continuous outcomes. All analyses were adjusted for the baseline value of the outcome. Besides crude analyses, also analyses adjusted for conservatory, age, gender, and distress were performed. Between-group differences were presented as overall mean difference $(95 \% \mathrm{Cl})$ in case of continuous outcomes, or odds ratio $(95 \% \mathrm{Cl})$ for dichotomous outcome measures. Additional analyses were performed to evaluate the differences between the groups at time point T3 (end intervention) and T5 (end follow-up). This was done by adding time and the interaction between time and group to the models.

\section{Results}

\section{Flow of participants, therapists, and centers through the study}

Figure 1 presents the flow chart of the study. In total, 170 students were interested in participation. All students were found eligible and were randomized. Thirty-four students were not able to start with the course, mainly because they were not available at the time of the class, meaning that 136 students (68 to each randomized group) started the allocated intervention. From the total of 170 randomized students, 52 (61.9\%) and 50 (58.1\%) of PRESTO-Play and PRESTO-Fit, respectively, were still enrolled by the end of the intervention. Number of participants in PRESTO-Play and PRESTO-Fit was 30 (35.7\%) and 36 (41.9\%) at 16-month follow-up, and 27 (32.1\%) and 25 (29.1\%) at 24-month follow-up. Ninety-seven (57\%) participants were female. Most (91.1\%) participants were studying in year 1 at the moment of inclusion. Most participants were enrolled in the bachelor classical music (64.5\%), followed by pop/jazz (14.8\%), music in education (14.2\%), and others (6.6\%). Instruments played were strings (40\%), wind (22.4\%), keyboard (15.9\%), and percussion (10\%). Ten percent studied voice, and $1.8 \%$ conducting. Of the students who answered the baseline questionnaire, median age was 20 years (19-22.25), 57.5\% was Dutch, 29.9\% from another European country, and $12.6 \%$ from another continent. Baseline characteristics are presented in table 4. No differences in baseline characteristics between groups were found. Analyses of differences between responders and non-responders showed that males were more likely to dropout compared to females and that students from other European countries (not including the Netherlands) were the least likely to stop. Five conservatories participated in the project, 27.1\% of participants was from Utrecht, 24.1\% Groningen, 20\% Maastricht, 19.4\% Rotterdam and 9.4\% from Tilburg. This last conservatory could not recruit participants in 2013-2014 because the conservatory decided to start offering an obligatory health course to all first year students. Five therapists provided PRESTO-Play. Due to health issues, two therapists could not participate in the second recruitment year anymore. Therapists from the other conservatories took over their classes. In total seven therapists provided PRESTO-Fit, two of the original therapists were replaced in the second year because of organizational reasons. 


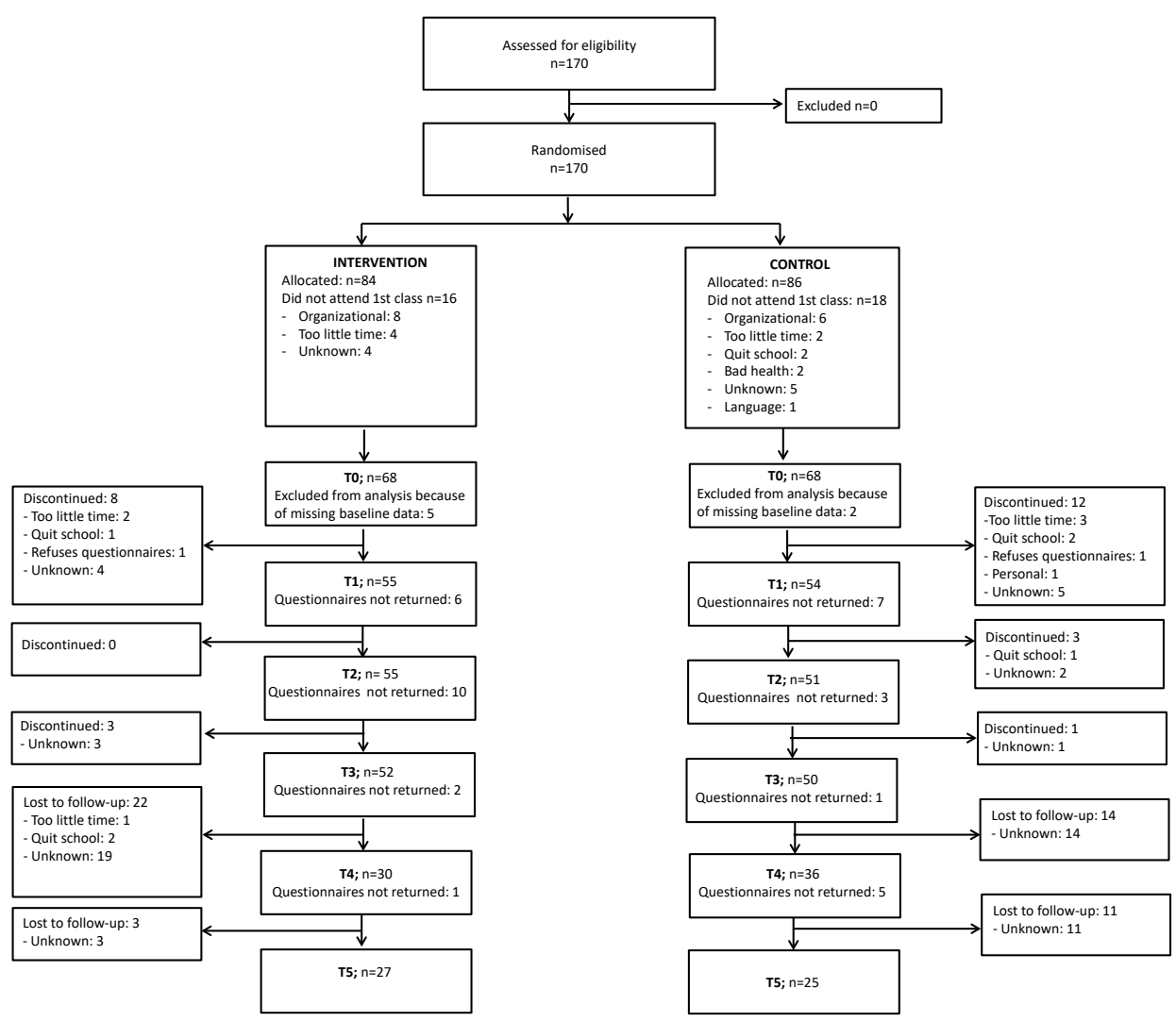

Figure 1: Flow chart 
Table 4: Baseline characteristics of participants

\begin{tabular}{|c|c|c|c|c|c|c|}
\hline & \multicolumn{3}{|c|}{ PRESTO-Play } & \multicolumn{3}{|c|}{ PRESTO-Fit } \\
\hline & $\mathbf{n}$ & n/mean/median & $\% / S D / I Q R$ & $n$ & $\mathrm{n} /$ mean/median & $\% / \mathrm{SD} / \mathrm{IQR}$ \\
\hline \multicolumn{7}{|l|}{ Sociodemographic variables } \\
\hline Gender (female) & 84 & 55 & $65.5 \%$ & 86 & 42 & $48.9 \%$ \\
\hline Age (years) & 65 & 20 & (19 to 23$)$ & 65 & 20 & (18.5 to 21.5 ) \\
\hline Body mass index & 63 & 21.03 & (19.49 to 22.89 ) & 60 & 21.46 & (20.32 to 24.08 ) \\
\hline Country & 65 & & & 62 & & \\
\hline Netherlands & & 37 & $56.9 \%$ & & 36 & $58.1 \%$ \\
\hline Other Europe & & 20 & $30.7 \%$ & & 18 & $29.0 \%$ \\
\hline Outside Europe & & 8 & $12.3 \%$ & & 8 & $12.9 \%$ \\
\hline \multicolumn{7}{|l|}{ Playing-related variables } \\
\hline Conservatory & 84 & & & 86 & & \\
\hline Rotterdam & & 16 & $19.0 \%$ & & 17 & $19.8 \%$ \\
\hline Tilburg & & 7 & $8.3 \%$ & & 9 & $10.5 \%$ \\
\hline Maastricht & & 18 & $21.4 \%$ & & 16 & $18.6 \%$ \\
\hline Groningen & & 20 & $23.8 \%$ & & 21 & $24.4 \%$ \\
\hline Utrecht & & 23 & $27.4 \%$ & & 23 & $26.7 \%$ \\
\hline Study year (year 1) & 84 & 77 & $91.7 \%$ & 86 & 77 & $89.9 \%$ \\
\hline Bachelor & 83 & & & 86 & & \\
\hline Classical music & & 60 & $71.4 \%$ & & 49 & $57 \%$ \\
\hline Music in education & & 7 & $8.3 \%$ & & 17 & $19.8 \%$ \\
\hline Pop/ jazz & & 12 & $14.3 \%$ & & 13 & $15.1 \%$ \\
\hline Other & & 4 & $4.8 \%$ & & 7 & $8.2 \%$ \\
\hline Instrument & 84 & & & 86 & & \\
\hline String & & 36 & $42.8 \%$ & & 32 & $37.2 \%$ \\
\hline Wind & & 18 & $21.6 \%$ & & 20 & $23.2 \%$ \\
\hline Keyboard & & 10 & $11.9 \%$ & & 17 & $19.8 \%$ \\
\hline Percussion & & 10 & $11.9 \%$ & & 7 & $8.2 \%$ \\
\hline Vocal & & 10 & $11.9 \%$ & & 7 & $8.2 \%$ \\
\hline Conductor & & & & & 3 & $3.5 \%$ \\
\hline Playing hours/day & 63 & & & 65 & & \\
\hline$<2$ hours & & 14 & $22.2 \%$ & & 11 & $16.9 \%$ \\
\hline $2-4$ hours & & 23 & $36.5 \%$ & & 26 & $40 \%$ \\
\hline 4-6 hours & & 22 & $34.9 \%$ & & 23 & $35.4 \%$ \\
\hline $6-8$ hours & & 4 & $6.3 \%$ & & 5 & $7.7 \%$ \\
\hline General health & 63 & & & 65 & & \\
\hline Smoke (yes) & & 10 & $16.1 \%$ & & 10 & $15.4 \%$ \\
\hline Drugs (yes) & & 6 & $9.5 \%$ & & 10 & $15.4 \%$ \\
\hline \multicolumn{7}{|l|}{ Alcohol frequency } \\
\hline Never & & 6 & $9.5 \%$ & & 6 & $10.8 \%$ \\
\hline Monthly or less & & 8 & $12.7 \%$ & & 9 & $13.8 \%$ \\
\hline $2-4$ times a month & & 27 & $42.9 \%$ & & 29 & $44.6 \%$ \\
\hline 2-3 times a week & & 18 & $28.6 \%$ & & 18 & $27.7 \%$ \\
\hline$\geq 4$ times a week & & 4 & $6.3 \%$ & & 2 & $3.1 \%$ \\
\hline Sleep (average $\geq 8$ hours per night) & 63 & 26 & $42.3 \%$ & 65 & 27 & $41.5 \%$ \\
\hline Nutrition (NRS 0-10) & 63 & 7.02 & 1.20 & 65 & 6.92 & 1.29 \\
\hline \multicolumn{7}{|l|}{ Other } \\
\hline Experienced complaints before (yes) & 63 & 51 & $82 \%$ & 66 & 52 & $80 \%$ \\
\hline Distress & 63 & 22 & (10 to 44$)$ & 66 & 24 & (8 to 36.5 ) \\
\hline Hypermobility (yes) & 63 & 27 & $42.9 \%$ & 66 & 25 & $37.9 \%$ \\
\hline Perfectionism & 61 & 71.59 & 13.56 & 66 & 69.76 & 16.34 \\
\hline
\end{tabular}

Numbers presented are $\mathrm{N}(\%)$, mean with standard deviation (SD) or median with interquartile range (IQR) 


\section{Compliance with the trial method}

Recruitment period did not diverge from intended. In both groups, several classes were rescheduled because they conflicted with project weeks, exams or holidays. Three PRESTO-Play and one PRESTO-Fit class were cancelled. On average 55\% of the students were present in PRESTO-Play, $60 \%$ in PRESTO-Fit. Blinding of outcomes assessor was successful. The majority of the students, 67\% in PRESTO-Play and 63\% in PRESTO-Fit, reported not to have heard about the contents of the course they were not allocated to. Numbers of students admitting to other therapy (i.e. physiotherapy) or taking part in other health classes (i.e. Alexander technique) did not differ between groups by the end of the intervention period.

\section{Differences in disability}

Percentage of students with performance-related disability changed from $66.7 \%$ at baseline to $44.4 \%$ at the end of follow-up in PRESTO-Play and from $78.8 \%$ to $40 \%$ in PRESTO-Fit. Performing arts module score changed from a median of 12.5 (0-31.25) to 0 (0-6.25) in PRESTO-Play and from 18.75 (6.25 - 32.81) to 0 (0-25) in PRESTO-Fit. General DASH changed from a median of $7.5(3.33-15.83)$ to $2.5(0-8.33)$ and from 8.33 (3.33-14.17) to 3.45 (0 -12.08) in PRESTO-Play and PRESTO-Fit, respectively. See table 5 . No significant differences were observed between the groups. Also for the secondary outcomes as well as for the differences at T3 and T5 no significant differences were found (table 6). 


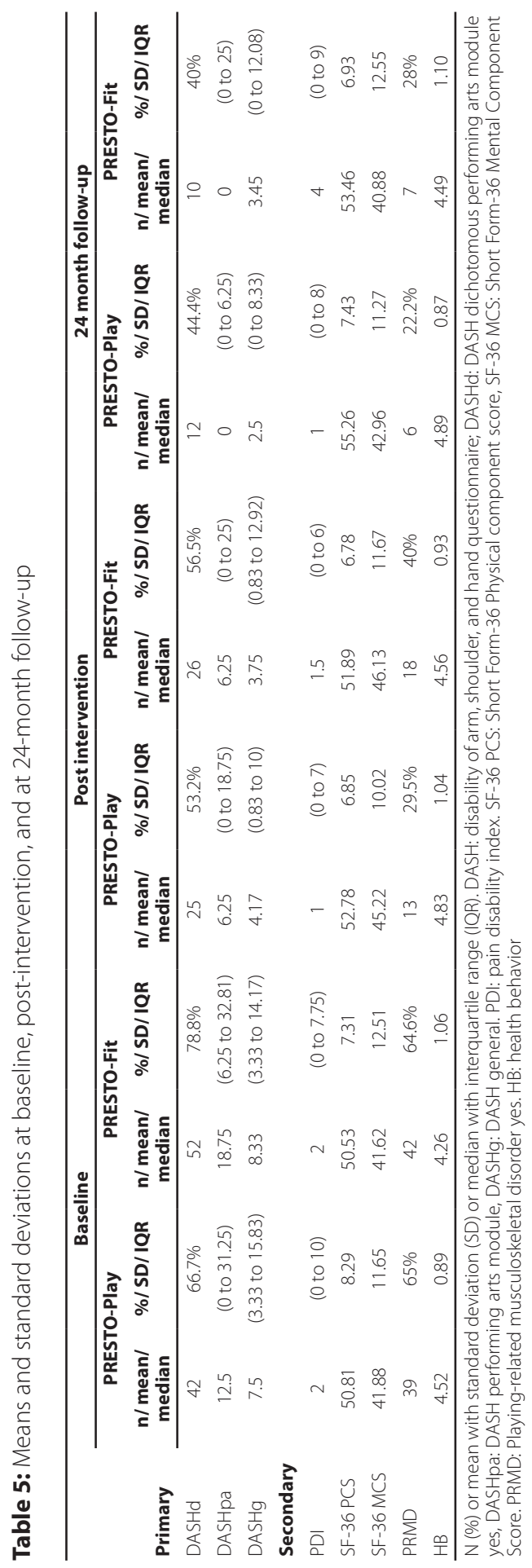




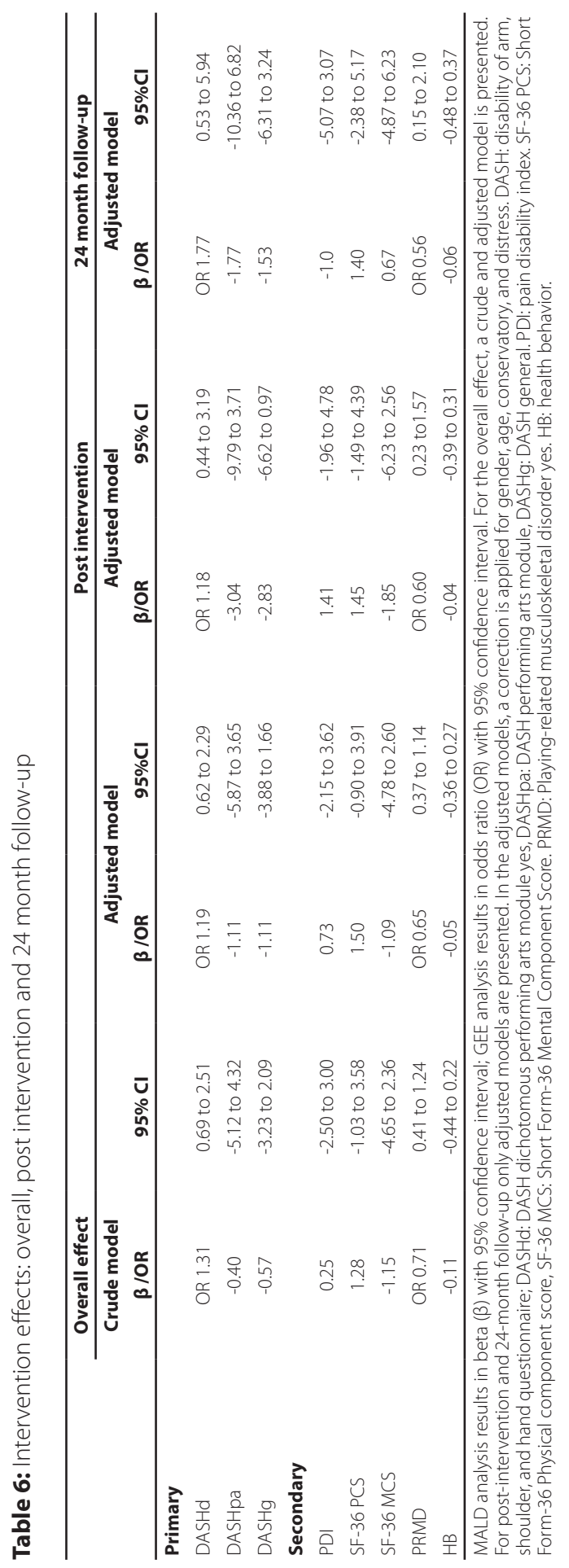




\section{Discussion}

This randomized controlled trial did not show differences in changes in disability or any other secondary outcome between PRESTO-Play and PRESTO-Fit. The biopsychosocial course was designed intending to induce a change in behavior, to teach students how to play in a biomechanically optimal posture and learn how to cope with the mental challenges of being a musician. Although the protocol was based on current evidence and clinical expertise, this pragmatic trial reflecting real practice did not result in the expected better results of the biopsychosocial PRESTO-Play course tailored for musicians as compared to the general PRESTO-Fit course, which was designed to control for attention. This could be due to four reasons: 1) results are hampered by the large number lost to follow-up; 2) the interventions were not implemented as intended; 3 ) the control group was also effective; 4) the outcome measures used were not sensitive enough to detect change.

First, numbers of loss to follow-up were high, and a selection bias cannot be ruled out. However, dropouts were equal between groups and the multilevel analysis used accounted for missing values. Unfortunately, these numbers of lost to follow-up are common in this population. ${ }^{6}$ Although a large amount of effort was undertaken to keep students actively engaged in the study, it was concluded in the process evaluation that music students prioritize music-related activities over health class and that engagement of the conservatory is paramount to success. Motivation and relevance seem key items in inducing health behavior change in this population. ${ }^{25}$

Second, in PRESTO-Play, behavioral change principles were not implemented fully as intended. External cues to action as delivered in this group setting might not have been sufficiently effective to engage in healthier behavior. ${ }^{25}$ Role models, and foremost, internal motivation by actually experiencing complaints that seriously disable the music performance, are likely to be more successful in inducing health behavior change. ${ }^{48}$ Further, it was not examined whether students truly generalized the preventive aspects in their regular routine. Additionally, the process evaluation also showed that psychosocial themes might have not been implemented optimally in PRESTO-Play and that inadequate fidelity in both groups and too little contrast between interventions could have further influenced results. ${ }^{25}$

Third, we could have underestimated the beneficial effect of physical activity promotion on musician's health, implying that education on the importance of physical activity for a musician might also be a good intervention to decrease disability. Next to the beneficial effect of physical activity on musculoskeletal complaints, ${ }^{49}$ participation in the current study increased awareness on the importance of healthy music making for participants in both PRESTO-Play and PRESTO-Fit since the trial was the only structural health course at the participating conservatories. Awareness is an important factor in health behavior change and it might have been that the selected population that remained in our trial was stimulated to take action to improve their health status, just by raising awareness on the issue. Future studies should elaborate on the role of awareness in the prevention of musculoskeletal complaints in music students. Notwithstanding the loss to follow-up and possible selection bias, results revealed that disability declined in both groups throughout the intervention and during follow-up. However, design of this study does not permit to conclude whether this is an intervention effect or natural course. Our pilot study among 
third and fourth year students in 2012 showed that the disability level was 52\%, with a median performing arts module score of $6.25(0-25) .{ }^{8}$ The disability levels of the primarily third year students after participation in the current trial were $44 \%$ and $40 \%$, with median performing arts module scores about a quartile lower compared to the pilot study, suggesting that both interventions could have reduced disability. This assumption is supported by the fact that the percentage change in disability level between start of the study and at 24 month follow-up almost reached to the a priori hypothesized clinically relevant reduction of 50\%. Thus, it is plausible that both PRESTO-Play and PRESTO-Fit were effective in reducing disability.

Fourth, a limitation is that disability values were in general quite low and it can be questioned whether the outcome measures used were sensitive enough to pick up relevant changes in disability in this specific population functioning at elite level. ${ }^{34}$ This single RCT does not permit to draw conclusions on what is the best way to prevent musculoskeletal disorders in musicians. As our results suggest that both a tailored biopsychosocial and physical activity promotion program are able to influence musician's disability, it is important to find out what the exact working mechanisms are to be able to improve future interventions.

In conclusion, a biopsychosocial prevention course tailored for musicians was not superior to physical activity promotion in reducing disability. Interestingly, disability declined in both groups throughout the intervention and up to 2 years of follow-up. Design of the current study does not permit to conclude whether this is an intervention effect or natural course. Future studies should incorporate a non-participant control group to be able to detect health benefits over natural course. 


\section{References}

1. Konczak J, Vander Velden H, Jaeger L. Learning to play the violin: motor control by freezing, not freeing degrees of freedom. J Mot Behav. 2009;41(3):243-52.

2. Rickert DL, Barrett MS, Ackermann BJ. Injury and the orchestral environment: part I. The role of work organisation and psychosocial factors in injury risk. Med Probl Perform Art. 2013;28(4):219-29.

3. Kok LM, Huisstede BM, Voorn VM, Schoones JW, Nelissen RG. The occurrence of musculoskeletal complaints among professional musicians: a systematic review. Int Arch Occup Environ Health. 2016;89(3):373-96.

4. Kok LM, Vlieland TP, Fiocco M, Nelissen RG. A comparative study on the prevalence of musculoskeletal complaints among musicians and non-musicians. BMC Musculoskelet Disord. 2013;14:9.

5. Spahn C, Strukely S, Lehmann A. Health conditions, attitudes toward study, and attitudes toward health at the beginning of university study: music students in comparison with other student populations. Med Probl Perform Art. 2004;19:26-33.

6. Spahn C, Voltmer E, Mornell A, Nusseck M. Health status and preventive health behavior of music students during university education: Merging prior results with new insights from a German multicenter study. Musicae Scientiae. 2017; 21(2):213-29.

7. Hildebrandt H, Nübling M, Candia V. Increment of Fatigue, Depression, and Stage Fright During the First Year of High-Level Education in Music Students. Med Probl Perform Art. 2012;27(1):43-8.

8. Baadjou VA, Verbunt JA, van Eijsden-Besseling MD, Huysmans SM, Smeets RJ. The Musician as (In)Active Athlete? Exploring the Association Between Physical Activity and Musculoskeletal Complaints in Music Students. Med Probl Perform Art. 2015;30(4):231-7.

9. Barton R, Killian C, Bushee M, Callen J, Cupp T, Ochs B, et al. Occupational performance issues and predictors of dysfunction in college instrumentalists. Med Probl Perform Art. 2008;23:72-8.

10. Rodriguez-Romero B, Perez-Valino C, Ageitos-Alonso B, Pertega-Diaz S. Prevalence and Associated Factors for Musculoskeletal Pain and Disability Among Spanish Music Conservatory Students. Med Probl Perform Art. 2016;31(4):193-200.

11. Kreutz G, Ginsborg J, Williamon A. Health-promoting behaviours in conservatoire students. Psychol Mus. 2009;37(1):47-60.

12. Williamon A, Thompson S. Awareness and incidence of health problems among conservatoire students. Psychol Mus. 2006;34:411-30.

13. Blanco-Pineiro P, Diaz-Pereira MP, Martinez A. Musicians, postural quality and musculoskeletal health: A literature's review. J Bodyw Mov Ther. 2017;21(1):157-72.

14. Barton R, Feinberg JR. Effectiveness of an educational program in health promotion and injury prevention for freshman music majors. Med Probl Perform Art. 2008;23:47-53.

15. Ackermann BPT, Adams R, Marshall EMPH. Strength of endurance training for undergraduate music majors at a university? Med Probl Perform Art. 2002;17:33-41.

16. Spahn C, Hildebrandt $H$, Seidenglanz K. Effectiveness of a prophylactic course to prevent playing-related health problems of music students. Med Probl Perform Art. 2001;14:24-31.

17. Zander MF, Voltmer E, Spahn C. Health promotion and prevention in higher music education. Results of a longitudinal study. Med Probl Perform Art. 2010;25:54-65. 
18. Martin Lopez T, Farias Martinez J. Strategies to promote health and prevent musculoskeletal injuries in students from the high conservatory of Salamanca, Spain. Med Probl Perform Art. 2013;28(2):100-6.

19. Baadjou VA, Roussel NA, Verbunt JA, Smeets RJ, de Bie RA. Systematic review: risk factors for musculoskeletal disorders in musicians. Occup Med. 2016;66(8):614-22.

20. Haugstad GK, Haugstad TS, Kirste UM, Leganger S, Klemmetsen I, Malt UF. Mensendieck somatocognitive therapy as treatment approach to chronic pelvic pain: Results of a randomized controlled intervention study. Am J Obstet Gynecol 2006;194:1303-10.

21. Haugstad GK, Haugstad TS, Kirste UM. Continuing improvement of chronic pelvic pain in women after short-term Mensendieck somatocognitive therapy: results of a 1-year follow-up study. Am J Obstet Gynecol 2008;199:615.

22. van Eijsden-Besseling MD, Staal JB, van Attekum A, de Bie RA. No difference between postural exercises and strength and fitness exercises for early, non-specific, work-related upper limb disorders in visual display unit workers: a randomised trial. Aust J Physiother. 2008;54(2):95-101.

23. Samama ALW. Making music without pain. Assen, The Netherlands: Van Gorcum; 1998.

24. Baadjou VA, Verbunt JA, Eijsden-Besseling MD, Samama-Polak AL, Bie RA, Smeets RJ. PREvention STudy On preventing or reducing disability from musculoskeletal complaints in music school students (PRESTO): protocol of a randomised controlled trial. J Physiother. 2014;60(4):232.

25. Baadjou VAE, Ackermann B, Verbunt JAMCF, Eijsden-Besseling van MDF, Bie de RA, Smeets RJEM. External validation and process evaluation of a health promotion and injury prevention intervention in music students: Lessons learnt from the PRESTO trial. submitted

26. de Vries H, Mudde A, Leijs I, Charlton A, Vartiainen E, Buijs G, et al. The European Smoking prevention Framework Approach (EFSA): an example of integral prevention. Health Educ Res. 2003;18(5):611-26.

27. Baadjou VAE, Eijsden-Besseling van MDF, Verbunt JAMCF, Bie de RA, Geers RPJ, Smeets RJEM, et al. Playing the clarinet: influence of body posture on muscle activity and sound quality. Med Probl Perform Art. 2017; 32(3):125-31.

28. Jackson EM, Howton A. Increasing Walking in College Students Using a Pedometer Intervention: Differences According to Body Mass Index . J Am Col Health. 2008;57(2):159-64.

29. Tully MA, Cupples M. UNISTEP (university students exercise and physical activity) study: a pilot study of the effects of accumulating 10.000 steps on health and fitness among university students. J Phys Act H. 2011;8(5):663-7.

30. de Cocker KA, De Bourdeaudhuji IM, Bron WK, Cardon GM. Effects of' 10.000 steps Ghent': a whole-community intervention. Am J Prev Med. 2007;33(6):455-63.

31. Sluijs van EMF, Kriemler S. Reflections on physical activity intervention research in young people - dos, don'ts, and critical thoughts. Int J Behav Nutr Phys Act. 2016:25.

32. Hudak PL, Amadio PC, Bombardier C. Development of an upper extremity outcome measure: the DASH (disabilities of the arm, shoulder and hand). Am J Ind Med. 1996;29:602-8.

33. Beaton DE, Katz JN, Fossel AH, Wright JG, Tarasuk V, Bombardier C. Measuring the whole or the parts? Validity, reliability, and responsiveness of the Disabilities of the Arm, Shoulder and Hand Outcome measure in different regions of the upper extremity. J Hand Ther. 2001;14(2):128-46.

34. Baadjou VAE, Bie de RA, Guptill C, Smeets RJ. Psychometric properties of the performing arts module of the Disabilities of the Arm, Shoulder and Hand questionnaire. Disabil Rehabil. 2017.16:1-7.

35. Pollard CA. Preliminary validity study of Pain Disability Index. Percept Mot Skills. 1984;59:974. 
36. Tait CR, Chibnall JT, Krause S. The Pain Disabilithy Index: psychometric properties. Pain. 1990;40:171-82.

37. Ware JE, Jr., Sherbourne CD. The MOS 36-item short-form health survey (SF-36). I. Conceptual framework and item selection. Med Care. 1992;30(6):473-83.

38. Aaronson NK, Muller M, Cohen PD, Essink-Bot ML, Fekkes M, Sanderman R, et al. Translation, validation, and norming of the Dutch language version of the SF-36 Health Survey in community and chronic disease populations. J Clin Epidemiol. 1998;51(11):1055-68.

39. McHorney CA, Ware JEJ, Lu JF, Sherbourne CD. The MOS 36-item Short-Form Health Survey (SF-36): III. Tests of data quality, scaling assumptions, and reliability across diverse patient groups. Med Care. 1994;32(1):40-66.

40. Zaza C, Charles C, Muszynski A. The meaning of playing-related musculoskeletal disorders to classical musicians. Soc Sci Med. 1998;47(12):2013-23.

41. Vanderiet K, Adriaensen H, Carton H, Vertommen H. The McGill Pain Questionnaire constructed for the Dutch language (MPQ-IN). Preliminary data concerning reliability and validity. Pain. 1987;30:395-408.

42. Hakim AK, Grahame R. A simple questionnaire to detect hypermobility: an adjunct to the assessment of patients with diffuse musculoskeletal pain. Int J Clin Pract. 2003;57:163-6.

43. Henry JD, Crawford JR. The short-form version of the Depression Anxiety Stress Scales (DASS-21): Construct validity and normative data in a large non-clinical sample. Br J Clin Psychol. 2005;44:227-39.

44. Silva HA, Passos MH, Oliveira VM, Palmeira AC, Pitangui AC, Araujo RC. Short version of the Depression Anxiety Stress Scale-21: is it valid for Brazilian adolescents? Einstein (Sao Paulo). 2016;14(4):486-93.

45. Frost RO, Marten PA, Lahart C, Rosenblate R. The dimensions of perfectionism. Cogn Ther Res. 1990;14:449-68.

46. Flos CHGM. Validity and reliability of the Frost Multidimensional perfectionism Scale. Maastricht: Maastricht University; 1998.

47. Fleiss JL. Statistical methods for rates and proportions. 3th edition ed. New Yotk: John Wiley \& Sons; 2003.

48. Spahn C, Burger T, Hildebrandt H, Seidenglanz K. Health locus of control and preventive behaviour among students of music. Psychol Mus. 2005;33:256-68.

49. Guddal MH, Stensland SO, Smastuen MC, Johnsen MB, Zwart JA, Storheim K. Physical Activity Level and Sport Participation in Relation to Musculoskeletal Pain in a Population-Based Study of Adolescents: The Young-HUNT Study. Orthop J Sports Med. 2017;5(1):2325967116685543. 



\title{
Chapter 9
}

\section{External validation and process evaluation of a health promotion and injury prevention progam in music students: Lessons learnt from the PRESTO trial}

\author{
Baadjou VA, Ackermann B, Verbunt JA, van Eijsden-Besseling MD, \\ de Bie RA, Smeets RJ. External validation and process evaluation \\ of a health promotion and injury prevention course in music \\ students: Lessons learnt from the PRESTO trial. Submitted
}




\section{Abstract}

Objectives: A randomized controlled trial (PRESTO) was conducted comparing the effects of a biopsychosocial course (PRESTO-Play) versus physical activity promotion (PRESTO-Fit) to prevent or reduce disability related to musculoskeletal disorders in music students. The current study provides an external validation of the study protocol and evaluates the implementation process of interventions, allowing for a better interpretation of results, and providing recommendations for future trials.

Methods: A group of experts was asked to complete a structured evaluation of design and content of the trial. Additionally, fidelity, dose delivered, dose received, reach, and context were evaluated. Quantitative and qualitative data was analyzed from different stakeholders (students, therapists, conservatory staff) using questionnaires, logs, field notes and emails.

Results: Although no difference in disability was found between interventions, closer evaluation revealed that participants in PRESTO-Play reported that they learned about prevention of physical complaints and rated the course significantly higher compared to the participants of PRESTO-Fit. The study design and contents of the interventions were found to be valid, with an appropriate dose delivered. Feedback from students and logs suggested that behavioral change and psychosocial principles in PRESTO-Play might have not been implemented optimally. Only moderate fidelity in both groups and too little contrast between interventions could have influenced results. Low attendance rates and a presumed lack of generalization further decreased possible effectiveness. Context greatly influenced implementation.

Conclusion: Implementing a future health course with closer collaboration with the institution could optimize accessibility and communication, encourage attendance, and enhance motivation for behavioral change. 


\section{Introduction}

Music students are at increased risk compared to non-music students of developing musculoskeletal complaints.' Music education in conservatories is dedicated to learning to play the musical instrument in the most virtuosic way. Musicians' health is of significant importance to performance quality due to the very high physical and mental skills required to excel; however, current health responsibility and health-promoting behavior in conservatory students are low. ${ }^{2}$ Therefore, it seems logical to address health and injury prevention during conservatory studies. Recently, a multicenter randomized controlled trial (RCT) was conducted at five Dutch conservatories to study the effectiveness of a biopsychosocial prevention course, compared to physical activity promotion, to prevent or reduce disability due to musculoskeletal disorders in music students: the "PREvention STudy On preventing or reducing disability from musculoskeletal complaints in music students", or "PRESTO" trial. The study protocol and results of the trial have been published elsewhere.,4 Included were 170 first and second year students who were randomly allocated and stratified by conservatory, to either experimental (PRESTO-Play) or control condition (PRESTO-Fit). The aim of PRESTO-Play was to educate students about body posture while playing the instrument, and to discuss psychosocial aspects related to the musician's health, while incorporating health behavior change principles. PRESTO-Fit was designed to control for attention and aimed at stimulating physical activity levels using a 10,000 step per day approach according Dutch guidelines for activity promotion for the general population. The courses were implemented as voluntary extra-curricular classes for music students during the first or second academic year in either 2012-2013 or 2013-2014. Time spent on both interventions was aimed to be equal, about 18 hours in total, with PRESTO-Play consisting of 11 classes, and PRESTO-Fit of 5 classes with additional time spent increasing daily activity level in leisure time. For further details see reference 4. Rationale for PRESTO-Play and PRESTO-Fit were supported by current literature and clinical experience. PRESTO-Play was provided by experienced postural exercise therapists Mensendieck/ Cesar, method Samama, and PRESTO-Fit by therapists with an affinity for physical activity education. All therapists were trained to follow a standardized protocol before the start of the first and second inclusion year. Outcomes were measured using questionnaires at baseline, during and at the end of the intervention, and at 16- and 24 month follow-up. By the end of the intervention, $62 \%$ and $58 \%$ of PRESTO-Play and PRESTO-Fit participants respectively were still enrolled in the trial. At 2-year follow-up, participation rate had dropped to 32\% and 29\% for PRESTO-Play and PRESTO-Fit respectively. Intention-to-treat analysis revealed that during the intervention and until the end of follow-up, there was no difference in disability between both interventions. Disability declined over 2 years with 33\% in PRESTO-Play and 49\% in PRESTO-Fit.

When conducting a multicenter, multifaceted trial in daily practice, a wide variety of factors is encountered during execution and follow-up that may influence study findings and outcomes. To be able to interpret results correctly, it is therefore important to evaluate study design and contents of the intervention under study, and to examine how the interventions were actually implemented. ${ }^{5}$ Independent external review may reveal strengths and weaknesses of the trial, and more specifically the content of treatments provided. In addition, including comprehensive views of all possible stakeholders provides valuable additional information on barriers and facilita- 
tors of implementation. The aim of the current study was to evaluate the PRESTO trial by answering two questions: 1) Were study design and contents of the interventions valid? 2) Were the interventions implemented as intended? This information can be used to better interpret trial results and inform future researchers.

\section{Methods}

\section{External validation}

An independent external review of the study protocol and contents of interventions was performed to assess external validity of the study. Experts were defined as researchers experienced in project design, exercise interventions, or musician's health and were approached for participation by the second author (BA). They were not involved in the PRESTO trial. Experts had to rate their own competency regarding these 3 themes on a 0 to 10 scale from no experience at all to highly specialized. Only researchers who reported a summed score of 8 / 30 or higher were included. The principal investigator (VB) presented a detailed standardized overview on study design, intervention contents and implementation of the trial. A questionnaire was designed and distributed prior to the presentation, to be completed during and immediately after the presentation (Appendix 1). The analysis focused on key themes from the interventions: body posture while playing, health behavior change, psychosocial aspects, and physical activity promotion. We expected that 10 experts would be needed to provide valuable feedback.

\section{Process evaluation}

The process evaluation included both formative and summative purposes and was inspired on work of Steckler and Linnan, ${ }^{6}$ Baranowski and Stables, ${ }^{7}$ and Saunders et al. ${ }^{8}$ The process evaluation intended to answer 5 key questions:

- To what extent was the intervention implemented as planned? (fidelity)

- To what extent were classes provided as planned? (dose delivered)

- How was the course received by the students? (dose received)

- What proportion of students participated in the study? (reach)

- Which aspects may have influenced the implementation? (context)

Stakeholders included music students, therapists, and conservatory staff engaged in the trial. Feedback was collected by questionnaire, logs, field notes, and email correspondence. Music students: Trial participants completed a process evaluation questionnaire by the end of the intervention, asking a range of questions, i.e. how the course was received, including key messages, grading the overall course ( 0 very bad - 10 very good), and describing reasons for being absent in class. A contamination check was performed by asking: "Did you discuss the contents of this course with students who participated in the other course?" and "Did you hear from students who participated in the other course about the contents of that course?". 
Therapists: Therapists kept a log of their courses, where components covered in class were ticked off and remarks could be made. At the end of the first and second intervention year, logs were evaluated, and the contents of the classes and experiences of the therapists were discussed in workshops to evaluate their perceptions of course efficacy and relevance. The principal researcher (VB) took field notes of these discussions and other verbal communication throughout the study.

Conservatory staff: At the end of year 1 and 2, evaluation meetings with conservatory staff engaged in the trial were scheduled. This was done to maintain conservatory engagement with the trial as well as being an opportunity to receive feedback on implementation. Field notes of these discussions and other verbal communication throughout the study were collected.

\section{Analyses}

Data included a mix of quantitative and qualitative data. Quantitative results were presented descriptively as means \pm standard deviations (SD) when normally distributed, and medians (interquartile ranges) when skewed. Differences between groups were investigated using independent samples t-tests or Mann-Whitney-U-test, for normal and non-normal distributed data respectively. Statistical testing was performed using IBM SPSS Statistics for Windows, version 23 (IBM Corp., Armonk, N.Y., USA). Qualitative data were provided in feedback from different stakeholders and were read thoroughly. Key responses were described. Two authors (VB and BA) independently evaluated and discussed results that progressed into themes. Citations were selected following this structured, themes-based approach.

\section{Results}

\section{Participants}

External validation: Fourteen experts participated in the expert review. Their median experience in research design was 7 IQR 5-8, exercise intervention 7 IQR $4.75-8.25$, and musician's health 5 IQR 0.75-8.5.

Process evaluation: In total, 88 process evaluation questionnaires (42 PRESTO-Play and 46 PRESTO-Fit) were available for analysis. Five experienced postural exercise therapists Mensendieck/ Cesar method Samama delivered PRESTO-Play. Seven therapists delivered PRESTO-Fit; they were physiotherapists (3), Alexander technique teachers (2), a postural exercise therapist without experience in treating musicians (1) and a movement scientist (1). All therapists' logbooks were analyzed and all therapists participated in the evaluation meetings. Five evaluation meetings were organized with the conservatory staff involved in local implementation of the trial.

External validation: An overview of frequencies of responses to the validation questionnaire is presented in Appendix 1. In summary, reviewers found the design of the trial appropriate for the research goal. Considering PRESTO-Play, general consensus existed on the appropriateness and relevance of contents covered in the course, which seemed "an appropriate comprehen- 
sive biopsychosocial approach." More specifically, 11 reviewers found the approach according to postural exercise therapy Mensendieck/ Cesar, method Samama feasible. However, four questioned the rationale of the spinal biomechanical principal as applied by Samama. Ten reviewers found the application of behavioral change principles in the course appropriate. The majority of the experts expected that PRESTO-Play would be likely to change behavior and diminish playing-related disability. However, six reviewers thought that PRESTO-Fit also would be likely to affect playing-related disability: "There is some evidence that cardiovascular fitness has some value in improving endurance \& some psychological benefits"; and 5 reviewers hypothesized that there was potentially too little contrast between PRESTO-Play and PRESTO-Fit. There was lack of consensus amongst experts regarding the psychological aspects of the experimental condition. While 50\% thought psychosocial aspects were covered adequately, others felt that the therapists were not adequately skilled to deliver this part of the intervention "Physiotherapists are not expertly trained in behavior change" and that psychosocial factors should better be evaluated individually "group programs do not allow for individual risks and resilience factors to be explored."

\section{Process evaluation}

- To what extent was the intervention implemented as planned? (Fidelity)

Analysis of logbooks showed that key themes, i.e. body posture while playing in PRESTO-Play and physical activity promotion in PRESTO-Fit, were delivered in accordance with the protocol. For PRESTO-Play only minor differences in timing and structure of the information on postural technique occurred. However, analysis of logbooks showed that health behavior change aspects were insufficiently incorporated in year 1 . Therefore a workshop was organized to improve knowledge and implementation skills which resulted in optimized understanding of teaching health behavior change in year 2 , which was reflected in a higher number of incorporated aspects in class reflected by the therapists' logbooks. For PRESTO-Fit, it was noticed during the evaluation meeting that four therapists had provided some extra information regarding physical activity promotion that was not incorporated in the course protocol. Therapists in both conditions reported that the group aspect of the course was of additional value, stimulating discussions, creating an open atmosphere to talk about playing-related problems, particularly in PRESTO-Play with more face to face classes. Two therapists from PRESTO-Play suggested providing handouts of psychosocial aspects covered in class. It was also suggested that recording body posture at the start and the end could help students visualize any postural changes. Considering contamination, the majority of the participants, 67\% in PRESTO-Play and 63\% in PRESTO-Fit, reported not to have heard about the contents of the course they were not allocated to.

- To what extent were classes provided as planned? (Dose delivered)

In both groups, several classes were rescheduled because they were first planned during project weeks, exams, holidays, etc. Only 3 out of a total of 99 PRESTO-Play classes and 1 out of 45 PRESTO-Fit classes were cancelled. Questionnaires were long and took more time to complete than expected, which then had an impact on the time for delivery of class contents. Therapists reported in the evaluation meetings that they felt that the questionnaires demotivated students. 
- How was the course received by the students? (Dose received)

Participants in PRESTO-Play awarded the course with a mean score of $7.71 \pm 1.63$. Students found that key themes of the classes were discussed at least moderately sufficient. The three most sufficiently discussed items were body posture while playing a musical instrument, body posture in general, and warm-up and cool-down. The three items, which were least sufficiently discussed, were care (Where can I get help when needed?), (performance) anxiety, and stress. Students agreed most with the statements that the course helped to recognize more of the benefits of healthy music making, that they learned new things about prevention of physical complaints related to music making, and they found that the course was an addition to education. (Table 1) Student 1: "I'm focusing more on my attitude than before. And I also started interval training and exercises for my back. So thank you for mentioning these physical aspects of musicianship."

Participants in PRESTO-Fit rated the course with a mean score of $6.02 \pm 1.91$, which was significantly lower than PRESTO-Play. However, some benefits of the generic physical activity were still noted by some, with one student reporting:

Student 2: "The course made me much more aware of the importance to be physically active; I make regular lunch walks now and started yoga."

Students in PRESTO-Fit indicated that the importance of physical activity was sufficiently discussed, however, scores were low when asked whether they had learned new things about physical activity. (Table 2) Compared to PRESTO-Play, participants in PRESTO-Fit scored significantly lower on the following aspects: "The course is an addition to my education", "I learned from the discussions in class", "I would recommend this course to my friends", "The course was fun." (Table 3) Verbal comments from students and therapists during the trial revealed that at start of PRESTO-Fit, students found walking daily routes and the movies shown were interesting, however, a common remark was that participants were disappointed that they did not receive specific advice on body posture while playing, and started looking for other ways to get such advice.

One PRESTO-Fit therapist, who was an Alexander teacher at that conservatory, reported:

Therapist 1:"A number of students now also follow Alexander lessons. They like the individual attention and the possibility to discuss their problems in more depth." 
Table 1: Student evaluation of contents: PRESTO-Play

\begin{tabular}{lcc}
\hline $\begin{array}{l}\text { Do you think that the following aspects were sufficiently } \\
\text { discussed? (0 not sufficient-5 sufficient) }\end{array}$ & Mean & SD \\
\hline General information about the human body & 3.79 & 1.03 \\
General information about physical complaints related to playing a musical instrument & 4.05 & 0.84 \\
Body posture in general & 4.55 & 0.63 \\
Body posture while playing a musical instrument & 4.61 & 0.63 \\
Warm-up and cool-down & 4.48 & 0.55 \\
Ergonomics & 3.93 & 0.82 \\
Practice behavior & 3.83 & 0.88 \\
Physical activity & 3.79 & 1.03 \\
Stress & 3.57 & 1.04 \\
(performance) Anxiety & 3.37 & 1.16 \\
Care (where can I get help when needed) & 3.27 & 0.95 \\
\hline
\end{tabular}

Table 2: Student evaluation of contents: PRESTO-Fit

\begin{tabular}{lcc}
\hline $\begin{array}{l}\text { Do you think that the following aspects were sufficiently } \\
\text { discussed? ( } 0 \text { not sufficient-5 sufficient) }\end{array}$ & Mean & SD \\
\hline Importance of physical activity & 4.00 & 0.91 \\
What is the Dutch guideline for physical activity? & 3.73 & 1.01 \\
How to increase physical activity? & 3.87 & 0.87 \\
How to stay active in the future & 3.69 & 0.95 \\
\hline
\end{tabular}

- What proportion of students participated in the study? (Reach)

Inclusion was performed at five conservatories in year 1. In year 2, one conservatory introduced obligatory health classes for first year students in their curriculum, which could have contaminated study results; therefore it was decided to exclude that conservatory from further recruitment in the second year. When implementing the classes, conservatories tried to find a free time period in which all students could participate. However, since students of different bachelor programs with different course schemes were included, this was practically impossible. Some $20 \%$ of randomized students had already dropped out between randomization and start of the first class, just because they were not able to attend the class at the time scheduled. The most common reasons for dropout at this stage were related to other activities for school or work, such as principal subject class, orchestra rehearsals, or teaching. For example, students reported in the email correspondence:

Student 3: "I have cello class then. If it'll be on a different day in the future I would love to join (it's something that's really interesting for me)."

Student 4: "I work on Friday afternoon, so I won't be able to come." 
Student 5: "I am sorry but I will not be able to come to the classes! And I think if the classes were later at the day more people would come, this is really early for musicians."

Student 6: "My schedule has been changed, I have theory class now at the same time. Although I would like to participate in class. What shall I do?"

Class attendance rate was on average 55\% in PRESTO-Play, and 60\% in PRESTO-Fit. Small incentives such as chocolate, and raffling tickets for a music festival did not seem very effective in stimulating the students to keep participating in the study, whereas providing study credits for participation lead to a higher attendance rate. The two conservatories that provided study credits reported the highest overall attendance rates (i.e. 66\% and 63\%). Emails from absent students indicated that activities as masterclasses, orchestra rehearsals, studying for exams, or rescheduling of their principal subject class prevented them from being able to attend the PRESTO course. Other students reported organizational reasons that led them to be unable to attend:

Student 7: ".. I want to sincerely apologize for not responding to your e-mails and forgot to cancel class. It's just that I can't see the forest for the trees now with all these reports, appointments, auditions, exams, etc...."

Student 8: "Please forgive my late response, dealing with musicians is horrible I know, I am having my exam tomorrow and I was travelling for concerts-very busy time, could you please send me a copy of the questionnaire in this travelling-hectic time I put it into one of my bags to fill it in and I'm unable to find it. I'm so sorry. But I want to keep doing it. After tomorrow I will keep on track of this and so many other things are hanging in the waiting list."

Student 9: "Oh, was there a PRESTO class? Didn't put it in my agenda. Just forgot."

- Which aspects may have influenced the implementation? (Context).

Three themes emerged from this question: students' motivation, institutional support, and communication with students.

Students' motivation: Both questionnaire and email correspondence remarks (with logs) from therapists, indicated that participants in PRESTO-Play were more motivated than PRESTO-Fit. However, participants in PRESTO-Play reported a decline in motivation during the third, fourth and fifth class, since they found the generic posture information not specific enough for their instrument playing. Once themes were more related to instrument playing and incorporated psychosocial aspects after class 5, motivation increased again. PRESTO-Play therapists confirmed this in comments such as these:

Therapist 2: "Giving this class was fun. The students get more enthusiastic whenever they can practice more and apply the principles learned directly while playing their instrument."

Some therapists felt that students appeared engaged and motivated when they attended despite many missing classes:

Therapist 3: "Hereby I send you the attendance list. The funny thing is that when students are present, they are enthusiastic -generally speaking-. And I notice that they really try to improve posture and movements while playing." 
Table 3: General evaluation: indicate whether you disagree or agree with the following hypotheses

\begin{tabular}{|c|c|c|c|c|}
\hline & \multicolumn{2}{|c|}{ PRESTO-Play } & \multicolumn{2}{|c|}{ PRESTO-Fit } \\
\hline & Mean & SD & Mean & SD \\
\hline This course is an addition to my education & 4.14 & 1.00 & 2.75 & $0.84^{*}$ \\
\hline It was easy to fit this course in my schedule & 3.10 & 1.27 & 3.33 & 1.26 \\
\hline I learned from the discussions in class & 3.62 & 0.83 & 2.49 & $0.92^{*}$ \\
\hline I would recommend this course to my friends & 3.86 & 1.12 & 2.76 & $1.07^{*}$ \\
\hline This course was fun & 3.88 & 0.89 & 2.78 & $1.04^{*}$ \\
\hline The therapist was enthusiastic & 4.52 & 0.80 & 3.98 & $0.87^{*}$ \\
\hline The conservatory contributed to the success of the course & 2.93 & 1.16 & 2.91 & 0.94 \\
\hline I put into practice what I learned from this course & 3.86 & 0.95 & & \\
\hline $\begin{array}{l}\text { The overall reactions of others (e.g. teachers, friends, } \\
\text { therapists) on my participation in this class are positive }\end{array}$ & 3.88 & 1.06 & & \\
\hline $\begin{array}{l}\text { I learned new things about prevention of physical } \\
\text { complaints related to music making }\end{array}$ & 4.17 & 1.03 & & \\
\hline $\begin{array}{l}\text { This course helped me to recognize more of the } \\
\text { benefits of healthy music making }\end{array}$ & 4.17 & 0.88 & & \\
\hline This course inspired me to take preventive actions & 3.90 & 0.96 & & \\
\hline I completed my homework assignments almost every time & 3.26 & 0.99 & & \\
\hline I learned from analyzing other students body posture while playing & 3.86 & 0.87 & & \\
\hline I learned some new things about physical activity & & & 2.93 & 1.10 \\
\hline $\begin{array}{l}\text { This course learned me to see the benefits that } \\
\text { are associated with physical activity }\end{array}$ & & & 3.18 & 1.11 \\
\hline I wore the step counter every day during the measurement periods & & & 3.33 & 1.41 \\
\hline This course helped me to become more physical active & & & 3.02 & 1.25 \\
\hline
\end{tabular}

Scores represent a Likert scale range from 0 (totally disagree) to 5 (totally agree). SD: standard deviation* significant difference between groups, $p<0.01$

In contrast, participants in PRESTO-Fit reported in their evaluation questionnaires that they were somewhat disappointed about the contents of the class. Others reported that they experienced too much trouble to wear step counters and note steps for 7 days a week during 7 weeks in one year. Also, as a consequence of the low attendance rate and motivation of the students, the PRESTO-Fit therapists' motivation was negatively influenced:

Therapist 4: "Only two students were present, came in late, did not have their logbook. I couldn't do the evaluation. This is hard for my motivation, which is an understatement."

Institutional support: To promote awareness about the trial at the participating conservatories, different social media sources, intranet, and email were used to inform all conservatory staff, although they were not directly involved in study processes. Original plans to inform music teachers by a lecture and possibility for personal contact were found impossible at all conservatories due to lack of common availability of music teachers. Instead, all music teachers received written information about the course. Students were asked to discuss class elements with their music teachers. Music teacher's comments on course contents were then discussed in the next class.

Therapist 2: "I heard from a student that her teacher now, as a consequence of her discussions with him on posture as induced by the PRESTO class, paid more attention to postural-related aspects as breathing." 
Students in PRESTO-Play and PRESTO-Fit reported low scores on the question whether they felt that the conservatory contributed to the success of the course. Therapists reported moderate to good cooperation from the conservatories. Feedback from the therapists at the moderately-engaged conservatories suggested that more cooperation of conservatory staff (music teachers, supporting staff) probably would have resulted in fewer dropouts.

Communication with students: According to protocol, regular class attendance reminders were sent to students by the principal investigator (VB), as well as reminders for them to hand in questionnaires. Because of low class attendance and problems with handing in questionnaires, communication strategies with the students adapted throughout the course in response to feedback regarding reasons for decreased class attendance. Conservatory staff suggested that they would be more active in stimulating students to come to class and hand in questionnaires. Every conservatory proposed his own method, which suited them best to help researchers prevent dropout. The conservatories that were the most active reported the lowest drop-out rates.

\section{Discussion}

This article describes a comprehensive external validation and process evaluation of a multicenter randomized controlled trial evaluating efficacy of a biopsychosocial health promotion and injury prevention intervention aimed to reduce disability due to musculoskeletal complaints in music students. The external experts' review supported the design and contents of the trial. Dose delivered was good. Participants in PRESTO-Play confirmed that they learned new aspects about prevention of physical complaints related to music making and found that the course was an addition to their education. The course created an open atmosphere to talk about physical and psychological problems. Postural exercise therapy was delivered according to protocol. Participants appreciated it most when education was focused on playing the instrument. Health behavior change principles were insufficiently applied in the first intervention year, but improved in year 2. Regarding psychosocial aspects covered, students found that anxiety and stress could be discussed more. Therapists advised to present handouts of the psychosocial topics discussed. Experts lacked consensus whether psychosocial aspects were covered appropriately. Participants in the control group were disappointed when they found out they did not learn about specific aspects of posture while playing. Participant's course ratings were significantly higher in PRESTO-Play compared to PRESTO-Fit.

No difference in disability was found between groups. This evaluation reveals that the contrast between PRESTO-Play and PRESTO-Fit might have been too small to cause differences. Although originally designed as control for attention, it is possible that PRESTO-Fit also provided a positive health effect, as was reported and expected by experts. It is also possible that the PRESTO-Play was not that effective as expected, since health behavior change principles were not applied according to protocol in the first year of intervention. In addition, despite the use of standardized training and logbooks, fidelity was only moderate. Individual backgrounds were anecdotally reported to have an impact on the fidelity of course delivery, such as inconsistencies in depth of discussion of psychosocial aspects in the PRESTO-Play and providing extra information on benefits of physical activity other than described in the protocol in PRESTO-Fit. Third, 
attendance rates in PRESTO-Play and PRESTO-Fit classes were not optimal. Especially the dose received in the PRESTO-Play course could have been too low for the course to become effective. Another potential limitation is that we did not measure whether the postural exercise principles were generalized into daily practice. Generalization of the contents of the PRESTO-Play class is obviously more likely to be able to reduce complaints and disability. Last, students from PRESTO-Fit reported to start looking for other ways to receive information about health, since they were disappointed in the contents of their course. This could have further reduced contrast between groups.

Optimal reach was a problem in this trial. Drop-out was high, class attendance was not optimal, and response to questionnaires during follow-up was poor. Due to busy schedules, students could often not participate in classes. Evaluation of implementation revealed that context seems to contribute to reach. Courses should be made accessible for everyone during the whole year, institutional support is vital for the course, and communication strategies need to be optimal to reach the participants.

\section{Lessons learned}

The initiative, design, and implementation of the PRESTO trial were driven by the researchers. Considering implementation, institutional support of participating centers, in this case conservatories, is of utmost importance. ${ }^{9}$ For many reasons it would be more feasible if the conservatory itself was the driving force of the health course and adopted the course in its regular curriculum. Prior research reports that it is believed that music schools can change collective values, beliefs and actions of their students and could be able to induce a cultural shift increasing the focus on health behavior. ${ }^{10}$ Both students and music teachers agreed that places of music education should offer structured music-health education. ${ }^{11}$ In addition, experience from our trial reveals that students are more motivated to participate when they notice that the conservatory encourages the course. It is known that professional musicians have more health awareness and better attitudes to injury than students. Students expect guidance from their teachers on this theme, however teachers do not feel equipped to do so. ${ }^{11}$ Therefore, involving music teachers in regular health classes at the conservatory, enables them to learn about teaching musician's health and start incorporating health-related aspects in their music classes as well. ${ }^{12}$ It is expected that accessibility would be less a problem when the courses are a regular part of the curriculum and dropout could be prevented more easily when the conservatory is the manager of the course. Furthermore, study credits should be given for participation in class to externally motivate students. Thus, it is expected that the problems considering reach and context in the current trial could have been prevented if the trial had been implemented by the conservatory staff itself, rather than by researchers outside the conservatory. However, conservatory staff are not researchers. A closer collaboration between researchers and staff is necessary in future trials. Results are supported by recent work on perceived barriers and enablers to optimal health among music students. ${ }^{13}$ Findings revealed that health promotion should focus on daily practices and routines 
of conservatories. Health and wellbeing should be embedded as an integral component of conservatory education. The culture at the conservatory towards health should be optimized towards health and wellbeing.

\section{Strengths and limitations}

Strength of this study is that we examined the experience of participation in a health promotion and injury prevention course for music students from different perspectives using a predefined structure. A limitation is that we did not incorporate structured interviews or focus groups, which could have provided additional themes of interest. Furthermore, reliability testing of therapists' compliance with the protocol by audio/video-taping and evaluation of the classes would have augmented information on fidelity. ${ }^{6}$

In conclusion, although no differences in primary outcome were found, this process evaluation revealed that participants in PRESTO-Play reported to have learned about prevention of physical complaints related to music making and rated the course significantly higher compared to PRESTO-Fit. The study design and contents of the interventions were valid. Dose delivered was good. Behavioral change and psychosocial principles in PRESTO-Play might have not been implemented optimally. Moderate fidelity in both groups and too little contrast between interventions could have further influenced results. Attendance rate and a presumed lack of generalizability further decreased possible effect of the interventions. Reach and context were found to be the largest influencing factors on study participation and study outcome. It is assumed that implementing a health course from the inside of the institution will optimize accessibility and communication, encourage attendance, and enhance motivation for behavioral change. 


\section{References}

1. Kok LM, Vlieland TP, Fiocco M, Nelissen RG. A comparative study on the prevalence of musculoskeletal complaints among musicians and non-musicians. BMC Musculoskelet Disord. 2013;14:9.

2. Kreutz G, Ginsborg J, Williamon A. Health-promoting behaviours in conservatoire students. Psychol Mus. 2009;37(1):47-60.

3. Baadjou VA, Verbunt JA, Eijsden-Besseling MD, Samama-Polak AL, Bie RA, Smeets RJ. PREvention STudy On preventing or reducing disability from musculoskeletal complaints in music school students (PRESTO): protocol of a randomised controlled trial. J Physiother. 2014;60(4):232.

4. Baadjou VAE, Verbunt JA, Eijsden-Besseling MD, et al. Preventing musculoskeletal complaints in music students. A biopsychosocial prevention course is not superior at reducing disability compared to physical activity promotion: a randomized trial. submitted 2017.

5. Oakley A, Strange V, Bonell C, Allen E, Stephenson J, Team RS. Process evaluation in randomised controlled trials of complex interventions. BMJ. 2006;332(7538):413-416.

6. Steckler A, Linnan L. Process evaluation for public health interventions and research. San Francisco: Jossey Bass; 2002.

7. Baranowski T, Stables G. Process Evaluations of the 5-a-Day Projects. Health educ behav. 2000;27(2):157-66.

8. Saunders RP, Evans MH, Joshi P. Developing a Process-Evaluation Plan for Assessing Health Promotion Program Implementation: A How-to-Guide. Health Promot Pract. 2005;6:134

9. McSweeney L, Araújo-Soares V, Rapley T, Adamson A. A feasibility study with process evaluation of a preschool intervention to improve child and family lifestyle behaviours.BMC Public Health. 2017;17(1):248.

10. Williamon A, Thompson S. Awareness and incidence of health problems among conservatoire students. Psychol Mus. 2006;34:411-430.

11. Rickert DLL, Barrett MS, Ackermann BJ. Are music students fit to play? A case study of health awareness and injury attitudes amongst tertiary student cellists. Int J Music Educ.2015;33(4):426-441.

12. Hildebrandt $H$, Nübling M. Providing further training in musicophysiology to instrumental teachers: do their professional students derive any benefit? Med Probl Perform Art. 2004;19:62-69.

13. Perkins R, Reid H, Araujo LS, Clark T, Williamon A. Perceived Enablers and Barriers to Optimal Health among Music Students: A Qualitative Study in the Music Conservatoire Setting. Front Psychol. 2017;8:968. 


\section{APPENDIX 1: External review questionnaire}

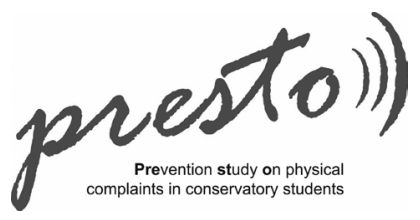

\section{Maastricht University}

\section{External review}

Thank you for participating in this external review of our study design.

Based on the presentation of our Presto intervention research project, there are questions below under the categories of contents, methodology, and implementation. Please answer these questions by agreeing (yes) or disagreeing (no), and you may also comment on why you don't agree, or if you see any possibilities for improvement. At the end of each section there is space for general remarks. Results from the review will be collated, and used as part of the process evaluation of this study.

To assist with interpreting the information obtained, could you please indicate your current profession:

Can you please indicate your previous experience in research project design by circling the appropriate number on the line below?

$\begin{array}{llllllllllll}0 & 1 & 2 & 3 & 4 & 5 & 6 & 7 & 8 & 9 & 10 \\ \text { No experience at all } & & & & & & & & & & & \text { Highly specialized }\end{array}$

Can you please indicate your previous experience in researching exercise interventions by circling the appropriate number on the line below?

$$
\begin{array}{lllllllllll}
0 & 1 & 2 & 3 & 4 & 5 & 6 & 7 & 8 & 9 & 10 \\
\hline
\end{array}
$$

No experience at all Highly specialized

Can you please indicate your previous experience in musician's health by circling the appropriate number on the line below?

\begin{tabular}{lllllllllll}
0 & 1 & 2 & 3 & 4 & 5 & 6 & 7 & 8 & 9 & 10 \\
\hline
\end{tabular}

No experience at all Highly specialized 


\begin{tabular}{|c|c|c|}
\hline \multicolumn{2}{|c|}{ CONTENTS of the intervention } & \multirow[t]{2}{*}{$\%$ positive } \\
\hline \multicolumn{2}{|c|}{ Experimental: PRESTO-Play } & \\
\hline 1. & $\begin{array}{l}\text { Do the principles of the method Samama make } \\
\text { sense to apply in a musician's population? }\end{array}$ & $78.6 \%$ \\
\hline 2. & $\begin{array}{l}\text { Was the application of behavioral change } \\
\text { principles in program delivery appropriate? }\end{array}$ & $71.4 \%$ \\
\hline 3. & $\begin{array}{l}\text { Would you expect a change in: } \\
\text { Knowledge } \\
\text { Risk perception } \\
\text { Relevance } \\
\text { Social support } \\
\text { Modeling } \\
\end{array}$ & $\begin{array}{l}1.78 .6 \% \\
\text { 2. } 64.3 \% \\
\text { 3. } 57.1 \% \\
\text { 4. } 57.1 \% \\
5.50 \% \\
\end{array}$ \\
\hline 4. & Are psychosocial aspects covered adequately? & $50 \%$ \\
\hline 5. & $\begin{array}{l}\text { Do you think some content that should have been } \\
\text { included was omitted in this intervention approach? }\end{array}$ & $50 \%$ \\
\hline 6. & $\begin{array}{l}\text { Did the use of different multimedia sources } \\
\text { and class discussion make the Presto- } \\
\text { Play program interactive enough? }\end{array}$ & $57.1 \%$ \\
\hline 7. & $\begin{array}{l}\text { Do you think running this program was } \\
\text { appropriate in a mixed group of students } \\
\text { playing different instruments? }\end{array}$ & $78.6 \%$ \\
\hline 8. & $\begin{array}{l}\text { Would you expect the Presto-Play intervention } \\
\text { to affect playing-related disability? }\end{array}$ & $78.6 \%$ \\
\hline \multicolumn{2}{|c|}{ Control: PRESTO-Fit } & \\
\hline 9. & $\begin{array}{l}\text { Do you think that there is enough contrast between } \\
\text { the two approaches: Presto-Play and Presto-Fit? }\end{array}$ & $64.3 \%$ \\
\hline 10. & $\begin{array}{l}\text { Did the use of different multimedia sources } \\
\text { and class discussion make the Presto-Fit } \\
\text { program interactive enough? }\end{array}$ & $57.1 \%$ \\
\hline 11. & $\begin{array}{l}\text { Would you expect the Presto-Fit intervention } \\
\text { to affect playing-related disability? }\end{array}$ & $42.9 \%$ \\
\hline
\end{tabular}

Free space for general remarks on content, not mentioned before:

\begin{tabular}{|c|c|c|}
\hline \multicolumn{2}{|c|}{ METHODS } & \multirow{2}{*}{$\begin{array}{c}\text { \% positive } \\
92.9 \%\end{array}$} \\
\hline 1. & $\begin{array}{l}\text { Was the design of the study appropriate } \\
\text { for the research goal? } \\
\text { Factorial randomized } R C T\end{array}$ & \\
\hline 2. & Do you think there is a risk for contamination of data? & $64.3 \%$ \\
\hline 3. & $\begin{array}{l}\text { Were the inclusion criteria appropriate? } \\
\text { All instrumentalists and vocalists, all } \\
\text { bachelor programs, } 1^{\text {st } \& 2^{\text {nd }} \text { year }}\end{array}$ & $78.6 \%$ \\
\hline 4. & $\begin{array}{l}\text { Were the primary outcome measures appropriate? } \\
\text { DASH performing arts module }\end{array}$ & $71.4 \%$ \\
\hline 5. & $\begin{array}{l}\text { Were the secondary outcome measures appropriate? } \\
\text { QoL, PDI, PRMD, Health behavior change, DASS-21 }\end{array}$ & $78.6 \%$ \\
\hline 6. & $\begin{array}{l}\text { Do you have suggestions for other outcome } \\
\text { measures that may have been sensitive } \\
\text { to the effects of this program? }\end{array}$ & NA \\
\hline 7. & $\begin{array}{l}\text { Was the statistical analysis technique appropriate? } \\
\text { Multilevel analysis }\end{array}$ & $57.1 \%$ \\
\hline 8. & $\begin{array}{l}\text { What additional strategies could have been implemented } \\
\text { to reduce the rate of drop-out to follow-up? }\end{array}$ & NA \\
\hline
\end{tabular}


Free space for general remarks on methods, not mentioned before:

\begin{tabular}{|c|c|c|}
\hline \multicolumn{2}{|c|}{ IMPLEMENTATION } & \multirow{2}{*}{$\frac{\text { \% positive }}{64.3 \%}$} \\
\hline 1. & Were the protocol choices ideal? & \\
\hline 2. & $\begin{array}{l}\text { Would the variability in intervention teachers } \\
\text { have had an effect on outcomes? }\end{array}$ & $64.3 \%$ \\
\hline 3. & $\begin{array}{l}\text { Was the communication with the students adequate? } \\
\text { Via researchers + conservatory, oral/email/social media }\end{array}$ & $92.9 \%$ \\
\hline 4. & $\begin{array}{l}\text { Was the communication with conservatory } \\
\text { staff, including music teachers, adequate? } \\
\text { Email, intranet }\end{array}$ & $71.4 \%$ \\
\hline 5. & $\begin{array}{l}\text { Was the communication with } \\
\text { intervention teachers adequate? } \\
\text { Email }\end{array}$ & $50 \%$ \\
\hline 6. & $\begin{array}{l}\text { One of the group of stakeholders that we did } \\
\text { not consulted during the formative evaluation } \\
\text { stages were the music teachers. Do you think } \\
\text { this may have influenced outcomes? }\end{array}$ & $35.7 \%$ \\
\hline 7. & $\begin{array}{l}\text { Do you think involving the conservatory staff from the } \\
\text { outset would have influenced attendance in classes? }\end{array}$ & $64.3 \%$ \\
\hline 8. & $\begin{array}{l}\text { Do you think involving conservatory staff from the } \\
\text { outset would have influenced completion of surveys? }\end{array}$ & $57.1 \%$ \\
\hline
\end{tabular}

Free space for general remarks on implementation, not mentioned before: 

Chapter 10

General Discussion 



\section{General discussion}

The main objective of this thesis was to examine how to effectively prevent musculoskeletal complaints in music students. Information was provided in nine chapters, divided into three sections, in which part 1 studied characteristics of playing-related musculoskeletal disorders, part 2 elaborated on physiological effects of body posture while playing a musical instrument and part 3 intended to answer the question whether musculoskeletal complaints in music students can be prevented. In this discussion we present the main findings of this thesis emphasizing the coherence between the different studies. Next, we describe methodological considerations on recurring issues such as outcome measures, response rate, and implementation. Subsequently, we present recommendations and suggestions for improvement of future health promotion programs and research trials in this domain and discuss future research directions. Finally, we present the clinical implications of the knowledge acquired in the current thesis.

\section{Main findings}

\section{Part I Characteristics of playing-related musculoskeletal disorders}

Prevalence of playing-related musculoskeletal disorders (PRMD) in musicians is high. Exact numbers in Dutch music school students were not known at start of this project. Therefore, we first explored current prevalence of musculoskeletal complaints in music students at Dutch conservatories (Chapter 2). We asked third and fourth year students of eight Dutch conservatories to participate in an electronic survey. We questioned the students about the existence of musculoskeletal complaints, and current levels of pain, disability, quality of life and physical activity; and analyzed whether these constructs were correlated. We used well-established validated outcome measures frequently used in the general population. We found that $67 \%$ of third and fourth year students already experienced musculoskeletal complaints in the past week, and 52\% experienced disability related to playing their instrument. Further, we found that higher pain intensity was related to more disability and worse physical and mental quality of life. More disability was associated with lower quality of life. Correlations between physical activity level and pain intensity, disability, and quality of life were low. Musculoskeletal complaints clearly have a significant influence on a musician's quality of life and playing capacity. However, as only 9.4\% of the students responded to the web-based questionnaire, a selection bias could not be ruled out and results have to be interpreted with caution.

Next, we conducted an extensive literature review (Chapter 3) to search for and synthesize the best available evidence on risk factors for musculoskeletal disorders in professional musicians and music students. We critically reviewed the methodological quality of the included studies. Results indicated that outcome and exposure assessments (potential risk factors) differed widely. A large variety of measurement instruments were used; often self-developed or not validated for use in this specific population. Currently, no prospective research that we know of has been done to investigate risk factors for musculoskeletal disorders in musicians. Therefore, causal relations could not be identified. Only one case-control study was found providing the best available evidence to 
date.' Other studies on risk factors for musculoskeletal complaints in musicians used a cross-sectional design, were of a generally low methodological quality and showed a large heterogeneity. Results on potential risk factors identified were categorized into socio-demographic, health-related, physical, psychosocial, work-related, and prevention-related risk factors. Consistent results indicated that (upper) string players experience more musculoskeletal complaints than other instrumentalists. An interaction effect of being female and playing the violin suggested that not sex, but rather type of instrument is the most important factor associated with musculoskeletal complaints. The presence of performance anxiety and work-related stress seemed to be related to experiencing more musculoskeletal complaints. Musicians who have experienced musculoskeletal complaints before seemed to be at higher risk of developing recurrent complaints. Consistent results indicated no association between musculoskeletal complaints and exercising, smoking, and work-related factors as choice or influence over work, support at work or orchestra category. Literature findings are not consistent with regard to influence of biomechanical or physical characteristics, playing load, age, number of years playing the instrument, or performing a warming-up. We concluded that there is a need for research using a prospective longitudinal design and provided suggestions for study design of these future studies.

As the systematic review showed that there is no uniformity in the use of outcome measures in musician's literature, and little is known about validity of outcome measures for musicians specifically, we felt the need to evaluate psychometric characteristics of our main outcomes of interest in our main intervention study. This will allow us to better interpret results of the applied interventions. Disability was the primary outcome of interest in this thesis and was measured using the Disabilities of the Arm, Shoulder, and Hand questionnaire (DASH). The DASH includes a performing arts module. The DASH has been validated extensively; however the performing arts module was not. ${ }^{2-5}$ In Chapter 4, we evaluated psychometric properties of the performing arts module. The performing arts module showed good internal consistency, good discriminative validity and moderate construct validity. We also found that the general DASH scores were rather low in our music student population, suggesting that musculoskeletal complaints have little influence on activities in daily life. The performing arts module appeared to be more sensitive to measure playing-related disability. Playing-related complaints are often referred to as playing-related musculoskeletal disorders (PRMD). ${ }^{6}$ In this chapter, we additionally analyzed the association between pain ${ }^{7}$ and PRMD. The constructs pain and PRMD are often used in musician's research. Whereas pain is only related to symptoms, the PRMD definition also incorporates disability related to playing the instrument. ${ }^{6}$ We found that the association between pain and PRMD was low, indicating that pain and PRMD are different constructs. PRMD are not always experienced as pain. So the results from studies measuring pain and PRMD cannot be merged. Based on these findings, we chose to include playing-related disability as measured with the performing arts module and the presence of playing-related musculoskeletal disorders in addition to the DASH as main outcomes in our subsequent studies. 


\section{Part II Physiological effects of body posture while playing a musical instrument}

Limited evidence is available on the (patho) physiology of playing a musical instrument. In clinical practice, strong associations between sustained 'poor' posture and the presence of musculoskeletal complaints in musicians are assumed. ${ }^{8}$ Body posture according to postural exercise therapy Mensendieck/ Cesar method Samama (MmS) is extensively described in this thesis. ${ }^{9}$ This therapy is frequently used in clinical practice to treat playing-related complaints and is hypothesized to contribute to prevention and/or treatment of complaints. Key element in MmS postural exercise therapy is the prevention of imbalance between muscles providing stability and muscles used to play the instrument. It is believed that while playing in a body posture according to MmS postural exercise therapy, stability is increased by higher activity levels of proximal muscles. Consequently, the improved control provided by these proximal muscles reduces the muscle load of distal muscles, thereby enabling the player to use the arm and shoulder muscles more dynamically and coordinated while playing the instrument. Next, musicians who have participated in MmS postural exercise therapy not only anecdotally report a decrease in musculoskeletal complaints, but also experienced less fatigue when playing in a body posture according to the MmS postural exercise therapy compared to their habitual posture. Therefore we also hypothesized that fatigue would be related to energy expenditure. In order to better understand the potential working mechanisms of the MmS postural exercise therapy we investigated the effect of body posture on energy expenditure (Chapter 5) and muscle activity (Chapter 6). Research questions were:

- Is energy expenditure when playing in a body posture according to MmS postural exercise therapy lower compared to playing in a non-optimized body posture?

- Does playing in posture according MmS postural exercise therapy lead to a higher activity of erector spinae, latissimus dorsi, lower trapezius and pectoralis major muscles and reduced activity of upper trapezius, biceps brachii and brachioradialis muscles compared to playing in habitual posture?

In the first study, contrary to our hypothesis, we found that energy expenditure was higher while playing a wind instrument in the MmS postural exercise therapy position. Two explanations come to mind: first, the assumption that a feeling of fatigue/ exertion would be related to energy expenditure is not correct. ${ }^{12}$ Fatigue can result from physical, cognitive, and emotional exertion ${ }^{10,11}$ and is therefore not necessarily related to energy expenditure. Another more general measure of exertion, for example Borg's ratings of perceived exertion, ${ }^{13,14}$ was not used, therefore could not provide additional information to support this explanation. Second, in retrospect, it can be assumed that energy expenditure in the MmS postural exercise therapy position is higher since it is a more active posture. Musicians must concentrate and focus on posture, and presumably muscle activity is higher to maintain this posture. In the second study, we used electromyography (EMG) to investigate differences in muscle activity pattern between MmS postural exercise 
therapy and the habitual posture. In a sample of clarinet players, it was shown that when playing in a posture according MmS postural exercise therapy, the erector spinae and lower trapezius muscle were more active, and left upper trapezius and right brachioradialis muscle were less active, compared to habitual playing posture; thereby partly confirming our hypothesis that by increasing activity levels of proximal muscles, a decrease in activity of upper extremity muscles can be induced.

\section{Part III Can musculoskeletal complaints in music students be prevented?}

In Chapters 7, 8, and 9, we present the study protocol, results, and evaluation of a randomized controlled trial. The multicenter randomized controlled trial is one of the first in this field. In line with prior findings discussed in this thesis, we hypothesized that a biopsychosocial intervention would be superior to physical activity promotion in reducing disability due to musculoskeletal disorders in music students. The biopsychosocial intervention group participated in 11 classes (18.5 hours) throughout one academic year incorporating MmS postural exercise therapy while playing the instrument, combined with addressing psychosocial aspects and the promotion of a healthy life style. Students in the physical activity promotion group spend an equal amount of time monitoring their daily steps, and increasing the physical activity up to 10,000 steps a day, conforming to guidelines regarding health promoting level of physical activity for the general population. No differences in disability were found between the groups by the end of the intervention and at 2 years follow-up. On the basis of change scores of disability between start and follow up, it seems plausible that both the biopsychosocial intervention and the physical activity promotion intervention were able to reduce disability. However, the design of this study does not permit to test and hence conclude whether this is an intervention effect or due to natural course. However, participants in the biopsychosocial group reported to have learned about prevention of physical complaints related to playing their music instrument, and rated the course significantly higher compared to the physical activity promotion group. The process evaluation revealed that behavioral change and psychosocial principles in the biopsychosocial intervention group might have not been implemented optimally. It is questioned whether issues concerning fidelity and lack of contrast between interventions could have further influenced results. Furthermore, attendance rate in the biopsychosocial intervention group was about $50 \%$ and dose received might have been too small for the intervention to be effective. Also, it is not known whether students did incorporate the intervention principles into their daily life. This is a prerequisite for the biopsychosocial intervention to be effective. The RCT encountered a high percentage of students who were lost-to-follow-up. Participation rate in the study (reach) and contextual factors were found to be the largest influencing factors. For example, it was not possible to schedule classes so that all students could participate, some students were not convinced of the importance to participate and many lacked engagement from their respective conservatories. In conclusion, our hypothesis that a biopsychosocial prevention program is more effective in reducing or preventing disability due to musculoskeletal disorders compared to physical activity promotion has to be rejected since no statistically significant differences between the interventions were found. We found that contextual factors greatly influenced motivation and implementation of the interventions. 


\section{Methodological considerations}

This thesis includes observational studies (one retrospective questionnaire-based study, two experimental studies, and an analysis of psychometric properties), a systematic review, results of a randomized controlled trial with a study protocol published before inclusion was finished, and a qualitative study. Based on the research questions, we chose the best research design for each particular question. Each research design has strengths and weaknesses, which are described in the discussion sections of the respective studies/chapters. We observed that there were recurring and overlapping themes in the subsequent studies, which can mostly be related to outcome measures. We now describe these considerations in relation to self-reported outcome measures, physiological outcome measures, performance-related outcome measures, and outcomes of qualitative studies.

\section{Self-reported outcome measures}

Self-reported outcome measures are accepted means of assessing population characteristics and disease..$^{15}$ Unfortunately we found that there is no uniformity in the use of outcome measures in musician's literature and often non-validated questionnaires are used which seriously impedes interpretation and extrapolation of results. Self-reported outcome measures can be very illustrative, if they measure the right construct in the right population. ${ }^{16}$ Only few validated questionnaires are available to measure musicians' complaints. In our first study on prevalence of musculoskeletal complaints (Chapter 2) we therefore decided to use frequently applied questionnaires validated in the general or chronic pain population. In a later study, we found that these general or chronic pain-related questionnaires are not specific enough to assess musicians' functioning at elite level. This means that some of the outcomes in Chapter 2 might not reflect the true problems of the musicians. Later on, we changed our main outcomes of interest from musculoskeletal complaints and pain in general to playing-related disability which is believed to better reflect musicians' complaints.

Survey-based research has advantages and disadvantages. For example, in our prevalence study (Chapter 2), an advantage was that it was easy to reach all the 1406 targeted students. Surveys can be easily designed, distributed, and collected using a web-based tool. The assumption was that a high percentage of the students came from abroad, therefore we chose to include questionnaires that were validated both in Dutch and in English and provided separate links to a Dutch and an English version of the questionnaire so that students could choose the questionnaire that suited them best. A major disadvantage was that response rate to this electronic questionnaire was low. Two reminder e-mails were sent to the students, posters and flyers were distributed at the conservatories to remind students to fill out the questionnaire. Using web-based questionnaires in the general population seems feasible, ${ }^{17}$ but the response rate is often lower than a postal survey. ${ }^{18}$ Other studies using electronic questionnaires in a music student population also reported low response rates, comparable to ours. ${ }^{19,20}$ In contrast, studies that distributed paper questionnaires in class showed higher response rates. ${ }^{21,22} \mathrm{~A}$ review of literature examining healthy volunteer motivations showed that a personal approach by the researchers is of great importance to stimulate participants to participate in research and complete questionnaires. ${ }^{23}$ 
To stimulate response rate to the questionnaires in the RCT (Chapter 8), we therefore decided to use paper versions, to distribute them personally or by conservatory employees and provide time in class to complete the questionnaire. However, this did not result in a high response percentage. During the intervention, the lowest response rate was observed for students who were not present in class and thus had to fill out the questionnaire in their leisure time. During follow-up, response rate was dependent on distribution method: i.e. students who received questionnaires from conservatory employees were more likely to hand in the questionnaire compared to students who received the questionnaire by post to their home address. Although a large amount of effort was undertaken to keep students actively engaged in the study, it was concluded in the process evaluation (Chapter 9) that music students prioritize music-related activities over health class and filling out the questionnaires and that engagement of the conservatory is paramount to success, i.e. a high response rate. Missing data can seriously hamper interpretation of results. In the RCT, we used a statistical analysis technique (multilevel analysis of longitudinal data) that is able to model and compare longitudinal response patterns, thereby being robust to missing data. ${ }^{24}$ Although we acknowledge that our analysis would have been stronger if more data were present, we believe that the statistical analysis technique used adequately compensates for missing data and thereby justifies interpretability of results, despite the high numbers lost to follow-up.

\section{Physiological outcome measures}

Physiological outcome measures provide valuable information helping to understand (patho-) physiology and eventually improve treatment. Measuring physiological outcomes as $\mathrm{CO}_{2}$ and $\mathrm{O}_{2}$ in a respiration chamber or neurophysiological measurement of muscle activity (electromyography) seem to be more objective then self-reported outcomes at first hand. However, physiological outcomes should also be interpreted with care since they greatly rely on study design and methodology. First requirement for a valid assessment is the use of well-calibrated assessment instruments. The risk of bias however lies more often in the measurement procedure: the methodology used and the accuracy of the researcher performing the tests can be of great influence to the study outcome. An example of a methodological challenge was the cross-over design AB/BA in the energy expenditure study (Chapter 5). The risk of using a cross-over design is that there might be a carryover effect of the first test period to the second, biasing results. The incorporation of lengthy washout periods can diminish the impact of carryover effects. ${ }^{25}$ Based on clinical experience, we assumed that after thirty minutes of playing, a one hour resting period would be sufficient to return energy expenditure levels back to baseline values. Results showed that energy levels declined between the end of the first period and start of the second period, but not fully up to baseline levels. However, statistical tests ruled out a carryover effect: i.e. there was no direct effect of the energy expenditure in period 1 on period 2. This possible carryover effect in crossover designs needs to be tested in order to correctly interpret the found results. Second, an example of the importance of the accuracy of the researcher is reflected by the EMG measurements (Chapter 6).The muscle signal can be influenced by extrinsic and intrinsic factors. Extrinsic factors can be influenced by the experimenter and are for example electrode configura- 
tion and electrode placement. ${ }^{26,27}$ Intrinsic factors are physiological, anatomical and biochemical characteristics of the muscles ${ }^{26,27}$ which vary between individuals, but can also fluctuate within a day within an individual. ${ }^{27}$ A researcher needs to be well aware of the assets of the assessment procedure. Therefore we used well-accepted European guidelines for EMG sensor placement. ${ }^{28}$ After placement by the principal investigator (registrar in physical medicine and rehabilitation), the placement was always double checked by a senior movement scientist experienced in EMG measurements. Only with a proper design and well-applied methodology, results can be interpreted reliably.

\section{Performance-related outcome measures}

Body posture seems not only to be related to PRMD, but also to sound and performance quality. As performance quality is the most important outcome for the musician, it is worthwhile to incorporate this variable in research as well. Examples of performance-related outcome measures are ease of movement, confidence, energy levels or playing capacity. ${ }^{29}$ In retrospect, we regret that we did not include a performance-related outcome measure in the RCT. Optimal health is prerequisite for a good performance. When evaluating the effectiveness of health programs, performance-related outcomes should therefore not be forgotten. One performance-related outcome measure that we explored in our study on the effect of body posture in clarinetists (Chapter $6 \mathrm{a}$ and $6 \mathrm{~b}$ ) is the quality of sound. We measured sound quality threefold: first, by asking the participants to rate their own sound quality, second, by review of a blinded jury, and third by conducting spectral analysis. This spectral analysis has not been reported in the article given the large methodological considerations. An overview of the experiment is presented in this thesis in addition to Chapter 6 (Chapter 6b) since we believe that it is worth replicating the experiment, applying the corrections we suggested. Since music tone is the most important outcome measure for the musician himself, it is a valuable measure to incorporate in future research.

\section{Outcomes of qualitative studies}

Whereas quantitative research methods are designed to collect numbers, qualitative research is designed to collect words. ${ }^{31}$ Qualitative data provide a detailed understanding of a problem, from the perspective of individuals. ${ }^{32} \mathrm{~A}$ limitation of the current thesis is that we did not use the full potential of qualitative research methods in our studies. It is known that engaging stakeholders in the research setup and design of a trial lead to refined research questions, facilitate selection of interventions to compare, inform choice of study outcomes and how they are measured, and contribute to strategies for recruitment. ${ }^{33}$ Especially for the RCT, we believe that interviews with all stakeholders before the start, during and by the end of the project would have resulted in valuable extra information which could have resulted in better implementation and increased motivation for participation. For example, although we did discuss organization of the implementation of the trial with each conservatory prior to study commencement, we feel that a more structured approach could have resulted in improved organization of the trial on site and better strategies to 
communicate with the students. Also, students could have been asked to denote which aspects they considered to be important in a prevention intervention. The prevention program therewith could possibly be more targeted towards the students' needs. Further, their opinion about implementation of the study could have improved motivation and reach. Students could have provided valuable information on the best available time or period to organize classes. Students would have felt more engaged in the trial and therewith might have been more motivated to participate. Also, as part of the process evaluation, interviewing students about implementation afterwards could have provided more themes of interest and extra information compared to the close-ended questions that were now gathered by questionnaires.

From the abovementioned methodologic considerations, we can conclude and recommend that playing-related musculoskeletal disorders and associated factors can be studied in varying ways. When using self-reported outcome measures, it is important to use valid and reliable outcome measures. There is a need for research on psychometric properties of questionnaires frequently used in the population of musicians. Establishment of outcome measurement guidelines, specifically involving musicians and a core outcome set for measuring musician's complaints will lead to more uniformity. In that way, more reliable, valid and responsive data will be available in this relative new and small research field. Data sets can be merged, norm data can be retrieved, aiding in interpretation of outcome and relevant change in outcome. Disadvantage of self-reported outcome measures is that response rate is often low. Large effort should be done to encourage participants to fill out questionnaires and statistical analysis should be used that can optimally correct for missing values. Measuring physiological outcomes seems to be more objective than self-reported outcomes at first hand. However, physiological outcomes should also be interpreted with care since they greatly rely on study design, methodology and accuracy of the researcher. Performance-related outcome measures are most important to the musicians themselves and seem to be valuable to add in future research trials as well. Furthermore, we encourage researchers to combine quantitative and qualitative data in mixed-methods research. Involving stakeholders, foremost the intended participants themselves, in study design and study evaluation leads to valuable contribution to study quality for the purposes of breadth and depth of understanding and corroboration. ${ }^{34}$

\section{Further recommendations and future research}

Based on the comprehensive evaluation of the prevention and treatment of playing-related musculoskeletal disorders as presented in the current thesis, and next to methodologic recommendations as presented above, we present suggestions to improve future health promotion programs and research trials with the aim to prevent musculoskeletal disorders in musicians. Three main aspects are of importance: i.e. conditional aspects (health behavior change), intervention contents, and implementation. Last, we describe considerations about future research on the pathophysiology of playing-related musculoskeletal disorders. 


\section{Health behavior change}

Key element for a prevention program to be effective is health behavior change. Awareness is prerequisite for motivation to change. Once awareness is present, attitudes, social influences and self-efficacy determine the motivation to change..$^{35}$ In the biopsychosocial intervention, students were made aware of the prevalence and consequence of musculoskeletal complaints, thereafter their motivation for change was stimulated by exploring personal attitudes towards health and exploring the influences of their peers and music teachers. Self-efficacy was influenced by teaching the students how to be responsible for their own health, and by giving them personal feedback. These steps are vital for a prevention program to become effective. It was noted that health behavioral change principles were not applied in full extent by all therapists in intervention year 1. Following, no differences in health behavior were found between students in intervention and control condition. Interestingly, a recent qualitative survey of perceived enablers and barriers to optimal health in music students showed that $95 \%$ of the students report to be aware of the importance of health. ${ }^{36}$ Notwithstanding that the students have benefitted from lectures, workshops or other services from the conservatory, they still perceived their health and wellbeing support not as developed, or as accessible, as they would like. This discrepancy is explained by the supposition that students expect to find an external answer to their problems, instead of changing their own behavior, reflected by a low health responsibility. ${ }^{20,36}$ These results suggest that motivation to health behavior change is more a problem than simply the awareness. Spahn et al. ${ }^{37}$ proposed to adapt the health education to the students' needs. They characterized three groups of students, based on their experience of PRMD, preventive actions, and locus of control. Students without PRMD, not taking preventive actions and with an external locus of control should be motivated to change their attitudes toward health and start taking preventive actions (primary prevention). Students with PRMD, who do engage in preventive activities and have an internal locus of control should be trained to maintain their healthy behavior. Students with PRMD and an external locus of control should be treated, and motivated to change attitudes towards health and practice preventive behavior (secondary prevention). Based on these results it seems important to target subgroups differently. In conclusion, when designing a prevention program to reduce musculoskeletal complaints in musicians, we recommend that much emphasis is placed on conditional aspects leading to health behavior change. Future research should expand current knowledge on how to improve health responsibility and health behavior in music students.

\section{Intervention contents}

The biopsychosocial program was based on postural principles according to MmS postural exercise therapy and further incorporated themes such as dealing with stress and performance anxiety, practice behavior and pain education. Considering the postural aspect, results of the energy expenditure and EMG study broaden our current knowledge on the physiology of playing 
a musical instrument. These two studies, and especially the EMG study, support the supposition that postural exercise therapy MmS could contribute to the prevention and treatment of musculoskeletal complaints in musicians. However, other studies also confirm that trunk strengthening supporting the playing musculature and an adequate scapulohumeral rhythm are essential for efficient upper limb movement and therewith seem to be related to health and playing quality. ${ }^{38-40}$ Besides, is also seems likely that cardiovascular fitness contributes to better performance..$^{29}$ These aspects are not specifically incorporated in postural exercise therapy MmS. As these interventions all seem plausible to contribute to musician's health, it should be investigated in future what works best for whom. Further, it could be worthwhile researching whether certain physical characteristics are predisposing to musculoskeletal complaints. For example, joint laxity was found to be related to arm pain in professional musicians ${ }^{41}$ and musculoskeletal complaints in adolescent string musicians. ${ }^{42}$ This could suggest that treatment might be adapted to the special needs of this population such as muscle strength training, proprioception and stabilization of the hypermobile joints. ${ }^{43}$ Furthermore, students indicated that they found the psychosocial aspects covered in class very important. It is striking that the mental component score of quality of life in music students has repeatedly been found to be low (Chapter 2 and 8) 44,45 and also significantly lower compared to other students. ${ }^{46}$ Should there be special attention to students that experience symptoms of depression, (music performance) anxiety or stress? Or should students be screened on coping style or perfectionism when entering the conservatory and should there be special attention to those with maladaptive coping styles and strivings? ${ }^{47}$ For those questions to be answered, longitudinal research following students over the course of their study is a prerequisite. Only then, we will get more information on risk factors for musculoskeletal complaints in music students and hopefully will be able to adapt prevention and treatment strategies to finally reduce musculoskeletal complaints and disability in this occupational group. In summary, although the RCT did not show superior effectiveness of a biopsychosocial program compared to physical activity promotion, electromyography of clarinet players showed that playing in a MmS body position reduced muscle activity in upper extremity muscles. Therefore we conclude that future interventions to prevent musculoskeletal complaints in musicians could benefit from including body posture. As the etiology of PRMD is believed to be multifactorial, musicians with musculoskeletal complaints should be approached from a biopsychosocial perspective. Students acknowledge the significance of addressing psychosocial issues. Future research should focus on identifying subgroups so that interventions can be designed targeted to individual needs.

\section{Implementation}

We described in Chapter 9 that the way a research trial is implemented greatly influences trial outcomes. Some recommendations on this topic have already been made in the methodologic considerations section of this discussion chapter. Continuing on this theme, it is clear that institutional support of the trial is of utmost importance. ${ }^{48}$ For many reasons, it is recommended that a health promotion program is implemented from within the institution, and research on effectiveness of health promotion programs should also be strongly enforced from within the institution to be executed properly. Prior research reports that it is believed that music schools can change 
collective values, beliefs and actions of their students and could be able to induce a cultural shift increasing the focus on health behavior. ${ }^{49}$ In addition, important experience from our trial reveals that students are more motivated to participate when they notice that the conservatory encourages the course. Second, we were not able to involve music teachers in our trial. Students expect guidance from their teachers concerning their health. Teachers do not feel equipped to do so. ${ }^{50}$ Therefore, music teachers need to be involved in health promotion at music schools. ${ }^{51}$ From our experience, we believe that this can only be implemented by action of the conservatory management. Third, we expect that accessibility would be less a problem when the courses are a regular part of the curriculum and dropout due to rescheduling or simultaneous scheduling with exams or project weeks could be prevented more easily when the conservatory is the manager of the course. In summary, we recommend that health courses and research should be embedded as an integral component of conservatory education, so that motivation for behavioral change is enhanced, accessibility and communication can be optimized, and attendance is encouraged.

\section{Pathophysiology of PRMD: the role of central sensitization}

Limited evidence is available on the pathophysiology of musculoskeletal disorders in general and even less information is available on the pathophysiology of PRMD in particular. Central sensitization has been proposed to play a role in the etiology of musculoskeletal disorders, fibromyalgia, low back pain, tennis elbow, subacromial impingement syndrome, and painful tendinopathies of the upper extremity. ${ }^{52-55}$ In future research, it is worthwhile investigating whether central sensitization is also related to PRMD. Measurements of central sensitization involves amongst others the determination of pain thresholds or stimulus response curves for sensory processing. ${ }^{56}$ Current knowledge regarding the presence of central sensitization in musicians with PRMD is restricted to a limited number of studies. Pain thresholds have been measured in pianists, ${ }^{57}$ violinists, ${ }^{58}$ and a mixed group of instrumentalists ${ }^{59}$ with and without pain. Steinmetz and Jul ${ }^{58}$ found that violinists with neck pain presented with thermal and widespread mechanical hyperalgesia compared to violinists without pain. In contrast, Zamorano et al. ${ }^{59}$ could not find differences in pressure pain, heat or cold sensitivity, or grading orientation between musicians with and without pain but did find that tactile sensitivity was lower for musicians with chronic pain compared to musicians without pain, also suggesting the presence of sensitization. Moreover, it is questioned whether the highly specialized sensorimotor musical training that leads to somatosensory cortical reorganization ${ }^{60}$ also causes increased pain sensitivity. Zamorano et al. ${ }^{59}$ hypothesized that effects of extensive musical training could predispose professional musicians to display an altered perception of painful and non-painful somatosensory stimuli similar to that of chronic pain patients. Therefore, they further explored differences between musicians and non-musicians and interestingly, found that pain-free musicians had greater touch sensitivity (lower mechanical detection thresholds), reduced tactile spatial acuity (higher grating orientation thresholds), and enhanced sensitivity to pressure and heat pain compared to pain-free non-musicians. This could be due to increased peripheral somatosensory input or by central sensitization and loss of central endogenous pain control mechanisms. However, Kuppens et al. ${ }^{61}$ studied the central endoge- 
neous pain control mechanisms and found that exercise- and stress-induced hypoalgesia were present in string instrumentalists with and without shoulder pain, suggesting an intact central pain control mechanism. Another explanation for the facilitation of sensitivity and pain perceptions in healthy musicians is that musicians display enhanced interoception, possibly as a result of strengthened associative connections between motor, sensory and multimodal integration areas in the brain of a musician. ${ }^{62}$ To expand knowledge on the role of central sensitivity in pain experience in musicians, future research should combine tests of central integration (e.g. temporal and spatial summation) and tests of descending control (e.g. inhibitory conditioned pain modulation). ${ }^{63}$ Furthermore, as it is known that the activity in descending pain inhibitory pathways can be modulated by the level of vigilance, catastrophizing, attention, and stress, ${ }^{64}$ these factors should not be forgotten. In summary, first results assume that central sensitization might play a role in the pathophysiology of pain in musicians. Whether this is because of a maladaptive response to prolonged stimulation of nociceptors or as a consequence of an expanded somatosensory receptive field as a consequence of music training is not known yet. Besides, enhanced interoception could play a role in the experience of pain in musicians. More data are needed on the differences in pain processing between musicians with and without pain and between musicians and non-musicians.

\section{Implications for daily practice}

The biopsychosocial prevention program was not found to be superior to a physical activity promotion program to prevent or reduce musculoskeletal disorders. What does this mean for daily practice? Our results do not allow to advice on implementation of a specific program, however evaluation of the overall results of this thesis point to the supposition that one prevention program may not fit all students. An adequate analysis of the individual musician should select the best treatment, i.e. body posture, strength, endurance, scapulohumeral rhythm, and/or cardiovascular fitness. We assume that music students should be approached dependent on the stage of their complaints following the model for primary, secondary, and tertiary prevention. Primary prevention aims to prevent injury before it even occurs. Secondary prevention aims to reduce the impact of injury that has already occurred. Tertiary prevention aims to soften the impact of ongoing injury. Unfortunately, very limited evidence is available supporting primary or secondary prevention strategies for music students and even no studies are known evaluating tertiary prevention. Therefore, assumptions are based on knowledge from a major study on occupational health and safety injury prevention strategies in professional orchestras, advising to focus on education, management of health issues, promotion of a positive health culture, physical preparedness, focus on injury prevention, on-going identification and awareness of injuries, sound, and mental health. ${ }^{65}$

In our opinion, health is a shared responsibility of students, conservatory staff and health care providers. Primary prevention is a task of the conservatory. All students should become aware of the importance of health by addressing knowledge and risk perceptions. ${ }^{35}$ As for professional musicians, we believe that education is also the cornerstone of occupational health of music students, since "increasing the understanding and self-efficacy of musicians in relation to their 
health is likely to decrease the risk and severity of playing-related injuries and other playing-related health issues". ${ }^{5}$ Foremost, students should be motivated to change their behavior. Teachers are important role models for their students. ${ }^{66}$ Teachers should set an example for health behavior and should incorporate elements of healthy music making in their regular classes as main causes of injury still relate to poor practice planning and scheduling. ${ }^{51,65}$ Furthermore, by linking health to performance quality, it is expected that students are more likely to incorporate care for their health into daily practice. As performance quality is an internal responsibility, taking care of health should become internalized as well. Further, the educational institute should provide health workshops in which the student is introduced to a variety of courses. Next, the educational institute has to stimulate healthy living, i.e. providing healthy nutrition and stimulating regular physical activity. Health promotion should focus on daily practices and routines of conservatories and the culture at the conservatory should be optimized towards health and wellbeing. ${ }^{36}$ All this should lead to positive attitudes toward health for every student.

Secondary prevention means early diagnosis and treatment. Since help-seeking behavior amongst music students is not optimal ${ }^{67}$ efforts must be made to make specialized health care easily accessible and affordable for every student, preferably at the conservatory. It has been shown that on-site health services for professional musicians providing education and advice related to their provisional diagnosis, provide basic acute management and/or referral to a suitable medical practitioner for further consultation are highly appreciated and encourage selfmanagement and early reporting of injuries. ${ }^{65}$ Translated to the conservatory, at least information must be provided to the students where to get specialized help. Preferably there is a contact person at the conservatory where students can get first advice on their complaints and are directed to the best health care provider. This could for example be done by a physical therapist specialized in the treatment of musicians. It is believed that the presence of a positive cultural health shift and proactive and early detection and management of injuries are prerequisite to a good musician's health. ${ }^{65}$

Last, tertiary prevention is the task of performing arts medicine specialists and involves diminishing performance-related disability. A thorough understanding of the biomechanical requirements of the instruments played and the psychosocial demands a musician encounters are required to optimally treat a musician. The physician should be keen on illness perceptions and should thoroughly explore all potentially influencing factors. ${ }^{68}$ Treatment should therefore be concentrated to specialized musician's clinics in cooperation with a diverse range of specialized therapists, including physical therapy, postural exercise therapy, occupational therapy, speech therapy, and psychology. A multidisciplinary approach with possibilities to focus on for example biomechanical postural aspects, cardiovascular fitness, body awareness, breathing, or mental wellbeing is believed to be needed to diminish performance-related complaints and disability. Physiatrists are trained in the examination and treatment of complaints of the musculoskeletal system and neurological conditions, and are used to work in an interdisciplinary manner. Health promotion is part of their regular job. As the focus of rehabilitation medicine is not only on disease, but focuses at activities and participation, with attention to external and personal factors, I believe that physiatrists are the best-equipped and trained leaders of a multidisciplinary performing arts medicine clinic. 


\section{References}

1. Zaza C, Farewell VT. Musicians' playing-related musculoskeletal disorders: an examination of risk factors. Am J Ind Med. 1997;32:292- 300.

2. Beaton DE, Katz JN, Fossel AH, Wright JG, Tarasuk V, Bombardier C. Measuring the whole or the parts? Validity, reliability, and responsiveness of the Disabilities of the Arm, Shoulder and Hand Outcome measure in different regions of the upper extremity. J Hand Ther. 2001;14(2):128-146.

3. Huisstede BMA, Feleus A, Bierma-Zeinstra SM, Verhaar JA, Koes BW. Is the Disability of Arm, Shoulder, and Hand Questionnaire (DASH) also valid and responsive in patients with neck complaints? Spine. 2009;34(4):E130-E138.

4. Hsu JE, Nacke E, Park MJ, Sennett BJ, Huffman GR. The Disabilities of the Arm, Shoulder, and Hand questionnaire in intercollegiate athletes: validity limited by ceiling effect. J Shoulder Elbow Surg. 2010;19(3):349-354.

5. Hunsaker FG, Cioffi DA, Amadio PC, Wright JG, Caughlin B. The American Academy of Orthopaedic Surgeons Outcomes Instruments. Normative values from the general population. J Bone Joint Surg Am.2002.

6. Zaza C, Charles C, Muszynski A. The meaning of playing-related musculoskeletal disorders to classical musicians. Soc Sci Med. 1998;47:2013-2023.

7. Vanderiet K, Adriaensen H, Carton H, Vertommen H. The McGill Pain Questionnaire constructed for the Dutch language (MPQ-IN). Preliminary data concerning reliability and validity. Pain. 1987;30(395-408).

8. Woldendorp KH, Boonstra AM, Tijsma A, Arendzen JH, Reneman MF. No association between posture and musculoskeletal complaints in a professional bassist sample. Eur J Pain. 2016;20(3):399-407.

9. Samama ALW. Making music without pain. Assen, The Netherlands: Van Gorcum; 1998.

10. Drinkwater EJ, Klopper CJ. Quantifying the physical demands of a musical performance and their effects on performance quality. Med Probl Perform Art. 2010;25:66-71.

11. Hanssen PA, Reed K. Common musculoskeletal problems in the performing artist. Phys Med Rehabil Clin N Am. 2006;17:789-801.

12. Kempen JC, de GrootV, Knol DL, Lankhorst GJ, Beckerman H. Self-reported fatigue and energy cost during walking are not related in patients with multiple sclerosis. Arch Phys Med Rehabil. 2012;93(5):889-895.

13. Borg G, Dahlstrom H. A pilot study of perceived exertion and physical working capacity. Acta Soc Med Ups. 1962;67:21-27.

14. Scherr J, Wolfarth B, Christle JW, Pressler A, Wagenpfeil S, Halle M. Associations between Borg's rating of perceived exertion and physiological measures of exercise intensity. Eur J Appl Physiol. 2013;113(1):147155.

15. Lenderink AF, Zoer I, van der Molen HF, Spreeuwers D, Frings-Dresen MH, van Dijk FJ. Review on the validity of self-report to assess work-related diseases. Int Arch Occup Environ Health. 2012;85(3):229251.

16. de Vet HC, Terwee CB, Mokking LB, Knol DL. Measurement in Medicine. Cambridge, UK: Cambridge University Press; 2011.

17. Ekman A, Dickman PW, Klint A, Weiderpass E, Litton JE. Feasibility of using web-based questionnaires in large population-based epidemiological studies. Eur J Epidemiol. 2006;21(2):103-111. 
18. Balajti I, Darago L, Adany R, Kosa K. College students' response rate to an incentivized combination of postal and web-based health survey. Evaluation \& the health professions. 2010;33(2):164-176.

19. Kok LM, Nelissen RG, Huisstede BM. Prevalence and Consequences of Arm, Neck, and/or Shoulder Complaints Among Music Academy Students: A Comparative Study. Med Probl Perform Art. 2015;30(3):163-168.

20. Kreutz G, Ginsborg J, Williamon A. Health-promoting behaviours in conservatoire students. Psychol Mus. 2009;37(1):47-60.

21. Zetterberg C, Backlund H, Karlsson J, Werner H, Olsson L. Musculoskeletal problems among male and female music students. Med Probl Perform Art. 1998;13:160-166.

22. Zaza C. Playing-related health problems at a Canadian Music School. Med Probl Perform Art. 1992;7:48-51.

23. Stunkel L, Grady C. More than the money: a review of the literature examining healthy volunteer motivations. Contemp Clin Trials. 2011;32(3):342-352.

24. Gibbons RD, Hedeker D, DuToit S. Advances in analysis of longitudinal data. Annu Rev Clin Psychol. 2010;6:79-107.

25. Piantadosi S. Crossover designs. Clinical Trials: A Methodologic Perspective. 2005.

26. Luca de C. The use of surface electromyography in biomechanics. J Appl Biomech. 1997;13:136-163.

27. Halaki M, Ginn K. Normalization of EMG Signals: To Normalize or Not to Normalize and What to Normalize to? Intech open science, 2012.

28. Hermens HJ, Freriks B, Disselhorst-Klug C, Rau G. Development of recommendations for SEMG sensors and sensor placement procedures. J Elektromyograph Kinesiol.2000;10(5):361-374.

29. Chan C, Driscoll T, Ackermann BJ. Effect of a musicians' exercise intervention on performance-related musculoskeletal disorders. Med Probl Perform Art. 2014;29(4):181-188.

30. Meyer J. Acoustics and the performance of music. Translation of the fifth edition, originally published in German by PPV Medien GmbH, Edition Bochinsky, Bergkirchen.: Springer; 2009.

31. Greene JC, Caracelli VJ, Graham WF. Toward a conceptual framework for mixed-method evaluation designs. Educational Evaluation and Policy Analysis. 1989;11(3):255-274.

32. Creswell JW, Plano Clark VL. Designing and conducting mixed methods research.: SAGE Publications, Inc.; 2011.

33. Forsythe L, Heckert A, Margolis MK, Schrandt S, Frank L. Methods and impact of engagement in research, from theory to practice and back again: early findings from the Patient-Centered Outcomes Research Institute. Qual Life Res. 2017.

34. Johnson RB, Onwuegbuzie AJ, Turner LA. Toward a definition of mixed methods research. Journal of Mixed Methods Research. 2007;1(2):112-133.

35. de Vries H, Mudde A, Leijs I, et al. The European Smoking prevention Framework Approach (EFSA): an example of integral prevention. Health Educ Res. 2003;18(5):611-626.

36. Perkins R, Reid H, Araujo LS, Clark T, Williamon A. Perceived Enablers and Barriers to Optimal Health among Music Students: A Qualitative Study in the Music Conservatoire Setting. Front Psychol. 2017;8:968.

37. Spahn C, Voltmer E, Mornell A, Nusseck M. Health status and preventive health behavior of music students during university education: Merging prior results with new insights from a German multicenter study. Musicae Scientiae. 2017;21(2):213-229. 
38. McCrary JM, Halaki M, Ackermann BJ. Effects of Physical Symptoms on Muscle Activity Levels in Skilled Violinists. Med Probl Perform Art. 2016;31(3):125-131.

39. Struyf F, Nijs J, De Coninck K, Giunta M, Mottram S, Meeusen R. Clinical assessment of scapular positioning in musicians: an intertester reliability study. J Athl Train. 2009;44(5):519-526.

40. Ackermann B, Adams R, Marshall E. The effect of scapula taping on electromyographic activity and musical performance in professional violinists. Aust J Physiother. 2002;48(3):197-203.

41. Brandfonbrener AG. Joint laxity and arm pain in a large clinical sample of musicians. Med Probl Perform Art. 2002;17:113-115.

42. Vinci S, Smith A, Ranelli S. Selected Physical Characteristics and Playing-Related Musculoskeletal Problems in Adolescent String Instrumentalists. Med Probl Perform Art. 2015;30(3):143-151.

43. Scheper MC, Engelbert RH, Rameckers EA, Verbunt J, Remvig L, Juul-Kristensen B. Children with generalised joint hypermobility and musculoskeletal complaints: state of the art on diagnostics, clinical characteristics, and treatment. Biomed Res Int. 2013;2013:121054.

44. Ackermann BJ, Kenny DT, O'Brien I, Driscoll TR. Sound Practice-improving occupational health and safety for professional orchestral musicians in Australia. Front Psychol. 2014;5:973.

45. Jabusch HC, Muller SV, Altenmuller E. Anxiety in musicians with focal dystonia and those with chronic pain. Mov Disord. 2004;19(10):1169-1175.

46. Spahn C, Strukely S, Lehmann A. Health conditions, attitudes toward study, and attitudes toward health at the beginning of university study: music students in comparison with other student populations. Med Probl Perform Art. 2004;19:26-33.

47. Stoeber J, Eismann U. Perfectionism in young musicians: relations with motivation, effort, achievement, and distress. Personality Individ Dif. 2007;43:2182-2192.

48. McSweeney L, Araújo-Soares V, Rapley T, Adamson A. A feasibility study with process evaluation of a preschool intervention to improve child and family lifestyle behaviours. BMC Public Health. 2017;17(1):248.

49. Williamon A, Thompson S. Awareness and incidence of health problems among conservatoire students. Psychol Mus. 2006;34:411-430.

50. Rickert DLL, Barrett MS, Ackermann BJ. Are music students fit to play? A case study of health awareness and injury attitudes amongst tertiary student cellists. 2015;33(4):426-441.

51. Hildebrandt $\mathrm{H}$, Nübling M. Providing further training in musicophysiology to instrumental teachers: do their professional students derive any benefit? Med Probl Perform Art. 2004;19:62-69.

52. van Tulder M, Malmivaara A, Koes B. Repetitive strain injury. Lancet. 2007;369(9575):1815-1822.

53. Visser B, van Dieen JH. Pathophysiology of upper extremity muscle disorders. J Elektromyograph Kinseiol. 2006;16(1):1-16.

54. Malfliet A, Leysen L, Pas R, et al. Modern pain neuroscience in clinical practice: applied to post-cancer, paediatric and sports-related pain. Braz J Phys Ther. 2017;21(4):225-232.

55. Plinsinga ML, Brink MS, Vicenzino B, van Wilgen CP. Evidence of Nervous System Sensitization in Commonly Presenting and Persistent Painful Tendinopathies: A Systematic Review. J Orthop Sports Phys Ther. 2015;45(11):864-875.

56. Arendt-Nielsen L, Yarnitsky D. Experimental and clinical applications of quantitative sensory testing applied to skin, muscles and viscera. J Pain. 2009;10(6):556-572. 
57. Linari-Melfi M, Cantarero-Villanueva I, Fernandez-Lao C, Fernandez-de-Las-Penas C, Guisado-Barrilao R, Arroyo-Morales M. Analysis of deep tissue hypersensitivity to pressure pain in professional pianists with insidious mechanical neck pain. BMC Musculoskelet Disord. 2011;12:268.

58. Steinmetz A, Jull GA. Sensory and sensorimotor features in violinists and violists with neck pain. Arch Phys Med Rehabil. 2013;94(12):2523-2528.

59. Zamorano AM, Riquelme I, Kleber B, Altenmuller E, Hatem SM, Montoya P. Pain sensitivity and tactile spatial acuity are altered in healthy musicians as in chronic pain patients. Frontiers in human neuroscience. 2014;8:1016.

60. Munte TF, Altenmuller E, Jancke L. The musician's brain as a model of neuroplasticity. Nat Rev Neurosci. 2002;3(6):473-478.

61. Kuppens K, Struyf F, Nijs J, et al. Exercise- and Stress-Induced Hypoalgesia in Musicians with and without Shoulder Pain: A Randomized Controlled Crossover Study. Pain Physician. 2016;19(2):59-68.

62. Schirmer-Mokwa KL, Fard PR, Zamorano AM, Finkel S, Birbaumer N, Kleber BA. Evidence for Enhanced Interoceptive Accuracy in Professional Musicians. Front Behav Neurosci. 2015;9:349.

63. Uddin Z, MacDermid JC. Quantitative Sensory Testing in Chronic Musculoskeletal Pain. Pain Med. 2016;17(9):1694-1703.

64. Nijs J, Van Houdenhove B, Oostendorp RA. Recognition of central sensitization in patients with musculoskeletal pain: Application of pain neurophysiology in manual therapy practice. Manual Ther. 2010;15(2):135-141.

65. Ackermann B. ARC Sound Practice Project Final Report Vol v 1/03/2017. University of Sydney, 2017.

66. Guptill C. The lived experience of working as a musician with an injury. Work. 2011;40(3):269-280.

67. Bruls VEJ, Bastiaenen CHG, De Bie RA. Non-traumatic arm, neck and shoulder complaints: prevalence, course and prognosis in a Dutch university population. BMC Musculoskel Disord. 2013;14:8.

68. Kok LM, Vliet Vlieland TP, Fiocco M, Kaptein AA, Nelissen RG. Musicians' illness perceptions of musculoskeletal complaints. Clin rheumatol. 2013 Apr;32(4):487-92. 

Chapter 11

\author{
Valorisation
}

Summary

Samenvatting

Dankwoord

About the author

Achievements 



\section{Valorisation}

"Valorisation is the process of creating value from knowledge, by making knowledge suitable and/ or available for social (and/or economic) use and by making knowledge suitable for translation into competitive products, services, processes and new commercial activities" (adapted definition based on the National Valorisation Committee 2011:8). Valorisation is next to education and research a core activity of universities. To describe valorisation in relation to the current thesis, I asked myself the following questions: "What is the relevance of these results? For whom, in addition to the academic community, are these research results of interest and why? Into which concrete services or activities can these results be translated? To what degree can results be called innovative in respect to the existing services? How can plans for valorisation be shaped?"

\section{Relevance}

My interest in performing arts medicine was raised during medical school. As a fanatical amateur musician I started watching musicians play from a "biomechanical" point of view. With increasing knowledge regarding motor learning acquired during my residency in Physical Medicine \& Rehabilitation I was more and more impressed with the elegance with which musicians play their instrument. An incredible refined fine motor control is a prerequisite to play the instrument in the best possible way. Not only the fine motor control, but also control over thoughts and emotions contribute to a great performance. Mental pressure while performing is high. Conductor, public and/ or colleagues expect a perfect performance. Hence, while I was enjoying a beautiful concert, the musicians were constantly striving to perform at their best.

In general, the musician's profession is seen as artistic and free. The fact that a musician's occupation comes with high physical and mental demands is not widely recognized. Musicians are prone to developing injuries. This thesis focused on prevention of musculoskeletal complaints in musicians. Performing arts medicine is a relative young field of interest related to health care and research. Experts commonly agree on the relevance and necessity of educating performing artists regarding occupational health issues. Awareness regarding the often troublesome physical and mental health state of musicians is lacking. Professional musicians, frequently having experienced playing-related musculoskeletal disorders themselves, acknowledge the importance of health for a good playing quality. Music students are however less aware of their risk for developing musculoskeletal complaints and the consequences for playing quality. When starting this project, health care provided to music students at Dutch conservatories was limited. Some conservatories were more engaged with health policy then others. Health education ranged from incidental workshops to possibilities for on-site consultation of a physiotherapist or medical specialist. None of the participating conservatories offered obligatory and structural health-related courses. 


\section{Target group}

Main goal of this work was to research whether a prevention program could contribute to the reduction of disability due to musculoskeletal disorders. It was hypothesized that participation in a biopsychosocial health course could lead to increased awareness about the importance of health, educate students about healthy behaviour, playing posture, and learn them to deal with psychosocial aspects of being a musician. Students participated in a biopsychosocial course or a physical activity promotion course and results were compared. Disability levels seemed to decline over the course of 3 years in both groups. No differences between groups were observed in any of the primary or secondary outcome measures. However, students in the biopsychosocial group confirmed that they learned new aspects about prevention of physical complaints related to music making and found that the course was an addition to their education. The course created an open atmosphere to talk about physical and mental problems which is very important considering the taboo that encompasses musicians' health complaints. Results are in first place relevant for students at the conservatory, but also for music teachers and conservatory management. A limitation of the current research, as mentioned in the process evaluation, was that implementation was performed from an outsiders (research) perspective. For many reasons it would be more feasible if the conservatory itself was the driving force of the health course and adopted the course in its regular curriculum. Prior research reports that it is believed that music schools can change collective values, beliefs and actions of their students and could be able to induce a cultural shift increasing the focus on health behavior.' Both students and music teachers agreed that places of music education should offer structured health education related to playing the instrument. ${ }^{2}$ In addition, experience from our trial reveals that students are more motivated to participate when they notice that the conservatory encourages the course. It is known that professional musicians have more health awareness and better attitudes to injury than students. Students expect guidance from their teachers on this theme, however teachers do not feel equipped to do so. ${ }^{2}$ Therefore, involving music teachers in regular health classes at the conservatory will enable them to learn about musician's health and start incorporating health-related aspects in their music classes as well. ${ }^{3}$

Next to a health-related effect, there could also be a beneficial societal and economical effect of offering a prevention program to music students at the conservatories. If a prevention program is able to actually reduce complaints, this could decrease direct and indirect health care costs. Direct health care costs are costs for consulting a general practitioner, medical specialist, physiotherapist, diagnostics, medications, etc. Indirect health care costs are costs due to absenteeism, tutoring, study delay, or drop-out from study. Conservatory management could be especially interested in the results of a prevention program on preventing drop-out or disease to minimize these indirect costs for the school. Although we planned to perform a cost-effectiveness analysis of the randomized controlled trial, acquired data were limited and did not allow to perform a reliable cost-effectiveness analysis.

Work-related injuries have larger financial and societal consequences later on in the musician's career. Musicians work mostly on a freelance base or are employed by an orchestra. Freelance working musicians often have no insurance, meaning that if they are not able to work because 
of disease, they do not have any income. This can have serious consequences for the family's financial situation and could lead to dependency of state support. Musicians who are employed by an orchestra are more likely to be paid when they are on sick leave. Professional associations, the musician's union, or employers of musicians could therefore also be interested in results from this first prevention trial in music students. It is acknowledged that results cannot be generalized from students to professionals one on one, still it is believed that the rationale of the prevention program is also applicable to professionals. Concluding, musculoskeletal complaints in musicians have an impact on health, society and economy. It is therefore important to implement effective preventive strategies, both for music students as for professional musicians.

\section{Activities/ products}

Our results do not allow to advice on implementation of a specific program, however evaluation of the overall results of this thesis point to the supposition that one prevention program may not fit all musicians. An adequate analysis of the individual musician probably can help to select the best treatment, i.e. body posture, strength, endurance, scapulohumeral rhythm, and/ or cardiovascular fitness. Besides, the influence of psychosocial factors as performance anxiety or stress should not be forgotten. An overlapping and recurring theme found to be a barrier for health promotion is the taboo to speak about one's problems. Our results did suggest that the biopsychosocial program was successful in stimulating discussions about health between students and their teachers. A larger cultural change is probably needed to be able to effectively address musician's complaints. This can only be accomplished when musicians, conservatories, unions, employers and performing arts specialist cooperate. Increasing awareness, knowledge, and motivation are the first important steps that need to be taken.

Based on information acquired during the project of this thesis, multiple activities have been undertaken to increase awareness and knowledge regarding playing-related musculoskeletal disorders for a diverse population. Next to the scientific output, we provided information for musicians, medical specialists and paramedics, and for the general population. An overview:

1. Musicians
a. Health workshop at conservatory
b. Health screening first year students conservatory
c. Publication of results in magazine: De Klarinet (The Clarinet)

2. Medical specialists / paramedics
a. Presentation for medical school students
b. Presentation for medical officers
c. Presentation for rehabilitation specialists
d. Workshop for rehabilitation specialists
e. Publication in postural exercise therapy magazine
f. Publication in ergonomics magazine

3. General population
a. Radio interview
b. Publication in newspaper 
In summary, it was noticed that musician's health is an appealing subject for the general population. Medical professionals lack knowledge about the specific characteristics and needs of musicians. Music students highly appreciated the workshop and screening and professional musicians seem to be interested to learn more about specific playing-related health issues. We therefore conclude that there is a need to further educate medical professionals and musicians. Education for medical professionals is a core task of the Dutch Performing Arts Medicine Association (NVDMG) were medical doctors and therapists meet and discuss their collective vision to provide "custom made medical guidance for the performing artist." Media attention is one of the pillars by which an increased awareness and knowledge about performing artists' health can be acquired and it is strongly encouraged that members share their information publicly. Next, education of musicians is a shared responsibility for the educators at the conservatories and performing arts specialists. Cooperation is necessary to optimally increase awareness and knowledge.

\section{Innovation}

During the course of this project, health care policy in conservatories has improved. More structural health screenings and courses are currently offered on a regular basis to music students. However, there still is a large variety between schools and courses are more practice-based then evidence-based. One innovative application is the performance of a health screening for first year music students conducted at the Sport Medisch Centrum Tilburg, in cooperation with the author of this thesis. Starting in the school year 2017-2018 all first year students were invited to participate in a health screening. Students filled out a screening questionnaire, as proposed by the Performing Arts Medicine Association, and were physically tested by a physiotherapist on aspects as physical condition, balance, strength, range of motion, and movement patterns. When playing-related complaints or psychological problems were present, students also consulted a physiatrist, specialized in performing arts medicine. Based on screening results, students received advice on how to optimize their health in relation to playing their instrument. Some students were surprised by the fact that they were invited for a health screening while pursuing a study in the arts; others were convinced about the importance of health when becoming a professional musician. It seemed that the screening did make the students aware of the importance of health, and provided them with relevant information on where to receive specialized care.

As this thesis pointed out, the current scientific knowledge regarding risk factors for musculoskeletal complaints in musicians is scarce. The contents and implementation of this health screening were therefore mostly practice-based, rather than evidence-based. There is no scientific evidence available that informs about which risk factors truly influence musculoskeletal complaints. The risk exists that tests are performed and advices are given that might be overdone. However, as these advices relate to optimizing health, it is believed these advices cannot harm the student. Benefit of implementing a health screening for music students at this time point is that it does create awareness on the importance of health for a musician and it lowers barriers to contact health professionals at moments truly needed. Future prospective research should assess the effectiveness of this health screening on the reduction of the (impact of) musculo- 
skeletal complaints. The tests performed during screening should be continuously evaluated and critically approached. It would be interesting to find out whether costs of screening outweigh costs attributable to disease at a later stage in career. Further, it should be questioned who is responsible for the additional costs of this health screening: the student himself, the school, or the health care insurance? Next, it would be interesting to find out whether this health screening with treatment advice could also be marketed into a health plan for the professional orchestras. The employers or the musician's union could support these screenings for the employees / members. It should be investigated whether there is a market to introduce this new product.

To conclude, the value of this thesis, next to the scientific output, lies in its effect on the improved awareness on the importance of health for musicians in a wide population. Knowledge was translated into a diverse range of publications, presentations, a workshop and an innovative health screening for music students. Still, a structural, evidence-based, health care approach for musicians is a hope for the future / in Dutch: "TOEKOMSTMUZIEK." 


\section{References}

1. Williamon A, Thompson S. Awareness and incidence of health problems among conservatoire students. Psychol Mus. 2006;34:411-430.

2. Rickert DLL, Barrett MS, Ackermann BJ. Are music students fit to play? A case study of health awareness and injury attitudes amongst tertiary student cellists. Int J Music Educ.2015;33(4):426-441.

3. Hildebrandt H, Nübling M. Providing further training in musicophysiology to instrumental teachers: do their professional students derive any benefit? Med Probl Perform Art. 2004;19:62-69. 


\section{Summary}

\section{Part I Characteristics of playing-related musculoskeletal disorders}

Prevalence of playing-related musculoskeletal disorders (PRMD) in musicians is high. A survey was conducted amongst third and fourth year music students of eight Dutch conservatories to explore current levels of musculoskeletal complaints and associated factors. Students answered questions about musculoskeletal complaints, disability, quality of life, and physical activity. As the physical exertion that is required to play a musical instrument is often compared to that of an athlete, it was hypothesized that physical activity level might be a factor related to musculoskeletal complaints. The second aim of this first study was therefore to explore the level of physical activity in music students and to study the relationship between different levels of physical activity (moderate and vigorous intensity) and the presence of musculoskeletal complaints in this specific population. It was found that $67 \%$ of the music students reported musculoskeletal complaints (pain, discomfort) in the past 7 days. Also, 52\% experienced disability related to playing the instrument. With respect to quality of life, the physical component score was in range with standardized values from the norm population, while the mental component score of music students was lower than the norm population. Higher pain intensity was found to be associated with lower level quality of life, and more disability. More disability was associated with lower quality of life. Next, music students were mainly involved in light- to moderate-intensity physical activities and were barely involved in vigorous-intensity physical activity. Sixty-two percent of music students accomplished 30 minutes of moderate-intensity physical activity on a minimum of 5 days/week. Ten percent of the students accomplished 20 minutes of vigorous-intensity physical activity on a minimum of 3 days a week. Physical activity was not significantly associated with musculoskeletal complaints in music students. Physical activity level was not associated with pain level on a numerical rating scale and there were no differences in prevalence of complaints in the past 7 days between students complying with moderate- or vigorous-intensity recommendations and students who did not. The hypothesis that a lower physical activity level is correlated with more musculoskeletal complaints has to be rejected. It is plausible that neither the amount nor intensity of physical activity, but rather the specificity of the training, is the most important element in the relationship between physical activity and PRMDs.

Following, an extensive literature review was conducted to search for and synthesize the best available evidence on risk factors for musculoskeletal disorders in professional musicians and music students. One case-control and 14 cross-sectional studies were included. Methodological quality was in general low. Large heterogeneity existed in study design, population, measurement of determinant and outcome and analysis techniques. Data were presented descriptively. The principle finding of this review was that no conclusion can be drawn regarding risk factors for musculoskeletal disorders in (pre-) professional instrumental musicians since no studies using a prospective design were found, making it impossible to draw conclusions about causality. Current available information only gives us an indication of possible relationships. Results were defined as consistent if at least two papers reported the determinant to be associated or not to be associated with the outcome. Univariate and multivariate results were described separately. 
Consistent results indicate that (upper) string players experience more musculoskeletal disorders than other instrumentalists. An interaction between being female and violin playing suggests that not gender, but rather type of instrument is the most important factor in the relationship between gender and PRMD. Performance anxiety and work-related stress seemed to be positively related with musculoskeletal disorders in musicians. Musicians who have experienced PRMD seemed to be at higher risk of developing recurrent PRMD. Consistent results indicating no association with PRMD were found for sports or exercise behavior, cigarette smoking and work-related factors such as choice/ influence over work, support at work or orchestra category. No consistent results were found considering the effect of physical/anthropometric features of the musician and biomechanical factors or playing load related to playing the instrument. Also, no conclusions can be made regarding the association of age, number of years playing or duration of employment with PRMD and the possible protective role of physical or musical warm-up. This systematic review highlights the lack of adequate research into risk factors for musculoskeletal complaints in musicians. Currently, no clear evidence on risk factors for (playing- related) musculoskeletal disorders in instrumental musicians could be found mainly due to the lack of prospective studies and large heterogeneity between studies.

As the systematic review showed that there is no uniformity in the use of outcome measures in musician's literature, and little is known about validity of outcome measures for musicians specifically, there was a need to evaluate psychometric characteristics of the Disabilities of Arm, Shoulder and Hand questionnaire (DASH), performing arts module. The performing arts module of the DASH was applied as primary outcome measure in our randomized controlled trial. The DASH has been validated extensively; however the performing arts module was not. The current research showed that the performing arts module has a good internal consistency, meaning that the items measure the same constructs. None of the items would increase reliability if deleted. The performing arts module showed a good discriminative validity between students with and those without PRMD. Construct validity was found to be moderate, the performing arts module correlated highly with the DASH and moderately with Pain Disability Index and physical sub score of Short Form-36 as expected. Besides, it was found that the general DASH scores were rather low in this music student population, suggesting that musculoskeletal complaints have little influence on activities in daily life. The performing arts module appeared to be more sensitive to measure playing-related disability. In addition, we analyzed whether pain and PRMD were associated. The constructs pain and PRMD are often used interchangeably in musician's research. The definition of PRMD is broader than pain, and incorporates also weakness, paresthesia, and lack of control, for example. PRMD were mostly reported in the arm, shoulder, and hand region; pain was mostly reported in the back and lower extremity region. Pain and PRMD showed limited correlation. One can have relatively mild symptoms, and these can still have a major impact on the ability to perform at the level to which one is accustomed. In other words, PRMD are not always experienced as pain. Our findings may point to an underlying tolerance for pain as a "normal" occurrence during the everyday work of conservatory students. Results underline that PRMD and pain are different constructs. The construct PRMD seems to be more sensitive than pain when assessing physical complaints that musicians encounter. 


\section{Part II Physiological effects of body posture while playing a musical instrument}

Limited evidence is available on the (patho) physiology of playing a musical instrument. In clinical practice, strong associations between sustained 'poor' posture and the presence of musculoskeletal complaints in musicians are assumed. Body posture according to postural exercise therapy Mensendieck/ Cesar method Samama (MmS) is extensively described in this thesis. This therapy is frequently used in clinical practice to treat playing-related complaints and is hypothesized to contribute to prevention and/or treatment of musculoskeletal complaints. Key element in MmS postural exercise therapy is the prevention of imbalance between muscles providing stability and muscles used to play the instrument. It is believed that while playing in a body posture according to MmS postural exercise therapy, stability is increased by higher activity levels of proximal muscles. Consequently, the improved control provided by these proximal muscles reduces the muscle load of distal muscles, thereby enabling the player to use the arm and shoulder muscles more dynamically and coordinated while playing the instrument. Next, musicians who have participated in MmS postural exercise therapy not only anecdotally report a decrease in musculoskeletal complaints, but also experienced less fatigue when playing in a body posture according to the MmS postural exercise therapy compared to their habitual posture. Therefore it was hypothesized that fatigue would be related to energy expenditure. In order to better understand the potential working mechanisms of the MmS postural exercise therapy, the effect of body posture on energy expenditure and muscle activity was investigated. Research questions were:

1. Is energy expenditure when playing in a body posture according to MmS postural exercise therapy lower compared to playing in a non-optimized body posture?

2. Does playing in posture according MmS postural exercise therapy lead to a higher activity of erector spinae, latissimus dorsi, lower trapezius and pectoralis major muscles and reduced activity of upper trapezius, biceps brachii and brachioradialis muscles compared to playing in habitual posture?

To answer the first research question, a study was designed in which woodwind musicians who were familiar with the posture according to postural exercise therapy MmS were invited to play their instruments in a respiration chamber. Eighteen musicians participated and played their instruments for 30 minutes twice: once in nonoptimized body posture, and once in a posture according to the MmS postural exercise therapy. Participants were randomized to the two different postures in a crossover design AB/BA. Playing sessions were preceded and followed by 60 minutes of rest. Energy expenditure was measured with indirect calorimetry. In contrast to the hypothesis, it was found that energy expenditure was higher while playing a wind instrument in the MmS postural exercise therapy position. Two explanations come to mind: first, the assumption that a feeling of fatigue/ exertion would be related to energy expenditure is not correct. Fatigue can result from physical, cognitive, and emotional exertion and is therefore not necessarily related to energy expenditure. Second, in retrospect, it can be assumed that energy expenditure in the MmS postural exercise therapy position is higher since it is a more active posture. Because musicians must concentrate and focus on posture, presumably their muscle activity is higher to maintain this posture. 
In the second study, electromyography (EMG) was used to investigate differences in muscle activity pattern between MmS postural exercise therapy and the habitual posture while playing the clarinet. Musculoskeletal complaints are highly prevalent in clarinetists and are related to high armload while playing. It was hypothesized that postural exercise therapy may be used to adapt muscle activity patterns while playing, and could also contribute to better sound quality. The sample consisted of 20 healthy (pre)professional clarinet players that each played a 60-second musical excerpt in their habitual posture, followed by instructions in body posture according to postural exercise therapy MmS, and then played in the latter position. Two-dimensional goniometric analysis was used to calculate body posture, muscle activity was measured bilaterally using surface EMG, and sound quality was judged by the musicians themselves and by a blinded expert panel who listened to recordings. In the MmS postural exercise therapy position, a significantly smaller low thoracic angle, smaller high thoracic angle, and larger pelvic tilt angle were found. Meaning that the upper body was placed forward and the pelvis tilts posteriorly, as compared to the habitual posture. EMG results indicated that the left and right erector spinae (measured at L3) and left and right lower trapezius were more active, whereas left upper trapezius and right brachioradialis were less active in the posture according MmS postural exercise therapy compared to the habitual posture. Clinically important changes in muscle activity pattern are the lower activity of the left upper trapezius and right brachioradialis. The left upper trapezius is often moved excessively in clarinet players to express musicality and is in that way hypothesized to be at risk for injury. The right brachioradialis is statically loaded for prolonged periods of time, by carrying the weight of the instrument, and is therefore also hypothetically at risk for injury. Any reduction of redundant muscle activity in these muscles above the muscle activity truly needed to play the instrument could be beneficial for the prevention and/ or treatment of PRMDs. Considering sound quality, most participants experienced better sound quality while playing in the posture according MmS postural exercise therapy. Blinded experts noticed that sound quality depended on body posture, but were not able to consistently elect whether one of the two postures had the better sound quality. In summary, a change in posture corresponded with a change in muscle activity pattern and a change in sound. It seems that postural exercise therapy may change muscle activity patterns. By increasing stability, a decrease in activity of the upper extremity muscles can be induced.

\section{Part III Can musculoskeletal complaints in music students be prevented?}

Music students are at increased risk compared to non-music students of developing musculoskeletal complaints. Music education in conservatories is dedicated to learning to play the musical instrument in the most virtuosic way. Musicians' health is of significant importance to performance quality due to the very high physical and mental skills required to excel; however, current health responsibility and health-promoting behavior in conservatory students are low. Therefore, it seems logical to address health and injury prevention during conservatory studies. The last part of this thesis focused on researching effectiveness of a prevention program. The "PREvention STudy On preventing or reducing disability from musculoskeletal complaints 
in music students," or "PRESTO" trial is a multicenter randomized controlled trial conducted at five Dutch conservatories to study the effectiveness of a biopsychosocial prevention course, compared to physical activity promotion, to prevent or reduce disability due to musculoskeletal disorders in music students. Included were 170 first and second year students who were randomly allocated and stratified by conservatory to either experimental (PRESTO-Play) or control condition (PRESTO-Fit). The aim of PRESTO-Play was to educate students about body posture while playing the instrument, and to discuss psychosocial aspects related to the musician's health, while incorporating health behavior change principles. PRESTO-Fit was designed to control for attention and aimed at stimulating physical activity levels using a 10,000 step per day approach according Dutch guidelines for activity promotion for the general population. The courses were implemented as voluntary extra-curricular classes during the first or second academic year in either 2012-2013 or 2013-2014. Time spent on both interventions was aimed to be equal, about 18 hours in total, with PRESTO-Play consisting of 11 classes, and PRESTO-Fit of 5 classes with additional time spent increasing daily activity level in leisure time. Rationale for PRESTO-Play and PRESTO-Fit were supported by current literature and clinical experience. PRESTO-Play was provided by experienced postural exercise therapists Mensendieck/ Cesar, method Samama, and PRESTO-Fit by therapists with an affinity for physical activity education. All therapists were trained to follow a standardized protocol before the start of the first and second inclusion year. Outcomes were measured using questionnaires at baseline, during and at the end of the intervention, and at 16- and 24 month follow-up. By the end of the intervention, $62 \%$ and $58 \%$ of PRESTO-Play and PRESTO-Fit participants respectively were still enrolled in the trial. At 2-year follow-up, participation rate had dropped to 32\% and 29\% for PRESTO-Play and PRESTO-Fit respectively. Intention-to-treat analysis revealed that during the intervention and until the end of follow-up, there was no difference in disability between both interventions for any primary or secondary outcome. Disability declined over 2 years with 33\% in PRESTO-Play and 49\% in PRESTO-Fit. However, the design of this study does not permit to test and hence conclude whether this is an intervention effect or due to natural course. Nevertheless, participants in PRESTO-Play reported to have learned about prevention of physical complaints related to playing their music instrument, and rated the course significantly higher compared to PRESTO-Fit.

When conducting a multicenter, multifaceted trial in daily practice, a wide variety of factors is encountered during execution and follow-up that may influence study findings and outcomes. To be able to interpret results correctly, it is therefore important to evaluate study design and contents of the intervention under study, and to examine how the interventions were actually implemented. Independent external review may reveal strengths and weaknesses of the trial, and more specifically the content of treatments provided. In addition, including comprehensive views of all possible stakeholders provides valuable additional information on barriers and facilitators of implementation. The aim of the last study was to evaluate the PRESTO trial by answering two questions: 1) Were study design and contents of the interventions valid? 2) Were the interventions implemented as intended?

The external experts' review supported the design and contents of the trial. Dose delivered was good. Participants in PRESTO-Play confirmed that they learned new aspects about prevention of physical complaints related to music making and found that the course was an addition to 
their education. The course created an open atmosphere to talk about physical and psychological problems. Postural exercise therapy was delivered according to protocol. Participants appreciated it most when education was focused on playing the instrument. Behavioral change and psychosocial principles in PRESTO-Play might have not been implemented optimally. Moderate fidelity in both groups and too little contrast between interventions could have further influenced results. Attendance rate and a presumed lack of generalizability further decreased possible effect of the interventions. The RCT encountered a high percentage of students who were lost-to-follow-up. Participation rate in the study (reach) and contextual factors were found to be the largest influencing factors. For example, it was not possible to schedule classes so that all students could participate, some students were not convinced of the importance to participate and many lacked engagement from their respective conservatories.

The biopsychosocial prevention program was not found to be superior to a physical activity promotion program to prevent or reduce disability due to musculoskeletal disorders. Our results do not allow to advice on implementation of a specific program, however evaluation of the overall results of this thesis point to the supposition that one prevention program may not fit all students. An adequate biopsychosocial analysis of the individual musician should select the best treatment. It is assumed that music students should be approached dependent on the stage of their complaints following the model for primary, secondary, and tertiary prevention. When designing a prevention program to reduce musculoskeletal complaints in musicians, it is recommended that much emphasis is placed on conditional aspects leading to health behavior change. Future research should expand current knowledge on how to improve health responsibility and health behavior in music students. Second, future research should focus on identifying subgroups so that interventions can be designed targeted to individual needs. Last, it is recommended that health courses and research should be embedded as an integral component of conservatory education, so that motivation for behavioral change is enhanced, accessibility and communication can be optimized, and attendance is encouraged. 


\section{Samenvatting}

\section{Deel I Musculoskeletale klachten gerelateerd aan het bespelen van een muziekinstrument}

Musculoskeletale klachten gerelateerd aan het bespelen van een muziekinstrument worden ook wel playing-related musculoskeletal disorders, of PRMD, genoemd. De prevalentie van PRMD is hoog. Om het voorkomen van klachten bij muziek studenten in Nederland te onderzoeken werd er een vragenlijst onder derde- en vierdejaars studenten op acht conservatoria verspreid. Tevens werden factoren die geassocieerd zijn met musculoskeletale factoren onderzocht. Studenten beantwoordden vragen over de aanwezigheid van musculoskeletale klachten (pijn, ongemak), beperkingen, kwaliteit van leven en de hoeveelheid lichaamsbeweging. Het tweede doel van dit onderzoek was om te onderzoeken hoe veel lichaamsbeweging muziek studenten hebben en of het activiteitenniveau gerelateerd is aan de aanwezigheid van musculoskeletale klachten. Er wordt namelijk vaak gezegd dat de inspanning die een musicus levert vergelijkbaar is met de inspanning van een atleet. Maar heeft de muziekstudent ook zo veel lichaamsbeweging als een atleet?

Ten eerste toonde dit onderzoek aan dat $67 \%$ van de muziek studenten musculoskeletale klachten heeft ervaren in de afgelopen week. In totaal 52\% van de studenten ondervond ook beperkingen bij het bespelen van hun muziekinstrument door deze musculoskeletale klachten. Kwaliteit van leven werd weergegeven in een fysieke en mentale score. De score voor fysieke kwaliteit van leven van muziek studenten was vergelijkbaar met de normpopulatie. Daarentegen rapporteerden de muziek studenten een duidelijk lagere mentale kwaliteit van leven in vergelijking met de normpopulatie. Resultaten toonden verder aan dat een hogere pijn intensiteit gerelateerd was aan een lagere kwaliteit van leven en meer beperkingen. Meer ervaren beperkingen waren ook geassocieerd met een lagere kwaliteit van leven. Resultaten betreffende het activiteitenniveau toonden aan dat muziek studenten vooral activiteiten verrichten van licht tot gemiddeld inspanningsniveau en maar zeer weinig intensieve inspanning leveren. Twee-en-zestig procent van de muziek studenten behaalt de Nederlandse Norm Gezond Bewegen, die stelt dat men gedurende 5 dagen per week minstens 30 minuten gemiddeld-intensief moet bewegen. Maar 10\% van de muziek studenten behaalde de Fitnorm, die gelijk staat aan 20 minuten intensieve activiteit gedurende minimaal 3 dagen per week. De hoeveelheid lichaamsbeweging was niet gerelateerd aan de aanwezigheid van musculoskeletale klachten. Het activiteiten niveau was niet geassocieerd met de mate van pijn en er waren geen verschillen in voorkomen van musculoskeletale klachten tussen studenten die wel of niet aan de Nederlandse Norm Gezond Bewegen of de Fitnorm voldeden. De hypothese dat minder (intensieve) lichaamsbeweging gerelateerd zou zijn aan meer musculoskeletale klachten kon op basis van deze studie niet bevestigd worden. Het is mogelijk dat niet de hoeveelheid of de intensiteit van lichaamsbeweging, maar juist de specificiteit van de training de belangrijkste factor is in de relatie tussen lichamelijke activiteit en PRMD.

Vervolgens werd er een systematisch literatuuronderzoek verricht naar de best beschikbare informatie over risicofactoren voor het ontstaan van musculoskeletale klachten bij professionele musici en muziek studenten (pre-professionals). Slechts één patiënt-controle onderzoek werd gevonden dat daarmee het hoogste niveau van bewijs tot op dit moment levert. Andere 
geïncludeerde studies, 14 in totaal, waren retrospectief in opzet en waren in het algemeen van lage methodologische kwaliteit. Bovendien bestond er veel variatie (heterogeniteit) in de studies betreffende studie opzet, populatie, uitkomstmaten, en analyse technieken. Verschillende meetinstrumenten werden gebruikt; vaak zelf ontwikkeld of niet gevalideerd voor het gebruik in deze specifieke populatie. Data werden daarom alleen beschrijvend gerapporteerd. De belangrijkste conclusie die getrokken kan worden na het verzamelen van de huidige beschikbare literatuur is dat er geen prospectief onderzoek gedaan is dat informatie geeft over risicofactoren voor musculoskeletale klachten bij musici. Daarom kunnen er geen causale verbanden worden aangetoond. De huidige literatuur geeft dus alleen associaties weer en geen causaliteit. Om de huidige stand van zaken weer te geven werd er gekozen om consistentie associaties te rapporteren. Resultaten werden consistent genoemd als er twee of meer artikelen een significante associatie met de risicofactor aantonen. Resultaten werden gecategoriseerd naar socio-demografische, gezondheidsgerelateerde, fysieke of psychosociale factoren, arbeids-gerelateerde factoren, en factoren gerelateerd aan preventie. Er werd een onderscheid gemaakt tussen univariate en multivariate resultaten. Consistente resultaten toonden aan dat spelers van snaarinstrumenten meer musculoskeletale klachten ervaren dan andere instrumentalisten. Een significant interactie effect tussen vrouwelijk geslacht en het bespelen van de viool suggereert dat niet het geslacht, maar juist het type instrument de belangrijkste factor is in de relatie met musculoskeletale klachten. Ook de aanwezigheid van podiumangst en arbeids-gerelateerde stress lijkt gerelateerd te zijn aan het ontstaan van klachten. Musici die al eens eerder klachten doorgemaakt hebben, hebben een hoger risico op terugkeer van klachten. Consistente resultaten laten zien dat er geen relatie lijkt te bestaan tussen musculoskeletale klachten en lichaamsbeweging, roken, en arbeids-gerelateerde factoren zoals keuze of invloed op werk, steun op het werk, of orkest categorie. Literatuur bevindingen zijn niet consistent wat betreft het effect van biomechanische of fysieke factoren, de duur of belasting tijdens het musiceren, leeftijd, aantal jaren ervaring, of het uitvoeren van een warming-up. In conclusie, deze literatuurstudie benadrukt dat er op dit moment een gebrek is aan adequaat onderzoek naar risicofactoren voor het ontstaan van musculoskeletale klachten bij musici. Er kunnen geen conclusies worden over risicofactoren. Onderzoek met een prospectief, longitudinaal design is nodig om meer te kunnen zeggen over risicofactoren voor het ontstaan van musculoskeletale klachten bij musici.

Uit het literatuuronderzoek bleek dat er geen uniformiteit is in het gebruik van uitkomstmaten in onderzoek naar gezondheid van musici. Er is ook weinig bekend over de validiteit van uitkomstmaten gebruikt in een populatie van musici. Daarom was het noodzakelijk om psychometrische eigenschappen te onderzoeken van de podiumkunsten module van de DASH vragenlijst. Deze vragenlijst meet namelijk onze primaire uitkomstmaat in onze gerandomiseerde en gecontroleerde trial (RCT), namelijk: beperkingen gerelateerd aan het musiceren. De DASH is al uitgebreid gevalideerd, maar de podiumkunsten module niet. Uitkomsten lieten zien dat de podiumkunsten module een goede interne consistentie heeft, hetgeen betekent dat de verschillende items vergelijkbare constructen meten. De betrouwbaarheid neemt niet toe indien een van de items verwijderd zou worden. De podiumkunsten module toonde goede onderscheidende vermogens (discriminatieve validiteit) tussen studenten met en zonder PRMD. De construct validiteit was matig, en de podiumkunsten module correleerde, zoals verwacht, hoog met de DASH en matig 
met de Pain Disability Index en fysieke sub score van de Short Form-36. Verder was het opvallend dat de algemene DASH scores vrij laag waren in deze specifieke populatie van muziek studenten. Dit suggereert dat musculoskeletale klachten maar weinig invloed hebben op algemene activiteiten in het dagelijks leven. Het bleek dat de podiumkunsten module sensitiever was in het meten van beperkingen gerelateerd aan het bespelen van een muziekinstrument. Ten tweede werd er bekeken of er een relatie is tussen pijnklachten en musculoskeletale klachten gerelateerd aan het bespelen van een muziekinstrument (PRMD). De constructen pijn en PRMD worden vaak door elkaar gebruikt in onderzoek. De definitie van PRMD is echter breder dan die van pijn en omvat bijvoorbeeld ook tintelingen, spierzwakte of controleverlies. In het huidige onderzoek werd pijn vooral aangegeven in de rug en onderste extremiteiten, PRMD werden vooral aangegeven in arm, schouder en hand. De associatie tussen pijn en PRMD was laag zoals verwacht. PRMD worden niet altijd ervaren als pijn. Dit wijst mogelijk op een onderliggende tolerantie voor pijn als "normaal" gedurende de dagelijkse activiteiten van de muziek student. Resultaten wijzen erop dat musici PRMD en pijn verschillend interpreteren en het construct PRMD lijkt het meest sensitief te zijn.

\section{Deel II Fysiologische aspecten van musiceerhouding}

Er is nog maar beperkt onderzoek gedaan naar de (patho)fysiologie van het bespelen van een muziekinstrument. In de klinische praktijk worden sterke associaties vermoed tussen een "slechte" musiceerhouding en het ontstaan van musculoskeletale klachten. Een Nederlandse oefentherapeut Mensendieck, mevrouw Samama, heeft haar eigen specifieke methode ontwikkeld voor de behandeling van musici met lichamelijke klachten. Deze musiceerhouding wordt uitgebreid beschreven in het huidige proefschrift. De methode wordt in de dagelijkse praktijk frequent toegepast ter behandeling of preventie van klachten bij musici. Een belangrijk element uit deze methode is de preventie van een dysbalans tussen spieren die stabiliteit bieden en spieren die gebruikt worden om het instrument te bespelen. Over het musiceren in de houding volgens oefentherapie Mensendieck, methode Samama (MmS), wordt aangenomen dat de stabiliteit vergroot wordt door een hogere activiteit van proximale spieren. De vergrote stabiliteit leidt hypothetisch tot een vermindering van de belasting op distale spieren, waardoor de arm en schouder spieren meer dynamisch en gecoördineerd gebruikt kunnen worden. Musici die behandeld zijn volgens oefentherapie MmS, rapporteren niet alleen een vermindering van klachten, maar voelen zich ook minder moe na het musiceren in vergelijking met het musiceren in hun oude, gewoontehouding. Mogelijk is vermoeidheid gerelateerd aan energiegebruik. Om de potentiële werkingsmechanismen van oefentherapie MmS te onderzoeken bekeken we de effecten van lichaamshouding op energiegebruik en spieractiviteit. Onderzoeksvragen waren:

1. Is energiegebruik tijdens musiceren in houding volgens oefentherapie MmS lager in vergelijking met energiegebruik gedurende musiceren in een niet optimale houding?

2. Leidt musiceren in houding volgens oefentherapie MmS tot een hogere activiteit van $\mathrm{m}$. erector spinae, $\mathrm{m}$. latissimus dorsi, $\mathrm{m}$. trapezius descendens, en $\mathrm{m}$. pectoralis major en leidt het tot een verminderde activiteit van $\mathrm{m}$. trapezius ascendens, $\mathrm{m}$. biceps brachii en $\mathrm{m}$. brachioradialis in vergelijking met de gewoontehouding? 
Om de eerste onderzoeksvraag te beantwoorden werd er een studie opgezet waarin blaasinstrumentalisten die al bekend zijn met oefentherapie MmS gevraagd werden om te komen musiceren in een respiratiekamer. Achttien musici deden mee en bespeelden hun instrumenten twee keer gedurende een 30-minuten durende periode: één keer in een niet optimale houding en één keer in de houding volgens oefentherapie MmS. De volgorde van houding waarin gemusiceerd werd, werd gerandomiseerd volgens een crossover design AB/BA. De 30-minuten durende musiceersessies werden voorafgegaan en gevolgd door 60 minuten rust. Energiegebruik werd gemeten met indirecte calorimetrie. In tegenstelling tot de hypothese, bleek dat energiegebruik in de houding volgens oefentherapie MmS hoger was dan in de gewoontehouding. Daarvoor kunnen twee verklaringen gegeven worden: Ten eerste is de aanname dat vermoeidheid gerelateerd is aan energiegebruik niet correct. Vermoeidheid kan ontstaan door fysieke, cognitieve, en emotionele factoren en is daarom niet noodzakelijk gerelateerd aan energiegebruik. Ten tweede lijkt het achteraf logisch dat energiegebruik hoger is in de houding volgens oefentherapie MmS, aangezien dit een meer actieve houding is. Musici moeten concentreren en focussen op hun houding, en er is vermoedelijk meer spieractiviteit nodig om de houding vast te houden.

In de tweede studie werd gebruik gemaakt van elektromyografie (EMG) om verschillen in spieractiviteit te meten gedurende het bespelen van de klarinet in de houding volgens oefentherapie MmS in vergelijking met de gewoontehouding. Musculoskeletale klachten komen vaak voor bij klarinettisten en zijn mogelijk gerelateerd aan een grote belasting op de arm gedurende het musiceren. De hypothese was dat oefentherapie MmS de spieractiviteit gedurende het musiceren kan veranderen. Daarnaast zijn de ervaringen vanuit de praktijk dat ook toonkwaliteit verbeterd in de houding volgens oefentherapie MmS. Twintig (pre)professionele klarinettisten namen deel aan dit onderzoek. Zij speelden eerste een 60 seconden durend muziekstuk in hun gewoontehouding. Daarna kregen ze instructies in de houding volgens oefentherapie MmS, waarna ze hetzelfde stuk nogmaals in de nieuwe houding speelden. Een twee-dimensioneel goniometrisch programma werd gebruikt om lichaamshouding tijdens het musiceren te objectiveren. Spieractiviteit werd gemeten met oppervlakte EMG. Deelnemers beoordeelden zelf hun toonkwaliteit. De muziekstukken werden ook opgenomen en later op toonkwaliteit beoordeeld door een blind, onafhankelijk, panel van experts. Gedurende het spelen in de houding volgens oefentherapie MmS werd een significant kleinere laag-thoracale hoek, kleinere hoog-thoracale hoek en grotere bekkenkanteling gevonden. Dit betekent klinisch dat het bovenlichaam tijdens het spelen in de houding volgens oefentherapie MmS meer naar voren geplaatst wordt waarbij het bekken naar achteren gekanteld is. EMG resultaten laten zien dat de linker en rechter $m$. erector spinae (gemeten ter hoogte van L3) en de linker en rechter m. trapezius ascendens meer actief waren in de houding volgens oefentherapie MmS. Daarentegen werd gevonden dat de linker $\mathrm{m}$. trapezius descendens en rechter $\mathrm{m}$. brachioradialis minder actief waren in houding volgens oefentherapie MmS in vergelijking met de gewoontehouding. Klinische belangrijke veranderingen in spieractiviteitenpatroon betreffen de lagere activiteit van de linker $\mathrm{m}$. trapezius descendens en de rechter $\mathrm{m}$. brachioradialis. De linker $\mathrm{m}$. trapezius descendens wordt vaak excessief gebruikt om muzikaliteit uit te drukken. Vermoedelijk kan deze overbelasting leiden tot meer klachten. De rechter $\mathrm{m}$. brachioradialis wordt gedurende langere perioden statisch belast omdat deze het gewicht van het instrument draagt. Elke vermindering van overmatige spierac- 
tiviteit in deze spieren kan hypothetisch ten goede komen aan preventie of behandeling van PRMD. Toonkwaliteit werd door de meeste deelnemers zelf als beter beoordeeld in de houding volgens oefentherapie MmS. Geblindeerde experts merkten dat toonkwaliteit afhankelijk was van houding, maar konden niet consistent aangeven welke van de twee houdingen een betere toonkwaliteit had. In conclusie, een verandering in lichaamshouding leidt tot een veranderd spieractivatiepatroon en een verandering in toonkwaliteit gedurende het bespelen van de klarinet. Het lijkt erop dat er in de houding volgens oefentherapie Mensendieck methode Samama een spieraanspanningspatroon ontstaat waarbij er meer activiteit optreedt proximaal met een verminderde activiteit van de armspieren.

\section{Deel III Kunnen musculoskeletale klachten bij muziekstudenten worden voorkomen?}

Muziek studenten hebben een hoger risico op het ontwikkelen van musculoskeletale klachten in vergelijking met andere studenten. Onderwijs op conservatoria is gericht op het leren bespelen van het muziekinstrument op de meest virtuoze manier. Er worden hoge fysieke en mentale eisen aan de musicus gesteld om optimaal te kunnen musiceren. De gezondheid van musici beïnvloedt de kwaliteit van het optreden. Het verantwoordelijkheidsgevoel van conservatorium studenten voor hun gezondheid is op dit moment laag. Het lijkt daarom logisch om gezondheid in het algemeen en preventie van blessures specifiek te behandelen in het reguliere lesprogramma gedurende de conservatorium studie. Het laatste gedeelte van dit proefschrift focust op onderzoek naar effectiviteit van een preventieprogramma. De "PREvention STudy On preventing or reducing disability from musculoskeletal complaints in music students", of "PRESTO" trial is een multicenter gerandomiseerde en gecontroleerde trial (RCT). Deze trial werd uitgevoerd op 5 Nederlandse conservatoria en had als doel om het effect te onderzoeken van een biopsychosociaal preventieprogramma, in vergelijking met een algemeen beweegprogramma, op het verminderen of voorkomen van beperkingen door musculoskeletale klachten bij muziek studenten. In totaal werden 170 eerste- en tweedejaars studenten geïncludeerd. Per conservatorium werden zij willekeurig ingedeeld in een biopsychosociaal programma (PRESTO-Play) of beweegprogramma (PRESTO-Fit). Het doel van PRESTO-Play was om studenten te informeren over lichaamshouding gedurende het bespelen van het instrument volgens principes van oefentherapie MmS en het bespreekbaar maken en leren omgaan met psychosociale invloeden. Gedragsveranderingsprincipes werden hierbij toegepast. De PRESTO-Fit groep was bedoeld als controle voor attentie en was gericht op het stimuleren van het activiteitenniveau tot 10,000 stappen per dag volgens Nederlandse richtlijnen voor gezond bewegen in de algemene populatie. Beide lesreeksen werden geïmplementeerd als vrijwillige, extra-curriculaire, lessen voor muziek studenten in hun eerste of tweede studiejaar in het schooljaar 2012-2013 en 2013-2014. De totale tijd die besteed werd aan beide programma's was gelijk, namelijk 18 uur. Daarbij bestond PRESTO-Play uit 11 lessen gedurende het gehele schooljaar. De studenten in PRESTO-Fit volgden 5 lessen gedurende het schooljaar, maar waren extra tijd kwijt aan het vergroten van hun dagelijkse lichaamsbeweging. De rationale voor de PRESTO-Play en PRESTO-Fit lessen wordt onderbouwd door de huidige literatuur en klinische ervaring. De PRESTO-Play lessen werden 
verzorgd door ervaren oefentherapeuten Mensendieck of Cesar, methode Samama. PRESTO-Fit docenten dienden een affiniteit met beweegprogramma's te hebben. Alle therapeuten werden getraind om de lessen volgens een gestandaardiseerd protocol te kunnen geven. Resultaten werden gemeten met vragenlijsten bij aanvang van de eerste les, gedurende en aan het eind van de lessenreeks en na 16- en 24 maanden. Aan het einde van de lessenreeks waren nog 62\% van de PRESTO-Play en 58\% van de PRESTO-Fit studenten betrokken bij het onderzoek. Twee jaar na de laatste les waren nog 32\% en 29\% van PRESTO-Play en PRESTO-Fit studenten betrokken. Statistische analyse toonde aan dat er aan het einde van de follow-up geen verschil was tussen beide groepen in de mate van beperkingen door musculoskeletale klachten of enige andere uitkomstmaat. Wel toonden resultaten dat de ervaren beperkingen over 2 jaar daalden met 33\% in PRESTO-Play en 49\% in PRESTO-Fit. De opzet van de studie laat echter niet toe om hier conclusies uit trekken. Er kan dus niet gezegd worden of dit een interventie effect is of natuurlijk beloop. Studenten zelf hebben ook de interventies beoordeeld. Studenten van PRESTO-Play gaven aan dat ze geleerd hebben over preventie van fysieke klachten gerelateerd aan het bespelen van het instrument en waardeerden het programma met een hoger cijfer dan studenten uit PRESTO-Fit.

Wanneer een multicenter en veelzijdige trial in de dagelijkse praktijk wordt uitgevoerd zijn er veel factoren die uitkomsten kunnen beïnvloeden. Om resultaten correct te kunnen interpreteren is het daarom noodzakelijk om de opzet en de daadwerkelijke implementatie van de studie te evalueren. Een onafhankelijke externe beoordeling kan sterktes en zwaktes van de studie opzet en rationale achter de interventie aantonen. Daarnaast is het waardevol om te onderzoeken of de interventies ook wel zo zijn uitgevoerd zoals ze bedoeld waren en de ervaringen van alle betrokkenen te evalueren. Het doel van de laatste studie uit dit proefschrift was dan ook om de PRESTO trial te evalueren door antwoord te geven op 2 vragen: 1) Waren de studie opzet en inhoud van de interventie valide? 2) Zijn de interventies geïmplementeerd zoals bedoeld?

Een extern panel van experts beoordeelde de opzet van de trial en de inhoud van de interventies als positief. Deelnemers aan PRESTO-Play gaven aan dat ze nieuwe dingen geleerd hadden over preventie van fysieke klachten gerelateerd aan het muziek maken en vonden dat de lessenreeks een waardevolle aanvulling was op hun onderwijs. De lessen creëerden een open sfeer om over fysieke en psychische problemen te praten. De deelnemers hadden de hoogste waardering voor de lessen waarin gefocust werd op lichaamshouding gedurende het bespelen van het instrument. Gedragsveranderingsprincipes en psychosociale principes werden wellicht niet optimaal geïmplementeerd. Opvallend was dat PRESTO-Play en PRESTO-Fit docenten zich niet altijd precies aan het protocol hielden. Het contrast tussen de interventies kan te klein geweest zijn om uiteindelijk verschillen te kunnen aantonen. De beperkte aanwezigheid van de studenten in de lessen en een vermoedelijk gebrek aan generalisatie van het geleerde in de dagelijkse praktijk heeft het effect van de interventies wellicht verder verminderd. De twee grootste beïnvloedende factoren op het effect van de trial waren het grote aantal studenten dat uitviel en contextuele factoren. Het was bijvoorbeeld niet mogelijk om de lessen in te roosteren op een moment waarop alle studenten beschikbaar waren. Daarnaast waren sommige studenten niet overtuigd van het belang van deelname aan de lessen en misten zij betrokkenheid van hun docenten of andere conservatorium medewerkers. 
Dit onderzoek toonde aan dat een biopsychosociaal preventie programma niet meer effectief is in het voorkomen of verminderen van beperkingen door musculoskeletale klachten dan een algemeen beweegprogramma. Op basis van de huidige resultaten kan er geen advies gegeven worden over de implementatie van een algemeen preventie programma voor muziek studenten. Er kan worden aangenomen dat studenten in verschillende stadia van hun klachten ook een andere benadering behoeven, volgens het model van primaire, secundaire, en tertiaire preventie. Mogelijk dat toekomstige preventieprogramma's dus beter specifiek op de biopsychosociale aspecten van de individuele student moeten focussen. Vervolgonderzoek dient gericht te zijn op het identificeren van subgroepen zodat interventies beter gericht kunnen worden op de behoeften van de studenten. Daarnaast dient vervolgonderzoek meer informatie te verschaffen hoe het gezondheidsgedrag van de muziek student het best beïnvloedt kan worden. Ten laatste wordt het aangeraden om gezondheidslessen op te nemen als een integrale component van het onderwijsprogramma. Voor toekomstig onderzoek onder muziek studenten is het van groot belang dat het conservatorium optimaal betrokken is. Aangenomen kan worden dat toegankelijkheid, communicatie, aanwezigheid, en motivatie voor gedragsverandering hierdoor kunnen verbeteren. 


\section{Dankwoord}

Mijn dank is groot aan ieder die mij geholpen heeft tijdens dit bijzondere traject. De weg was lang, maar was het absoluut waard. Zeker verwachtte ik veel te gaan leren, maar wat heb ik ook veel onverwachte zaken geleerd! Zonder hulp was ik nooit tot dit prachtige resultaat gekomen. Nadrukkelijk wil ik een aantal mensen benoemen:

Ten eerste, Marjon, je was de eerste die me in aanraking bracht met muziekgeneeskunde en me meteen wist te enthousiasmeren. Jouw passie werkt aanstekelijk! Met je contacten regelde je de basis voor dit project. Als inhoudelijk expert was je altijd bereikbaar voor commentaar en ondersteuning. Je daadkracht en bedrijvigheid doen me nog steeds versteld staan. Ik ben blij dat ik jouw stokje heb mogen overnemen.

Daarnaast natuurlijk de andere leden van mijn promotiecommissie: Rob Smeets, Jeanine Verbunt en Rob de Bie. Jullie wisten de begeleiding perfect aan te laten sluiten bij mijn opleidingsniveau. leder van jullie droeg zijn eigen noten bij om tot deze mooie compositie te komen. Rob Smeets, je kritische vragen stimuleerden me steeds om mijn onderzoek nog verder te verfijnen. Jeanine, jij bent ook ooit als AIOSKO begonnen en kon me daarom heel goed begeleiden in de combinatie kliniek en wetenschap. Rob de Bie, als epidemioloog pakte jij je rol om te zorgen dat de methodologie van de studies steeds correct bleef. Jullie allen lieten me inzien dat het opzetten en uitvoeren van een RCT meer management- dan onderzoekskwaliteiten behoeft. Ik heb een grote vrijheid ervaren tijdens dit project, maar wist wel dat ik altijd bij jullie terecht kon. Jullie hebben me alle mogelijkheden geboden om me verder te ontwikkelen. Dank voor jullie inhoudelijke en persoonlijke betrokkenheid tijdens dit project.

Mevrouw Samama, uw donatie aan het Universiteitsfonds maakte dit promotieproject in eerste instantie mogelijk. Ik heb diep respect voor uw grote ambitie voor uw vak. Natuurlijk weet $u$ zelf als geen ander hoe waardevol oefentherapie Mensendieck is in de behandeling van musici met klachten. Bijzonder vind ik het dat $u$ dat ook wetenschappelijk en objectief getoetst wilde zien. $U$ liet ons vrij in de opzet en uitvoering van de studies, maar wilde wel altijd geïnformeerd worden over de redenaties achter onze wetenschappelijke overwegingen. Daar heb ik ontzettend veel van geleerd.

Verder wil ik de beoordelingscommissie van mijn proefschrift, bestaande uit prof. Annelies Boonen, prof. Eckart Altenmüller, prof. Clemens Rommers, dr. Janine Stubbe en dr. Mariëlle Goossens, graag bedanken voor het beoordelen van mijn proefschrift.

Alle betrokken conservatoria en in het bijzonder de conservatoria betrokken bij de RCT: Academy of Music and Performing Arts Tilburg, Conservatorium Maastricht, Codarts Rotterdam, Hogeschool voor de Kunsten Utrecht, Prins Claus Conservatorium Groningen. Bedankt voor jullie bereidheid tot deelname aan dit project. Dank aan iedereen die een steentje heeft bijgedragen aan de organisatie en implementatie van de studie en het opvolgen van de studenten.

Dank ook aan de therapeuten die geholpen hebben om deelnemers voor studies te rekruteren, of zelf daadwerkelijk therapie hebben gegeven ten behoeve van de verschillende studies. Bedankt voor jullie inzet en enthousiasme. 
Alle deelnemers aan mijn studies: zonder proefpersonen geen uitkomsten, jullie bijdrage is onmisbaar. Dank ook voor jullie waardevolle commentaar en discussies die mijn inzichten in dit onderwerp hebben laten groeien.

Alle andere betrokkenen bij mijn studies: co-auteurs, raadgevers, onderzoekassistenten, studenten, proef-proefpersonen, etc. Nadrukkelijk ook dank aan het secretariaat (Veronique, Sonja, Margareth en Jolanda). Het was geen gemakkelijke taak om de studenten "bij de les" te houden. Maar dankzij jullie inzet heb ik er toch het maximale uit kunnen halen.

Alle medewerkers van Adelante Kenniscentrum, de vakgroep revalidatiegeneeskunde UM en in het bijzonder alle kamergenootjes. Een proefschrift schrijf je niet alleen, tussentijds sparren, koffie drinken en een "challenge" doen is ook heel belangrijk. Alle AIOS: dank dat jullie me opnieuw de weg wezen in Hoensbroek toen ik na een lange onderzoeksperiode in een vernieuwd gebouw terecht kwam. Ik hoop dat ik jullie met dit proefschrift kan overtuigen dat onderzoek doen heel waardevol is!

Margot en Karin, met een psychiater en een vaatchirurg aan mijn zijde voel ik mij optimaal gesteund tijdens de verdediging.

Het thuisfront: Pap en Mam: goede eigenschappen die helpen om een proefschrift te maken komen niet vanzelf, die heb ik van jullie mee gekregen. Bedankt dat jullie me altijd gesteund hebben in mijn studie. Bartel en Mia: relativeren is een kunst die ik nog niet altijd even goed beheers. Bedankt dat jullie me laten inzien dat er zo veel andere belangrijke dingen in het leven zijn. Loate veer nog lang same geneete van 't laeve! 


\section{About the author}

Vera Baadjou was born on October 22th 1985 in Heerlen, The Netherlands. Playing music has been part of her life from a very young age. She started taking lessons on the recorder even before she could read or write. Later, the flugelhorn became her primary instrument. After obtaining her athenaeum diploma at the Sophianum college in Gulpen, she started medical school in Maastricht. Early during medical training, she participated in an elective course at the department of rehabilitation medicine at the academic hospital Maastricht. After having attended the musician's clinic there, she knew: "This is what I want to do", and future directions were clearly pointed toward starting her AIOSKO trajectory combining a traineeship to become a physiatrist with a PhD trajectory at Adelante/ Maastricht University in 2011. During her PhD trajectory, Vera has received great acknowledgements from within the field of performing arts medicine, and has won several (inter)national prices for her work. Currently, she is working as a resident at Adelante Center for Rehabilitation and Audiology and is expected to finish her residency in June 2018. She runs the specialized musician's inpatient clinic located at MUMC + and is chair of the multidisciplinary arts team at MUMC+. She is involved in (preventive) health care at the conservatories in Maastricht and Tilburg. In future, she wants to continue working as a physiatrist with a special interest in performing arts medicine. Besides, she wants to continue research in the fields of performing arts medicine and chronic pain. 


\section{Achievements}

\section{Awards}

2017 Alice G. Brandonbrener Young Investigator Award, Performing Arts Medicine Association. Snowmass, Colorado.

"NVDMG Aanmoedigingsprijs voor jong talent 2014", Nederlandse Vereniging van Dans- en. Muziekgeneeskunde. Maastricht. April 2014. (Young Talent Award Dutch Performing Arts Medicine Association)

Poster award. Deutsche Gesellschaft für Musikphysiologie und Musikermedizin. Frankfurt am Main, Germany. 2012.

"NVDMG Aanmoedigingsprijs voor jong talent 2011", Nederlandse Vereniging van Dans- en Muziekgeneeskunde. Leiden. April 2011. (Young Talent Award Dutch Performing Arts Medicine Association)

\section{WI1-publications (accepted)}

Baadjou VA, van Eijsden-Besseling MD, Verbunt JA, de Bie RA, Geers RP, Smeets RJ, Seelen HA. Playing the clarinet: influence of body posture on muscle activity and sound quality. Med Probl Perform Art.2017;32(3)125-31.

Baadjou V, de Bie R, Guptill C, Smeets R. Psychometric properties of the performing arts module of the Disabilities of the Arm, Shoulder and Hand questionnaire. Disabil Rehabil.2017;Aug 16:1-7.

Baadjou VA, Roussel NA, Verbunt JAMCF, Smeets RJEM, de Bie RA. Systematic review on risk factors for musculoskeletal disorders in musicians. Occup Med.2016;66(8):614-622.

Baadjou, VA, Verbunt, JAMCF, Eijsden-Besseling, MDF van, Samama-Polak, AL., Bie, RA de \& Smeets, RJEM. PREvention STudy On preventing or reducing disability from musculoskeletal complaints in music school students (PRESTO): protocol of a randomised controlled trial. J Physiother.2014;60(4),232.

Baadjou VA, Verbunt JA, van Eijsden-Besseling MD, Huysmans SM, Smeets RJ. The musician: (in)active athlete? Exploring the association between physical activity and musculoskeletal complaints in music students. Med Probl Perform Art. 2015;Dec 30(4):231-7.

Baadjou VA, van Eijsden-Besseling MD, Samama-Polak AL, Smeets RJ, Lima Passos V, Westerterp KR. Energy expenditure in brass and woodwind instrumentalists; the effect of body posture. Med Probl Perform Art. 2011; 26(4):218-222. 


\section{WI1-publications (submitted)}

Baadjou VA, Verbunt JA, van Eijsden-Besseling MD, de Bie RA, Girard O, Twisk JW, Smeets RJ. Preventing musculoskeletal complaints in music students. A biopsychosocial prevention course is not superior at reducing disability compared to physical activity promotion: a randomized controlled trial.

Baadjou VA, Ackermann B, Verbunt JA, van Eijsden-Besseling MD, de Bie RA, Smeets RJ. External validation and process evaluation of a health promotion and injury prevention course in music students: Lessons learnt from the PRESTO trial.

Baadjou VA, Lee H, Smeets RJ, Kamper S. Do depressive symptoms mediate the effect of exercise and advice on subacute low back pain?

\section{WN publications}

Meer, P. van der \& Baadjou, V. (2014). Revalidatiegeneeskunde over de grens: België: België Nederland: Over fysische geneeskunde en revalidatie. Nederlands Tijdschrift voor Revalidatiegeneeskunde, 36 (6), 314-315.

Meer, P. van der \& Baadjou, V. (2014). Revalidatiegeneeskunde over de grens: Curaçao:'Een bijzondere plek waar ik kennis heb gemaakt met de veelzijdigheid van ons vak'. Nederlands Tijdschrift voor Revalidatiegeneeskunde, 36 (2), 93-95.

Andela, M., Werf, M. van der \& Baadjou, V. (2014). Evaluatie aios revalidatiegeneeskunde: Eerste inventarisatie circuitgebonden en lokaal onderwijs. Nederlands Tijdschrift voor Revalidatiegeneeskunde, 36 (1), 48-49.

Meer, P. van der \& Baadjou, V. (2013). Jonge klare over de grens: Zwitserland. Nederlands Tijdschrift voor Revalidatiegeneeskunde, 35 (4), 188-189.

Baadjou, V.A.E., Rommers, G.M., Kempen, T.M.P.A. van \& Kuijk, A.A. van (2013). De CAT in de opleiding tot revalidatiearts: Critial appraisal of the CAT. Nederlands Tijdschrift voor Revalidatiegeneeskunde, 35 (3), 132-135.

Baadjou, V.A.E., Verbunt, J.A.M.C.F., Eijsden-Besseling, M.D.F van, Bie, R.A. de \& Smeets, R.J.E.M. (2013). Musculoskeletale klachten bij musici: van vóórkomen naar voorkómen. Tijdschrift voor Ergonomie, 38 (2), 5-7

Roussel, N., Kooning, M. de, Baadjou, V., Struyf, F., Schütt, A., Nijs, J., Verbunt, J. \& Smeets, R. (2013). Musculoskeletale klachten bij (pre)professionele dansers. Sport \& geneeskunde, 1-10. 
Baadjou, V. \& Meeteren, A. van (2012). Vechten voor je specialisme. Nederlands Tijdschrift voor Revalidatiegeneeskunde, 34 (3), 145-146.

Baadjou, V., Eijsden-Besseling, M.D.F van, Samama-Polak, A.L.W., Smeets, R.J.E.M., Lima Passos, V. \& Westerterp, K.R. (2012). Energy expenditure in brass and woodwind instrumentalist: the effect of body posture. Beweegreden-vakblad voor oefentherapeuten Cesar en Mensendieck, 8 (4), 41553.

\section{Contributions to books}

Baadjou VA, Smeets RJ. Pijn, stoppen of doorgaan? In: Balthasar et al. Probleemgeoriënteerd denken in de pijngeneeskunde. Een praktijkboek voor de opleiding en de kliniek. De Tijdstroom, 2017.

\section{Workshop (international) scientific congress}

Van Kuijk A, Brouwer C, Maas M, Baadjou V. (2013). Workshop: Critically appraising the critical appraised topic. In VRA Annual Congress, Rehabilitation Medicine Unlimited. Noordwijkerhout.

Baadjou V, van Eijsden-Besseling M, van Loon-Felter A, Woldendorp KH. (2017) Workshop: pARTicipation: performing arts medicine in rehabilitation. In Dutch Congress of Rehabilitation Medicine, Moving ahead towards participation. Maastricht.

\section{Congress presentations (inter)national}

\section{Oral presentations}

June 2017: PAMA, Snowmass, CO, USA. Playing the clarinet: influence of body posture on muscle activity and sound quality. Winner AGB Award.

May 2017: ResearchClub UZA Antwerp, Belgium. Invloed van musiceerhouding op spiergebruik en klank tijdens het bespelen van de klarinet.

April 2016: NVDMG, Zwolle. Systematic review on risk factors for musculoskeletal disorders in musicians

March 2015: Pain Science in Motion, Brussel, Belgium. STudy On preventing or reducing disability from musculoskeletal Pcomplaints in conservatory students (PRESTO): protocol of a randomised controlled trial.

April 2014: NVDMG, Maastricht. Preventie van musculoskeletale klachten bij conservatoriumstudenten. 
February 2014: Maastricht University, Onderzoek in Beweging. Klachten arm, nek, schouder (KANS) bij musici.

April 2013: NVDMG, Den Haag. De musicus: atleet of niet?

April 2011: NVDMG, Leiden. Energy expenditure in brass and woodwind instrumentalists; the effect of body posture.

\section{Poster presentations}

November 2017: Dutch Congress of Rehabilitation Medicine. Playing the clarinet: influence of body posture on muscle activity and sound quality.

November 2016: Dutch Congress of Rehabilitation Medicine. Systematic review on risk factors for musculoskeletal disorders in musicians.

September 2016: IASP, Yokohama, Japan. Systematic review on risk factors for musculoskeletal disorders in musicians.

May 2016: assistentencongres MUMC +. Systematic review on risk factors for musculoskeletal disorders in musicians.

November 2014: Synposium der Deutsche Gesellschaft für Musikphysiologie und Musikermedicin: Kassel, Germany. PREvention STudy On preventing or reducing disability from musculoskeletal complaints in conservatory students (PRESTO): protocol of a randomized controlled trial.

November 2012: Symposium der Deutsche gesellschaft für Musikphysiologie und Musikermedizin: Frankfurt am Main, Germany. Musculoskeletal complaints among conservatory students: results of a cross-sectional in 8 Dutch conservatories.

November 2012: Annual Congress of the Netherlands Society of Physical and Rehabilitation Medicine. Musculoskeletal complaints among conservatory students: results of a cross-sectional in 8 Dutch conservatories.

November 2010: Annual Congress of the Netherlands Society of Physical and Rehabilitation Medicine. Energy expenditure in brass and woodwind instrumentalists; the effect of body posture. 